Przemysław Żywiczyński / Sławomir Wacewicz

\title{
The Evolution of Language: Towards Gestural Hypotheses
}

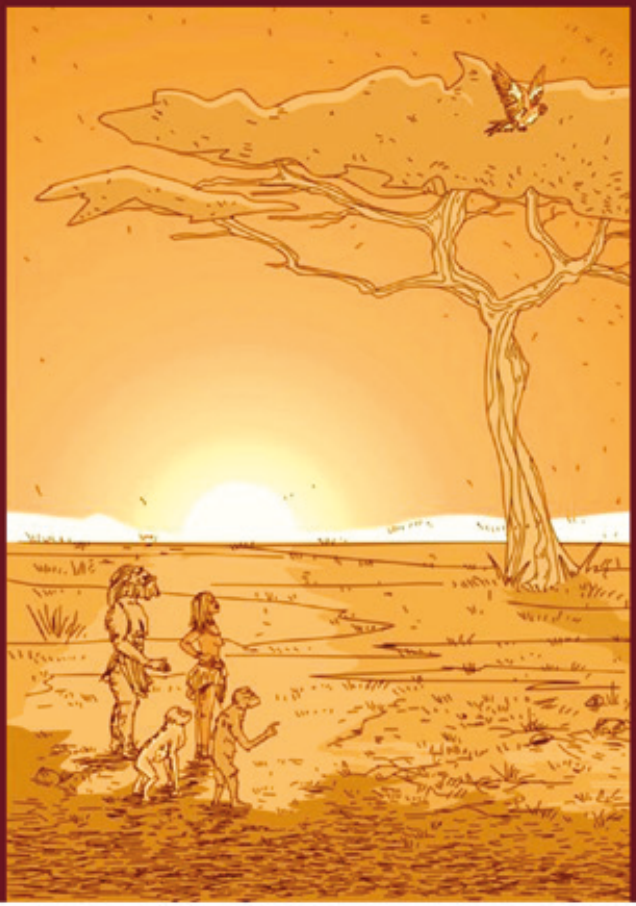




\section{Przemysław Żywiczyński / Sławomir Wacewicz}

\section{The Evolution of Language: Towards Gestural Hypotheses}

This book discusses the scope and development of the science of language evolution - a newly emergent field that investigates the origin of language. The book is addressed to audiences who are not professionally involved in science and presents the problems of language origins together with introductory information on such topics as the theory of evolution, elements of linguistic theory, the neural infrastructure of language or the signalling theory.

The Author

Przemysław Żywiczyński is an Associate Professor of Linguistics at the Department of English, Nicolaus Copernicus University, Toruń, Poland.

Sławomir Wacewicz is an Assistant Professor at the same department.

The authors are the founders of NCU's Center for Language Evolution Studies (CLES). 
The Evolution of Language: Towards Gestural Hypotheses 


\title{
DIS/CONTINUITIES TORUŃ STUDIES IN LANGUAGE, LITERATURE AND CULTURE
}

Edited by Mirosława Buchholtz

\author{
Advisory Board \\ Leszek Berezowski (Wrocław University) \\ Annick Duperray (University of Provence) \\ Dorota Guttfeld (Nicolaus Copernicus University) \\ Grzegorz Koneczniak (Nicolaus Copernicus University) \\ Piotr Skrzypczak (Nicolaus Copernicus University) \\ Jordan Zlatev (Lund University)
}

Vol. 20

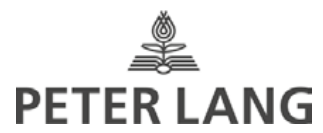


Przemysław Żywiczyński / Sławomir Wacewicz

\section{The Evolution of Language: Towards Gestural Hypotheses}

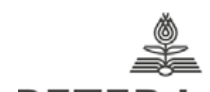




\section{Bibliographic Information published by the Deutsche Nationalbibliothek}

The Deutsche Nationalbibliothek lists this publication in the Deutsche Nationalbibliografie; detailed bibliographic data is available in the internet at http://dnb.d-nb.de.

The translation, publication and editing of this book was financed by a grant from the Polish Ministry of Science and Higher Education of the Republic of Poland within the programme Uniwersalia 2.1 (ID: 347247, Reg. no. 21H 160049 84) as a part of the National Programme for the Development of the Humanities. This publication reflects the views only of the authors, and the Ministry cannot be held responsible for any use which may be made of the information contained therein.

\section{-1) national programme \\ 1 FOR THE DEVELOPMENT OF HUMANITIES}

Translators: Marek Placiński, Monika Boruta Supervision and proofreading: John Kearns

Cover illustration: @ Mateusz Pawlik

Printed by CPI books GmbH, Leck

ISSN 2193-4207

ISBN 978-3-631-79022-9 (Print)

E-ISBN 978-3-631-79393-0 (E-PDF)

E-ISBN 978-3-631-79394-7 (EPUB)

E-ISBN 978-3-631-79395-4 (MOBI)

DOI $10.3726 / \mathrm{b} 15805$

\section{PETER LANG}
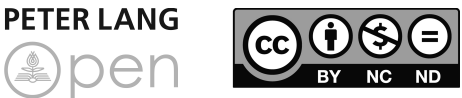

Open Access: This work is licensed under a Creative Commons Attribution Non Commercial No Derivatives 4.0 unported license.

To view a copy of this license, visit https://creativecommons.org/licenses/by-nc-nd/4.0/

(c) Przemysław Żywiczyński / Sławomir Wacewicz, 2019

Peter Lang - Berlin · Bern · Bruxelles .

New York · Oxford · Warszawa $\cdot$ Wien

This publication has been peer reviewed. www.peterlang.com 


\section{Contents}

Introduction to the Translation

Introduction

\section{The Beginnings of Language and Language Origins}

1.1 Religious beginnings

1.1.1 On the divinity of language, the forbidden experiment, and the Adamic language ............................. 18

1.1.2 Language as the object of investigation ........................... 20 Jewish tradition ......................................................... 24

1.1.3 Reflections on language in Indian philosophy ................. 25

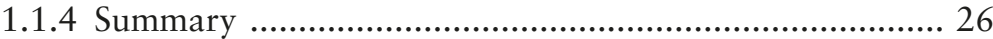

1.2 Glottogenetic thought: A naturalistic concept of language

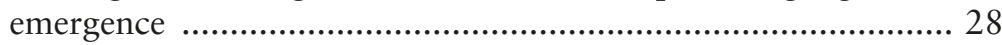

1.2.1 How to recover from the state of nature? ........................ 28

Vico ………........................................................... 29

The beginnings of comparative research .......................... 30

Monboddo ………………………………………….... 33

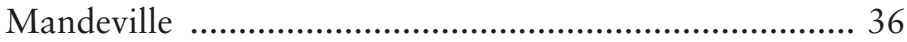

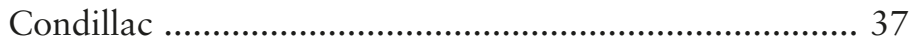

Rousseau …………............................................ 38

Herder ...................................................................... 41

Parisian ideologists ........................................................... 43

Comparative philology ..................................................... 45

1.2.2 Darwin: The beginnings of the science on the evolutionary origin of language ....................................... 49

Early Darwinism and the glottogenetic problem .............. 51

Empirical advances ……………………………………... 54 
Anthropology and psychology on the beginnings of language …............................................................. 56

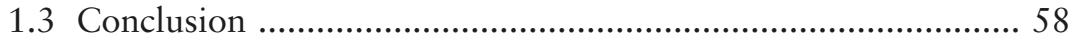

2 Evolution, Evolutionism, Evolutionary Thinking ………….. 59

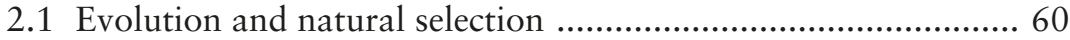

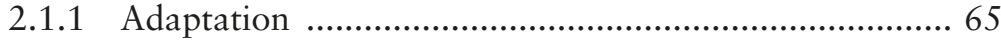

2.1.2 Gene's eye view and inclusive fitness ........................... 66

2.2 Universal Darwinism and cultural evolution ........................... 69

2.3 Evolutionary psychology ….................................................... 71

2.4 Popular reception and the sins of evolutionism ...................... 74

2.5 Evolution: Myths and misconceptions ................................... 77

2.5.1 Simplification: Evolution $=$ natural selection ................ 79

2.5.2 Misconception: Panadaptationism (naïve selectionism) ..... 79

2.5.3 Misconception: Survival of the fittest ......................... 81

2.5.4 Misconception: Preservation of the species/The good of the species .................................................... 82

2.5.5 Misconception: Lamarckism ...................................... 84

2.5.6 Misconception: Macromutation and saltationism ......... 85

2.5.7 Misconception: Evolution has a purpose (teleology) ..... 87

2.5.8 Misconception: Evolution means progress or going up in the great chain of beings ...................................... 88

2.5.9 Misconception: Recapitulationism ("ontogeny recapitulates phylogeny") ........................................... 90

2.5.10 Misconception: Confusing explanatory levels ............... 91

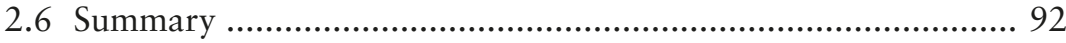

\section{The Evolution of Language: A Departure from} Glottogenetic Scenarios .............................................................. 95

3.1 Road to the science of language evolution ................................ 99

3.1.1 Renewed interest ........................................................ 99 
3.1.2 Chomsky, internalism and the biological foundations of language .............................................................. 105

3.1.3 Advances in the neurosciences ................................... 107

Research on primates ............................................ 107

Genetics ..................................................................... 112

Palaeontology and archaeology .................................. 114

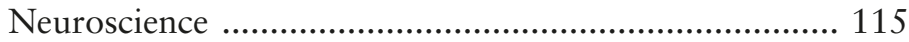

3.1.4 Evolutionism .......................................................... 120

3.2 Contemporary Evolution of Language ................................ 122

3.2.1 The evolution of language: A new research programme ............................................................ 122

3.2.2 New research trends in the evolution of language ......... 124

3.3 Evolution - of what? The taxonomy of "language" ............... 127

3.3.1 Syntactic parser and the narrow sense of "language"

3.3.2 Language in the broad sense ..................................... 133

Language: Not only syntax ..................................... 134

Language: Not only speech ...................................... 136

Language: Not only innateness ................................. 138

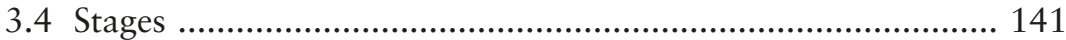

3.4.1 Baseline ................................................................. 142

3.4.2 Preadaptations ...................................................... 143

3.4.3 Prelinguistic communication ..................................... 144

3.4.4 Protolanguage ....................................................... 144

3.4.5 From protolanguage to language ................................ 148

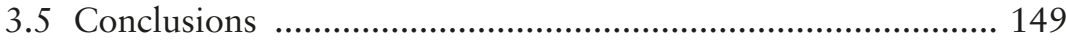

4 Preadaptations for Language ............................................ 151

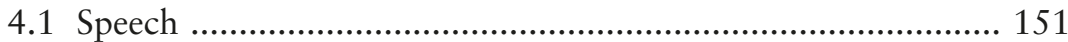

4.2 Speech reception ............................................................. 157

4.3 The brain ........................................................................... 160 


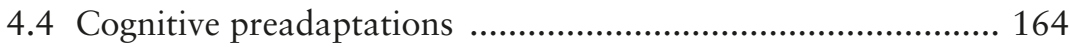

4.4.1 Mimesis ...................................................................... 164

4.4.2 Theory of mind .................................................... 166

4.4.3 Metarepresentation ................................................ 168

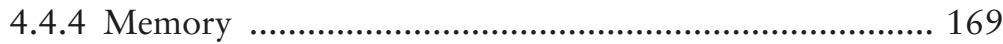

4.4.5 Executive functions ................................................... 171

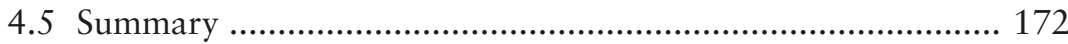

\section{Cooperative Foundations: An Essential Requirement} for Language ........................................................................ 173

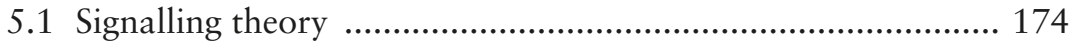

5.2 The evolutionary stability of communication ....................... 176

5.3 How to ensure the honesty of communication? ...................... 178

5.4 The sources of human cooperativeness ................................. 180

5.5 Summary ....................................................................... 184

\section{The Problem of Modality Transition in Gestural}

Primacy Hypothesis ............................................................ 185

6.1 Gestural primacy hypotheses in language evolution .............. 186

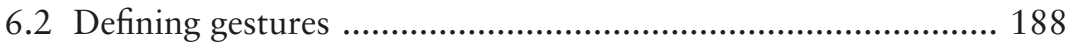

6.2.1 Gestures in interpersonal communication .................... 188

6.2.2 Gestures in nonhuman primates' communication ......... 190

6.3 Arguments in favour of the gestural primacy hypotheses ....... 193

6.3.1 Gesture and language origin - A brief historical background .............................................................. 193

6.3.2 Hewes's position and the revival of concern with gesture in language evolution .................................... 193

6.3.3 Contemporary gestural hypotheses ............................. 195

Iconicity of gestures .................................................. 196

Handedness and lateralisation ................................... 197

Broca's area and mirror neurons ................................ 198 
Mimesis and pantomime .......................................... 200

Further arguments ...................................................... 202

6.4 The problem of transition to speech ..................................... 202

6.4.1 Homo sapiens's adaptations to speech ......................... 203

6.4.2 Sign languages as fully-fledged languages ................... 204

6.5 Solutions ............................................................................ 206

6.5.1 Traditional arguments ............................................. 207

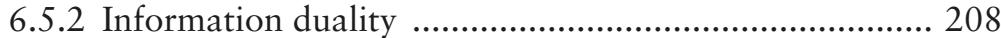

6.5.3 Acquisition of sign and spoken languages in children ....................................................................... 209

6.5.4 Natural connections between the hand and the mouth ......................................................................... 210

6.5.5 Articulatory movements as a type of gesture ............... 212 Orofacial gestures ................................................... 212

6.6 Conclusion - Towards multimodal hypotheses? ..................... 214

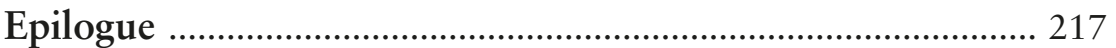

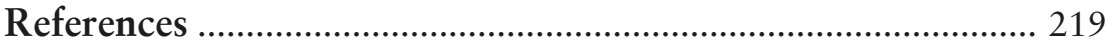

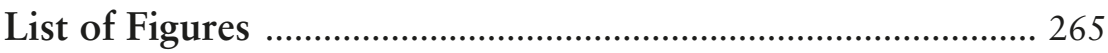

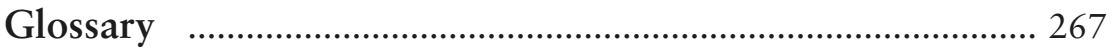

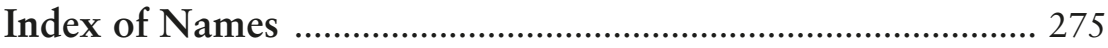

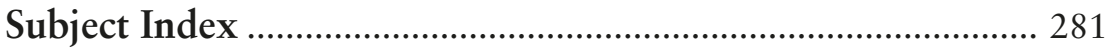





\section{Introduction to the Translation}

The Evolution of Language: Towards Gestural Hypotheses is an English translation of the first Polish book devoted the problems of language evolution, published in 2015. This context bears on the character of the book and its content. The Evolution of Language was written for general audiences, who are not professionally involved in science, including the science of language evolution. Hence, it offers introductory information on topics such as the theory of evolution, the discussion of which serves to bring out the basics of evolutionary thinking, including popular misconceptions about evolution, and stays away from more technical and detailed issues (Chapter 2), elements of linguistic theory (e.g. definitions of language (3.3), universal grammar (3.1.2) or the neural infrastructure of language (4.3) or the signalling theory (5.1)). To further help the reader, we provide a glossary of technical terms at the end of the book. Another limitation of the book has to do with the fact that it was (and still is) the first book on the science of language evolution for the Polish reader who has not had access to the English literature on the subject: excellent introductions by Sverker Johansson (2005) and Tecumseh Fitch (2010) and other forms of secondary and tertiary literature on language evolution, such as a handbook of language evolution by Maggie Tallerman and Kathleen Gibson (2011) or James Hurford's broad-scope monographs - The Origins of Meaning (2007) and The Origins of Grammar (2011). Hence, our presentation is for the most part confined to sketching an outline of the problems of contemporary language evolution, and not an in-depth, extensive discussion of these problems.

Working on the English version, we have decided to reduce the number of supplementary texts, particularly in Chapters 2 and 3. We have also radically shortened the Chapter 1 on the historical context out of which the modern-day science of language evolution emerged. This area is certainly underexplored, but after the publication of Przemysław Żywiczyński’s book Language Origins: From Mythology to Science (2018), we felt there is no reason to repeat what can be found there, in a more extensive form. 



\section{Introduction}

The half-art, half-instinct of language still bears the stamp of its gradual evolution.

Charles Darwin, The Descent of Man (1871)

For Darwin (1871), language was the greatest invention of humankind alongside fire. Maynard Smith and Szathmáry (1995) consider the emergence of language to be the last of the greatest evolutionary breakthroughs, and its explanation was called to be the most difficult problem in science (Christiansen and Kirby, 2003b). ${ }^{1}$ Language is a unique communication system in which symbolic units can be combined into larger wholes with the use of syntactic rules, and since it is human-specific, language also defines our uniqueness.

This book is the first monograph written originally in Polish on the evolution of language - a new field of science, which emerged at the end of the $20^{\text {th }}$ century. As a field, it is developing dynamically, which should not be surprising, given that rapid development is an inherent aspect of youth. The evolution of language, by being a thoroughly interdisciplinary enterprise, derives its impetus from other sciences, such as modern evolutionary theory, genetics, linguistics, neuroscience, palaeoanthropology, comparative psychology, and primatology, to name only a few. Yet, the evolution of language, as a scientific project, is successful because of the questions which determine the direction of its investigations: "Where does language come from, and why do, out of all living forms, only humans have it?"

Language is the feature that unambiguously shows the difference between humans and other animals. Contemporary science provides a wealth of evidence that other traits, which traditionally were considered to be humanspecific, are actually possessed by other species, mainly other apes. We can cite self-awareness, for example. Comparative psychologists have assumed the so-called "mirror test" (developed by Gordon Gallup, 1970) as a rough indicator, which showed self-awareness not only in all great apes the chimpanzee, bonobo, gorilla and orangutan - but also dolphins and

1 See the beginning of Chapter 3. 
elephants. At the beginning of the $20^{\text {th }}$ century it seemed that the ability to use tools, as a non-instinctive, complex behaviour, might also be specific to humans. However, Jane Goodall's pioneering research on chimpanzees in the 1960s put paid to this view. It turned out that the remaining great apes, as well as some Old World monkeys (macaques) and New World monkeys (capuchins), and numerous other species, including birds, can use tools. Chimpanzees do not cease to amaze us: in 1999, the existence of cultural traditions was confirmed in chimpanzee groups, and in 2007 it was established that they use tools in hunting. Even making stone tools can be a problematic criterion for humanness - if the marks on bones dating back to 3.4 million years ago are confirmed as resulting from cutting with stone tools, it would imply that lithic technology predates the emergence of the genus Homo. ${ }^{2}$

Similar research may soon point to language as the only unambiguous qualitative difference between humans and other animals. The evolution of language takes up the challenge of formulating hypotheses which seek to verify how this human-specific and extremely complex trait could have emerged in the history of our evolutionary line.

2 Gallup test and Great Apes - see, for example, Heyes (1998), in elephants: Plotnik et al. (2006), culture in chimpanzees: Whiten et al. (1999), hunting with tools: Prutez and Bertolani (2007); traces of using stone tools: McPherron et al. (2010). 


\section{Structure of the book}

The first two chapters provide an introduction to our study. "The Beginnings of Language and Language Origins" report ideas on the genesis of language as it was cultivated in religion and philosophy, and which predate scientific inquiry into the evolution of language. The second chapter "Evolution, Evolutionism, Evolutionary Thinking" explains the notions and terms that are indispensable to understanding the later chapters. We then devote two chapters to the evolution of language itself. In Chapter 3, entitled "Evolution of Language: A Departure from Glottogenic Scenarios", we discuss the historical and scientific background from which the science of language evolution and its research programme emerged; in the next chapter, "Preadaptations for Language", we focus on reviewing the anatomical and cognitive dispositions which made the emergence of language possible. We devote the fifth chapter to the most important of these dispositions - cooperation. The concluding chapter of the book, "The Problem of Modality Transition in the Gestural Primacy Hypothesis", focuses on a very specific issue which concerns one of the hypotheses of language emergence - the Gestural Primacy Hypothesis - and shows how arguments in language evolution are constructed and verified.

To make reading easier, we have compiled a glossary of the most important terms used in the text, and the main part of the monograph is supplemented with secondary texts, which constitute an extended illustration of the issues under discussion. 



\section{Chapter 1 The Beginnings of Language and Language Origins}

The history of enquiry into language origins shows how the emergence of language was regarded as a key issue from the earliest times - one that is crucial for understanding of what makes us human. Interest in the genesis of language is universal - it appears in various cultural and historical periods, inspiring thinkers to construct scenarios of language creation based on contemporary evidence and ideas. In addition to emphasising the element of universality, this line of enquiry provides inspiration for contemporary researchers: questions posed in the distant past continue to attract the attention of scholars. These include, for example, whether in the initial phase of its development, language imitated the sounds of nature or what the original modality of language was. Our reconstruction also has another, equally important goal, which is to raise awareness of the qualitative difference between speculations about the beginnings of language in even the recent past, and the strictly scientific approach adopted by the contemporary research on language evolution, the modern field of knowledge that deals with the problem of language origins.

This chapter is divided into two parts. In Section 1.1, "Religious beginnings", we discuss religious reflections on the beginnings of language, particularly the divine origin of language. Drawing on examples from both the occidental Christian and Jewish traditions, as well as that of India, we illustrate the universality of ideas about the origins of language and its diversification. Section 2.1, "Glottogenetic thought", is devoted to naturalistic scenarios of the emergence of language, which were formulated by European thinkers with the advent of the modern era.

\subsection{Religious beginnings}

Reflection on the origin of language has always been present in thinking about what makes us human. The intellectual historian José Ignacio Cabezón notes that the problem of language is an important motif in religious discourse. Firstly, religious thinkers are interested in language as a medium of revelation, and the typical outlet of these investigations are the 
conceptions of its divine origin (Cabezón, 1994). The Vedic doctrine of the deification of language (Sanskrit: $v \bar{a} c$ ) or the biblical story of language diversification (Genesis 11: 1-9) are perhaps the best-known attempts in the history of religions to reflect on the nature of language and its origin. The next stage of religious reflection on language, which Cabezón calls "the scholastic phase", focuses primarily on language itself: scholars are gradually becoming aware of the complicated relationship between language and the reality, which leads to questions about the ontological and epistemological status of language description. Moving these considerations to a more theoretical plane enabled the formulation of more philosophically oriented views on language. In medieval thought, the dispute over universals, or general ideas, led to the demarcation of basic positions in reflections on meaning, such as realism, conceptualism, and nominalism. However, theories of meaning were also formulated in India, where the plane of debate was delimited on the one hand by the naturalistic concept of language created by Vedic orthodoxies from the mimmāmsà school, and on the other, by the anti-essentialist (conventionalist) doctrine of apoha proposed by Buddhist scholars from the pramana school.

\subsubsection{On the divinity of language, the forbidden experiment, and the Adamic language}

When it comes to religious discussions that may be valuable to studying the origin of language, attention should be paid to the problem of the innateness of language and the nature of linguistic meaning. In a monograph on the evolution of language, Tecumseh Fitch (2010: 390) quotes the famous verses from Genesis (2: 18-20):

Now the Lord God had formed out of the ground all the beasts of the field and all the birds of the air. He brought them to the man to see what he would name them; and whatever the man called each living creature, that was its name. So the man gave names to all the livestock, the birds of the air and all the beasts of the field. But for Adam no suitable helper was found.

Fitch argues that since God did not know how Adam is going to name animals, the biblical author favours the arbitrary Saussurean notion of meaning. Such a definitive statement, without reference to the historical and philosophical context, carries the risk of simplifying the issue, which 
in the theological traditions of Judaism, Christianity and Islam is known as the problem of the Adamic language (see e.g. Eco, 1995). For example, explanations referring to the Jewish tradition of midrash ${ }^{3}$ state that God bestowed a language upon Adam. This language was Hebrew. Such a conviction of the innateness of language, in this case Hebrew, was also very strong among medieval Christian thinkers, many of whom believed that a child left unattended would naturally speak Hebrew. There was a cruel, quasi-experimental procedure to test this hypothesis, which goes back to antiquity. The test, later referred to as the Forbidden Experiment, involves isolating the child from language stimuli (Shattuck, 1994: 41-46). Probably the most extensive "experiment" of this type was that commissioned by the Holy Roman Emperor Frederick II (1194-1250), who deprived an entire orphanage of contact with language (Shattuck, 1994: 41-46). The chronicler Salimbene reported that the imperial experiment failed, resulting in death of the orphans (see, for example, Coulton, 1906: 242-243 or Benzaquen, 2006: 111).

A major figure who contributed to the emergence of non-mythological reflections on language and its origins in Europe was Dante Alighieri (1265-1321). In his magnum opus The Divine Comedy, Dante discusses the problems of changeability and arbitrariness that would begin to characterise language after Adam's fall. Hebrew, argues Dante, cannot be the language that Adam spoke in paradise, but rather a language that emerged from that spoken in Paradise even before the construction of the Tower of Babel:

The language I did use

Was worn away, or ever Nimrod's race

Their unaccomplishable work began

(Dante, The Divine Comedy, Paradise, Canto XXVI, 124-126)

The poet, probably influenced by Thomas Aquinas (1225-1274), introduces a naturalistic element, expressing the conviction that while the shape of a given language is the result of historical influences, linguistic ability itself is innate to all people:

3 A rabbinic Judaic method of explaining the Hebrew Bible (Tenach) with the help of sentences and parables (see Rosik and Rapoport Introduction to the Jewish literature and exegesis of the biblical and rabbinic period, 2009: 318). 
That he speaks,

Is nature's prompting: whether thus, or thus,

She leaves to you, as ye do most affect it.

(Dante, The Divine Comedy, Paradise,

Canto XXVI, 130-133)

\subsubsection{Language as the object of investigation}

The growing interest in the problem of language-to-world relations is characteristic of medieval thought. It became evident in the centuries-long debate about universals (i.e., general concepts) and the meaning of the names referring to them. In this intellectual climate, the biblical story of the origins of language was no longer taken literally. Alongside, there was a growth in the popularity of theological discussions concerning "the veil of language" - the belief that language conceals the true nature of reality. Among Christian thinkers, the most influential discussion of this problem comes from Augustine (354-430), who expresses the view that after the fall of Adam, cognition based on linguistic description is deceptive ( $D e$ Doctrina Christian, cf. Fyler, 2010). Augustine, referring to philosophical solutions originating primarily from the Stoics, proposes a version of linguistic scepticism, the source of which is the belief that after Adam's fall, there was a permanent break between the word (signum) and the thing that it relates to (res) in language. Furthermore, in language itself, there is a gap between a word as a mental entity (verbum) and its external articulation (vox, locutio), and consequently linguistic communication is indirect (it only guides language users to mental content), and unreliable (because the mental content differs from user to user) (De Trinitate, cf. Ferretter, 1998: 261-264).

Augustine's tendency to treat the biblical story in philosophical rather than historical terms was representative of both Christian and Jewish theology of late antiquity and the Middle Ages, a tendency which Muslim thinkers joined later (Reeves, 2014). In this intellectual tradition, whose origins can be traced to Philo of Alexandria (10 BC-40 AD), Adam's fall and the confusion of languages symbolise cognitive and communicative degeneration: man separated from God lives in a world of his own imagination and, owing to the imperfections of language, is never able to express himself in a full and unambiguous way (Reeves, 2014). 
Such reflections have created an environment in which medieval scholars abandoned issues relating to the origin and the original form of the Adamic language in favour of discussions about how language relates to the world or the mind. As already mentioned, Augustine's concept of the veil of language gave rise to scepticism (see e.g. the work of John Duns 1266-1308), which later found expression in nominalism, questioning the intuition that language is a mapping of reality (e.g., Jean Buridan circa 1295-1361) (Beuchot, 1996). On the other hand, speculative grammar

\section{Box 1.1 The Tower of Babel Myth}

An occidental myth that explains linguistic and ethnic diversity is the story of the Tower of Babel. According to the biblical message, after the Deluge there was only one language and one community, whose members built the Tower:

11.1 The whole earth was of one language and of one speech

11.2 It happened, as they travelled east, that they found a plain in the land of Shinar, and they lived there

11.3 They said one to another, "Come, let's make bricks, and burn them thoroughly." They had brick for stone, and they used tar for mortar.

11.4 They said, "Come, let's build ourselves a city, and a tower whose top reaches to the sky, and let's make ourselves a name, lest we be scattered abroad on the surface of the whole earth."

11.5 Yahweh came down to see the city and the tower, which the children of men built.

11.6 Yahweh said, "Behold, they are one people, and they have all one language, and this is what they begin to do. Now nothing will be withheld from them, which they intend to do.

11.7 Come, let's go down, and there confuse their language, that they may not understand one another's speech."

11.8 So Yahweh scattered them abroad from there on the surface of all the earth. They stopped building the city.

11.9 Therefore the name of it was called Babel, because there Yahweh confused the language of all the earth. From there, Yahweh scattered them abroad on the surface of all the earth. (Genesis 11.1-9)

The story of the Tower of Babel in the Torah plays on the meaning of the word Babel (balal), which means "confusion, disruption, chaos" (Cesare, 2011: 56-57). According to some Jewish sources, the language of Abraham did not get confused because he left Babel and went to Caanan before the fall of the Tower (Sherwin, 2014; 83-84). However, according to a majority of Torah commentators, the original language has been lost forever (Cesare, 2011). 


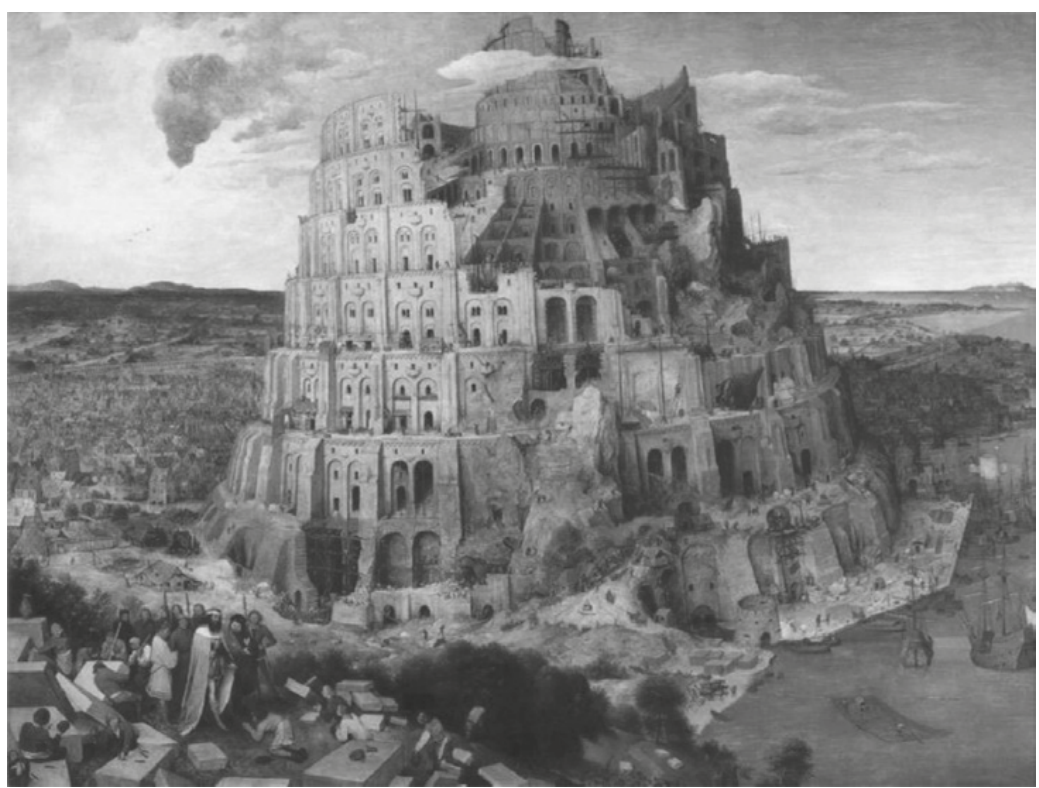

Fig. 1.1: The Tower of Babel by Pieter Bruegel the Elder https://commons. wikimedia.org/wiki/File:Pieter_Bruegel_the_Elder_-_The_Tower_of_Babel_ (Vienna)_-_Google_Art_Project.jpg. DOA 12 June 2019.

(Latin speculum, that is mirror) also gained adherents. It postulated that the structure of language, understood as part of the speech system, reflects reality through the ability of words to represent reality in three different ways (Latin modi significandi, hence "modism"): what a given thing is (modus essendi), how it is understood (modus intelligendi) and how the word referring to this thing fulfils the representational function (modus significandi) (Rogalski, 2008). Modists, and Roger Bacon in particular (1214-1294), were the precursors of the idea of "universal grammar" which assumes that the structure of all languages is fundamentally the same.

An important element for the development of reflection on language was the problem of arbitrariness. The best-known classical text discussing the arbitrariness of language is the Platonic dialogue Cratylus. The dialogue contrasts two views on the relation of words (Greek onomata) to reality: the first position, expressed in the text by Hermogenes, assumes 
that the meaning of words is the result of a contract or convention (Greek sunthéke $\bar{e}$ ) and refers to the philosophy of the sophists. Cratylus is the adversary of Hermogenes who claims that there is a natural relationship between names and their references, and thus proposes an onomatopoeic scenario for the genesis of words. Although the dispute is not settled by the end of the dialogue, it had a great influence on the philosophy of the Middle Ages. One of the commentators of that time was a Neoplatonist philosopher Proclus (412-485 AD), who stated that Plato himself had been a proponent of naturalism, understood as a motivated bond between the signifier and the signified (see Pickstock 2011: 259, note 21).

Based on Plato's authority, naturalism contributed to the emergence of the medieval etymological tradition. Its best-known advocate was Isidore of Seville (560-636), the author of the voluminous work Libiri Etimologiarum (also Codex Etimologiarum). The goal that Isidore and his followers set themselves was to reconstruct forms of expression so that it would be possible to determine the original onomatopoeic relationship between the reconstructed word and its meaning. And so, Isidore argues: "[They are called] ... lashes (flagrum) and floggings and scourges (flagellum) because they resound on the body with a whistling (flatus) and a crack" (Barney et al., 2006: 124).

However, in later medieval philosophy, which appreciated the complexity of the relationship between language, the world, and the mind, the conviction regarding the conventional nature of linguistic meaning was articulated. The most influential version of conventionalism was proposed by William of Ockham (1287-1347). The key concept of this idea is signification which, as Ockham states, consists of two basic types: verbal signification and conceptual signification. According to Ockham, verbal signification, which concerns the representation of individual words, is arbitrary (i.e., it is not based on the similarity between the word form and its meaning) and is an expression of a contract between users (e.g., English speakers use the form $d o g$, while French speakers use the analogous form chien). Verbal signification is different from conceptual signification described by Ockham as involving natural signifiers - i.e. those that resemble in a justified way what they relate to, in the way that the concept of a dog captures the features common to many individual dogs. Ockham's theory of signification separated the representations of word forms from 
their conceptual content and equated conventionality with arbitrariness. These two threads, clearly visible over the centuries, have not lost their relevance and form the basis for the modern understanding of lingusitc meaning in Ferdinand de Saussure's work (1916) on the one hand, and on the other in the works by Charles K. Ogden and Ivor A. Richards (1923).

\section{Jewish tradition}

A similar change took place in the Jewish intellectual tradition. The view of the natural relationship between the word and the meaning occupied an important place in religious currents such as the Kabbalah or the exegetical tradition of midrash (Hebrew: Midrashim), where religious experience is often understood as finding a pure language - the "breath of God" (Hebrew: ruach elohim), which is key to understanding the divine and earthly realities (Cesare, 2011: 89). The original version of naturalism was developed by the influential Kabbalist Abraham Abulafia (1241-1291), one of the leading scholars of the medieval Kabbalah. Abulafia refers to gematria, or numerology based on the Hebrew alphabet, and aims to show that Hebrew is the model for all languages, illustrating his considerations with examples from such languages as Arabic, Basque, Greek and Latin (Idel, 1989: 1-26). On the other hand, Philo of Alexandria espoused naturalism, referring to the Greek philosophy of language. Although the Kabbalistic fascination with Hebrew has never disappeared, there was a significant, intellectual change in the mainstream Jewish thought. This stems in particular from the thought of Moses Maimonides (1138-1204), one of the greatest minds of the Middle Ages, who inspired Thomas Aquinas and contributed to the creation of scholastic philosophy. Maimonides consistently fought against Jewish mysticism, including the view of the special status of Hebrew, which he believed had the same power of expression as other languages (Kellner, 2006: 166). His views on meaning, influenced by both Plato and Aristotle, could be described as conceptualism, similar to Ockham's proposal, whose characteristic feature is treating the linguistic sign (Greek semeion, Hebrew, simman) as a symptom indicating the existence of a concept or an idea in the mind of the language user. Maimonides used this theory of meaning as an argument for his negative theology, according to which the category of divinity is completely beyond human comprehension: if language, in Maimonides' approach, refers primarily to 
concepts and ideas in the human mind, it does not grant any possibility of describing the attributes of God, even with the use of metaphors or other non-literal devices (Benor, 1995).

\subsubsection{Reflections on language in Indian philosophy}

Interestingly, the dispute between linguistic naturalism and conventionalism did not take place only in Western circles. The best-known nonoccidental version is found in classical Indian philosophy, where the cult of the Vedic scriptures and the role of Sanskrit were conducive to the development of naturalistic views. They became the foundation of the philosophy of mimanmsāa, whose adherents, through the deification of Sanskrit, sought to defend the authority of the Vedic scriptures. They argued that words as ideal objects (Sanskrit: pada) have different physical, or phonic, realisations (Sanskrit: dhvani). Sometimes words are spoken quietly, sometimes loudly, sometimes clearly, sometimes vaguely. In spite of this instability, words invariably refer to appropriate meanings. This is because, due to their internal potency (Sanskrit: sakti), words refer to substantially existent general properties (Sanskrit: sāmānya) with which they are naturally associated (Sanskrit: svābhāvikaka). The natural and direct relationship between words and general properties is particularly marked in the case of terms from Vedic Sanskrit, which is regarded as a language par excellence (see Dreyfus, 1997: 214-213; Żywiczyński, 2004).

Supporters of this school believe in the divine nature of language, especially Sanskrit, which has existed since the beginning of the Indian civilisation. An important expression of this view is the cult of Vāc - the Hindu goddess of speech. She is mentioned in the Rigveda, the oldest part of the Vedas. According to a later myth, the world was created by the union of Prajāpati, the creator of creatures, and the goddess Vāc. Similarly to the Greek logos, Vāc is viewed as an intelligible principle of the world; however, in contrast to the Greek conception, Vāc is not an abstract principle, but it exists as Sanskrit stanzas of the Vedic revelation (Dreyfus, 1997). The Hindu concept of language diversification contains a story similar to the Biblical message, in which the "Tree of the World" (Sanskrit: aśvatthahvrksha, often identified as Ficus religiosa) decided to grow to such an extent that all people could find shelter beneath it. The god Brahma punished the proud tree, cutting off and scattering its branches across the earth, out 
of which banyan trees (Ficus benghalensis) sprouted, thus giving rise to various languages and customs (Doane, 1910: 36). Unlike Christians and Jews, Hindus did not argue about the language that had prevailed before the diversification and agreed that the original language - Sanskrit - was preserved in the Vedic scriptures.

The radical naturalism of mimmāmsa-which resembled some conceptions of the Adamic language - met with opposition coming both from those who acknowledged the spiritual authority of the Vedas, and those who followed heterodox religious currents, mainly Buddhism. The most influential anti-naturalistic position was articulated within Buddhist philosophy (Dreyfus, 1997; Żywiczyński, 2004). According to the traditional Buddhist ontology, only what is momentary, literally what only lasts for a moment (Sanskrit: kșana), has the status of "being” (Sanskrit: bhāva). Speaking in the language of Buddhist philosophy, only momentary entities have "causative power" (arthakriyāśakti), i.e. the power to create further temporary entities. In the dualistic conception of abhidharma, such a capacity is characteristic of the sets of atoms disintegrating after a while (Sanskrit: paramānu), whose disappearance brings to life the aggregations of atoms existing in the next moment, as well as discrete moments of consciousness (Sanskrit: vijñanna), which are the cause of the subsequent moments of consciousness. The Buddhist doctrine of temporality (Sanskrit: kșanika) denies that phenomena that make up the world of everyday experience, such as material objects or personality traits, have the status of being. Since, as argued by Buddhist philosophers, language (Sanskrit: śabda) refers to such phenomena (arthasamanya, literally "an object's generality"), it therefore acts to reinforce the illusion of permanence. Hence, in the philosophies of mimàmsa and Buddhism, there are two extremely different concepts of language: on the one hand, language is seen as the key to understanding reality; in the other approach, language is responsible for hiding the nature of reality (cf. the "veil of language", above).

\subsubsection{Summary}

In this section, we have tried to capture the themes that characterise traditional reflection on language and its origins. The religious phase is 
defined by a belief in the divine origin of language. Language is sanctified because it comes from a deity, or is itself a deity, as in the case of the Hindu goddess Vāc, or its creation is at least inspired by the deity. Deification of language is usually combined with semantic naturalism, according to which words (e.g. of the original Hebrew, as believed in the Kabbalistic tradition, or of Vedic Sanskrit, as believed by Mīmāṃsiks) are not accidental but express the essence of their referents. Thus understood, the language not only reflects reality in an undistorted way, but also becomes an ordering principle: in Abulafia's approach, the biblical Hebrew is the model of all languages, while the supporters of mīmāmsa go even further and believe that Vedic Sanskrit is the intelligible principle of the world. Traditional religious approaches to the origins of language, apart from the problem of its very origin, suggest mythological explanations of polylingualism (the existence of a multitude of languages). Language diversification is presented as a result of a divine intervention, which is usually negatively evaluated as the loss of a language common to all people. Although our discussion refers only to a selection of issues of the occidental and Indian philosophies, according to the findings of anthropologists and religious scholars, myths about the divine origin of language and its diversification are a common mythological motif (see e.g., Allison, 1971 or Carneiro, 2001).

The second phase of the traditional reflection on language and its origins, referred to as the "scholastic" phase by Cabezón, took place apparently only within the occidental, Indian and probably Chinese thought. The characteristic feature of this new approach was stepping away from a literal interpretation of the sacred texts - in the Christian tradition, this is visible in Augustine, and in the Judaic tradition, in Maimonides. The naive conviction about the natural bond between words and things was replaced by a reflection that emphasises the complexity of the relationship between language, the world and the mind, and that often does not trust the knowledge mediated by language (see "veil of language" by Augustine or the linguistic scepticism in Buddhist philosophy). In early modern Europe, this state of reflection on language clashed with changes caused by the Copernican revolution, which gave rise to research into language origins as a part of a new, scientific approach. 


\subsection{Glottogenetic thought: A naturalistic concept of language emergence}

As noted by Gordon Hewes (1977a: 98), an important condition for the development of naturalistic concepts of language origins was the increase in knowledge about distant countries and populations, resulting from the Age of Discovery at the turn of the $15^{\text {th }}$ and $16^{\text {th }}$ centuries. This kind of speculation will be referred to as "glottogenetic reflection", to contrast it with both the earlier thought on the origins of language referring to religious revelations and the strictly scientific approach within the "evolution of language".

\subsubsection{How to recover from the state of nature?}

Interest in the "wild" man was connected with questions about the universal features of humanity and the nature of civilisation. In this context, views on the origin of people and language that contradicted biblical stories gained popularity. Giordano Bruno revived the pre-Adamism of the late antiquity, which denied that all people came from the biblical Adam (Graves, 2003: 25). What is more interesting, however, was the search for naturalistic explanations of how people had left the state of "savagery", gaining the attributes of humanity, among which was language (see Hewes, 1977a: 98). Even in ancient philosophy, there had been threads that anticipated such reflection. Although most of the ancient Greeks and Romans adhered to the belief that language was given to people by gods, the Epicurean tradition attempted a naturalistic explanation of how language had originated. Epicurus argued that words (onomata) arose as a natural expression of internal emotional states and concepts, which then underwent conventionalisation within particular ethnic groups:

So, originally it was only in virtue of express agreements that one gave names to things. But men whose ideas and passions varied according to their respective nations, formed these names of their own accord, uttering divers sounds produced by each passion, or by each idea, following the differences of the situations and of the peoples.

(Diogenes Laërtius Letter to Herodotus X)

The development of this concept can be found in Lucretius, in the poem De rerum natura, along with an interesting analogy in which the creation 
of the first words is compared with gestures made by a child who is not yet able to speak. ${ }^{4}$

The return to ancient philosophy and naturalistic thinking, which lay at the basis of the Renaissance, contributed to the popularity of the Epicurean view on the beginnings of language. Pierre Gassendi (15921655), a prominent mathematician and Catholic priest, argued in favour of empiricism in Syntagma philosophiae Epicuri. ${ }^{5}$ Another Catholic priest, the biblical scholar Richard Simon (1638-1712), wrote Histoire critique $d u$ Vieux Testament (A Critical History of the Old Testament), in which he fiercely opposed the view of the divine origin of language (see Formigari, 1988: 8). In turn, the lawyer Samuel von Pufendorf (1632-1694) in De Jure, discussed the issue raised by both Epicurus and Lucretius that the conventionalisation of language resulted from the progress of civilisation, which required a new means of coordinating actions (Formigari, 1988: 29).

\section{Vico}

Giambattista Vico (1668-1744) also advocated the Epicurean rationale for the origins of language (Formigari, 1988: 276) although he did not avoid criticising Epicurean philosophy for its materialistic reductionism (Vico, [1725] 1948: 90-92, 150, 210-211). In his work, The New Science (Scienzia Nuova, 1725), he presents the hypothesis that the first language, which he describes as the language of gods, did not have a vocal form, but relied on gestures, pictograms, artefacts and religious rituals. This communication system used analogy and iconicity as the basic tools for conveying meaning, and was a natural system in which semantics was based on similarities literal or metaphorical - between the form of the sign and its reference (Vico, [1725] 1948: 125-126). Referring to Plato and Iamblichus (245-325 BC), Vico claimed that the inhabitants of Atlantis communicated using such a language. In the next era (i.e. during the "age of heroes", according

4 For an overview of the concept of the origin of language in Epicurus and Lucretius, see Reinhardt's "Epicurus and Lucretius on the Origins of Language" (Reinhardt, 2008).

5 Full title: Syntagma philosophiae Epicuri: cum refutationibus dogmatum quae contra fidem Christianam ab eo asserta sunt. Lyon: Guillaume Barbier, 1649. 
to Vico's chronology), language underwent gradual conventionalisation without losing its original metaphorical character, and the dominant form of its expression was poetry. In the last era, which Vico called the "age of people", language was already a system of conventionalised graphic and vocal symbols that enabled the expression of thoughts. The author of The New Science argued that the three stages of development, which mark the epochs of the gods, heroes and people, determine the general development of humanity, the development of individual communities, as well as the child's development. According to Vico, in the development phase corresponding to the age of gods, children primarily try to understand the surrounding creatures and objects with the help of perceptual attributes; in the second, heroic phase, children identify with the heroes of the cultures in which they are raised, and with the power of fantasy they create innumerable imagined situations and roles; in the end, the transition from childhood to adulthood is connected with the acquisition of abstract thinking, which marks the entry in the age of people (Vico, [1725] 1948: 66-70, see also Danesi, 1993: 64-66). One should therefore consider Giambattista Vico not only one of the first proponents of the idea of gestural protolanguage, but also a pioneer in postulating a relationship between onto- and phylogenetic processes.

\section{The beginnings of comparative research}

Vico and other thinkers of the $16^{\text {th }}$ and $17^{\text {th }}$ centuries working in the Epicurean tradition articulated the evolutionary conviction that humans obtained such features as rationality, socialisation, or language through the influence of natural causes. Thus began the erosion of the barrier between animals and humans that traditionally characterised intellectual discourse in Europe. Of course, the old view still had many prominent supporters, such as Descartes (1596-1650), who believed in the total separation between people, characterised by rationality, and animals - creatures devoid of internal experiences and resembling machines. To him, it was the use of language that was a testimony to this qualitative difference between people and animals, which attested that people had souls and thoughts, whereas animals lacked these qualities.

On the other hand, the exploration of the fauna of Africa, Asia and America made Europeans aware that species similar to humans existed. It 
is in this context that we see the birth of comparative research. A Dutch physician Nicolaes Tulp (1493-1674) made the first dissection of an African ape, and was surprised by its morphological similarity to humans (Hewes, 1977a: 99). Edward Tyson (1651-1708) is considered to be the father of comparative anatomy, and his book Orang-Outang, ${ }^{6}$ published at the dawn of the Enlightenment (1699), exerted a great influence on the perception of relations between apes and humans. The title Orang-Outang does not refer to the orangutan (Pongo), the ape that lives in the forests of Borneo and Sumatra. Tyson, exploiting the original meaning of the term (which in Malay means "inhabitant of the forest"), applies it to the chimpanzee (Pan) (1699: 3-5) and, having dissected it, describes the animal's anatomy in detail. While it is not known if it was a common chimpanzee (Pan troglodytes) or a bonobo (Pan paniscus), Tyson concludes that the specimen was more related to humans than to primates, and further states that neither the structure of its larynx nor the brain would preclude the use of language by such a creature (Hewes, 1977a: 99).

During this period, it was uncertain who should be included in the species Homo sapiens and who is able to use language. Europeans often refused to regard the members of tribes they considered wild as "human". When in 1502 Sebastian Cabot brought natives from an expedition to the Arctic and exhibited them in London, a witness to this event described the arrivals as representatives of a primitive species whose speech was like that of beasts (Nash, 2009: 56). Although Pope Paul III in his Papal bull Sublimus Deus (1537) stated that Native Americans are humans, which opened the possibility for missionary work in America, the discussions regarding to what extent they were humans lasted a long time (Robe, 2009: 47-51). Such doubts concerned not only the inhabitants of the Americas, but also those who lived in other, little-known parts of the world. For example, in $17^{\text {th }}$-century England, the Hottentots, or members of the Khoikhoi ethnic group inhabiting South Africa, were generally considered to be animals. A preacher who visited the Cape of Good Hope in 1615 argued that they are "beasts in the skin of men, rather than men in the skins of beasts", and their

6 Full title Orang-Outang, sive Homo Sylvestris: or, the Anatomy of a Pygmie Compared with that of a Monkey, an Ape, and a Man. 
speech is "an articulate noise rather than language, like the clucking of hens or gobbling of turkeys" (Novak, 2009: 188). Thomas Herbert (1606-1682) spoke in a similar fashion on the pages of a popular travel book Some Yeares Travels into Africa and Asia the Great, where he suggested that the language of Hottentots was something between a human language and sounds produced by animals; when speaking of this ethnicity, he concluded that they are the descendants of satyrs, mentioned in the writings of ancient authors (Novak, 2009: 188).

It was not only preachers and travellers who encountered problems with the definition of "human", but also those who constituted the intellectual avant-garde of Europe at that time. Even in the $18^{\text {th }}$ century, which was the golden age of taxonomies, there was a belief among many naturalists that there are inferior forms of the human species - subhumans - which were collectively referred to as Homo ferus or "wild men". This conviction was shared by the inventors of biological systematics, Carl Linnaeus (17071778) and Georges-Louis Buffon (1707-1788) (see Burke, 2009: 266). In subsequent editions of his work Systema Naturae (1735-1758), Linnaeus worked on the definition of Homo (which he did not cosider a genus but a spieces), which included - as a morpha-Homo sapiens (Burke, 2009: 266), and finally, in the tenth edition, presented a complete description of the species. He distinguished two varieties: Homo sapiens and Homo troglodytes. Homo sapiens included types corresponding to four races: American, European, Asian and African, as well as Homo ferus, the wild man who was hairy all over his body, moved on four limbs and was supposed to be mute. In turn, representatives of the troglodytes species were to be active at night, live in caves and have a communication system that was based on hissing and whistling.

Linnaeus' disciple Christianus Hoppius focused on "organising” the taxonomic description of man, and described five varieties of the Homo species: along with Homo sapiens, there was Homo troglodytes, Homo caudatus, who supposedly had a tail and lived on the archipelago of the Nicobar Islands, Satyrus tulpii (chimpanzee) and Pygmaeus edwardii (orangutan) (Burke, 2009: 266-270). One may smile when reading about Linnaeus' and Hoppius' classification ideas, which were used by the founder of biological anthropology, Johan Friedrich Blumenbach (1752-1840), but it should be remembered that large areas of the world in the $18^{\text {th }}$ century 
remained unknown to Europeans and all travel revelations aroused interest and stimulated the human imagination.

The efforts of Linnaeus and other biologists of this period testify to the difficulty of carrying out the taxonomic characterisation of humans. Comparative primatology was in the initial stages of its development (see Tulp and Tyson above), and there was simply a lack of empirical material to establish species-specific differences between apes, including the definition of Homo sapiens. This state of affairs was conducive to various kinds of speculation that derived inspiration from travellers' tales. The problem of language as characteristic of the human species occupied an important place in these speculations. On the one hand, as already noted, a popular view assumed that at least some non-Europeans lack language, and their speech bears strong similarities to the communication of wild animals; on the other, it was also argued that great apes either have language or are able to learn it. We have already mentioned that Tyson was a supporter of the latter position. Samuel Pepys (1633-1703), in his famous Journal ([1666] 1970), describes a primate brought from Angola (it remains unknown whether it was a baboon or a chimpanzee) and wonders whether it would be possible to teach it to speak or communicate with manual signs (cf. Hewes, 1975: 5-6). Julien Offray de La Mettrie (1709-1751), one of the first advocates of French materialistic thought, wrote Machine Man (L'homme machine [1748] 2011), in which he not only states that apes are able to learn a language, but also proposes how to achieve this goal. La Mettrie was keenly interested in attempts to create sign languages for the deaf, which were described in The Talking Deaf Man (1692, Surdus loquens) by the sign language pioneer Johan Konrad Amman (1669-1724). La Mettrie expresses the view that an ape would be able to acquire a language if it were to be taught using the system that Amman ([1692] 2009) adopted in his work with deaf people. What is more, the French thinker concludes that a properly raised ape could be completely socialised and become a "real human being, a small man of the town" (La Mettrie, [1748] 2011: 35; cf. Hewes, 1975).

\section{Monboddo}

In $18^{\text {th }}$-century Britain, a figure that drew attention to the problem of language origins was an eccentric Scottish judge, James Burnett, better 
known as Lord Monboddo (1714-1799). ${ }^{7}$ In a six-volume study entitled Of the Origin and Progress of Language (1774) he presented a naturalistic account of the emergence of man and language, which referred to the latest biological and ethnographic findings. Monboddo devoted a lot of attention to the principles governing the development of languages. He argued that the original languages consisted of monosyllabic words in the imperative mood. He tried to explain the phonetic and grammatical changes that led to the formation of many different languages as a result of migration and social change. Monboddo, for the purposes of his speculations, drew examples from non-European languages - Tahitian, the Huron language, Indian Caribbean languages, Eskimo, Algonquian and Araucanian languages and it would be perfectly reasonable to call him the father of comparative philology. It was comparative reflections that led him to the idea of monogenesis of both language and man.

Monboddo shocked the British public with the thesis that man had evolved from an ape. Citing Tyson, he claimed that the "orangutan" (the name used to refer to apes at the time) and man belong to the same species (1774, vol. 1: 360). In addition, citing in turn his own informants, he argued that these "orangutans" exhibit socialisation, characteristic of humans, and have rudimentary technology, although they lack language:

Orang-outangs live together in society; act together in concert, particularly in attacking elephants; build huts, and no doubt practise other arts, both for sustenance and defence: ... they may be reckoned to be in the first stage of human progression, being associated, and practising certain arts of life; but not so far advanced as to have invented the great art of language. (Monboddo, 1774, vol 1: 268-269 in Lovejoy, 1933: 285)

Monboddo's descriptions of apes are often full of sentimentalism, and he does not hesitate to attribute such qualities as modesty, honour, justice, and civility to "orangutans" (1774, vol 1: 289-293). When it comes to the origin of man, Monboddo proposes an evolutionary scenario, according to which people were not originally different from the "orangutans" described above, and even exceeded them in brutality (1774, vol 1: 147). However, thanks to the innate pursuit of perfection, man has gradually grown out

7 The reconstruction of Lord Monboddo's views is based on the works of Arthur Lovejoy (1933) and Alan Barnard (1995). 
of the state of nature by creating language, institutions of social life and intellectual culture (1774, vol 1: 360, 437-441). According to the influential historian of ideas, Arthur Lovejoy, Lord Monboddo - with the thesis that man evolved from an ape - should be considered the first British advocate of biological evolution, whose work preceded the classic exposition of evolutionism by Erasmus Darwin (1731-1802) Zoonomia (1794-1796) (Lovejoy, 1933: 289).

The Scottish thinker was also interested in the discussions of wild or feral children, who had captured the imagination of many in Europe at the time. Monboddo himself visited one of them - Peter the Wild Boy (c. 1711-1785, German: Wilder Peter von Hameln), a handicapped boy who was found in 1726 near Hamel in northern Germany. Peter had fed on plants found in the forest and walked on all fours; he never learned a language. When Monboddo visited him in 1782, 70-year-old Peter had been in England for many years and, as the author of $O f$ the Origin and Progress of Language reported, Peter could only barely pronounce two phrases: "Peter" and "King George” (1811, see Hewes, 1977a: 15). For Monboddo, Peter was a link between an orangutan and a fully formed man; he argued that Peter's lack of language shows that man in a state of nature, like an orangutan, does not have language, and can only acquire it through a process of civilisation (Novak, 2009: 194-196).

Another thinker who was particularly concerned with feral children was Jean Marc Gaspard Itard (1774-1834). His work, Mémoire et Rapport sur Victor de l'Aveyron, ([1801] 1802) tells the story of a wild child, Victor (1788-1828), and Itard's efforts to teach him to speak. For many months Itard tried to teach Victor to speak French through laborious exercises which involved imitation. ${ }^{8}$ Although Victor - as Itard says - had properly developed senses, was in full mental power and was able to communicate using gestures and pantomime, the efforts to teach him language failed. ${ }^{9}$ Itard concludes with the view that imitative abilities, which he saw as

8 Although Itard knew of attempts to create sign languages, undertaken by the Parisian school for deaf-mutes (L'Institut National des Sourds-Muets) and elsewhere, he did not decide to teach his pupil any communication system that would be based on signing.

9 Victor grew to say two French phrases: lait ("milk") and Mon Dieu ("My God"). 
primarily enabling language acquisition, disappear with puberty: "It may be observed, that this imitative power, adapted for the education of all his organs, and especially for the acquisition of speech, although very energetic and active during the first years of life, is rapidly enfeebled by the progress of age, insulation, and from all other causes which tend to deaden the nervous sensibility" ([1801] 1802: 144). Therefore, it can be said that Itard is the author of the first formulation of the critical period hypothesis.

In the Enlightenment, a lot of reflection on the origin of language was focused on the issue of how humanity had managed to emerge from the state of nature. It was debated whether humans had been noble in nature, as Vico, Rousseau or Monboddo maintained, or whether we had been selfish and brutal, as Hobbes argued in Leviathan (1588-1679), and whether language and socialisation were characteristic of man already in the wild state, or were they the result of the process of civilisation.

\section{Mandeville}

An increasing number of thought experiments began to be formulated about what sort of communication system would be developed by children left outside society. The character of this hypothetical communication system was thought to resemble the original language of mankind. In the second edition of the famous economic and social poem entitled The Fable of the Bees (1728), Mandeville stated that children would use gestures because gestures are humanity's most natural form of communication and have more expressive power than speech. He further argued that gestural communication would be accompanied by cries associated with emotions which, according to Mandeville, were innate to all human beings (1728: 286-287).

The expressive potential of gestures and the innateness of emotional cries led Mandeville to the thesis that the original human communication system had to be based on these two types of signals. He assumed that many generations must have passed before this gestural-exclamatory protolanguage could evolve into vocal language, and regarding the reason for the change in modality, he stated that sound is better at communicating phenomena that are not grasped by the senses. He also highlighted the role of children in the development of language, and spoken language in particular. In doing so, he appealed to the view already present in his day that children's articulators have greater plasticity that those of adults. 


\section{Condillac}

Historical reconstructions often identify Étienne Bonnot de Condillac (1715-1780) as the author of the gestural hypothesis of the origin of language, ignoring Mandeville (see Johansson, 2005), or mentioning him only briefly (Hewes, 1975, 1976, 1977b; Fitch, 2010). The description of the origin of language presented in Condillac's work Essai sur l'origine des connaissances humaines, (Essay on the Origin of Human Knowledge, [1746] 1756), was widely known and discussed during the Enlightenment in Europe, mainly due to the influential role that its author played in the intellectual life of the time. However, it should be noted that although the French thinker never refers to Mandeville, Condillac's narrative is a fairly faithful copy of the scenario which Mandeville presented in The Fable of the Bees. ${ }^{10}$ In the second part of the Essay on the Origin of Human Knowledge, Condillac proposes the same thought experiment: two children, a girl and a boy, find themselves in the wilderness and live in seclusion before they gain a knowledge of any language. Condillac asks whether they will discover a language themselves, and if so, what it will be and how it will develop among the couple's descendants ([1746] 1756: 169-170)?

Unlike Mandeville, the French philosopher, who was also a Catholic clergyman, puts his story in a biblical context, proposing that the isolation of children was caused by the Deluge. However, the course of the experiment itself is told in a fashion similar to what we find in Mandeville's writings. Condillac states that children will begin to communicate with each other using a natural language consisting of emotional cries accompanied by the movements of the entire body ([1746] 1756: 172). Repetition of these vocalpantomimic combinations will lead to their conventionalisation, which will accelerate the communication process, and sharpen mental abilities, thanks to which the language users will be able to create more pantomimic signs ([1746] 1756: 173-174). Subsequent explanations refer back to Mandeville's scheme - the emergence of vocal language is going to take

10 This similarity was noticed and described by Frederick Benjamin Kaye (1924). The following description is based on Kaye's analysis. Condillac had access to a French translation of Mandeville's work, which appeared in 1740, 6 years before the publication of the Essay on the Origin of Human Knowledge. 
a long time mainly due to the "stiffness of the tongue", and successive generations of children will be responsible for its development because they surpass adults when it comes to the elasticity of their articulatory organs ([1746] 1756: 174-175). Another factor which, according to Condillac, will impede the development of spoken language is the great expressiveness of pantomimic communication, or - as he described it - the "dance of gestures" and the "dance of steps". For a long time, language would have exploited two modalities: the visual and the vocal. Condillac even sought to document the existence of bimodal languages, citing for example the testimony of Herodotus and the Old Testament ([1746] 1756: 176-177).

As already noted, Condillac was an influential figure in French intellectual life. He was a close friend and collaborator of Denis Diderot (17131784) (he prepared several entries for Diderot's Encyclopaedia) and of Jean-Jacques Rousseau. Condillac was also a member of the Académie française, the first academic society in the world, founded in 1635. Certainly, Condillac's position contributed to the popularisation of his version of the story of the beginnings of language at the expense of Mandeville's narrative. More importantly, the Mandeville/Condillac scenario was in line with the $18^{\text {th }}$ century state of knowledge about man, from both a biological and a cultural perspective, which certainly contributed to its popularity. Their story referred to the taxonomic ideas of Linnaeus, nascent research on primates, as well to the studies of feral children and the deaf. It was in keeping with the beliefs of what a Homo ferus is and how human nature is influenced by civilisation (Homo politus). No wonder that Condillac's account was widely accepted by thinkers of the Enlightenment. Even scholars who were not interested in studying the origins of language, such as Diderot or Voltaire, accepted his solution because at the time it seemed to make the most sense (see Hewes, 1975: 6, 1976: 483).

\section{Rousseau}

Jean-Jacques Rousseau (1712-1778) was another intellectual giant of the Enlightenment who put forward a scenario of language emergence. For the Genevan thinker, an explanation of the emergence of language was an important element of his theory of the development of humanity. His view of human development expressed antinomic motifs: on the one hand, the apotheosis of the wild state in which man once lived; on the other, 
Tyson's orangutan - an ape deprived of language. However, it should be remembered that Rousseau, especially in the Discours sur l'origine et les fondements de l'inégalité parmi les hommes (1755), distinguishes the state of nature from the state of savagery. ${ }^{11}$ Man in the state of nature leads an animal life that Rousseau compares to the life of a gorilla - lonely, focused on physical needs, and free from any moral constraints (cf. Lovejoy, 1923: 170-173).

Though far from ideal, living in the state of nature, in the bonté naturelle, gave man much more happiness, despite the fact that it was a happiness derived entirely from physicality, unregulated by social norms (Lovejoy, 1923: 171). The progress of humanity began as struggle for survival described by Rousseau in a truly Darwinian (or Spencerian) style: when it was more difficult to obtain food, man began to compete more with other species, being often attacked by carnivorous animals: “[n]ature treats them in exactly the same way as Spartan law treats the children of citizens; it supports and strengthens ones' in shape, and kills all the others..." ([1755] 1965: 145). This led to the development of a typically human characteristic - le caractère spécifique de l'espèce humain - intelligence, understood by Rousseau as the skill of self-improvement, faculté de se perfectionner (Lovejoy, 1923: 174). This feature was initially used for survival and facilitated the invention of primitive tools, weaponry, control of fire, and adaptation to life under different environmental conditions, which enabled man to explore and grow in population. In this way, the benefits of intelligence gradually led humanity to change their way of life - from an animalistic existence in which people, driven by l'amour de soi-même, cared only for their individual well-being, to a socialised life that was dominated by l'amour propre - a tendency to compare with others and to compete for power, recognition, or material goods (Lovejoy, 1923: 178). In this way, civilisation pushed man towards egotism and the constant discontent resultant from it. The intermediate level between animalistic and civilised life was the state of savagery, understood by Rousseau to be the first stage of social development based on a patriarchally organised family. Savagery

11 The reconstruction of Rousseau's views on social evolution presented in the book is based on Lovejoy's work The Supposed Primitivism of Rousseau's "Discourse on Inequality" (Lovejoy, 1923). 
allowed people to enjoy the achievements of civilisation without losing themselves in the egotism characteristic of later hierarchical communities (Lovejoy, 1923: 179). For this reason, the epoch of savagery - or of sociétés naissantes - was, according to Rousseau, the best period in human evolution, and it was at this level of development that he placed the "savage" peoples from travellers' descriptions, glorifying the simplicity of morals and political egalitarianism which he attributed to their mode of life (Lovejoy, 1923: 179-180).

Rousseau's views on the origins of the language, which he presented primarily in the Essay on the Origin of Languages (L'Essai sur l'origine des langues, published posthumously in 1781) and partly in his pedagogic treaty Emile, or On Education (Émile, ou De l'éducation, 1762), are strongly associated with his theory of social development. In the state of nature, man did not have language, although he was able to express simple ideas with gestures and emotional cries (see Hewes, 1976: 484). The development of intelligence and the progress of socialisation resulted in an ongoing improvement of this basic system of communication. Gradually, two communication modalities were adopted for separate functions: the pantomimic-visual modality was used to communicate everyday events and objects, while the voice was used to express emotions and excite others with melodies (Hewes, 1976: 484). Although Rousseau accepted Condillac's scenario, in the Essay on the Origin of Human Knowledge ([1746] 1756) he objected to the assumption that the mere use of pantomimic-vocal language transmitted from generation to generation of users will lead to the emergence of a modern language based on articulated sounds and conventional meanings. According to him, the emergence of articulated speech and a system of fully conventionalised signs that could refer to abstract concepts developed as a result of the migration of people to the north (Hewes, 1976: 484). More difficult living conditions were conducive to the emergence of larger and more organised communities, which in turn required a better means of coordinating activities, i.e. a more conventionalised communicative system, for the development of which - according to Rousseau - the vocal channel was more suitable than the visual one (see Hewes, 1976: 484). In the treatise Emile Rousseau disconsolately states that this change made the human voice lose its original expressive-musical function (Hewes, 1976: 484). 


\section{Herder}

The essay contests organised in Berlin by the Royal Academy of Sciences were an important forum for debates about human nature. ${ }^{12}$ The members of the Academy included the luminaries of $18^{\text {th }}$ century Europe: Montesquieu, Diderot, Kant, Voltaire or the Grimm brothers. The competition, which was announced in 1769 , concerned a glottogenetic question: "Was man able to create a language only through the power of his own intellect?" The anonymous author of the essay number two claimed that language arose from gestures and emotional cries, but he did not give any arguments in support of this thesis; in the essay number five there was an interesting comparative remark that apes can imitate sounds, although for reasons yet unknown, cannot imitate human vocalisations. In turn, Copineau, one of the few participants whose name we know, argued that children deprived of socialisation are able to develop systemic forms of communication, one of which would be based on gestures and movements of the whole body similar to signs used by deaf people (Hewes, 1975: 8-9, 1976: 485).

Johann Gottfried von Herder (1744-1803) won the competition with a work published in 1772 entitled Abhandlungüber den Ursprung der Sprache (Treaty on the Origin of Language, 1967-1968), which opens with the sentence: "Already as an animal man had language" ("Schon als Tier hat der Mensch Sprache”). Herder thus considered the matter of language in a fundamentally different way than Monboddo, Condillac or Rousseau did - which is somewhat reminiscent of the idea of the divine origin of language. Yet, he also rejected such an alternative, with the Treaty being conceived as an attack on the work of the Lutheran philosopher and pastor Johann Peter Süssmilch (1766). Süssmilch's ideas had enjoyed popularity in German-speaking circles, notably his claim that language, due

12 Following the initiative of Gottfried W. Leibniz in 1701, the Prussian Academy of Sciences (Preussische Akademie der Wissenschaften) was established. It was reformed by Frederick II in 1774 and renamed the Royal Academy of Sciences (Königliche Akademie der Wissenschaften). It was the first scientific institution that integrated the natural sciences and the humanities. More about the role of the Society in the intellectual life of $18^{\text {th }}$-century Europe can be found in the monograph by Avi Lifschfitz (2012). 
to its complexity, must come from God (Kastinger Riley, 1979: 617). ${ }^{13}$ Herder strongly advocated a naturalistic scenario for the emergence of language, and his starting point was the analysis of emotional cries, in particular those caused by pain. According to Herder, screams, sighs, and sounds triggered off by pain were already a language, because on the one hand they had a communicative function indicating a certain emotion or physical state, and on the other they had a representative function, because emotional cries were the expression of the inner Sprache, a feature which enables humans to recognise various sounds and connect them with mental representations (1967-1968: 40, 60; Kastinger Riley, 1979: 618). What distinguishes man from animals are the abilities to represent and to perfect what is already present in the perceptual and emotional experience of physicality. Herder is probably the first thinker who used the analogy between language and the bee communication system. In his comparison, he did not deny that animals lack communication skills, and such communication is exemplified by the behaviour of the honey bee; he claimed, however, that the communication of bees is not based on representations and, more importantly, it is completely innate - bees during their lifetime are unable to improve it (1967-1968: 97). Man has always had language, because being human means having the power to construct mental representations, connect them with signals, and refine a communication system (Kastinger Riley, 1979: 619).

This led Herder to criticise Condillac's and Rousseau's glottogenetic scenarios; he claimed that the first of the two turned animals into humans, and the other aimed to turn people into animals (1967-1968: 21-22). The accusation against Condillac concerned the assumption adopted in The Origin of Human Cognition ([1746] 1756) that man was able to elevate himself from the state of nature by perfecting the capacity for articulation. Herder noted that the development of language could only take place on the basis of pre-existing representative skills (Feber, 2010: 206-207). The criticism of Rousseau's views, not always consistent with the spirit and the letter of the Genevan's works, is related to the alleged lack of any clear distinction

13 The work entitled: Der göttliche Ursprung der Sprache was presented in 1756 as a lecture at the Royal Academy of Sciences in Berlin, and published in 1766. 
between language and animal communication, or at least a distinction that is sufficiently pronounced, which - according to Herder - leads to blurring of the border between human cognitive ability and animal cognition (Feber, 2010: 207). Simultaneously, Herder addressed Süssmilch's theories, noting that if man had cognitive powers that would enable him to understand a language coming from a deity, then there is no reason why those same cognitive powers could not enable man to gain language without any divine intervention (1967-1968: 618).

Herder's glottogenetic scenario was based on two conditions that had to characterise humans before they could develop language: (i) the capacity for forming representations, which would allow vocalisations to be assigned to appropriate concepts, and (ii) the ability to improve the communication system. The combined effect of these predispositions made it possible to create vocalisations referring to the surrounding world (19671968: 53-56). According to Herder, the first onomatopoeic proto-words were imitations of activities, which leads him to conclude that the verb is the most basic element of language, and that poetry is the oldest type of linguistic expression (1967-1968: 53-56, cf. Fitch, 2010: 391-392). The emergence of modern language consisted in a gradual simplification and systematisation, at least regarding the scope and organisation of semantic fields, because the onomatopoeic protolinguistic units were not assigned to specific meanings, and there was a considerable semantic redundancy (Kastinger Riley, 1979: 619-620).

\section{Parisian ideologists}

Herder was the only significant theorist of his time who did not seek the origins of language in gestural-pantomimic communication, but posited that language had always functioned in the vocal-auditory channel. Glottogenetic speculation of the time was dominated by the work of Condillac, and much of the ensuing discussion focused on the expressive potential of gestures. A good example of this trend is the activity of the Idéologues group, which was formed at the end of the $18^{\text {th }}$ century in Paris. It included, for example, Gaspard Itard, the teacher of Victor from Aveyron, and Roch-Ambroise Cucurron Sicard (1742-1822), the head of the Institut National des SourdsMuets (the National School for the Deaf) and the author of textbooks on sign language. Another member of this group, Joseph Marie de Gérando 
(1772-1842) was a philosopher and philanthropist who published several multi-volume works on semiotics (1799-1800) and teaching the deaf (1827). In 1799 the Idéologues society established the Société des observateurs de l'homme (Society of Observers of Man), the world's first society devoted to the study of man, based on a programme written by de Gérando and the pedagogist Louis F. Jauffret (1770-1840). The society's ambitious plans included ethnographic projects aimed at documenting the habits of "primitive peoples", but also projects directly connected with questions about the origin and trajectories of language development; for example, one of the objectives was to describe sign systems used by deaf people around the world and to create a gesture atlas. Pierre Laromiguière (1756-1837) proposed to use this research to create a universal pantomimic-gestural language, while Jauffret forged a macabre idea to repeat, on a large scale, the famous "forbidden experiment" (Hewes, 1975: 485-486, 1976: 9, 1977a: 100-101). None of these plans could be fulfilled because in 1804, upon Napoleon's order, the Society was dissolved; yet, its brief existence provided an impetus for the development of anthropology.

The second half of the $18^{\text {th }}$ century was certainly a golden age of reflection on the origins of language. Enlightened naturalism dicated a tone of intellectual debates on elaborating new definitions of man and his place in the surrounding world. As the examples of Monboddo, Condillac, and Rousseau show, the problem of glottogeny was an important thread in these efforts and a flag issue explored even by thinkers who did not study language. It could be said that having a view on language emergence at that time was a testimony to one's intellectual refinement. For example, the father of political economy, Adam Smith (1723-1790), presented his glottogenetic scenario in the Considerations Concerning the First Formation of Languages (published in 1767 as an appendix to the third edition of Theory of Moral Sentiments), where he tried to show that grammatical structure evolved in early humans from the basic ability to categorise phenomena into objects (which gave rise to nouns) and events (which gave rise to verbs). ${ }^{14}$ Interestingly, Smith's publisher, Dugald Stewart (1753-1828),

14 A detailed discussion of Adam Smith's glottogenetic views can be found in the work by Stephen K. Land entitled: Adam Smith's "Considerations concerning the First Formation of Languages” (Land, 1977). 
a professor of philosophy, had his own scenario of language emergence. Philosopher Claude Adrien Helvétius (1715-1771) advocated the gestural origin of language, while Mikhail Vasilyevich Lomonosov (1711-1765), a Russian scholar and the founder of the Moscow State University, was, like Herder, an advocate of the vocal genesis of language (Hewes, 1976: 484485 ). Examples of the ubiquity of the topic of glottogeny could easily be multiplied.

\section{Comparative philology}

With the advent of Romanticism, the demand for such speculations weakened considerably. This change took place for two reasons. First of all, there was no new knowledge that could provide an impulse for glottogenetic reflection. There were no great advances in primatology, except perhaps for the anatomical observations made by the comparative biologist and palaeontologist Georges Cuvier his famous book The Animal Kingdom (Le règne animal, 1817 $)^{15}$. Cuvier stated that despite being endowed with high intelligence, apes are not able to learn language (Hewes, 1975: 9). Although in the first half of the $19^{\text {th }}$ century some fossil evidence of the existence of species similar to Homo sapiens were discovered (for example, the first Neanderthal remains, found in 1829), it was difficult to appreciate their significance until the inception of Darwinism. Similarly, to use arguments derived from psychology and brain studies, researchers had to wait until the second half of the $19^{\text {th }}$ century. The second, arguably a more important reason for the paucity of publications on the origins of language, was the rise and rapid development of comparative linguistics, or, as it was referred to at that time, comparative philology (Hewes, 1976: 486). In 1786, William Jones (1746-1794) gave a landmark lecture outlining a research plan for the field ${ }^{16}$, which gained in strength throughout the $19^{\text {th }}$ century, particularly among those scholars who wanted to study language with scientific rigour. They developed their own methods of collecting and analysing data - the comparative method and the method of internal reconstruction, developed

15 Full title: Le règne animal distribuéd'après son organisation.

16 Third Anniversary Discourse presented to the Asiatic Society. 
by Rasmus Rask (1787-1832), Carl Verner (1846-1896), and Jacob Grimm (1785-1863).

The emphasis comparative philologists put on the application of empirical procedures made them distrustful of speculations about the very origin of language. It was not long before they realised that the comparative method is not capable of reconstructing the language of the first people, although still in 1823 the Scottish clergyman and philologist Alexander Murray (17751813) in his book A Philosophical History of the European Languages tried to prove that the sounds of all languages are derived from nine protosyllables (see Hewes, 1976: 486). The most ambitious speculations made by the mainstream of comparative philologists concerned the question of whether languages originated from one original language or whether they developed independently from many original languages. There were many supporters of the second position - the polygenetic hypothesis - one of whom was August Schleicher (1821-1868), the author of the first reconstruction of Proto-Indo-European. Schleicher pursued diachronic linguistics but approached this subject from a biological perspective, maintaining that language families form linguistic correlates of species, with individual languages being equivalent to individual organisms (1863). This led him to the idea of language family trees (Stammbaumtheorie), in which biological taxonomy is used for modelling kinship between languages. ${ }^{17}$ Schleicher describes the polygenic hypothesis in the following manner:

To assume one original universal language is impossible; there are rather many original languages: this is a certain result obtained by the comparative treatment of the languages of the world which have lived till now. Since languages are continually dying out, whilst no new ones practically arise, there must have been originally many more languages than at present. ([1850] 1874:2)

Interestingly, the polygenic linguistic hypothesis was transposed onto the anthropological plane by the biologist Ernst Haeckel (1834-1919), the founder of the theory of recapitulation, which we discuss in the second chapter (see 2.5.9). Basing his theory on Darwinism, Haeckel stated that just like languages emerged independently in different parts of the world, humanity evolved from monkey ancestors separately in various parts of

17 For more on Schleicher's biologism, see Taub (1993). 
the world (1874). Had it not been for the racist conclusions that Haeckel consistently drew from his interpretations, he might well be regarded as the father of the multiregional hypothesis of human origins.

But the intellectual climate of the $19^{\text {th }}$ century promoted racist and nationalistic sentiments. Deriving from the Romantic movement, and in particular from the philosophies of Georg Hegel (1770-1831) and Wilhelm Humboldt (1767-1835), the concepts of nation and language rose to importance in $19^{\text {th }}$ century philological discourse. Many scholars appealed to the intuition, derived from Schleicher's work, that language imposes on their users a certain way of perceiving reality. Many years later, such a belief was at the heart of the work of Edward Sapir (1884-1939) and Benjamin Lee Whorf (1897-1941), the founders of the linguistic relativity hypothesis. However, in the $19^{\text {th }}$ century philology, Schleicher's ideas were commonly used to formulate evaluative statements that asserted a cultural and even a biological (see Haeckel) ${ }^{18}$ superiority of certain ethnic groups (Harpham, 2009). One of the advocates of such a form of racism was Joseph Ernest Renan (1823-1892), a French Indo-Europeanist and Semitist, author of the Khazar hypothesis, according to which Ashkenazi Jews ${ }^{19}$ did not descend from the ancient Israeli stock but from the Turkish Khazar people. In his popular work On the Origin of Language (De l'Origine du langage, 1858), he argued that glottogeny had taken place twice in the history of mankind: one episode had led to the emergence of Aryan or Indo-Germanic languages, while the second had given rise to Semitic languages. In his opinion, the languages from the two groups activated different cognitive processes in the minds of their speakers: Aryans, according to Renan, were at the forefront of civilisation, because the languages they spoke facilitated the use of rational thinking; the minds of the Semites, on the other hand, were sentenced by the structure of their languages to dogmatic ways of thinking ([1848] 1858: 80-90; cf. Ashcroft, 2001: 319-321). Oddly, Renan identifies conjugation as the key element that played a decisive role in the

18 Haeckel claimed, for example, that toes of the black inhabitants of Africa had greater mobility, which meant that they were closer to monkeys than Caucasians (Jahoda, 1999: 83).

19 Jews inhabiting Eastern, Central and Western Europe, and from the $18^{\text {th }}$ century on, also America. 
different fates of these two groups, allowing Indo-Europeans to make great theoretical and technological discoveries, while imprisoning Semites in a life of intellectual stagnation.

Arguments that are shocking from today's perspective were received in mid- $19^{\text {th }}$ century Europe with interest and, to a large extent, understanding. Regarding the issue of glottogenetic reflection, Renan's book revived the debate about the beginnings of language, a debate which came to be dominated by comparative philologists, who were less and less worried about the methodological correctness of their arguments. This tendency could be seen in the work of even the most eminent scholars, as is the case of Friedrich Max Müller (1823-1900). Müller, an excellent Sanskritist and the first professor of comparative philology at Oxford, was critical of the Enlightenment's hypotheses of language emergence. In his Lectures on the Science of Language (1866), he proposed a typology distinguishing several types of glottogenetic hypotheses: bow-wow, which sought the beginnings of language in the imitations of sounds produced by animals; pooh-pooh, which derived language from emotional cries; and finally yo-he-ho, according to which the evolutionarily primary function of language was to coordinate actions by means of vocalisation combined with gestures (1866: 358-370). Müller did not take the trouble of identifying supporters of the views that he defined with the names given above. While bow-wow can be linked with the highly simplified onomatopoeic scenario proposed by Herder, it is difficult to find adherents for the poob-pooh or yo-he-ho hypotheses among $18^{\text {th }}$ century thinkers. Of course, emotional exclamations or coordination of actions were important but not the principal elements in the glottogenetic considerations of Condillac and Rousseau (Sprinker, 1980: 117). On the other hand, Müller does not mention gesturalpantomimic scenarios of language emergence, which reached the apex of their popularity during the Enlightenment. It is hard to believe that the well-educated Müller overlooked this matter; rather, it seems that this was his way of expressing contempt for speculations about the beginnings of language (Gode, 1986: vii). This attitude did not stop him from describing his own idea of how language emerged, which his descendants maliciously referred to as the ding-dong hypothesis. His proposal seems much more speculative than those he mocked, and is based on the essentialist idea drawn from Cratylus, that for each thing in the world there is a sound 
that expresses the nature of this thing (1866: 384). The original language was to consist of phonetic types, which were vocal imitations of these sounds and whose number Müller estimated at 400 or 500 (1866: 384). As Müller, a firm supporter of monogenesis explains, these phonetic types subsequently gave rise to stems that can be found in all languages of the world (1866: 384; cf. Spinker, 1980: 124-126).

The English Anglican priest and philologist Frederic William Farrar (1831-1903) in An Essay on the Origin of Language (1860) voiced his scepticism about onomatopoeic scenarios of language emergence, whereby the ability to imitate the sounds of nature sufficed to give rise to language (1860: 72-74), and was particularly critical of Renan and Müller. Onomatopoeia was able to explain the creation of the basic lexicon, but as Farrar insists - language is not only lexis, but also grammar: "Language may be regarded as the union of words and grammar, of which words are analogous to matter, and grammar to form. (...) That which originates language, like that which originates thought, is the logical relation which the soul establishes between external things" (1860: 62).

This attention to the role of cognitive processes in the origins of language relates to one of the main theses proposed by Herder in Abhandlung, a point which was missed by both Renan and Müller. In a less Herderian style, Farrar argues that the imitation skills of the first peoples made it possible to create proto-words or lexical labels, while the emergence of language proper was possible due to the typically human tendency to form metaphors based on analogical thinking. Onomatopoeia is dubbed by Farrar as a mechanical principle of language, analogy - an intellectual function of language (1860: 117). In his remark upon the metaphorical nature of language, Farrar, as he admits himself, follows Rousseau (1860: 51; see Spinker, 1980: 120-122).

\subsubsection{Darwin: The beginnings of the science on the evolutionary origin of language}

The revival of glottogenetic discussions in the mid-19 $9^{\text {th }}$ century coincided with the publication of Charles Darwin's (1809-1882) On the Origin of Species (1859), where he presented a theory of evolution based on natural selection. We introduce the basic concepts of Darwinian evolutionism in the next chapter; here, we only discuss its influence on reflections on 
the emergence of language in the intellectual context of $19^{\text {th }}$ century. It should be noted that in On the Origin of Species, Darwin not only refrained from speaking about the origin of language, but did not even write about human evolution, in order not to disturb his more conservative readers. $\mathrm{He}$ presented his views on anthropogenesis only 12 years later in The Descent of Man (1871), where he also outlined his famous "musical" hypothesis of language origin.

However, readers of On the Origin of Species quickly realised that Darwin's evolution by natural selection applies as much to humans as to other species. In the 1860s, especially in Victorian England, there was a strong polarisation in the reception of Darwin's work. On the one hand, Darwin had many allies, such as the outstanding geologist Charles Lyell (1797-1875) or the botanist Joseph D. Hooker (1817-1911), although the most radical of them, particularly when it came to rhetoric, was Thomas Huxley (1825-1895), who earned the nickname "Darwin's bulldog". Huxley, who himself was a biologist specialising in comparative anatomy, wrote enthusiastic reviews of Darwin's work, fiercely attacking opponents of the theory of natural selection, most of whom were associated with the Anglican church. In his work Evidence as to Man's Place in Nature (1863), he emphatically stated that man is an animal, and more specifically: an ape, and one should use the theory of natural selection to explain both his physical and mental qualities.

As for the anti-Darwinian camp, it brought together people who were driven by various motivations: there was no shortage of defenders of the Christian vision of the world, but there were also biologists who were not convinced by the idea of species variability, at least in the shape suggested by Darwin. Quite a large group of researchers representing various disciplines were willing to accept Darwinian theses, as long as they did not concern man, or at least his spiritual qualities. One of the best-known exclusivists ${ }^{20}$, as they began to be called, was Friedrich Max Müller, who in his Lectures on the Science of Language emphatically states that it is language that separates man from animals:

20 To indicate the exclusion of man from the impact of evolution by natural selection. 
Where, then, is the difference between brute and man? What is it that man can do, and of which we find no signs, no rudiments, in the whole brute world? I answer without hesitation: the one great barrier between the brute and man is Language. Man speaks, and no brute has ever uttered a word. Language is our Rubicon, and no brute will dare to cross it. (1866: 340)

\section{Early Darwinism and the glottogenetic problem}

This does not mean, however, that linguists unanimously agreed with Müller. Schleicher, who wrote a treatise addressed to Haeckel entitled Darwinian Theory and the Science of Language (Die Darwinsche Theorie und die Sprachwissenschaft), embraced Darwinism also with regard to the study of language. In the treatise, he argued that diachronic linguistics, which studies linguistic changes from a historical perspective, can provide direct evidence for the Darwinian theory. Schleicher's text shows that he understood the logic of natural selection poorly, and that his evolutionary considerations were inherently Lamarckian (Richards, 2008: 125-126). Farrar published an interesting article entitled "Philology and Darwinism" (1870) in which he defended Darwin's theory against Max Müller's rhetoric and very accurately demonstrated how the theory of natural selection can be used to explain the way language families diverged. However, it must be stressed that in the 1860s and 1870s - apart from the musical scenario developed by Darwin himself in The Descent of Man (1871) - there was no attempt to employ the Darwinian theory of evolution to explain the origins of language. This fact is important in assessing the role of edicts banning speculations about glottogeny, such as the famous ban on speculations about the origins of language imposed by the Linguistic Society of Paris in 1866 and a similar one issued in 1872 by the Philological Society of London

The second article of the statute of the Sociéte de linguistique de Paris clearly states that: "The society does not admit any accounts about the origins of language [or] a universal language".

It is commonly assumed in the literature on the evolution of language that these bans were directed against the Darwinian interpretation of glottogeny (e.g., Scott-Phillips, 2010; Gong et al., 2014). Such an assumption is often supplemented with more (Christiansen and Kirby, 2003a) or less (Gong et al., 2014) dramatic statements that these bans prevented the development of an evolutionary perspective in linguistics and for many years hindered 


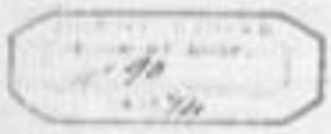

SOCIETE DE LINGUISTIQUE

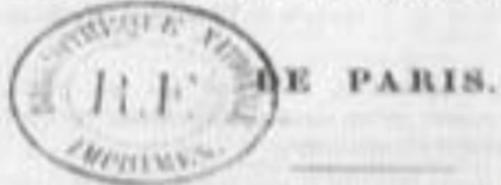

STATUTS

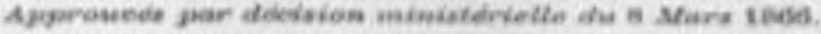

Andele premier.

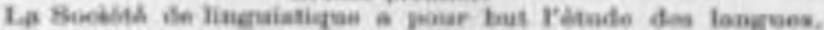

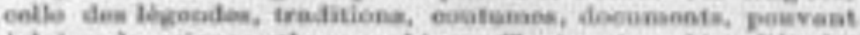

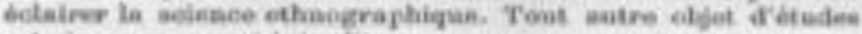
est rigtoareusement interilit.

\section{Artiein $\mathbf{2 .}$}

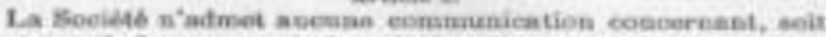

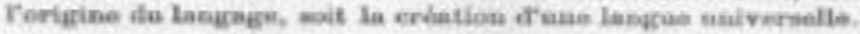
arteie 3.

La Soeibth poblie chaque sunde as moins un volume de maitenirea:

Ble pest y iasiner des truvaix, do abvants btrangers.

Aralab 8 .

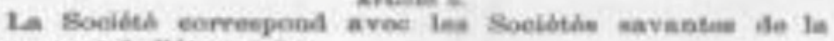
Prabee et de rétranger.

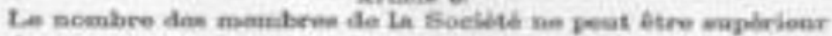
h diaq cents.

Tout canifidat eet prómenté par deux membres çui font oos-

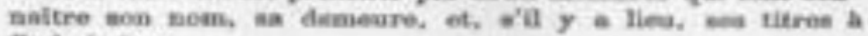
Tedminaioe.

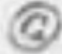

Fig. 1.2: Statement of the Société de linguistique de Paris banning glottogenetic speculation. 
serious research on the origins of language. In fact, the Parisian ban resulted from the social and political context, particularly from the rivalry between the humanistically oriented Linguistic Society and the naturalistically oriented Anthropological Society, which was led by Paul Broca, the pioneer of neurology (see Yamauchi et al., 2012). However, the bans were not so much directed against Darwinian scenarios (which did not yet exist), as they were against speculations of the sort that Murray, Renan, or Müller presented, who supported their statements about the origins of language using the methods of comparative philology. The Parisian ban was lifted after ten years, and the one in London was never implemented (Sampson, 1980: 13-33). The fact that linguists stopped discussing glottogeny was not because they were afraid of the reaction of scientific bodies, but because there was a growing incline that the comparative method is able to shed little light on the problem of language origins (Sampson, 1980: 13-33).

As we have already mentioned, the only notable Darwinian scenario about the origins of language was formulated by Darwin himself in The Descent of Man (1871). He devoted a relatively brief section of the third chapter to the topic of language, entitled "Comparison of the Mental Powers of Man and the Lower Animals", which pinpointed sexual selection (see 2.1) as the mechanism which - in Darwin's opinion - led to the emergence of language. His starting point (and that of any biologist) is a comparison of language with animal communication - capuchins' calls, dogs' barking, or the sounds produced by fowl. Darwin displays a certain naivety concerning language, writing that, for instance, dogs are able to understand many words and sentences, and their communicative development corresponds to that of children of ten or twelve months of age. However, very many of Darwin's ideas and insights have been supported by future research, such as his remark about the instinctual readiness of children to acquire language. This assumption leads to the analogy between language and bird songs. Darwin argues that, similarly to humans, bird hatchlings demonstrate an instinct to sing, but they can learn the melodies typical of their species only by imitating adult birds.

From the ontogenetic plan, Darwin moves onto the phylogenetic speculations and states that human ancestors - using their capacity to imitate and modify the sounds of nature - created melodies which served to express emotions such as love, envy, or triumph, and only later these melodies were 
transformed into words referring to emotions. The context in which this musical form of communication emerged was the fight for females. Darwin repeats Condillac's argument that the use of a rudimentary, vocal protolanguage led to the increasing of articulatory capacities in subsequent generations, which facilitated the development of the repertoire of linguistic vocalisation characteristic of modern languages. He also states that the emergence of language greatly influenced the development of the brain and exclusively human cognitive capacities. As he argues, using words allowed humans to create long strings of thoughts in their minds, which contributed to the development of the brain and intelligence in our ancestors.

\section{Empirical advances}

In the meantime, new scientific discoveries were made that had implications for the understanding of language and its evolutionary history. The second half of the $19^{\text {th }}$ century saw the pioneering work on the relation between language and the brain done by the French surgeon Paul Broca (1824-1880) and the German neuroanatomist Carl Wernicke (1848-1905). The discovery of two language areas in the cerebral cortex of the left hemisphere of the brain - Broca's area (1861) and Wernicke's area (1874) - and the two related types of aphasia - expressive and receptive, opened up new areas of language study (Hewes, 1976: 492).

The publication of Darwin's works coincided with paleoanthropological discoveries - of a Neanderthal in 1856 and a Cro-Magnon Man in 1868 but none of these findings was "primitive enough" to provide evidence for the existence of intermediary stages between nonhuman apes and Homo sapiens (Hewes, 1977a: 103). Many supporters of the evolutionary theory of the time questioned even the possibility of finding such a missing link, as was the case with the co-author of the theory of natural selection, Alfred Wallace (1823-1913). ${ }^{21}$ Eugène Dubois's discovery of Homo erectus in

21 In a book entitled Darwinism (1889: 499), he argued that the development of higher-order cognitive functions in humans cannot be explained with natural selection, although earlier he advocated applying the theory of natural selection in anthropogenesis, and his paper from 1864 entitled "The Origin of Human Races" can be considered to be visionary, because he intuitively stated there that the evolution of human ancestors occurred in two stages, the development of bipedalism preceding the development of the brain. 
Java in 1891 led some to hope that the missing link could be found, but the fact that this specimen lacked the facial part and the jaw limited any speculations about its linguistic capabilities.

Unfortunately, glottogenetic reflection in the $19^{\text {th }}$ and at the beginning of the $20^{\text {th }}$ century could not use new comparative findings. Isolated attempts were made to conduct ethological observations of primates, the notable of which is Richard Lynch Garner's (1848-1920) work in recording the vocal behaviour of African primates. The book he published in 1900, despite its promising title - Apes and Monkeys: Their Life and Language - became a token of his failure, mostly because of the poor quality of the data that he had so diligently collected using an Edison phonograph (Hewes, 1975: 10). William Furness was the first person to attempt to teach an ape a language (1916), and his efforts also ended in failure. After five years of training, the orangutan Furness was able to produce sounds which resembled three words: "mama", "papa", and "cup".

It is not difficult to see that such conditions did not attract early Darwinists to seriously consider the problem of glottogeny. As we have explained, the topic became unpopular, or even suspicious, among linguists. To illustrate this attitude, we can cite the opinion of the distinguished Sanskritist William D. Whitney:

No theme in linguistic science is more often and more voluminously treated than this, and by scholars of every grade and tendency; nor any, it may be added, with less profitable result in proportion to the labor expended; the greater part of what is said and written upon it is mere windy talk, the assertion of subjective views which commend themselves to no mind save the one that produces them, and which are apt to be offered with a confidence, and defended with a tenacity, that are in inverse ratio to their acceptableness. This has given the whole question a bad repute among sober-minded philologists. (1872: 279)

Clearly, there were some exceptions, even among linguists of great renown. Edward Sapir addressed issues related to the emergence of language in his works, writing about orofacial gestures and sound symbolism. He also devoted a whole monograph to Herder's conception of glottogeny (1907). Otto Jespersen's work (1922) stands out from all the linguistic publications of the time due to its empirical orientation. Jespersen distances himself both from the taboo which surrounded the topic of the emergence of language and from speculative "theories", and he postulates that there are three sources of insights into language origins: the development of language in 
children, the languages of "primitive races" (requiring a comparative approach) and, most importantly, the historical development of languages. Jespersen opted for the musical version of protolanguage, not so distant from Darwin's proposition. In his view, the first systems of communication were supposed to be based on musical means of emotional expression: the early human "sang his emotions long before he was able to express his thoughts” (Jespersen, 1922: 436).

\section{Anthropology and psychology on the beginnings of language}

Reflections on glottogeny were made in such areas as anthropology (on its brink), and psychology, whose birth can be dated back to the second half of the $19^{\text {th }}$ century. Although comparative philologists who wrote about glottogeny in mid- $19^{\text {th }}$ century were in favour of the vocalic genesis of language, anthropologists and psychologists returned to the scenarios of Mandeville, Condillac, and Rousseau, which assumed pantomimic and gestural origins of language. Edward Tylor (1832-1917) became interested in glottogeny, and especially in gestural theories of language origins, and wrote about feral children (1893, 1867, cf. Hewes, 1977a: 101-102). These themes were developed in an article on the psychology of early humans (1867), and in his works on general anthropology - the two-volume Primitive Culture (1871) and the single-volume Anthropology (1881) in which he documented traditional sign language systems, devoting long sections to considerations on the beginnings of these systems. In a review of Anthropology, Alfred Wallace argued for the mouth-gesture theory of language origin (1881). Lewis Henry Morgan (1818-1881), the founder of the American school of anthropology, also supported the gestural theory of language origin in his Ancient Society (1887) (Hewes, 1977a: 102).

In the same period, Wilhelm Wundt (1832-1920), the father of experimental psychology, probably showed the most scientific approach to glottogeny. The starting point for his scenario, which he presented in the first two volumes - collectively entitled Language (Die Sprache) - of his masterpiece Social Psychology (Völkerpsychologie, 1900) is the so-called microgenesis of utterance in the mind of the speaker. By appealing to the expressive power of gestures and the universality of pantomimic and gestural communication, Wundt concluded that pantomime and gestures both in terms of microgenesis and phylogeny - are the predecessors of 
language (Levelt, 2004: 544-546). A crucial element of Wundt's hypothesis is the role of orofacial gestures in effecting the transition from pantomimic to vocal language. According to Wundt, orofacial gestures did not initially serve vocalisation, but were connected with whole-body expression. Vocalisations became re-connected with gestural meanings, and later on started to gradually play a leading role in linguistic communication (Levelt, 2004: 545-546).

R. A. S. Paget (1869-1955) had more detailed views on the role of orofacial gestures in the emergence of language. Paget stresses the embodied nature of vocalisations - vocal sounds are after all a result of the movement of the articulators. Inspired by Darwin's observation, Paget remarks that the movements of the lips and other articulators "echo" the movements of the hand. This forms the basis for his hypothesis that human speech originated in unconscious imitation of hand movements by the lips, tongue and other articulators (Hawhee, 2006).

Between 1939 and 1962, no new solutions to the problem of the origin of language were proposed; nevertheless, a great number of works, mainly psychological, referred to the problem of the emergence of language. An overview of these publications provides an interesting insight into the state of glottogenetic thought of the period. The most important authors who wrote about glottogeny at that time are: Friedrich Kainz (1960-1962), Géza Révész (1946), MacDonald Critchley (1960), Oddone Assirelli (1950), Wiktor W. Bunak (1959), Eduard Rossi (1962), Alf Sommerfelt (1954), Björn Collinder (1956), A. S. Diamond (1959), Bernhard Rosenkrantz (1961) and Giorgio Fano (1962). ${ }^{22}$ Judging from the number of reviews, Révész's The Origins and Prehistory of Language (Ursprung und Vorgeschichte der Sprache, 1946) attracted the greatest attention. In this book, Révész presented the theory of social contract and - stressing our instinctual need to maintain contact with others - argued that language must have developed from vocalisations, which originally served the phatic function of making and maintaining contact. According to Révész, these phatic vocalisations led to the development of words.

22 This list of authors is adapted from Hewes (1977a: 105). 


\subsection{Conclusion}

Summarising and choosing the most important works always leads to simplifications. The same applies to this chapter, where we aimed to separate glottogenetic speculations from scientific research on the origins of language. The efforts of Wundt, Jespersen and Paget led to the dawn of a new era in which the scenarios of language origins would be verified empirically. The scientific developments of the 1960s in such fields as the neurosciences, cognitive science, and evolutionary biology based on genetics or palaeontology, led to refining the research on language origins. From this point onwards, we will refer to the genesis of the science of the evolution of language - a new science which addresses the old, glottogenetic problem. However, before we do that, we will explain the basic notions and conceptions of the Darwinian theory of evolution. 


\title{
Chapter 2 Evolution, Evolutionism, Evolutionary Thinking
}

\author{
Is evolution a theory, a system, or a hypothesis? \\ It is much more: it is a general postulate to which \\ all theories, all hypotheses, all systems must \\ henceforward bow and which they must satisfy \\ in order to be thinkable and true. Evolution is \\ a light which illuminates all facts, a trajectory \\ which all lines of thought must follow, this is what \\ evolution is.
}

Pierre Teilhard de Chardin (1881-1955, philosopher and Jesuit)

We live in a Darwinian world. If we stop to think, we realise that, without exception, the whole organic world which surrounds us - from the simplest organisms to people - is the effect of evolutionary processes whose principles are best described by the Darwinian theory of evolution. Although this has been accepted in the Western intellectual tradition for over 150 years, it is only in recent decades that its implications have been fully appreciated: since the principles of evolution (and especially those of natural selection) are so fundamental, universal and ubiquitous, their application as a research approach can open new dimensions of learning about the world. Theodosius Dobzhansky (1973) said that "nothing in biology makes sense except in the light of evolution". One of the effects of the research conducted in the recent years is an expansion of this approach beyond the domain of biology in its classical sense, and applying evolutionary thinking as a key to understanding an extremely broad and varied range of phenomena.

Evolutionary thinking is growing in significance in the academic discourse, too: it is a trend which inspires discussion and synthesis. ${ }^{23}$ The reasons for this success are two-fold. First of all, the evolutionary logic

23 The most recent example is Handbook of Evolutionary Thinking in the Sciences, (eds. Heams et al., 2014) whose 42 chapters include texts discussing the 
Box 2.1 The Interdisciplinary Beginnings of Darwinian Theory

Darwin's theory is a strong case for interdisciplinarity not only by way of its current applications, but also by way of its beginnings. When he started writing The Origin of Species, Darwin was working from the findings of many scientific disciplines; among the figures who inspired him were geologists Adam Sedgwick (1785-1873) and Charles Lyell (1797-1875), the economist and sociologist Thomas Malthus (1766-1834), and the philosopher of the free-market economy Adam Smith (1723-1790). Darwin also relied on analogies to the genealogical classifications of languages, which were to be found in the works of the first comparative philologists.

The theory of evolution owes its later development to such fields as genetics and statistical methods (which gave rise to the emergence of population genetics), geology, paleontological discoveries, or even the discovery of radiation, which made it possible to re-evaluate former estimates of the age of the Earth in a way compatible with the long timescales implied by evolutionary processes.

In the $21^{\text {st }}$ century, evolutionism in its broad sense still benefits from the discoveries of a wide range of disciplines, but also itself constitutes a limitless source of inspiration for scientists.

itself, and especially the logic of natural selection, can be generalised beyond the domain of biological organisms; this creates possibilities to describe non-biological systems. Secondly, human beings and their minds are the products of evolutionary processes; hence, using evolutionary logic - and especially natural selection - allows us to recreate its complex construction by means of reverse-engineering. ${ }^{24}$

\subsection{Evolution and natural selection}

Grand ideas do not come out of nowhere - Darwin also "stood on the shoulders of giants" when he was creating the framework for his idea of evolution through natural selection. The world at the time was already

philosophical fundamentals of evolutionism, as well as its practical applications in medicine, automated technology and robotics, and cognitive sciences.

24 We are aware of simplifications. Our goal here is to depict the most important elements of the standard evolutionary theory. This is why we avoid the most recent trends in evolutionism, e.g., the extended synthesis (cf. Pigliucci, 2009). 
gravid with this idea, due to the heritage of such thinkers as Pierre-Simon de Laplace (1749-1827) (non-teleological universe), naturalists such as Carl Linnaeus (the foundations of systematics) and Georges-Louis de Buffon (advances in systematics), or Georges Cuvier (the foundations of palaeontology). As some historians say, the intellectual atmosphere of times in which Darwin lived indicated that "evolution was in the air" (Warren, 1987). ${ }^{25}$

We use the term "evolution" here in its technical sense (though extending beyond biology - see below). Evolution, in its metaphorical meaning, denoting any type of gradual change or transformation ("the evolution of Hegel's philosophical views") is beyond the scope of this book. What is vital here is the differentiation between evolution and selection. Evolution is a broader concept, and natural selection constitutes just one of its mechanisms. As we will find out, the strength of Darwinian evolution through natural selection lies in its universality, as it can be applied to the description of non-biological systems; for instance, neural systems (Changeux et al., 1973), language forms (Christiansen, 1994), cultural units or memes (see esp. Dawkins, 1976) and a plethora of other systems "from universes to religious dogmas" (Johansson, 2005: 14) can all evolve through natural selection. Nevertheless, biology remains the source domain of these notions.

Biological evolution occurs when in the gene pool of a given population - i.e. the collection of all genes of all individuals of the population the proportion of occurrence of specific genes (units of inheritance which remain unchanged over a relatively large number of generations) changes in subsequent generations. There are a number of reasons for this, including natural selection or other phenomena like mutation (through which new alleles - new versions of genes - arise) or genetic drift (arbitrary change, such as when a random part of a population dies in an earthquake). We

25 The intellectual history of the development of Darwinian theory is probably one of the best-described topics in the history of science and the history of ideas, and because its reconstruction is not the key purpose of this chapter, we recommend that the reader should refer to one of the other numerous studies for an account (e.g., Buss 2003: 25-32; Guttman 2005; Futuyma 2008). 
exclude migrations, assuming for simplicity that a population is reproductively isolated from others.

Selection is the most important of all the mechanisms of biological evolution (e.g. Darwin, 1859: 33) ${ }^{26}$ because it acts against entropy - only through natural selection can complex and well-organised organisms emerge, whose intricate biological construction makes them look as if they were created by an intelligent being (the "illusion of design"). In most cases, we use "selection" to mean natural selection. Natural selection should be distinguished from artificial selection (selective breeding), that is the process by which humans breed animals and plants, and in which the selection pressures do not come from nature, but rather are created by humans. However, the mechanism of both is basically the same. Sexual selection is often distinguished from natural selection, but here we assume a broad definition of natural selection that includes sexual selection as a subtype of natural selection (see also remark a) below).

It is precisely the notion of natural selection that constituted Darwin's most original contribution. The idea of evolution in the sense of macroevolution had its predecessors, but proposing natural selection as its specific mechanism was a breakthrough idea. Darwin's 1859 study discusses the mechanism, but the last paragraph provides a synthetic summary of the mechanism at work:

These laws, taken in the largest sense, being Growth with reproduction; Inheritance which is almost implied by reproduction; Variability from the indirect and direct action of the conditions of life, and from use and disuse; a Ratio of Increase so high as to lead to a Struggle for Life, and as a consequence to Natural Selection, entailing Divergence of Character and the Extinction of less improved forms. (Darwin [1859] 2013 Volume 2: 345) [highlights in the text - PZ, SW]

Essentially, evolution by means of natural selection must fulfil three conditions: diversity, heredity, and differential reproductive success. The organisms of a given population:

- have different traits from one another;

- these traits and so these differences, at least to some degree, originate in their genes and are thereby inherited;

26 "Furthermore, I am convinced that natural selection has been the most important, but not the exclusive, means of modification." (Darwin, [1859] 2013 Volume I: 33). 
- reproductive success is not the same for all organisms - those who have certain traits produce more offspring than the organisms who lack these traits.

The notion of differential reproductive success (dRS) is key to understanding natural selection because, in contrast to variation and heredity, it is multi-faceted. Reproductive success is a combined measure of both the organism's ability to survive and its ability to produce offspring (see remark a) below). It is also strictly connected with limitations on resources and the organisms' struggle for them. Komnicki (2012: 26) provides the following description: "[V]ariability, which determines chances for survival and producing offspring, is best visible when resources are limited, so that some organisms do not reach sexual maturity, and there are large differences in the number of offspring produced among those who do reach maturity".

By way of example: there are individuals which run faster (variability) in a population of cheetahs, faster parents have faster offspring (heredity), and being faster translates into being a better hunter; in turn, being a better hunter increases chances of survival, which means that fast-running individuals also have a better chance of producing offspring (differential reproductive success). As long as speed does not incur additional costs, faster cheetahs will produce more offspring in subsequent generations than will slower cheetahs. Therefore, the number of genes correlated with speed will increase in the genetic pool of later generations. This - a change in the relative proportion of specific genes in a given population - fulfils our definition of evolution. ${ }^{27}$

Owing to its simplicity, the mechanism of natural selection can briefly be summarised as follows: "[T] raits that increase an individual's chances to survive and reproduce are inherited and become more widespread at the cost of those traits that decrease the same chances"

We must make four remarks in this regard:

a) First of all, natural selection defined in this fashion includes sexual selection. Survival of individuals and their ability to find a mate are both parts of one's reproductive success. From an evolutionary perspective,

27 The example of cheetahs is often used in course books which discuss evolution (see Krukonis and Barr, 2011). 
it makes no difference whether an individual does not reproduce due to dying young or due to not having sexual partners - in both cases, that individual's reproductive success equals zero.

b) Secondly, natural selection itself is a mechanism which acts exclusively to reduce variability. Organisms who do not reproduce do not pass on their genes, meaning that their genes are lost from the population, and so all variability would ultimately be bound to disappear, and all individuals would become identical copies - or at least their genotypes. However, mutation works in parallel with natural selection. Mutation introduces random changes in the gene pool and ensures a constant supply of variability which, as we know, is a prerequisite for selection to work. Thus, when we discuss natural selection, we often mean natural selection together with mutation, which provides the necessary variation.

c) Thirdly, evolution, selection and mutation all work at different levels. Evolution concerns the whole population or its genetic pool; selection, although it could be applied at the genetic level, concerns individuals; mutation, in turn, concerns changes at the genetic level: "[G]enes mutate, individuals are selected, and populations evolve" (Colby, 1996; but cf. Box “Genes or Individuals?" below).

d) Finally, the process of selection is a statistical process, and not a deterministic law like the law of universal gravitation. Selection is illustrated by statistical generalisations: as in our example, not every fast cheetah must have more offspring, but it is enough that speed on average is positively correlated with reproductive success.

\section{Box 2.2 Genes or Individuals?}

We do not directly inherit phenotypes (the individual appearance or behaviour, etc.). What we inherit are genes, and only through genes do we inherit phenotypic traits. The opposite is true of natural selection: what is subject to natural selection is the organism's phenotype and only through the phenotype are genes selected. Bearing this in mind, we can talk about natural selection at the genetic level, and this is the view preferred by modern biology:

Natural selection is the process whereby certain genes gain representation in the following generations superior to that of other genes located at the same chromosome positions (Wilson, 1975: 3).

A gene is being favoured in natural selection if the aggregate of its replicas forms an increasing fraction of the total gene pool (Hamilton, 1972). 
Box 2.3 Natural Selection (Adapted from Lewin and Foley, 2004)

\begin{tabular}{|l|l|}
\hline Conditions & heredity, reproduction, variability, competition \\
\hline Mechanism & natural selection \\
\hline Effects & adaptation, evolutionary change \\
\hline
\end{tabular}

Fig. 2.1: How natural selection works (chart adapted from A.R. Wallace). http://www.globalchange.umich.edu/globalchange1/current/lectures/selection/ boxes.gif. DOA: 08 Aug 2015.

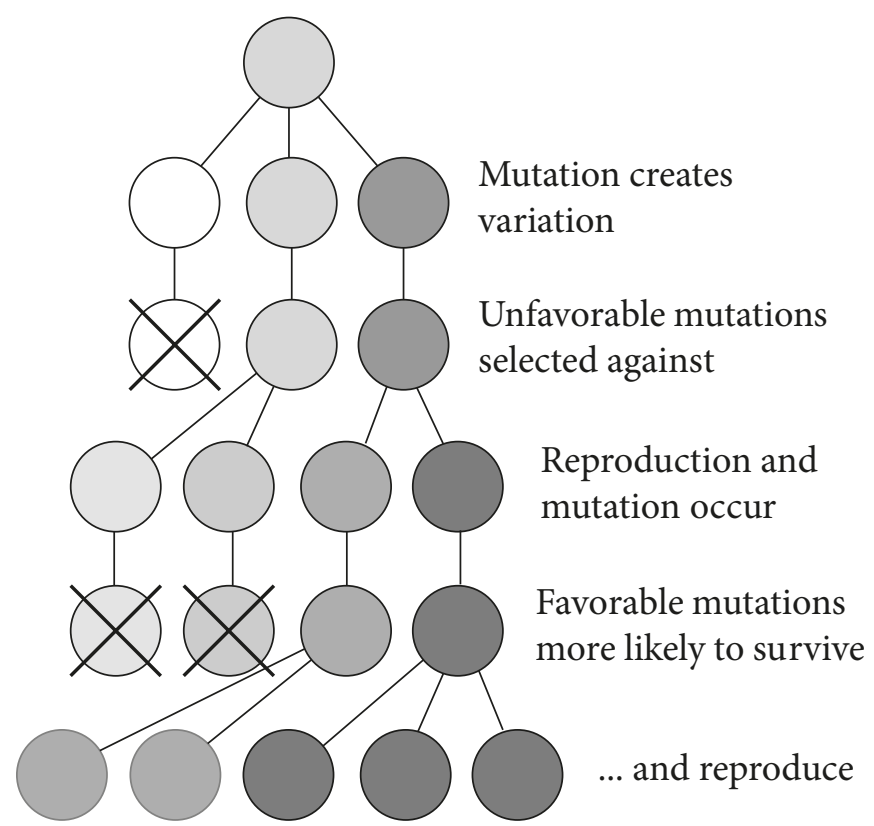

Fig. 2.2: Mutation and natural selection. http://www.daviddarling.info/ images/natural_selection.png. DOA: 08 Aug 2015

\subsubsection{Adaptation}

Following Darwin and his continuators, we have distinguished natural selection as the most important of all evolutionary mechanisms. Natural selection owes this status to what it brings about: natural selection leads 
to adaptations. Adaptation is a term which denotes any phenotypic trait which increases fitness, and by this token increases the reproductive success of an organism in a given environment. In our example of cheetahs, running speed was such a trait; however, adaptations are all changes which exert a positive influence on survival and reproduction, including morphological traits (e.g., the bat's wings which enable it to fly), or behaviours (e.g., the sucking reaction in infants). Not every trait is inherently adaptive - we also distinguish the by-products of adaptation and noise. The by-products of adaptations are random effects of adaptation which, in contrast to adaptation, do not have a functional structure and have not emerged "to solve adaptive problems": for example, the redness of blood is not an adaptation in itself, but a by-product - because blood uses haemoglobin for oxygen transportation (Tooby and Cosmides, 2005: 28). Noise, on the other hand, is a completely random variation which does not affect survival and reproduction, thus being neutral for natural selection - such as the patterns produced by discolourations on the iris in the eye (Tooby and Cosmides, 2005: 28).

\subsubsection{Gene's eye view and inclusive fitness}

The notion of evolution by means of natural selection is often said to have developed at a time when there was no knowledge of the laws and mechanisms of heredity. The origins of genetics can be traced back to the pioneering experiments of Gregor Mendel (1822-1884), and its dynamic development in the 1920s and 1930s; still, the full consequences that genetics bore for the theory of evolution only became obvious in the 1960s. Thanks to the work of George C. Williams, William D. Hamilton and John Maynard Smith, and the subsequent synthesis and popularisation of this research by Richard Dawkins (1976), a revolution which changed the perception of evolutionary phenomena took place. Evolution began to be understood and formulated not at the level of traits of organisms, but from a gene's eye view: bodies are only vectors for genes - "survival machines" manufactured by genes - which serve genes to produce and disseminate their copies. A quotation from Samuel Butler (2005 [1878]) neatly captures the core idea: "A hen is only an egg's way of making another egg".

Evolution is a change in a relative frequency of (different variants of) a gene in the gene pool of a population over a number of generations. 
Box 2.4 Infanticide

The revolutionary "gene's eye view" enables us to explain a significant number of phenomena that are inexplicable from the point of view of the benefit to the individual or the group, examples being "parasitic DNA" or genetic imprinting. However, infanticide remains the most distinct example (Hrdy, 2000). In many mammals - including endangered species such as gorillas or lions - the male that takes over leadership in a group immediately kills all cubs which are not his offspring, so that the females stop feeding them. This causes the females to become fertile again, which means that they are ready to bear the current male's offspring. This behaviour is an adaptation produced by natural selection, and while it threatens the species with extinction, it acts to make that male's genes more numerous in the next generation; as a result, this adaptation is inherited by the next generation.

Organisms can pass their genes to other generations in a number of ways, reproduction being the most obvious of them - their "personal" reproductive success. However, it is not the only possible strategy. An organism can also influence the number of its genes in the genetic pool of the next generation by undertaking actions to help individuals which are closely related to this organism. Fitness measures how efficiently an individual passes on its genes. From the gene's perspective, it does not make any difference how it is passed to another generation. Hence, from the gene's eye view, fitness needs a complement of kin selection, which promotes the reproductive success of closely related organisms, sometimes even at the expense of that individual's "personal" fitness (Hamilton, 1964a, b). What expresses this notion is inclusive fitness, which measures how successful an organism is in passing on the copies of its genes, both directly (its own reproductive success) as well as via its relatives (their reproductive success). This idea is usually illustrated by the assertion often attributed to J. B. S. Haldane, who supposedly stated that he would sacrifice his life for "two brothers or eight cousins".

The theory of inclusive fitness, which is tightly linked to the gene's eye view, constitutes a very useful explanatory tool. Inclusive fitness explains the ubiquity of nepotism (preferential treatment of relatives) in the world of humans and other animals; furthermore, extending this theory to the social sciences helps us understand numerous phenomena, such as polyandry (having more than one husband), ritual exaggeration of the degree 
Box 2.5 Why Do We Share $98.5 \%$ of Our Genes with a Chimpanzee and Only $50 \%$ with Our Sister?

These comparisons are made on two different levels. When we discuss the differences between species, we compare whole genomes. However, when we consider kinship, we simply discard all genes which are the same for all members of a given population, and we only look at that part of the genome where we find differences. "Having $50 \%$ of genes in common" means that $50 \%$ of the genes which have different variants in a population are identical.

of relatedness (ritual kinship, blood brotherhood) or exaggeration of the lack of relatedness (xenophobia, racism).

The theory of inclusive fitness also has a direct application in the analysis of animal communication. Let us consider alarm calls, which are vocal signals emitted by many species of birds and mammals to warn the group about an approaching predator. Kin selection is considered to be an important - possibly the most important - mechanism of the evolutionary emergence of such calls: although the caller puts itself at more risk, it warns numerous close relatives. This of course increases their chance of survival, and when they reproduce, they will pass copies of its genes - and with them, the tendency to produce alarm calls - to the next generation (Sherman, 1977). Tecumseh Fitch $(2004 ; 2010)$ has discussed kin selection in relation to the evolution of language, suggesting that communication between relatives, especially between mothers and children, may have been crucial for the origins of language (see 5.4).

Kin selection ${ }^{28}$ sheds new light on the intriguing system of communication in the honeybee. Researchers such as von Frisch and Hockett marvelled at it, unaware that the inability to "lie" is the most important reason for such efficient communication (Chapter 5). Owing to such a unique reproductive system, all bees in a swarm are very closely related to one another;

28 Kin selection is often used to explain eusociality - a form of social organisation existing primarily in insects. It involves a population where there is only one female (or a limited number of females) performing the reproductive role, and the rest of the colony providing for the offspring. Eusociality in bees exists because individuals in a society are closely related. 
e.g. honeybees in a colony have $75 \%$ of their genes in common, so from a genetic point of view, it is not so much an individual bee but the whole swarm that should be considered "one organism": "[Bees] have more in common with the individual cells of a multicellular organism" (Maynard Smith and Harper, 2003). Similarly to the different cells forming one body, all bees work towards the same genetic purpose, and lying to each other would not make any sense from a genetic point of view. Their interactions are inherently cooperative, which in turn constitutes a principal condition for the emergence of efficient and complex forms of communication (see Chapter 5).

\subsection{Universal Darwinism and cultural evolution}

It eats through just about every traditional concept, and leaves in its wake a revolutionized world-view, with most of the old landmarks still recognizable, but transformed in fundamental ways.

Daniel Dennett (1995: 63)

Biological organisms are not the only entities which undergo evolution by means of natural selection, and we do not mean this in the metaphorical sense of the word "evolution". The conditions formulated by Darwin in the last paragraph of The Origin of Species are not only necessary, but also sufficient for natural selection to act; thus, any system which fulfils these conditions will become an arena for natural selection. When appropriately generalised, these conditions turn out to hold in a plethora of systems - as we said before, "from universes to religious dogmas" (Johansson, 2005). Universal Darwinism (Dawkins, 1983) is the term used to describe the generalised concept of evolutionary change by means of natural selection.

Let us then define evolution by means of natural selection more generally, beyond the biological level:

Evolution is any change in the relative frequency of inheritable units in a population over a course of generations.

Natural selection is a non-random mechanism of that change, such that the proportions of different types of inheritable units in a population depend on the qualities of these units. 
As Johansson (2005: 14) points out, "evolution" and "selection" defined at this level of abstraction do not require the distinction between genotype and phenotype. Thus, it is unnecessary to talk about organisms and their genes (see Box 2.2 “Genes or Individuals?"). Units that are subject to heredity can be the same units that are subject to selection.

Computer programs are a very good example of non-biological evolution. Some of them, for example computer viruses, have the ability to spread their own copies. Replication, however, does not equal evolution: what evolution needs is variation which leads to differential reproductive success. Genetic algorithms meet this requirement - small changes in the structure of the code, similar to changes in DNA, introduce variation. Versions of the same program arise that are marginally different and reproduce at a different pace. Those versions that are worse at propagating their copies become less prevalent until they become completely extinct, whereas those versions of the program that are better at reproducing become increasingly numerous.

Culture also evolves. Richard Dawkins (1976) proposed the best-known notion of cultural evolution and called the evolving units memes. Memes are "tunes, ideas, catch-phrases, clothes fashions, ways of making pots or of building arches" (Dawkins, 2006: 192). Every meme fulfils the key conditions: ideas replicate, are passed from one mind to another, and in that process they undergo modifications and distortions. Their reproductive success - their proliferation - depends on their traits: easy and interesting ideas are easier to remember, so they spread better. Cultural evolution is not limited to the world of humans because animals also have cultures, at least in the sense of non-genetic inheritance of behaviour pattern ${ }^{29}$ - and so, for example, bird songs can culturally evolve as they are learned by successive generations of birds. Although memetics is a promising concept, it has not been successfully developed theoretically, mainly because in practice it is difficult to convincingly identify its basic units, i.e. individual memes.

The concept of cultural evolution has a great significance in reference to complex cultural entities such as language. The next generation will

29 The existence of cultural traditions in wild communities of the common chimpanzee (Pan troglodytes) has been authoritatively confirmed by the leading chimpanzee researchers in a paper in Nature (Whiten et al. 1999). 
not create language from scratch, but will inherit the language of the preceding generation. However, heredity is not completely faithful - new units compete with old ones and sometimes replace them; we must bear in mind that these units are units of replication and need not neatly correspond to traditional linguistic units such as phonemes, morphemes or lexemes. To achieve reproductive success - to have a growing representation in language use - individual linguistic forms must be easy to remember and to pronounce, and they must also be well suited to performing their communicative function. However, the main condition for the general structure of language is learnability, i.e. being easy to acquire by children. Their brains, or more specifically their cognitive capacity for acquiring linguistic structures, are the environment which creates selection pressures to which these structures must adapt. Language, as a system of signs and rules for combining them, is a cultural analogue of a biological organism - a beneficial parasite (Christiansen, 1994) - which must be well-adapted to its environment, that is to the brain of the host, in order to be transmitted to the next generation.

As we see here, biological evolution can also influence cultural evolution, and vice versa. Genes build brains adapted to language use. In turn, linguistic ability itself can be a selective factor, i.e. how well one speaks a language can influence position in the group or competition for mates (Miller, 2000). If proficient use of language increases reproductive success, then selection will promote the genotypes favouring the mastering of language faster and more accurately. This points to the notion of biological and cultural co-evolution in the evolution of language (e.g. Deacon, 1997; see 3.3.2).

\subsection{Evolutionary psychology}

In the future I see open fields for far more important researches. Psychology will be securely based on the foundation already well laid by $\mathrm{Mr}$. Herbert Spencer, that of the necessary acquirement of each mental power and capacity by gradation. Much light will be thrown on the origin of man and his history.

Charles Darwin, The Origin of Species (1859: 488) 
Since the early 1990s, and particularly in the last decade, we have been witnessing an expansion of evolutionism in the sciences connected with a "fashion" for the evolutionary explanation of cultural phenomena. The social sciences have been markedly influenced by evolutionary inspirations. David Buss (2003), in the final chapter of his course book on evolutionary psychology, gives examples of the applications of evolutionary thinking in various subfields of psychology: to cognitive, social, developmental, clinical and personal, as well as to cultural phenomena. Łukasz Budzicz's (2012) overview provides another account. He lists eighty papers with studies conducted from an evolutionary perspective, and assigns them to 45 thematic fields, such as physical attractiveness, empathy, rape, intelligence, popular culture, memory, gossip, body image in women, decision-making, violence, racism, relations between relatives, religion, consciousness and happiness. We must emphasise that this body of literature comprises recent research published in the leading psychological journals, mainly within the last decade. This comprehensive list can be easily extended or elaborated in more detail (e.g., depression, suicide, etc.), but as it stands we can state categorically that there is no field in the humanities or the social sciences where the influence of evolutionary thinking is absent.

Evolutionary psychology functions in at least two senses. First of all, it is a research paradigm in the prototypical meaning of the term, i.e. with its own institutionalised base (journals, scientific societies, courses and study programmes at universities) and a set of core statements universally accepted by researchers in that field. Secondly, evolutionary psychology in a broader sense can be understood as a general theoretical perspective or as a research approach towards human behaviour - as a way of thinking about humans that has been inspired by evolution.

What characterises this perspective is the assumption that the human cognitive system, similar to the body, is the product of evolution by means of natural selection. By analogy to the heart or kidney, which are highly specialised organs shaped by natural selection to fulfil their functions efficiently, we can talk about "mind" organs which were also shaped by natural selection to fulfil their functions best: to control the behaviour of the organism in such a way that it can cope with recurring issues, that is selection pressures.

This approach has been developed by two American researchers - Leda Cosmides, a psychologist, and John Tooby, an anthropologist (see for 
Box 2.6 Evolutionary Humanities and Arts

The evolutionary approach towards human behaviour enables us to find - or at least bring us closer to finding - solutions to many fascinating issues, such as the functions of blushing or sleeping. However, evolutionary thinking also finds applications in fields which may seem quite resistant to naturalistic explanations.

Darwinian literary theory is a controversial area of research which explains literary trends and motifs by referring to human evolutionary history, e.g. the basic adaptive problems in the evolution of Homo (see below). A similar logic finds a broader application in the analysis of culture and the media (Szlendak and Kozłowski, 2008). Yet another example of evolutionary inspiration in literary research is the use of phylogenetic trees, inspired by reconstructions of the relations between biological species. This method allowed researchers to settle the relations between nearly sixty preserved historic copies of Chaucer's Canterbury Tales, and to establish which of them were closest to the original (Barbrook et al., 1998). A 2013 study (Tehrani, 2013) traces "The Phylogeny of Little Red Riding Hood", i.e. the origins of the European, Asian and African versions of this story. Additionally, it shows that those motifs which were not altered when they were passed from generation to generation are the reflections of the fundamental adaptive problems of humans, e.g. reproduction, avoiding predators, and evaluation of the reliability of information.

example, Cosmides and Tooby, 1997). Below, we quote a summary of their work by Szymon Wróbel (2005; see also Komendziński, 2002: 135):

(1) The brain is a physical system which functions like a computer. The purpose of its circuits is to generate adaptive behaviour, i.e. a behaviour adapted to the variable events of the external world. (2) The neural systems of the brain (modules) were developed through natural selection to solve problems which our ancestors faced in the course of our evolutionary history. (3) Consciousness is only the tip of the iceberg; we cannot introspectively access most of the processes which take place in our minds. As a result, our conscious experience may mislead us as to the complexity of the components included in our software. Processes which may seem simple, obvious and natural to us (such as perception or the rules of entering into marriages) frequently are not so simple and obvious, and postulate the existence of very complex and highly specialised structures (rules). (4) The components (modules) included in our mind were designed to solve basic evolutionary problems; as such, these circuits are unable to solve other problems (for which they have not been designed). (5) The skull of the modern human houses a Stone Age mind, which means that modern humans struggle by having to use an obsolete organ. 
Box 2.7 Evolutionary Research on Behaviour

Apart from evolutionary psychology, such sciences as ethology, sociobiology and behavioural ecology have also studied behaviour from a Darwinian perspective. The rudiments of ethology were created by scientists working in the 1930s, for example Konrad Lorenz, Niko Tinbergen and Karl von Frisch, who emphasised the distinction between innate instinctive actions and conditioned actions. Classical ethology often explained phenomena by referring to group selection - the so-called "good of the species" - which is refuted by contemporary evolutionism (see Section 2.5.4). The principle of ethological methodology is the observation of organisms in their natural environments, i.e. the environments in which evolution occurred.

Sociobiology emerged from the ethological research of groups, which was undertaken in the 1960s and 1970s. Its emergence is connected with the work of Edward O. Wilson $(1975,1979)$, an entomologist. The main aim of researchers working in this paradigm is to explain the evolution of social behaviours in functional terms. They construe the functionality of behaviours as an evolutionary benefit which such behaviours brought about in the past, and which contributed to their proliferation.

Behavioural ecology, similar to sociobiology, has its roots in classic ethology. Its methodology combines tools developed by ecology with an ethological approach to research on behaviour. Behavioural ecologists notably John Krebs, Nicolas Davies and Richard Dawkins - discover the mechanisms of making rational decisions that optimise the benefit-to-cost ratio in such complex behaviours as finding food, choosing a mate and fighting.

(summary adapted from Workman and Reader, 2004: 14-15)

\subsection{Popular reception and the sins of evolutionism}

Evolutionism has a special place not only in contemporary science, but also at the meeting point of science and popular reception. The theory of evolution has long constituted a key paradigm which, to a degree, has represented science as a whole, or an ideal of science and academic research in public discourse. It also led to deep divisions in terms of conflicting worldviews. Communities which perceive the Darwinian theory of the emergence of the biological world, and particularly the emergence of humans (anthropogenesis), as conflicting with their religious dogmas have always been interested in undermining the scientific status of evolutionism. Ideological opposition to evolutionism is connected with the doctrines of creationism and Intelligent Design, and the notorious battles 
Box 2.8 Why Are Black Women Ugly?

"Why Are Black Women Less Physically Attractive Than Other Women?" is the title of a 2011 Psychology Today blog post authored by Satoshi Kanazawa. In his post, the controversial evolutionary psychologist from the prestigious London School of Economics presented data that was supposed to indicate that black women are less attractive than other women, suggesting that the matter may boil down to testosterone levels. Critics immediately identified flaws in both the data analysis and the argumentation, Psychology Today removed the post from its blog, and Kanazawa himself acknowledged that his conclusions were incorrect.

An incorrect understanding of evolutionary psychology can fuel racist or sexist arguments. However, a proper understanding of an evolutionary approach to humans provides us with the strongest arguments against racism because it undermines the idea of "race" itself - the traditional division into human races is not corroborated by any actual genetic differences (e.g. Marks, 2002). Although evolutionary psychology touches on important and sensitive social issues, it is a science - and as such is subject to evaluation by scientific criteria and not its social implications. Among those who responded to the entry from Psychology Today, there were 68 influential evolutionary psychologists who, despite severely criticising Kanazawa's paper, agreed on one issue: topics which are politically incorrect should not be topics closed to science. ${ }^{a}$

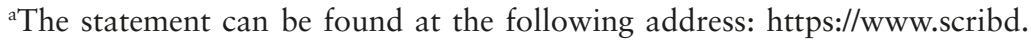
com/document/231350957/Kanazawa-Statement

against teaching the theory of evolution at schools waged by the supporters of the two doctrines. ${ }^{30}$

However, not all ideological opposition to evolutionism originates in religion. The vision of the human being constituted by traditional social sciences (Standard Social Science Model, cf. Tooby and Cosmides, 1992) assumed the human body has been moulded by evolution, but the human mind has been shaped by culture, science, and socialisation. Evolutionism undermines this dogma by referring to the genetic and innate foundations of behaviour, which some circles may not find easy to accept. Moreover, evolutionary views have been connected with such discredited views and ideologies as

30 Take John T. Scopes's court case of 1926, which has become an inspiration for novels and films. 
predatory (laissez-faire) capitalism, social Darwinism, eugenics, Nazism and racism. Arguments referring to Darwin's theory have been used, for example, to legitimise sterilisation of the mentally challenged or to justify aggressive colonial expansion at the expense of the "inferior races".

The assumptions of evolutionary psychology, due to their strong emphasis on differences between the structure of male and female psyches, also raise concerns and resistance in feminist circles, as the assumptions can be used to legitimise the traditional division of sexual roles as well as male dominance, and in its extreme (and extremely erroneous) interpretation, to justify violence or rape by referring to the "natural order of things". The stakes are thus very high when it comes to the proper interpretation of evolutionary mechanisms in humans.

The evolutionary inspiration for the analysis of phenomena - and psychological phenomena in particular - is not only fashionable but also frequently taken up by popular media, and as a result of the general turn towards naturalist thinking, biological explanations are becoming even more widespread. This prompts us to investigate the quality of explanations based on evolutionary thinking. Such explanations are obviously nothing new, but the majority of them are superficial, unverified or simply erroneous, and their history dates back at least to 1960s. Desmond Morris (1967) formulated some of the most popular evolutionary accounts, such as concerning the origin of the prominent red lips and female breasts in Homo sapiens as a sort of visual imitation of genitals and buttocks respectively. Aside from Morris's Naked Ape we also have Elaine Morgan's (1982) "aquatic ape", which postulates that human traits such as hairlessness are a remnant of an aquatic period of our evolutionary history. Similar adaptationist accounts (see 2.5.2) are widely known, but scientifically they are simply unconfirmed anecdotes.

As early as 1979, Stephen J. Gould and Richard Lewontin warned against what they referred to as just-so stories ${ }^{31}$ - creating possible, but unverified, adaptive explanations. Gould and Lewontin ironically refer to Voltaire's doctor Pangloss, who states that "everything was created for a purpose. Our noses are created for glasses and this is why we wear glasses, our legs are

31 The reference is to the collection of tales about animals by Rudyard Kipling. 
evidently created for trousers - and this is why we wear trousers"; that is how they illustrate the "adaptationist programme" (panadaptationism - see 2.5.2) - an unjustified assumption that the existence of a trait itself means that this trait has an adaptive function: it is "useful" and has emerged as a result of natural selection.

Steven Pinker (1997: 37) provides more examples: "Why do men avoid asking for directions? Because our male ancestors risked being killed if they approached a stranger. What purpose does music serve? It brings the community together". Note, however, that Pinker's goal in bringing them up was polemical - as Pinker indicates, such explanations are not bad because they are evolutionarily inspired - they are simply bad explanations.

Although - as we see - the fashion for evolutionary explanation has its own history, the unprecedented scale of this fashion and the ever-increasing scope of its influence on everyday life is a novelty. This practical influence and its consequences lead us to realise the growing contemporary importance of evolutionism. The evolutionary approach functions broadly in the media not only in its descriptive version, which allows us to explain and understand reality, but also in the applied version: it has been popularised in concepts which have direct practical implications. An example is the area of relations between men and women, where various gurus offer their strategies of seduction that supposedly refer to the evolutionary principles. ${ }^{32}$ Another example - the recent "paleo" fashions, which promote diets or physical exercise in line with "the evolutionary history of humans", actually have little basis in scientific literature.

\subsection{Evolution: Myths and misconceptions}

If you think you understand [evolution], you don't know nearly enough about it.

Michael Le Page "Evolution: 24 Myths and Misconceptions" (2008)

The simple logic of the theory of evolution by means of natural selection undoubtedly has its advantages. Using the evolutionary logic as a research tool does not require any technical knowledge or hi-tech scientific equipment.

32 For example, Wacewicz 2009 offers a critical analysis. 
Box 2.9 Paleo Fashion

"Paleo" training programs and diets are experiencing a growing popularity. They refer to the assumption that the human body has been shaped by selection pressures typical of the Palaeolithic (i.e. during the Stone Age, circa 2.6 million to 11 thousand years ago). The metropolis, industry or even farming are fairly recent developments in the evolutionary history of our species, and thus our organisms are adapted to the types of physical strain and types of food typical of the lifestyle and diet of a Palaeolithic hunter-gatherer, and not these of a city slicker. Advocates of paleofitness make a number of recommendations regarding an optimal "natural" training regime (such as running barefoot), and the followers of the "paleo" diet recommend avoiding products obtained by farming, for example dairy and cereal products.

The main assumptions of this "paleo" fad are justified, but its advocates are inconsistent in applying their evolutionary logic, which also suggests a few critical arguments against going on such a diet. First of all, the evolution of human beings did not end in the Palaeolithic - natural selection has influenced human populations after it, and these populations have been adapting to new lifestyles. One example is a mutation enabling adults to digest lactose in many populations, an ability that is near-unique in adult mammals. Secondly, our diet is composed of organisms which, just like us, live in a Darwinian world and are subject to the laws of selection. In the wild, the genes of organisms which were not eaten are transmitted to the next generation: natural selection thus promotes the development of defensive mechanisms, such as toxins in plants. Crops, however, are subject to artificial selection whereby humans purposefully develop the strains which do not have toxins, are easy to digest and are generally suitable for the human digestive system. Finally, palaeoanthropologists (such as Gowlett, 2003) indicate that the concept of a single "Stone Age diet" is a myth because even the diets of our distant ancestors were extremely varied in certain populations and depended on their local environments (see also Wrangham, 2009). The most detailed criticism of paleofitness and paleodieting can be found in the work of Marlene Zuk (2013).

Yet, this apparent accessibility has its price, and the image of evolution generated by popular culture, manufactured by the press and popular science programmes is largely false. As we will find out, such an image frequently permeates academic discourse, which is full of erroneous references to the theory of evolution made by academic communities that do not have a firm grasp of the theory of evolution. That is why many introductions to evolutionary theory (e.g., Colby, 1996; Gould, 1999: 131-227; Guttman, 
2005: 9-12; Johansson, 2005: 16-20; Krukonis and Barr, 2011: 335-343), and especially to evolutionary psychology (Cosmides and Tooby, 1997; Buss, 2003: 40-44), include chapters which place a special emphasis on explaining evolutionary myths and misconceptions.

We must bear in mind that the account provided below is rather basic. Readers have at their disposal a wide range of resources which offer a more detailed discussion of the topic. We recommend the classic, but still up-todate, introduction by Dawkins $(1976,2006)$. Here, we relate our choice of myths and misconceptions to the threats that they pose to language evolution as a research field.

\subsubsection{Simplification: Evolution $=$ natural selection}

In many cases, identifying evolution solely with natural selection constitutes an intentional, or at least a conscious, simplification. Darwin was convinced that "natural selection has been the most important, but not the exclusive, means of modification" (1859: 333). Talking simply about evolution, without the burdensome modification "mainly by means of natural selection", is a useful shorthand. However, it is imperative that the simplification not become an error: we have to remember the other mechanisms, such as genetic drift, and be wary of the dangers of panadaptationism, too.

\subsubsection{Misconception: Panadaptationism (naïve selectionism)}

What was the purpose of the earlobe? What was its evolutionary function? Posing this kind of questions assumes that an organism can be analytically reduced to a set of traits, each of which must be then considered in isolation from the others. It further assumes that a separate adaptive function may be identified for every trait which defines its "use". This logic assumes that every trait has a separate raison d'etre which is a reflection of specific selection pressures which led to its evolutionary emergence. As we found out in Section 2.4, Gould and Lewontin objected to such an approach in their 1979 manifesto. They criticise the proliferation of superficial adaptive explanations in which natural selection is an all-powerful and unrestricted force which arbitrarily shapes phenotypes, so that all aspects of form, function and behaviour of organisms are a priori considered to be adaptations. 
Gould and Lewontin call such an approach "the adaptationist program" and indicate several problems of this approach. They emphasise that natural selection is not the only evolutionary mechanism, but most importantly that its productivity is restricted by the laws of physics, biology, or even logic. Some highly adaptive solutions may be physically impossible (invisibility), some may be unworkable (an additional pair of limbs would not fit the general body plan of a mammal), and others may not be beneficial overall (even bigger human brains would use enormous amounts of energy and would cause problems during childbirth). ${ }^{33}$ Gould and Lewontin, without questioning the principal importance of the role of adaptation, propose explanatory pluralism which says that before we conclude that the trait is an adaptation, we must consider alternative hypotheses - for example, that the trait is "noise" or it is a spandrel: a by-product of selection pressures which influence other aspects of organisms. This is exactly how the ear structure and the chin structure (the result of reorganisation of the bones in the skull) are explained.

In the evolution of language:

There are numerous implications for the evolution of language, but they must all be treated with caution. Even though the biological ability to acquire language, understood as a complex functional system, has the hallmarks of adaptation, the adaptive scenarios of its emergence are restricted. Each component of linguistic ability could have evolved under different selection pressures, which additionally could have changed at different stages in the emergence of language. The process could have been influenced by mechanisms different from natural selection, such as genetic drift. Moreover, restrictions and construction trade-offs have undoubtedly played a role in the whole process. After all, linguistic ability did not evolve in isolation, but as a trait of complex organisms whose populations were under other numerous selection pressures, not related to language. Furthermore, we should not expect that linguistic ability is either "optimised" to perform a specific function or that there will be only one function, or even that the contemporary functions of language are a good reflection of the functions performed during earlier evolutionary stages. Most of all, we should adopt

33 Examples: PZ \& SW. 
a research attitude which foregrounds constraints, as proposed by Terrence Deacon:

What I think is important about my scenario, compared to many others, is not what it claims, but what it refuses to assume at the outset. Knowing the facility with which we can create stories to explain almost anything, I imposed certain restrictions on my search for a "likely story." I began with a list of limiting caveats. ${ }^{34}$

\subsubsection{Misconception: Survival of the fittest}

Darwin's doctrine is commonly identified in public discourse with the statement about "survival of the fittest", which leads to viewing the organic world as an arena where individuals fight for their lives ("nature red in tooth and claw"). ${ }^{35}$ However, the statement about "survival of the fittest" should not be attributed to Darwin but to his contemporary philosopher, Herbert Spencer (1820-1903). Although On the Origin of Species emphasises the aspect of survival, Darwin was well aware of the role of reproduction, and he used the term "struggle for existence" in a broader sense, which explicitly included producing offspring. Natural selection does not simply favour "strength" or even the ability to survive (when not accompanied by reproduction). Natural selection increases the prevalence of these genes, and of the traits connected with them, that enable an organism to have more offspring than other organisms in its population.

In the evolution of language:

Emphasising the significance of sexual selection is also reflected in some of the concepts in the evolution of language. The most obvious uses of language that translate into its probable adaptive functions (but see 2.5.2) relate to ecology, e.g. gathering information about the environment (see Dennett, 1994; Harnad, 2002), or the making of tools (Morgan et al., 2015); however, many authors indicate functions of languages which could have been directly or indirectly related to the social mechanisms of sexual selection. The indirect connection is explained by language being

34 From an interview conducted by Sławomir Wacewicz http://www.cles.umk.pl/ PDF/WywiadTD.html

35 From Tennyson's poem In Memoriam, Canto 56. 
an instrument for interaction and social manipulation, for example, Robin Dunbar's (1996) concept of gossip, or Jean-Louis Dessalles's (2007) concept of vigilance. More directly, language use itself has been proposed to function in sexual selection as an honest signal of the reproductive value of an individual (Miller, 2000).

\subsubsection{Misconception: Preservation of the species/ The good of the species}

The fundamental assumptions of synthetic theory of evolution are that transmitting genes to the next generation is the most important task of every species. It constitutes the driving force behind evolution and the basis for the existence of a species.

Quote from a statement by The Lech Kaczyński Academic Civic Club (Poznań, 30th January, 2013)

Please note that evolution is not a purposeful process, therefore species have no tasks... Because the emergence or extinction of species are evolutionarily rare events, natural selection only acts at the species level in a weak way and it does not lead to the emergence of adaptations useful to the species. It can, however, lead to the evolution of traits which are beneficial for individuals, but damaging for the demography of a species.

Statement of the Committee for Evolutionary and Theoretical Biology, Polish Academy of Sciences in response to the statement by The Lech Kaczyński

Academic Civic Club from January 2013

(Cracow, 6th February, 2014). ${ }^{36}$

The belief that organisms act for the good of a group or species was present in the mainstream biology even as late as in the mid- $20^{\text {th }}$ century. The 1960s completely changed it with the advent of the genocentric approach. However, statements about the "good/survival/preservation of the species"

36 The full text can be accessed at: http://www.kbet.pan.pl/_http://www.kbet.pan. pl/images/stories/Stanowisko_KBEiT_odnosnie_listu_AKO.doc 
have become part of everyday language, the media and collective awareness, including - as the first quotation shows - the awareness of some academic circles. The view about "the good of the species" is quite intuitively plausible because it is easy to imagine that individuals who are similar to one another and live in one group will act to achieve some common goal. However, the reality is quite different, perhaps dramatically. Dawkins believes that the level of "species" is arbitrary - if we consider the interactions one level up the taxonomy, we would have to expect a lion to help an antelope "for the good of the mammals" (Dawkins, 2006 [1976]: 10). Yet, competition for resources is fiercest at the level of species because organisms which belong to the same species compete for exactly the same resources (food, territory, mates). The concept of evolution of behaviours for the good of the species is also incompatible with observable facts, infanticide being the most remarkable instance (which we described in Box 2.4, and which was mentioned in the statement issued by Committee for Evolutionary and Theoretical Biology of the Polish Academy of Sciences) - this adaptive behaviour works against the good of the species, even these threatened with extinction, such as gorillas and lions.

In a more general sense, the notion of group selection is not completely discredited and has recently re-emerged mainly in mathematical and technical considerations. A formal perspective on the conditions for group selection was specified by George R. Price (1972). However, multilevel selection proposed by Elliot Sober and David S. Wilson (1998) is currently the most popular version of the general concept of group selection. Sober and Wilson argue that due to the configuration of environmental conditions, selection can occur at several levels: at the level of genes in which alleles compete for spreading in the genetic pool of a given population; at the level of organisms (the standard understanding of selection in Darwinism), in which individuals compete with one another; and finally, as Sober and Wilson emphasise, under certain conditions selection can also occur at the level of groups. These conditions include the existence of fierce competition between groups, which lowers competition between individuals within one group, and also takes into account the fact that every now and again groups split up and form anew. Sober and Wilson's group-selectionist logic assumes that members of a group who have a beneficial trait that undergoes selection attain reproductive success, and therefore this group gains an advantage in the rivalry against other groups. However, we must emphasise that the 
threshold conditions under which the power of group selection becomes significant are extremely strict, hence group selection is a process several orders of magnitude weaker than selection at other levels.

In the evolution of language:

The consequences of the status of group selection are crucial for the evolution of language. First and foremost, the benefits that language brings to the group, or to individuals when they function with other linguistic individuals, cannot be logically relied on when explaining the selection pressures leading to language. The challenge is to explain the individual adaptiveness of language to the first language users embedded in otherwise non-linguistic groups. Before language could have emerged, there must have existed such environmental and social conditions which promoted changes leading to language at the level of individual benefits in reproductive success.

\subsubsection{Misconception: Lamarckism}

Lamarckism refers to the views originating in the work of Jean-Baptiste de Lamarck (1744-1829) on the heredity of acquired traits, frequently illustrated by the example of a giraffe which, when reaching for leaves at the tops of trees, will extend its neck and then transmit this trait, i.e. extended neck, to its offspring. In reality, the differences which occur at the level of phenotype - such as greater strength acquired through heavy lifting workouts - generally cannot modify the genotype, and by extension cannot be inherited (the consequence of the so-called "central dogma" of molecular biology). Broadly speaking, it is assumed that changes in the genotype are solely the result of mutations which are not influenced by changes in the phenotype. Such a view is perhaps intuitive to some degree - in the end, we do not expect to transmit our acquired traits such as a broken leg or fluent French to our children through our genes. What is more, mutations are random by nature, which means that the occurrence of a certain mutation does not depend on whether the trait (a change in phenotype) is going to be in any way beneficial to an organism or not: the "demand" for a given mutation does not make its emergence more likely. It bears significant consequences for the speed of evolution: Darwinian evolution by means of natural selection is a gradual and multigenerational process, and big 
phenotypic changes in a population require a lot of time to appear, spread and stabilise.

\section{In the evolution of language:}

Although Lamarckism does not provide an accurate description of biological evolution, numerous authors (see Łastowski, 2004) indicate that cultural evolution is inherently Lamarckist, which explains its relatively rapid pace. The different paces of Darwinian and Lamarckist mechanisms may also explain the evolution of language. The phylogenetic distance between humans and non-human apes is relatively small: we share $99.5 \%$ of our phylogenetic history and approximately $98 \%$ of our genome with chimpanzees (although interpreting this value is tricky - see Marks, 2002). The huge phenotypic differences at the level of behaviour or social organisation are the result of processes of cultural evolution, such as technological development. This resonates with the arguments we present in Section 3.3.2, which say that we should not discuss language only in the sense of biological adaptation - a language-ready brain (Arbib, 2005; see 3.3) - but also languages, plural, as systems of cultural replicators whose present state is the effect of hundreds or thousands of generations of cumulative cultural evolution (Christiansen and Chater, 2008).

\subsubsection{Misconception: Macromutation and saltationism}

An alternative for the gradualist evolution made with "small steps" would be the scenario of a "catastrophic" sudden change which would involve the occurrence of a significant transformation in one or a few generations, for example, the emergence of a complex phenotypic trait. Saltationism (from Latin saltus, meaning "a jump") is the term used to describe this sudden change. Saltationism is a view refuted by the theory of evolution, as generally natura non facit saltum (nature does not make leaps).

On the one hand, we know one possible mechanism of saltationism, namely macromutation, which entails a major change in the phenotype, such as in the body structure (e.g., a leg replacing an antenna in an insect). Although macromutations do occur in nature, in the overwhelming majority of cases they are eliminated by natural selection. This stems from the fact that an organism is not a collection of individual traits, but a well-balanced whole, whose complexity and degree of organisation is frequently 
Box 2.10 Gradualism, Punctuated Equilibria, Saltationism

Saltationism should not be confused with punctuated equilibria (Gould and Eldredge, 1972). Punctuated equilibria differ from gradualism considerably, in assuming that the tempo of evolution is changeable rather than constant. The theory of punctuated equilibria claims that the phenotype of a population remains stable for a large number of generations until the environmental conditions "suddenly" change causing new and powerful selection pressures driving the phenotype to a new stable form, so large changes can be accomplished over a relatively small number of generations. The adjective "sudden", however, is relative and should be understood in reference to geological time, rather than truly sudden "jumps" over single generations, like in the case of saltationism.

compared to a jet plane, and every change of a single parameter influences a number of others. To understand the after-effects of macromutation, we must bear in mind that it is a result of a completely random "tinkering" of evolution. The chance that a random modification to the engine of a jet plane will improve its performance is low, but this cannot be ruled out entirely if the change is slight enough. A randomly chosen major modification in such a complex machine, however, simply must bring about negative results.

\section{In the evolution of language:}

Without referring to supernatural occurrences (in other words: wonders), the saltationist scenario of language emergence in just one step is quite impossible, and in a few steps is still extremely unlikely. While Derek Bickerton (compare 1998 and 2009) has renounced his "catastrophic" scenarios, Noam Chomsky (e.g. 2010: 59) still seems to be a proponent of saltationism in the evolution of language, which may be connected with his quite specific definition of the term "language" (see Section 3.3). Recent research in the evolution of language has been characterised by a gradual move away from simple scenarios (especially those of the "magic X component" variety, see Section 3.3.2). Currently, the majority of researchers agree that the evolution of such a complex functional system as human language ability must have been a long, multi-stage process, regardless of whether it emerged by means of punctuated equilibria or gradual processes (see Pinker and Bloom, 1990). 


\subsubsection{Misconception: Evolution has a purpose (teleology)}

Evolution is an impersonal, natural process which is not governed by any design: it does not plan, it does not have any intentions, it does not set any objectives and does not try to achieve them. Our everyday experience leads us to believe that complexity can only be a result of well-thoughtout actions, and that is why when we see the enormous complexity of organisms, we easily succumb to the "illusion of design", taking them for forms which were purposefully created. However, the timescale of natural selection is completely different from the length of human life. Evolution is a "blind watchmaker" (Dawkins, 1996), "not an engineer with a drawing board, but a tinkerer" (Jacob, adapted in Pinker and Bloom, 1990), who "acts as an opportunist, not a perfectionist" (Lem, 1984: 32).

It is hard to talk accurately about the non-purposeful nature of evolution without running up against a linguistic problem. The language of the description of evolutionary processes itself creates an illusion of teleology (Johansson, 2005). Talking about evolution or selection which "shape", "favour" or "eliminate" cannot be avoided - this is a feature of the conceptual metaphors which we use to describe the phenomenon (see Drogosz, 2013). Richard Dawkins's books are a telling example, as he emphasises the impersonal and nondeliberate features of evolution, but he simultaneously and consciously chooses metaphors which personify evolution - for example, the eponymous "blind watchmaker" and "selfish gene" (1976) - for the greatest rhetorical effect. ${ }^{37}$

One of the consequences of the non-purposeful characteristics of evolution is its short-term action. Since selection always takes place on a current basis, natural selection does not plan for the future or make "long term investments" - it favours changes which are adaptive here and now and not those which are likely to become adaptive after some time. The type of a long-term morphological change which increases reproductive success can occur if and only if all intermediate stages also result in an increased reproductive success that is not below the population average. In other words, the fact that the final result would be useful does not suffice for the complex system to evolutionarily emerge - all the intermediate stages must be better, or at least not worse, than their alternatives.

37 A detailed explanation of this nomenclature can be found, for example, in the anniversary edition of The Selfish Gene (Dawkins, 2006). 


\section{In the evolution of language:}

This feature of natural selection has direct implications for the evolution of languages, as it eliminates scenarios which claim that the adaptive value of language (that is the usefulness of language itself) is sufficient explanation for its evolutionary emergence. Similar to other complex systems, in the emergence of the human language capacity, every stage must have had its own evolutionary sense whose presence can be substantiated independently of its role in language. Each subsequent change had to lead to a well-functioning phenotype before the sum of such changes could have been able to equip us with language; otherwise, the alleles responsible for such changes would have been eliminated by natural selection before this final result could be accomplished.

\subsubsection{Misconception: Evolution means progress or going up in the great chain of beings}

Because of the way the term has been used in common parlance, "evolution" has come to connote development and progress, thus acquiring an axiological and evaluative dimension. The evolutionary process, however, is not purposeful or axiological in nature and does not aim at developing forms that are "better" than its predecessors; it actually often leads to the emergence of such forms which are simpler than their predecessors (see Gould, 1994). Similarly, it is only by habit that we speak about "higher" and "lower" organisms because from an evolutionary point of view there are no bases for such an evaluation - for every current population of organisms, their existence is the evidence of their proper adaptation to the environment.

Thinking about evolution in terms of values, especially when committing the teleological fallacy (2.5.7 above), is frequently applied to human evolution. Its reflection is the popular image (Fig. 2.3) suggesting that anthropogenesis - the evolutionary process by which humans emerged was based on the replacement of ape ancestors by "better", "more intelligent" etc., forms.

Such a depiction often leads to two erroneous conceptualisations. First of all, human phylogeny is not linear, with one species replacing another, but is more akin to a tree with various branches, depicting many - often contemporaneous - forms. For example, the modern Homo sapiens overlapped in time with Homo erectus and Homo floresiensis, and when it comes to the 


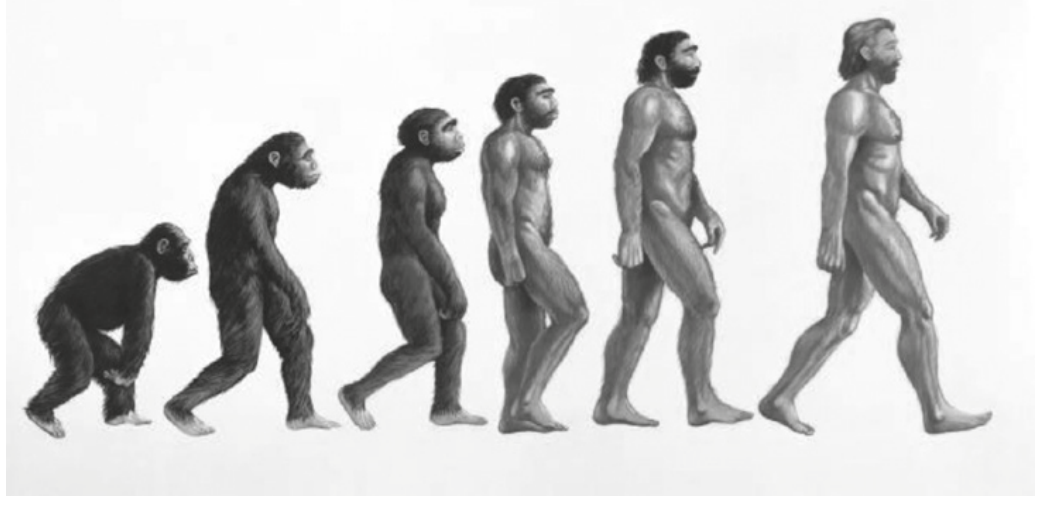

Fig. 2.3: The traditional - and erroneous - depiction of anthropogenesis. http:// www.bbc.co.uk/worldservice/news/2008/10/081007_endofevolution.shtml. DOA: 08 Aug 2015.

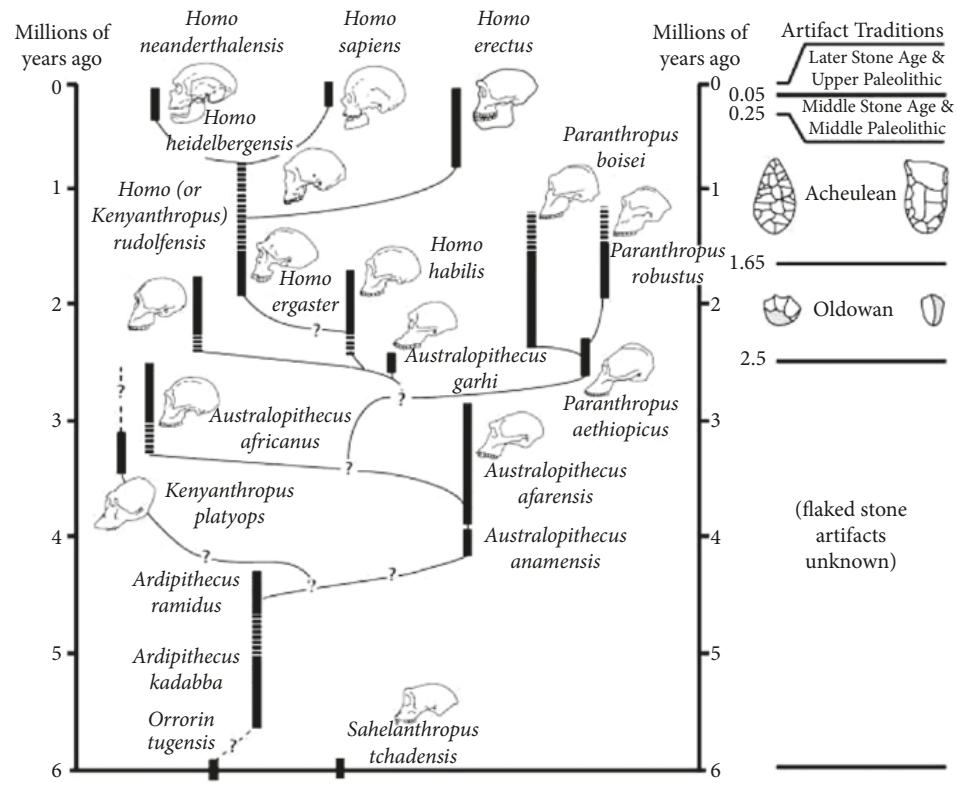

Fig. 2.4: The correct depiction of anthropogenesis. http://www.amnh.org/ education/resources/rfl/web/hhoguide/family-tree.html. DOA: 08 Aug 2015. 
Neanderthals and the Denisovans (see Box 3.4 "Selected Hominins"), they lived in the same areas and almost certainly interbred with Homo sapiens, producing hybrid offspring. ${ }^{38}$

Secondly, it is highly unlikely that all abilities only improved in anthropogenesis. Although there is no straight correlation between brain volume and intellectual potential, it is worth noting that Neanderthals had bigger brains than Homo sapiens and that in the Neolithic period - approximately within the last 10,000 years of our history - the average volume of the human brain has significantly reduced (Hawks, 2011). Apes too can surprise us with their cognitive abilities, some of which can be better than in humans, e.g., some forms of spatial memory appear to be better in chimpanzees that in humans (see Section 4.4.4).

\subsubsection{Misconception: Recapitulationism ("ontogeny recapitulates phylogeny")}

The myth regarding evolution as progress was widespread in the $19^{\text {th }}$ century. As a result of this misconception, Ernst Haeckel, a German biologist, assumed that the "higher" forms are the evolutionary extensions of the "lower" forms, so in their development they have to go through all the "primitive" stages characteristic of the "lower" forms, with the more advanced stages only added on top of these more basic ones. On this basis, Haeckel formulated the recapitulation theory, or the biogenetic law, according to which an individual's stages of evolution reflect and summarise analogous stages in the evolutionary development of the whole genus and species: “ontogeny recapitulates phylogeny”. Later research has undermined both the accuracy of Haeckel's reconstructions (especially of the embryonic stages of individual species) on which he based his conclusion, and the adequacy of the notion of recapitulationism as a whole (e.g. Gould, 1999). But the misconception about ontogeny recapitulating phylogeny continues to linger even in the academic literature.

38 Currently, the non-African populations have approximately 1-4\% of genes identified as Neanderthal (most probably inherited from the Neanderthals) (Green et al. 2010). On the other hand, the Malaysians have 4-6\% of genes identified as Denisovan (most probably inherited from the Denisovans) (Reich et al. 2011). 


\section{In the evolution of language:}

In the light of recapitulationism, data from language acquisition in children may be adequate to reflect the problems of the evolution of language. As there are no other "simpler" forms of language in animal communication, we might be led to imagine that the early phylogenetic stages of language development resembled those in ontogeny. Such an approach would be invalid, however, as there are no reasons why these two processes should be parallel.

On the other hand, it is worth emphasising that research in language acquisition has provided a large number of useful analogies and a wealth of data which, juxtaposed with others (converging evidence, see Section 3.2.1), can support some arguments over others: for example, children's readiness for the acquisition of sign languages (see Sections 6.4.2 and 6.5.3) can be interpreted as evidence that the human innate language capacity is not limited to the vocal modality.

\subsubsection{Misconception: Confusing explanatory levels}

Why do people have sex - is it because of their hormones, to satisfy their sexual drive, in order to have children, or maybe because they inherited the tendency from their ancestors? Niko Tinbergen (1963), one of the founders of ethology, has presented an important scheme for evolutionary explanations. He has remarked that explanations of behaviour pertain to four levels of description:

- Explaining how a given behaviour works and what are the conditions which trigger it;

- Function - understood as the influence of the behaviour on the organism's fitness;

- The behaviour's evolutionary history; and

- Ontogeny, a pattern according to which organisms acquire the behaviour in the course of their lives.

The research scheme based on this reflection came to be referred to as “Tinbergen's Four Whys”. According to Tinbergen, the evolutionist who aims to fully explain a certain behaviour should research all four causes which cumulatively create the full picture of the development of that behaviour. It is a grave error to treat the answers as mutually exclusive 
alternatives, only one of which can be true. For example, the explanation "humans like eating sweets because it is pleasant" is not an alternative to "people like eating sweets because it is their adaptation" - both statements can simultaneously be true. The first statement stops at the proximate level of explanation, which describes the mechanism, but it does not answer the question " why is the taste of sweets so pleasant to people?" On the functional and ultimate level, the physiological mechanism of sweet taste perception, connected with the reward system in the brain, is an adaptation in itself, which emerged in the process of natural selection: individuals motivated by the mechanism to consume sweet food were better nourished than others and transmitted this trait to the next generations.

Similar to other evolutionary concepts, this scheme can also be applied beyond the boundaries of evolutionary biology, such as with reference to traffic lights, by asking questions: How do they work? (mechanism); How has their construction changed over the years? (phylogeny); How are they manufactured? (ontogeny); and finally, to What extent does their function influence the chances of survival of the road users? (function) (Bateson and Laland, 2013).

In the evolution of language:

Remembering to keep apart the different explanatory levels is rather important for research on language evolution. For example, it points to the need to consider all types of available data, whether their relevance is phylogenetic (e.g., comparisons with extant apes) or ontogenetic (language acquisition in children). It also serves as a useful reminder that the current functions of language may be different from those language had at its beginnings. Finally, considering language evolution on four parallel levels makes it possible to better appreciate the complexity of language and so avoid the false "innate $v$ s learned" dichotomy.

\subsection{Summary}

Unfortunately, the above list could be longer. There are many myths, simplifications and fallacies in the application of evolutionary logic. We have not mentioned, for example, the misconceptions related to erroneous beliefs about genes - such as genetic determinism or assuming a one-to-one 
mapping between genes and phenotypic traits (which could suggest that there is a single "language gene").

Our aim was to discuss language evolution in terms of the general theoretical bases of evolutionism. While identifying the assumptions and mechanisms of the evolution of language, and especially specific hypotheses and evolutionary scenarios of the emergence of this trait, it is important to be careful and to be moderate in our assumptions. Knowledge of the influence of Darwinian ideas on the theoretical frameworks in language evolution enables us to shift our focus from speculative glottogenetic scenarios to the role of constraints. This will be the topic of the next chapter. 



\title{
Chapter 3 The Evolution of Language: A Departure from Glottogenetic Scenarios
}

\author{
We study evolution to understand the present as \\ much as the past, about which we shall be forever \\ uncertain. \\ Michael Studdert-Kennedy (2005: 12) \\ The short answer to the question of How the Brain \\ Got Language is "through biological and cultural \\ evolution." The challenge is to be more specific.
}

Michael Arbib (2013: 107)

Is language the most important trait the Homo species has evolved? The emergence of linguistic communication was certainly a milestone: Darwin (1871) considered language to be the greatest invention of humankind, alongside fire. Maynard Smith and Szathmáry (1995) share the view that it was a major transition, equal only to such developments as the emergence of chromosomes or the cell nucleus. From a cognitive perspective, the evolutionary emergence of language probably constitutes "the hardest problem in science" (Christiansen and Kirby, 2003b). This label is both controversial and useful. The list of riddles which may contend for this title is certainly long, though Christiansen and Kirby's intention is to underscore the second element of the phrase - to recognise the issue of the origin of language as a scientific problem. They describe a new consensus because the scientific status of the issue of the origins of language and the scientific field which investigates it - the evolution of language - became established only at the beginning of the $21^{\text {st }}$ century. Language evolution is an interdisciplinary area of research comprised of different discourses that are united by a common goal - explaining the evolutionary emergence and development of the human-specific capacity to acquire and use language.

Even as late as in the 1970s and 1980s, especially in linguistic reflection, a different approach seemed to dominate, one which considered the search 
Box 3.1 Language Evolution and Related Areas of Research

Language evolution (also called the evolution of language, sometimes EvoLingo or EoL) - understood not as a process but as an area of research is an interdisciplinary science about the biological and non-biological mechanisms of the emergence and development of language; its aim is to answer the question "How did it happen that people (and not other primates) have language?" Language evolution also includes the evolution of languages. Defined more narrowly, language evolution is a science that examines the phylogenetic emergence of the language faculty, which is a genetically conditioned and human-specific ability to acquire natural language.

Language origins, or the study of the origins of language, is a term pertaining to the same domain and the same type of investigation as the evolution of language, though it is used less commonly due to the connotations with the speculative, non-scientific tradition on reflecting on the origins of language (see "glottogony" below).

Evolutionary linguistics, is a term that is sometimes used interchangeably with language evolution, though it generally connotes research which is less interdisciplinary and more strictly linguistic, quantitative, and whose subject is the evolution of languages.

Biolinguistics also investigates the origins of human linguistic capacity, but within a narrow theoretical framework delineated by Chomsky's generativist paradigm - as such, it is one of the contemporary currents in language evolution.

Evolution of languages - which we differentiate by the plural (following Hurford, 1999; 2003) from language evolution, is a field of study not concerned with the biological evolution of language faculty, but with the development of linguistic structure via mechanisms of cultural evolution; the evolution of languages is currently closely tied with language evolution and, in the broad sense of the latter term, can be considered its subfield.

Glottogeny - reflection upon the beginnings of language; here, we narrow down the use of this term to naturalistic speculations on the origins of language. Such study began at the beginning of modernity and has continued until the emergence of language evolution as an area of research (cf. language evolution).

Glossogeny - a synonym for the evolution of languages. The term refers to the study of the development of linguistic structure via the mechanisms of cultural evolution.

Historical linguistics, or diachronic linguistics, investigates the history of specific languages and their pre-history, aiming esp. at describing the degree to which languages are related and of grouping them into family trees. Historical linguistics, which studies the nature, chronology and dynamics of 
language change, is closely related to research on the evolution of languages (see above), but differs in its timescale, and when it comes to stating the relation between languages and reconstructing their earlier forms (i.e. protolanguages in historical, not evolutionary, sense) it is part of comparative linguistics (originally comparative philology).

Adapted from: Wacewicz 2013

\begin{tabular}{|c|c|c|c|}
\hline Perspective & Science & Timescale & Subject of Research \\
\hline Ontogeny & $\begin{array}{l}\text { language } \\
\text { acquisition }\end{array}$ & $\begin{array}{l}\text { years (a few, a } \\
\text { dozen years) }\end{array}$ & $\begin{array}{l}\text { spontaneous acquisition } \\
\text { of an ethnic language, } \\
\text { learning a foreign language } \\
\text { by children and adults }\end{array}$ \\
\hline Glossogeny & $\begin{array}{l}\text { evolution of } \\
\text { languages }\end{array}$ & $\begin{array}{l}\text { thousands, tens } \\
\text { of thousands, } \\
\text { potentially } \\
\text { hundreds of } \\
\text { thousands of } \\
\text { years }\end{array}$ & $\begin{array}{l}\text { evolutionary changes in } \\
\text { the general structure of } \\
\text { communicative code, the } \\
\text { shift is cultural in nature, } \\
\text { and replicators are freely } \\
\text { (e.g.. statistically) defined } \\
\text { units of language }\end{array}$ \\
\hline Phylogeny & $\begin{array}{l}\text { evolution of } \\
\text { language (nar- } \\
\text { rowly defined) }\end{array}$ & $\begin{array}{l}\text { from the mo- } \\
\text { ment when phy- } \\
\text { logenetic lines } \\
\text { of chimpanzees } \\
\text { (Pan) and } \\
\text { hominins } \\
\text { diverged - } \\
\text { approximately } \\
6 \text { to } 7 \text { million } \\
\text { years }\end{array}$ & $\begin{array}{l}\text { evolutionary changes, } \\
\text { especially those which } \\
\text { have adaptive value, } \\
\text { leading to the biological } \\
\text { capacity of humans to } \\
\text { acquire natural language; } \\
\text { the change is biological } \\
\text { and the replicators are } \\
\text { genes. }\end{array}$ \\
\hline
\end{tabular}

for both the pre-historic and biological beginnings of language to be an unscientific and non-academic pursuit. For instance, while Gerhard Doerfer compared the reconstruction of the Proto-Indo-European language to "a large clearing dimly lit by scarce rays of sunlight", he made the following statement about comparative research into the origins of language:

However, this clearing is surrounded by a dark forest of glottogony (...) full of absolute silence, eternal darkness and overgrowing thickets where one can easily get entangled. This dark forest we should not enter, because where it begins, all knowledge ends. (cited from Kuckenburg, 2006) 
Jacek Fisiak makes an even more blatant statement (1985):

The problem has two aspects, i.e. a phylogenetic one - the emergence of language in the history of our species, and an ontogenetic one - the emergence of language in children. The reflection on the phylogeny of language was pursued in myths and religious doctrines, in the works of philosophers; however, it constituted a problem situated far from the centre of linguistic research of the 20th century, with some notable exceptions (Jespersen 1922).

But Kendon (1991) writes that:

Discussion of the problem of language origins has by now become quite widespread and certainly highly informed. It may still not be fully respectable; and many still regard it as, at best, a kind of intellectual game. If this is what it is, it is nevertheless a much more interesting and challenging game than it once was, and it provides a focus through which a wide range of highly diverse fields of knowledge and theory may be brought into relationship with one another. (Kendon, 1991: 202)

Kendon was right. A year earlier, in 1990, in a breakthrough paper entitled "Natural Language and Natural Selection", Steven Pinker and Paul Bloom claimed that language constitutes a complex adaptation specific to humans, and that it should be investigated in an evolutionary context. This text and the date of its publication are considered to be a turning point by many language evolution researchers (e.g., Johansson, 2005: 3; Dessalles, 2007: 103; Wacewicz and Żywiczyński, 2012) - a symbolic re-opening of the discussion which had remained dormant since 1866 (see 1.2.2). ${ }^{39}$ It is true that the following years saw a surge in interest in the topic of language evolution, which can be seen in the rapid growth of the number of publications about language evolution; their number, according to some estimates, was ten times greater in 1990-1999 in comparison to

39 Some even suggest that between 1866 and 1990 the topic of the origins of language was not explored at all (e.g., Scott-Philips, 2010). As Chapter 1 and section 3.1 (see also Fitch, 2010: 16) indicate, this is a misunderstanding, and the 1866 edict and Pinker and Bloom's paper from 1990 should be treated merely symbolically. On the other hand, Pinker and Bloom's text is the most often cited source in research on the evolution of language (according to the "Language Evolution and Computation Bibliography"), and the Journal of Evolutionary Psychology issued a special edition on the 20th anniversary of its publication. Evidently, symbols are also needed. 
the previous decade. ${ }^{40}$ The next turning point that confirmed the status of the evolution of language as an area of research was the launch of the Evolang conference series.

What made the 1990s so different from previous decades and led to this research breakthrough? It seems that this was the effect of the convergence of four major factors:

- a renewed interest in the origins of language and a growing openness to research into the issue (3.1.1);

- a nativist and cognitive revolution in the language sciences (3.1.2);

- developments in empirical disciplines and, following on from this, a richer and more complete research material (3.1.3);

- advances in evolutionary thought (3.1.4).

\subsection{Road to the science of language evolution}

\subsubsection{Renewed interest}

At the turn of the 1950s and 1960s, questions about the origins of language were ceasing to be a taboo topic among linguists. This resulted, on the one hand, from the development of Generative Grammar, and more specifically, from the more biologically oriented description of language formulated by Chomsky. On the other hand, it was connected with the fact that some of the more prominent linguists had been trying to tackle this problem as well. Undoubtedly, Charles Hockett (1916-2000) contributed to undermining the "glottogenetic taboo" in linguistics. He developed the famous idea of the design features (see Box 3.2 below) of language. In a series of publications (1958; 1959; 1960a; [1960b] 1977; Hockett and Altmann, 1968), he proposed a new model of defining language via a direct confrontation of its

40 See Christiansen and Kirby (2003b) who measured the number of publications about 'evolution' and 'language' together [Topic=(evolution) AND Topic=(language)] according to the ISI Web of Knowledge. Currently, browsing the ISI Web of Science (all databases) reveals research output in the field in the 1990 s to be 5.6 times what it was in the previous decade, while research in the period 2000-2009 was 3.6 times what it was in the 1990s; these growth rates are significantly higher than the comparable growth rates of research output in the language sciences in general, the figures for which are 2.5 and 2.3 respectively. 


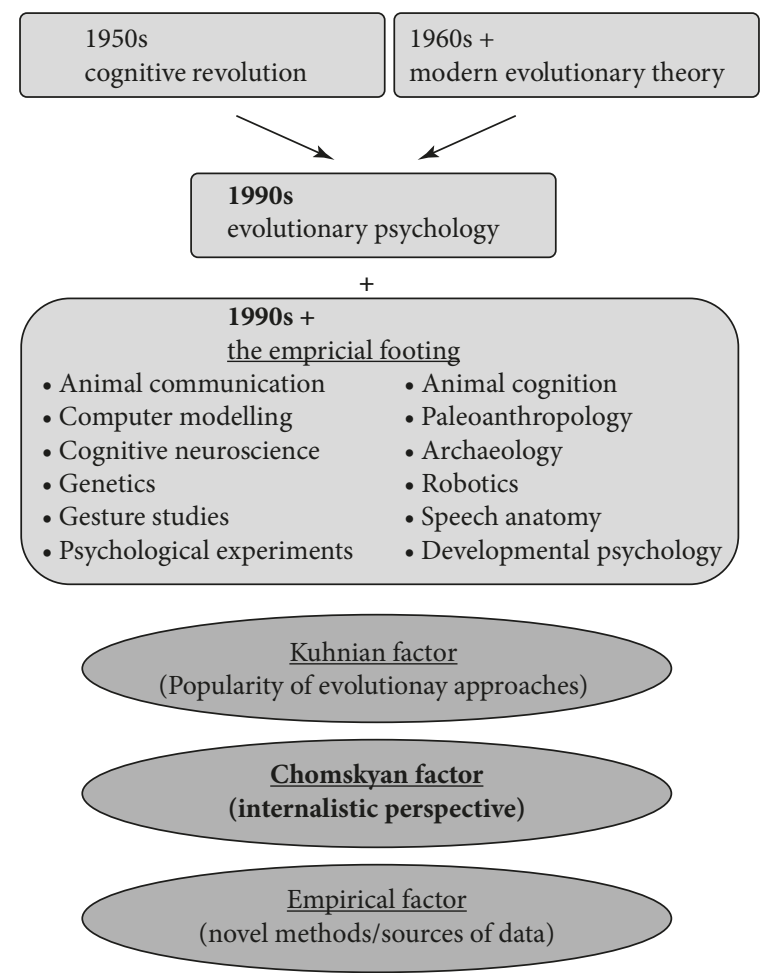

Fig. 3.1: Developments that led to the contemporary research field of the evolution of language.

features with the codes of animal communication. According to Hockett, there was no single feature of language which could not be found in animal communication; the uniqueness of language consisted instead in the simultaneous presence of features which otherwise existed only in some codes, for instance, the use of the vocal-auditory channel in parrots, interchangeability in duos of singing gibbons, or displacement in the dance of the honeybee (Hockett, 1960a; 1960b).

In his description of these features, Hockett does not avoid making evolutionary remarks; he even proposes an evolutionary scenario in which the communication of what he refers to as protohominids had all the design 
features of language apart from displacement, productivity and the full range of cultural transmission. In a paper from 1964 entitled "The Human Revolution", Hockett, together with the anthropologist Robert Ascher (1931-2014), derived language from the alarm calls which apes use and which were supposed to belong to the communicative repertoire of the last common ancestor. The revolution referred to in the title involved opening the closed "lexicon" of signals by opening the possibilities to combine them, first in two- and later in multi-phrasal strings. Hockett's design features became a textbook reference point for comparing human language and animal communication; however, currently the system should be considered obsolete because it emphasises the logistics of human communication, and not its cognitive infrastructure (for a detailed criticism, see Wacewicz and Żywiczyński, 2014).

Yet another influential, albeit much more controversial, linguist of the period is Morris Swadesh (1909-1967). Swadesh is particularly well known for being the creator of lexicostatistics, which involves a quantitative comparison of cognates in selected languages; and of glottochronology, which uses lexicostatistical observation in order to establish the dynamics and direction of change in the history of languages. These lexicostatistical reflections led Swadesh to the problem of the origins of language, which he described most extensively in his posthumously published The Origin and Diversification of Language (1971). Swadesh begins with the idea that there is an evolutionary continuity between animal calls and language, the legacy of which may be seen in contemporary language in the form of exclamations (1971: 179). The system based on exclamations was supposed to evolve in two stages: in the first, which Swadesh termed "eoglottic", the sounds of protolanguage became phonomimetic and in this way they became tied to schematic symbolic contents. To illustrate, plosives were supposed to relate to violent stimuli, nasals to mild stimuli, and spirants were supposed to express recurrence (1971: 200). In the second - "paleoglottic" - era, these sounds started to be used in expressions referring to actions and shapes that they phonomimetically resembled (1971: 208). Although Swadesh's ideas are no longer seriously considered by linguists, the problems he raised about (i) the continuity between ape vocalisations and the sounds of language, and (ii) the scope of sound symbolism in contemporary languages and its 


\section{Box 3.2 Hockett's Design Features}

Hockett worked on defining the design features of language for about ten years. He began by specifying seven features $(1958$; 1959), then he postulated thirteen (1960a; [1960b] 1977), and the number finally grew to sixteen (1966; with Altmann, 1968). It is his proposal featuring thirteen design features that is best-known, especially among linguists, and it is these features that will be discussed here.

Vocal-auditory channel: the sound of speech - the prototypical signal in linguistic communication - is transmitted via the mouth of the speaker to the ear of the listener.

Broadcast transmission and directional reception: the sound of speech is transmitted in all directions, but the recipient is able to perceive which direction the sound is coming from.

Rapid fading: the sounds of speech disappear once they have been produced by the signaller.

Interchangeability: speakers can produce a signal they have received and understood.

Total feedback: speakers are also recipients of the sounds they produce.

Specialisation: the only purpose of speech is to communicate.

Semanticity: elements of speech signals have meanings tied to them.

Arbitrariness: there is no direct link between the form of a sound signal and its meaning.

Discreteness: sound signals are not continuous and are made of discrete elements, such as sounds, syllables, morphemes or grammatical constructions.

Displacement: speakers can communicate messages about things which are not present in the here-and-now, or which are abstract.

Productivity: the discrete and countable elements of language can be used in order to produce novel utterances.

Cultural transmission: languages are transmitted from one generation to another, and a person has to learn a language in order to use it.

Duality of patterning: phonetic elements of language signals (phonemes) do not have any meaning, but their combinations (lexemes) do.

Sources: Crystal, 1987, 396-397; Jasiński, 2010; Wacewicz and Żywiczyński, 2014.

role in the emergence of language, are still the subjects of heated debates (e.g., Hauser et al., 2002; Zlatev, 2014a).

Roger W. Wescott (1925-2000), an American linguist and anthropologist, attempted to re-engage linguists in a discussion about the early stages of language in a paper entitled "The Evolution of Language: Re-Opening 
a Closed Subject" (1967), which was written in the Chomskyan paradigm. On his initiative, the first symposium on the origins of language was convened during a meeting of the American Anthropological Society in 1972, which resulted in the publication of a volume of papers edited by Wescott, Gordon Hewes, and William C. Stokoe (1974). In the mid-1970s, several more symposia and conferences devoted to the topic were organised, the most important of which was the one organised (again) by Wescott during a meeting of the New York Academy of Sciences in 1975 and a meeting in Munich convened under the auspices of Gesellschaft Teilhard de Chardin in 1975 .

Yet another important field of research which was integral to developments in thought about the origins of language was gesture studies. This field developed first as a branch of psychology and later, in the mid-20 ${ }^{\text {th }}$ century, emerged as an independent research area in its own right. Adam Kendon (1972; 1975; 1983a; 1983b), David McNeill (1985) and Paul Ekman with Wallace V. Friesen (1969a; 1969b; 1972) made pioneering efforts in the field. The person who connected the arguments from gesture studies to reflections on the origins of language was the American anthropologist Gordon W. Hewes (1917-1997). He was familiar with the history of the glottogenetic thought and had a talent for reconstruction, which he demonstrated in several research papers (e.g., papers from $1975 ; 1976 ; 1977 \mathrm{a}$ and 1996). However, Hewes's ambition was to make glottogenetic speculations an area of knowledge which would unconditionally be subject to empirical findings. He was convinced that language had developed from gestural behaviours, a claim for which he coined the term the "Gestural Primacy Hypothesis" (1973), and demonstrated his own scenarios of the emergence of a gestural protolanguage, its development and its transition to the vocal-auditory channel (see e.g., Hewes, 1977a).

However, his greatest achievement was identifying those research areas which could be used to galvanise powerful arguments in gestural scenarios of language origin. Firstly, he indicated the enormous expressive potential of gestures and pantomime in contemporary humans. Gestures in natural linguistic communication always co-exist with speech and facilitate the understanding of spoken messages; pantomimic communication, in situations in which interlocutors do not know the same language, can 
express even extremely complex ideas. Hewes refers to the accounts of European travellers from the period of the great geographical discoveries, who were able to obtain information about topography, the dangers that awaited newcomers, and even the political systems of tribes from the indigenous populations, all through non-linguistic communication. It led him to the conclusion that totality of facts does not support the view of a purely vocal character of language, and that this characterisation is only the result of "the long obsession of linguistics" with speech (1973: 11). Yet another important intuition of Hewes related to the lack of continuity of the vocal communication of nonhuman primates and language, which was to make the gestural primacy scenario more credible (1973; 1975; $1977 \mathrm{a} ; 1977 \mathrm{~b})$. In developing this line of argument, he referred to the failed attempts to teach apes spoken language (Furness, 1916; Kellogg and Kellogg, 1933; Hayes and Hayes, 1952), and on the other hand he documented promising attempts to teach them visual systems of communication. He primarily concentrated on the use of sign language to educate chimpanzees by R. A. and B. T. Gardner $(1969 ; 1971)$ and David Premack (1970; Premack and Premack, 1974) (see 3.1.3 RESEARCH ON PRIMATES). In his considerations, Hewes also refers to data from neuroscience. Writing before the technological turn which allowed the study of the brain in vivo (see 3.1.3 NEUROSCIENCE), Hewes draws his remarks from neuropathology, indicating the immense robustness of gestural-visual communication, which tends to be spared in disorders related to language (e.g., 1977a: 132-133). Finally, Hewes refers to research on sign languages used both by hearing and deaf people, suggesting that sign languages are widespread, can emerge spontaneously, are very iconic, and are easier to comprehend by non-users than spoken languages (1977a: 111). Although some of Hewes's ideas are still controversial (such as, for example, his final postulate about the greater iconicity of sign languages in comparison with spoken languages; Brentari, 1998), the majority of his intuitions turned out to be accurate, and they set paths which contemporary researchers have followed. By connecting erudition with empirical sensitivity and interdisciplinary approach, he is both a representative of a long glottogenetic tradition and the first researcher to represent the contemporary evolution of language. 


\subsubsection{Chomsky, internalism and the biological foundations of language}

The events we have described happened at a time of the biggest revolution in linguistics since de Saussure, a revolution which resulted from the work of Noam Avram Chomsky. Starting with a critique of behaviourism, which reduced all cognitive processes to stimulus-reinforcement patterns, he proposed a new framework for language and linguistics, which assumed that cognitive processes were real. Although Chomsky's linguistic ideas have changed quite frequently - beginning with a grammar based on rewrite rules (1957; 1962), through transformational-generative grammar (1965), to the minimalist programme (1995), the way he has viewed language has always been based on the same motifs and intuitions. First of all, as noted earlier, Chomsky argues that language - and more specifically the "language faculty" - primarily involves cognitive processes; thus, he understands linguistics to be a part of psychology (1972). Assuming such a perspective leads him to focus exclusively on "linguistic competence", that is the linguistic knowledge possessed by every native speaker of a given language; the way language is used in communication (performance) is of no concern to him. Chomsky goes a step further and states that the only linguistic reality is I-Language. This concept refers to the linguistic knowledge internalised by a speaker of a language (1986). The notion of I-Language is contrasted with E-Language, i.e. externalised language, which encompasses de Saussure's langue and parole (see Jackendoff, 2002); for Chomsky, E-language is a hypostasis derived from existing I-Languages and is thus only epiphenomenal in nature. This is where Chomsky's strong biological nativism comes to light. I-Language is the final state of a bio-programme which is innate in each human being. Similar to the way anatomical organs such as the liver develop in a living organism, conditioned by the genetic code, language develops in a child's mind/brain under the influence of environmental stimuli. I-Language is the fully developed state of the language organ (1986), whereas Universal Grammar constitutes its initial state in a child's mind; the development of Universal Grammar into a natural language is governed by a Language Acquisition Device (a notion which Chomsky borrowed from Lenneberg, see below). This biological understanding of the language faculty made it possible to think about language in terms 
of adaptation (even though Chomsky himself rejects such a possibility). Another characteristic feature of this approach pertains to modularity, i.e. the thesis that language constitutes a separate module in the brain and the mind, independent of other cognitive processes. Strictly speaking, language is syntax that is defined by Universal Grammar (1965).

Eric Heinz Lenneberg (1921-1975), a linguist and a neuroscientist, played an important role in the formulation of a biological interpretation of Chomsky's idea. Working from his own research on language acquisition in children, he advanced the thesis that there exists an innate, biological mechanism which is responsible for the process (1964) - "the ability to acquire language", as he initially called it, was later on replaced by the Chomskyan notion of a Language Acquisition Device (LAD). In a seminal monograph entitled Biological Foundations of Language (1976), he propounded the critical period hypothesis, which assumes that acquiring a language needs to happen before a certain age, the end of which he set at the period of adolescence, after which the LAD, comprising of rules of universal grammar, stops working.

Chomsky greatly influenced the intellectual thought of the $20^{\text {th }}$ century, reaching far beyond linguistics. Cognitive science, a contemporary branch of knowledge which studies the mind/brain, drew inspiration from Chomsky's internalistic conception of language. Cognitive science, which is interdisciplinary in principle, came into being as an "alliance" between linguistics, artificial intelligence, philosophy, comparative psychology, and neuroscience (see Bechtel et al., 1998); however, its further development, especially since the 1990s, has been connected with even greater interdisciplinarity, ${ }^{41}$ i.e. stronger ties and a greater scale of cooperation between a growing number of disciplines (see Wilson and Keil, 1999). Cognitive science was a platform that provided the opportunity for interdisciplinary research into language evolution of language to develop (see Box 3.6).

41 And with expansion (Klawiter, 2004), i.e. a situation in which we solve a problem and we see that it goes beyond the framework we assumed, thus requiring a new type of data. 


\subsubsection{Advances in the neurosciences}

One of the major reasons, if not a decisive one, why the breakthrough came in the 1990s were developments in the empirical sciences. Around this time, great progress was being made in primatology, neuroscience, palaeoanthropology, computer modelling and other key disciplines, which yielded a wealth of data. The advances in these areas of study made it possible to draw conclusions about language and its origins that were firmly based on empirical material, thus departing from earlier speculations.

\section{Research on primates}

As we have already mentioned, significant progress has been made in comparative studies, especially in the research on apes. After pioneering and unsuccessful attempts made by Garner (1900), primate ethology started to develop dynamically in the mid-20 ${ }^{\text {th }}$ century. Jane Goodall began her observations of the common chimpanzee (Pan troglodytes) in Gombe National Park in the mid-1960s, documenting a range of features for the first time, including the use of tools, hunting small game, and patterns of aggression against members of their own species $(1969 ; 1971 ; 1986)$. Meanwhile, researchers from Japan noticed elements of cultural transmission in Japanese macaques (Macacafuscata), which involved cleaning food (Kawamura, 1959; Kawai, 1965) and using vocalisations (Itani, 1963). When it comes to vocalisations in primates, and more specifically to the famous gibbon duets, the existence of local, quasi-cultural variations had been detected earlier by Clarence R. Carpenter (1940).

From the perspective of the evolution of language, trying to teach apes language was even more important. We have already mentioned the unsuccessful attempt made by William Furness (1916), and other failed experiments with chimpanzees conducted by the Kelloggs (1933) and the Hayes (1952). Successes came with a change of approach, which started to occur under the influence of Robert M. Yerkes (1876-1956), a psychologist who worked with chimpanzees. Working from Yerkes's intuitions, instead of teaching apes a spoken language, American researchers taught and worked with apes at the end of 1960s using a code based on a sign language. Their first success came when a female chimpanzee, Washoe (1965-2007) made progress. She was adopted by the Gardners, who taught 
her American Sign Language. Washoe mastered nearly 350 signs, which she was able to use in order to communicate by combining them into simple structures (Gardner and Gardner 1969, 1971). Similar results were achieved by David Premack, who independently used a modified sign language in his work with another female chimpanzee, Sarah (1970; Premack and Premack, 1974). Roughly at the same time as the Gardners were conducting the

Box 3.3 Primates: Classification and Description

Primates include small prosimians, which are distantly related to humans, as well as larger simians (Anthropoidea). Among the latter, there are New World Monkeys, Old World Monkeys (e.g., baboons and macaques) and apes, which are divided into Hylobatidae and Hominidae (Great Apes), the latter being most closely related to humans. Strictly speaking, humans also belong to this last taxon.

Great Apes, in contrast with Old World Monkeys, do not have a tail, are much bigger, and their diets include a larger proportion of fruit; furthermore, features which are typical of primates are further pronounced in great apes: they have even smaller litters and a higher parental investment than other primates. Their encephalisation quotient is also higher, and thus their cognitive abilities are greater too. All species of great apes use tools in captivity as well as in the wild.

Apart from humans, we distinguish three main groups (species/genera) of great apes (see photos):

The Orangutan (Pongo) lives in the equatorial forests of Asia (on the islands of Borneo and Sumatra).

Its fur is orange and brown; the orangutan leads a relatively solitary arboreal life. There is a high degree of dimorphism between the sexes: females weigh up to about $45 \mathrm{~kg}$, and males up to about $90 \mathrm{~kg}$.

Humans' and orangutans' lines diverged approximately 12-20 million years ago.

The Gorilla (Gorilla Gorilla) lives in the equatorial forests of Africa

Herbivorous; lives in harems with one dominating male; infanticide is common; there is a high degree of dimorphism between the sexes. Females weigh up to about $68 \mathrm{~kg}$, males up to about $180 \mathrm{~kg}$.

The humans' and gorillas' lines diverged approximately 8-10 million years ago.

Chimpanzees (Pan) live in the equatorial forests of Africa

Humans' and chimpanzees' lines diverged approximately 6-7 million years ago.

The Pan troglodytes' and Pan paniscus' lines diverged 1-2 million years ago. The Common Chimpanzee (Pan Troglodytes) 
Omnivorous; apart from fruit, leaves and sprouts, their diet includes nuts, insects and meat of vertebrates (including small monkeys and antelopes) which they hunt. They live in small groups of varying numbers and structure. Males, who establish coalitions, are dominant.

Use a wide range of tools; promiscuous system of mating; aggressive behaviours are widespread.

Some sexual dimorphism. Females weigh from $32 \mathrm{~kg}$ to $47 \mathrm{~kg}$, males from $40 \mathrm{~kg}$ to $60 \mathrm{~kg}$.

Bonobo (Pan Paniscus)

Its diet comprises fruit and other vegetation, with meat constituting a smaller dietary proportion in comparison to the common chimpanzee.

Females are often dominant. Although aggression and violence are quite frequent, their scale and intensity is lower than in common chimpanzees. Bonobos are very promiscuous - they practise all kinds of sexual activity. Although traditionally called "the pygmy chimpanzee", they are nearly as big as the common chimpanzee, but they are lighter. A small degree of sexual dimorphism. Females weigh about $31 \mathrm{~kg}$, males up to $39 \mathrm{~kg}$.

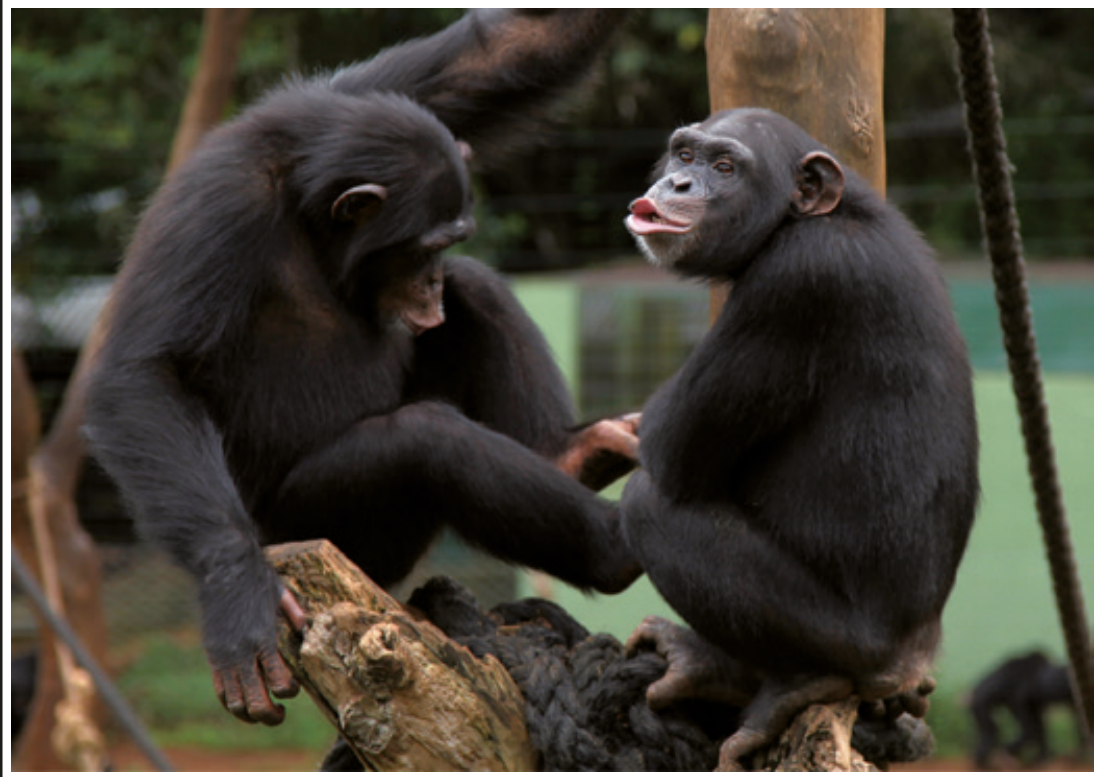

Common chimpanzee (Pan troglodytes). Photograph: Jeremy Weate, licence cc-by 2.0 


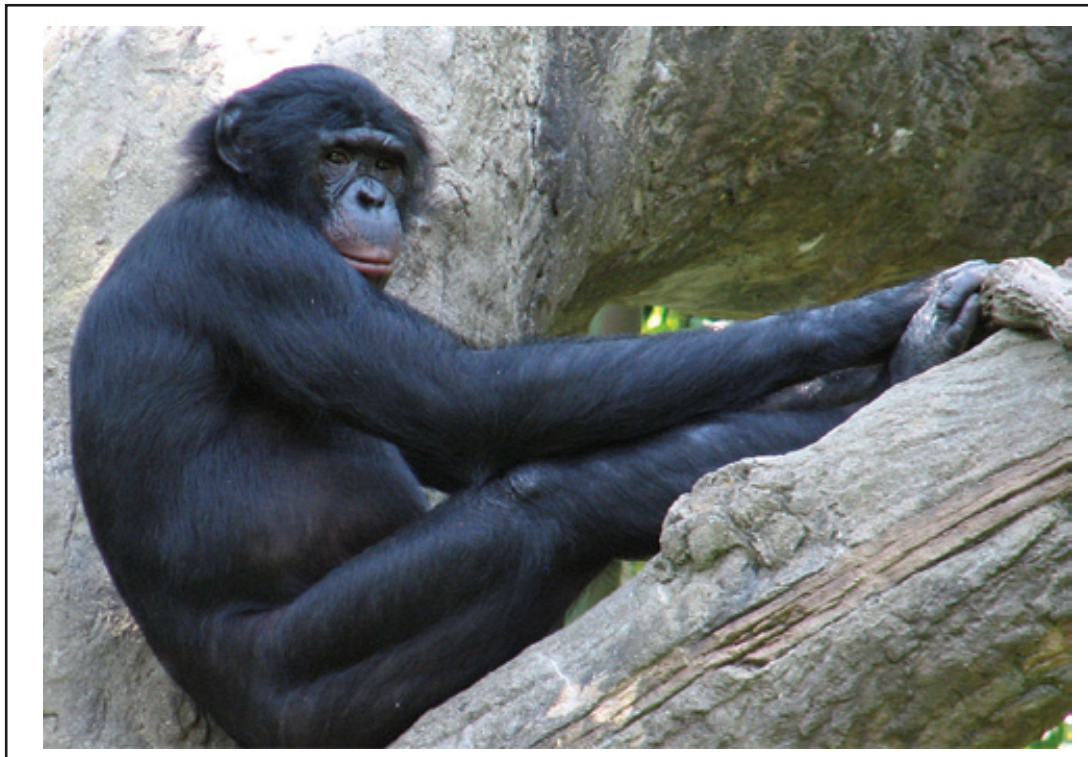

Bonobo (Pan paniscus). Photograph: Trisha Shears, licence cc-by-3

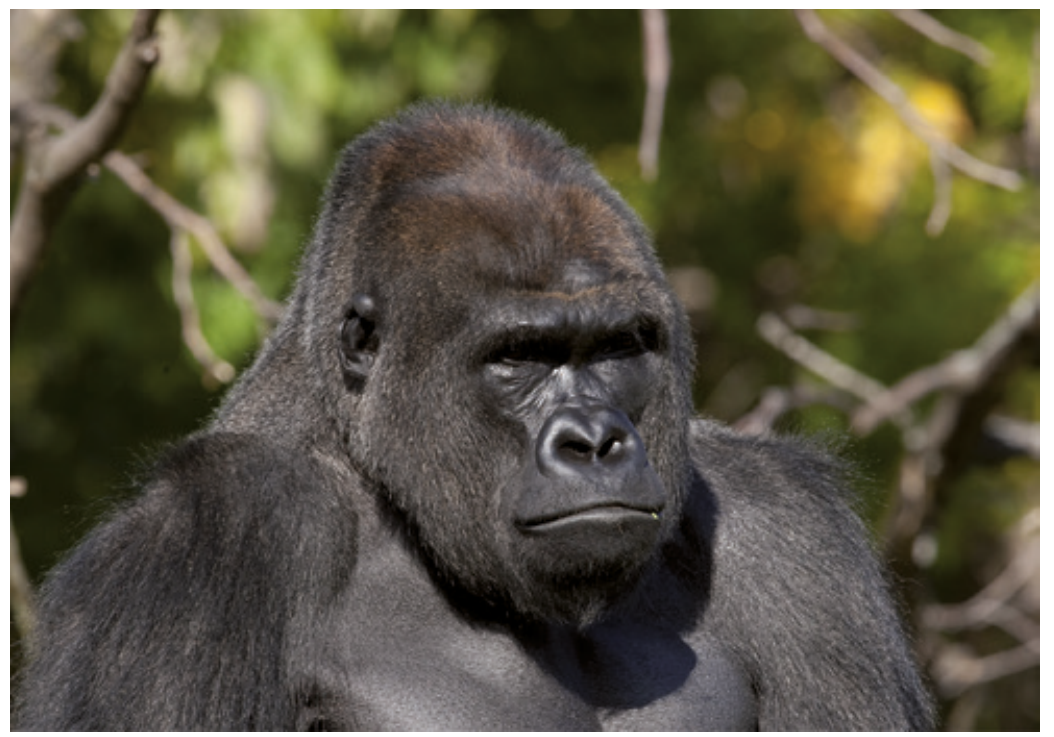

Gorilla (Gorilla). Photograph: Scott Calleja, licence cc-by-2.0 


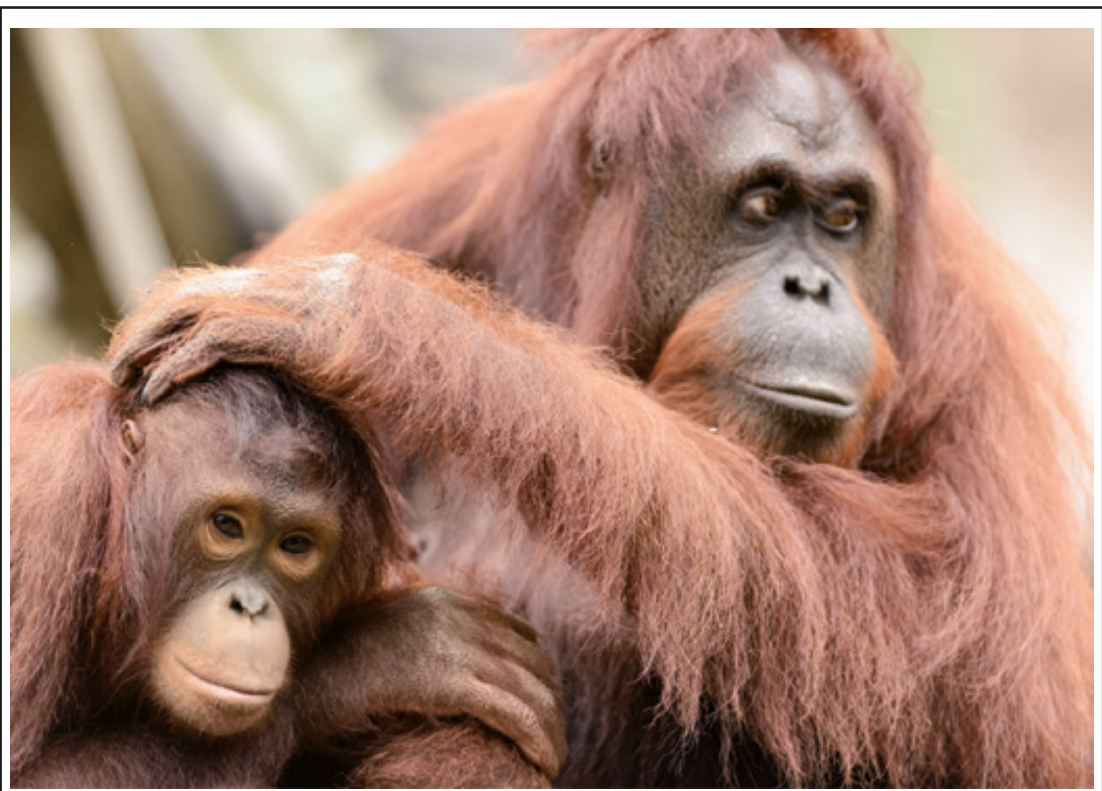

Orangutang (Pongo). Photograph: Eric Kilby, licence cc by-sa 2.0

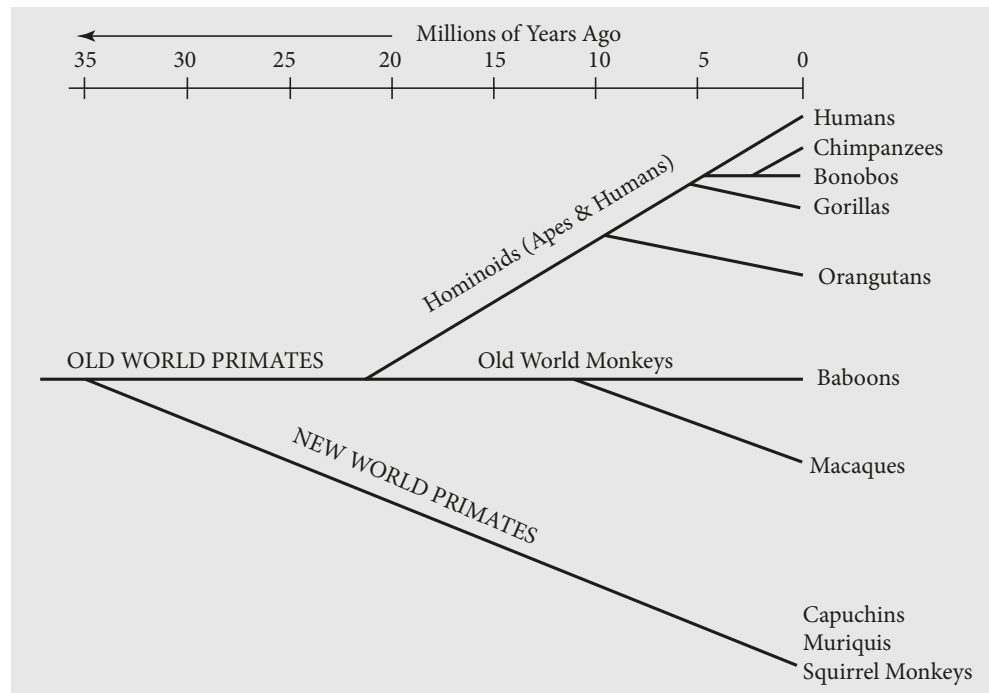

Fig. 3.2: The evolution of primates. 


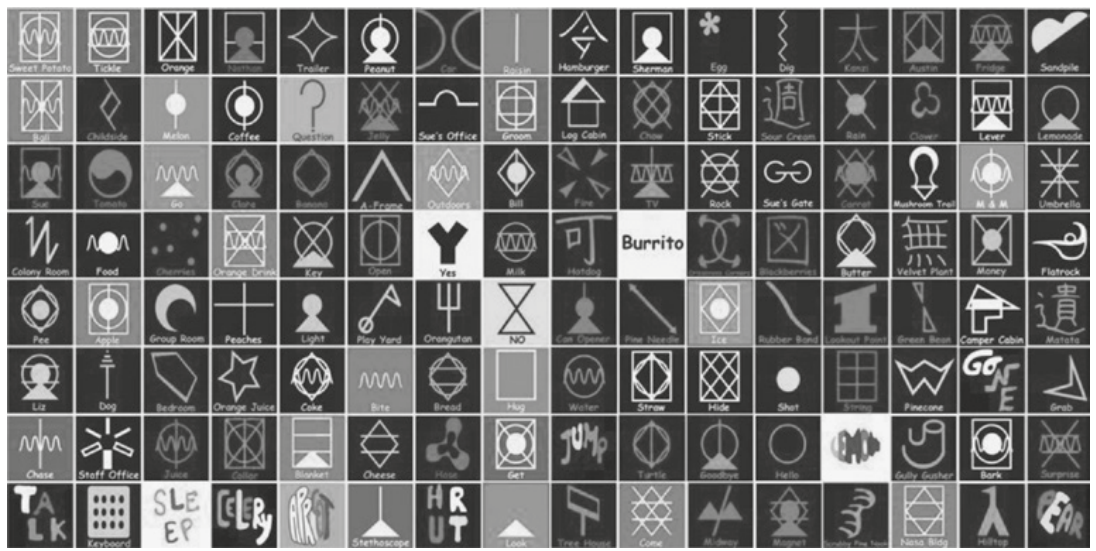

Fig. 3.3: Lexigrams used by Duane Rumbaugh and Sue Savage-Rumbaugh's research group. https://sites.google.com/site/austinstoll12communication/home/ lexigram. DOA: 15 Mar 2017.

experiment with Washoe, and Premack with Sarah, Duane Rumbaugh together with his collaborators commenced the Lana Project, in which a female chimpanzee was taught to communicate via colourful blocks, called lexigrams (Rumbaugh and Gill, 1975). Sue Savage-Rumbaugh later used the same method when she was working with the two chimpanzees, Austin and Sherman. Plenty of control tests - such as categorical tasks - showed that the chimpanzees were able to use lexigrams and understood their meaning (Savage-Rumbaugh et al., 1978; 1980). Another breakthrough happened in Savage-Rumbaugh's research group when a bonobo called Kanzi spontaneously acquired the ability to use lexigrams taught to his mother, Matata, in his presence (Savage-Rumbaugh et al., 1985a; 1985b). Kanzi is considered to be the most linguistically developed ape, and his skills have become a major point of discussion in works devoted to the evolution of language (see e.g., Bickerton, 1990; Deacon, 1997; Johansson, 2005; Fitch, 2010).

\section{Genetics}

One of Darwin's greatest concerns, and a source of problems of his theory, was the lack of a theory of heredity. Gregor Mendel's works, published in 1866 , delivered the first solutions, although they were not discovered 
by the scientific community until 1900 . The following years saw the rapid development of genetics, focusing on mutation at the expense of the role of Darwinian selection. Hugo de Vries (1848-1935), for example, believed mutation to be the main mechanism of evolutionary change, and thus saw it as more important than natural selection. This view started to change under the influence of works published by such geneticists as Thomas Hunt Morgan, Ronald Fisher, J. B. S. Haldane, and Sewall Wright, who noted the gradual influence of the accumulation of numerous mutations which had small effects on the phenotype. In the 1930s genetics became consonant with the theory of natural selection, giving rise to the neo-Darwinian synthesis. Technological progress later in the $20^{\text {th }}$ century allowed the biochemical study of genes at the level of their molecular substrate, gradually leading to the greatest breakthrough: the discovery of the structure of DNA (Watson and Crick, 1953).

The considerable progress which has been made in recent decades in molecular biology translated directly into research on the evolution of language. In the 1960s a team of neuroscientists and language experts discovered a peculiar language disorder - childhood apraxia of speech - in members of one family (the "KE" family). The later discovery of the FOXP2 gene, whose mutation leads to speech disorders, indicated a genetic basis for this specific language deficit (Gopnik, 1990). Identifying a genetic component responsible for the disorder was possible only in the early 2000s (Lai et al., 2001). By the end of the decade, there were numerous experiments conducted to investigate the role of the FOXP2 gene in other organisms, such as mice (Enard et al., 2009). In mice, this gene seems to be important in finding paths and, to a lesser degree, for vocalisations; in bats it appears to be connected with echolocation.

FOXP2 (Forkhead Box, from the P family, the second gene discovered) is a "higher order" regulatory gene - a gene which regulates the expression of other genes. By "switching" them "on" and "off" during certain stages of human development, FOXP2 influences many phenotypic attributes, including the morphology of the lungs, the heart, the bowels and the brain. For language to develop properly, both copies of the gene the child inherits must be functional (Fisher et al., 1998). The mutation of either of them will lead to a speech disorder (developmental verbal dyspraxia, DVD), which involves major problems with articulation, such as the inability to 
repeat words or even issues with coordinating complex facial movements not connected with language. On the other hand, the disorders caused by the FOXP2 mutation also have a receptive nature connected with understanding language, and complex sentences in particular. This indicates that a deficit connected with FOXP2 is a language deficit, and not exclusively a motor one.

Geneticists are also interested in studying genes related to the development of the brain. As it turns out, when hominins were evolving, some genes responsible for the anatomy of the skull became pseudogenes - they were deactivated and did not exert any influence on phenotype. Some examples include MYH16, which may have been deactivated approximately 5.32.4 million years ago, and CMAH which may have been deactivated 3.22.8 million years ago. The loss of these functions is assumed to result in a decrease in the musculature of the skull, which would have created conditions to increase the volume of the neurocranium.

\section{Palaeontology and archaeology}

The first hominin ${ }^{42}$ fossils were found in the $19^{\text {th }}$ century: those of the Neanderthal (1856) and Homo erectus (Java Man (1891)). Many spectacular discoveries have been made since the early 1970s that have radically changed the picture of the early hominin phylogeny. The most famous discoveries include AL 288-1 (Lucy) in 1974, KNM-WT 15000 (Turkana Boy) in 1984, and TM 266-01-060 (Toumaii) in 2001. From the multiple features of skeletons, hominins are believed to have been at least partially adapted to bipedal locomotion at an early stage, which allows us to speculate about the ecological conditions in which our ancestors lived. Although the data is scarce and reconstructions are error-prone, some attempts have been made to infer our ancestors' articulatory capabilities, based on the hyoid bone which we can find in the throat (Lieberman and Crelin, 1971). Other work has speculated on their cognitive processes, based on the layout of fissures in endocasts - internal casts of ancient skulls (Wilkins and Wakefield, 1995). Attempts have also been made to reconstruct our ancestors' diets, working

42 We use the term hominins here to refer to humans and their bipedal ancestors from the Homo line, Australopithecus and others, but not to Great Apes. 
from the chemical substances found in fossils (Sponheimer et al., 2005). Some DNA analysis of fossils has been conducted in the past decade (e.g., Green et al., 2010), though material which can be used for analysis is rare and comes from deposits which are in close proximity to one another.

Other valuable data comes from fragments of material culture which have survived to date, such as ornaments, weapons, burial artefacts and the use of dyes. Stone tools provide surprisingly useful information about early hominins - for example, they have enabled us to determine whether the tool was made of materials found locally, or whether the materials had to be transported to this end (Roebroeks et al., 1988); microtraces of wear and the way the tool was processed have indicated its purpose (e.g., Rots, 2005), as well as the handedness of its users (e.g., Uomini, 2011); comparing multiple tools makes it possible to discuss whether the tools were standardised, or whether users were instructed on how to make them (but cf. Gowlett, 2009a); finally, ornaments lead to speculation about the concept of art (e.g., d'Errico et al., 2005). All conclusions drawn from the artefacts about the cognitive abilities of their creators should be treated with care (Gowlett, 2009b). However, archaeological data supported by other evidence can provide a lot of information, and convergent evidence can substantiate hypotheses (see 3.2.1). What is more, archaeology itself also develops by enriching its methodology with new experimental methods, such as crafting tools with the use of prehistoric techniques (e.g., Morgan et al., 2015).

\section{Neuroscience}

Under the influence of Chomsky and of the cognitive revolution he sparked, the 1970s witnessed a dynamic development of disciplines which investigated diverse aspects of language empirically. These experiments were led by psycholinguists, and they were oriented at analysing the psychological processes connected with language acquisition and language use. Neurolinguistic research, focused on investigating the anatomical and physiological correlates of linguistic behaviours (Gleason and Ratner, [1998] 2005: 17-18), was also particularly important in the evolutionary context. The development of neurolinguistics owed much to the emergence of technology which allowed the brain to be investigated not only postmortem (as in the classic work of Broca and Wernicke), but also in-vivo. 
Box 3.4 Selected Hominins

Sahelanthropus tchadensis

Announced: 2002 (M. Brunet).

Age: 6 to 7 million years.

Brain size: $320-380 \mathrm{~cm}^{3}$.

Specimens: Toumaï (TM 266-01-060-1)

\section{Orrorin tugenensis}

Announced: 2001 (B. Senut, M. Pickford).

Age: about 6 million years.

Brain size: no data available.

Specimens: Millennium Man (BAR 1000’00)

\section{Ardipithecus ramidus}

Announced: 1994 (T. White).

Age: about 4.4-4.2 million years (subspecies or species: kadabba - 5.55.8 million years).

Brain size: no data available.

Specimens: ARA-VP-1/129 - A. Asfaw, 1992, Aramis, Afar, Ethiopia. BIPEDAL SAVANNAH APES

\section{Australopithecus anamensis}

Announced: 1995 (Meave Leakey).

Age: 4.2-3.9 million years.

Brain size: no data available.

Specimens: Hominid from Kanapoi (KNM-KP 271) - B. Patterson, 1965; Kanapoi, Kenya; KNM-KP 29281 - P. Nzube, 1994, Kanapoi, Kenya; KNM-KP 29285 - K. Kimeu, 1994, Kanapoi, Kenya.

Australopithecus afarensis - an early hominin which we know the most about. The skull of Afarensis, despite having teeth which resemble those of humans, is more similar to a chimpanzee's because of its appearance and braincase volume. Afarensis was bipedal, although some features indicate that it was adapted to arboreal life. It was characterised by a major sexual dimorphism, which may suggest that its social structure was organised in harems.

Announced: 1978 (D. Johanson, T. White).

Age: 3.9-3.0 million years.

Brain size: $350-500 \mathrm{~cm}^{3}$, some sources: $375-550 \mathrm{~cm}^{3}$.

Specimens: Lucy (AL 288-1) - D. Johanson, T. Gray, XI 1974, Hadar, Ethiopia; Laetoli footprints - P. Abell and Mary Leakey's team, 1978, Laetoli, Tanzania.

\section{Kenyanthropus platyops}

Announced: 2001 (Meave Leakey).

Age: about 3.5 million years. 
Brain size: about $450 \mathrm{~cm}^{3}$.

Example: KNM-WT 40000 - J. Erus; 1999; Lomekwi, Nachukui formation, Kenya.

\section{Australopithecus africanus}

Announced: 1925 (R. Dart).

Age: about 3.0-2.5 million years, (in sources: 3.3-2.5 million years/3-2 million years).

Brain size: about $400-500 \mathrm{~cm}^{3}$, other sources $435-530 \mathrm{~cm}^{3}$.

Specimen: KNM-WT 40000 The Taung Child - M. De Bruyn, X 1924, Taung, Transvaal region, South Africa.

\section{Australopithecus garbi}

Announced: 1999 (T. White, B. Asfaw et al.).

Age: about 2.5 million years.

Brain size: about $400-500 \mathrm{~cm}^{3}$.

Specimen: BOU-VP-12/130

Robust australopithecines - also classified as the Paranthropus genus. They constituted a side-branch and were not ancestors of the Homo line, but they were the contemporaries of its early representatives. They were characterised primarily by being adapted to eat hard plants, as evidenced by their firm jaws and molars, as well as their sagittal crest, which was the place the muscles of the mandible were connected to. The average brain size was about $420 \mathrm{~cm}^{3}$ in aethiopicus and about $530 \mathrm{~cm}^{3}$ in later robustus and boisei.

A. aethiopicus - 2.6-2.3 million years; announced in the 1980s (R. Leakey, A. Walter).

Example: The Black Skull (KNM-WT 17000) - A. Walter, VIII 1985, West Turkana, Kenya.

A. robustus - about 2.0-1.2 million years; announced in 1938 (R. Broom). Specimen: TM-1517 - G. Terblanche (a student who led R. Broom to the location of the discovery), 1938, Kromdraai, South Africa.

A. boisei - about 2.1-1.1 million years; announced in 1959 by Louis Leakey, initially as Zinjanthropus boisei (Ch. Boise - sponsor of the Leakey family). Specimens: Zinj (OH-5) - Mary Leakey, VII 1959, Olduvai Valley, Tanzania. The specimen is also known as the Nutcracker Man because of its enormous molars, and also as Dear Boy (reportedly this is what Mary Leakey shouted when she discovered the fossil).

\section{EARLY INTELLIGENT OMNIVORES}

Homo habilis - the first African Homo, has been the subject of numerous controversies since first announced. It used modified stone tools, hence the name - "handy man". This species is sometimes considered to be a member of the australopithecines (Australopithecus habilis); there are also disputes about assigning specific individuals to the genus, e.g. D-2700 (Homo georgicus) found in Georgia; see especially Homo rudolfensis below. 
Announced: 1964 (L. Leakey, J. Napier, P. Tobias).

Age: about $2.4-1.5$ million years.

Brain size: about $500-800 \mathrm{~cm}^{3}$.

Specimens: OH-7 - Jonathan Leakey (Mary and Louis's son), XI 1960; Olduvai Valley, Tanzania; Twiggy (OH-24) - P. Nzube, X 1968, Olduvai Valley, Tanzania (named after the British model); KNM-ER 1813 - K. Kimeu, 1973, Koobi Fora region, eastern shore of Lake Turkana, Kenya.

\section{LATER INTELLIGENT OMNIVORES}

\section{Homo ergaster}

Ergaster was strikingly different from other early hominins and resembled the contemporary human more than the "ape-like" habilis. It had a much larger brain, and was much bigger (about 160-180 cm and weighing about $56-66 \mathrm{~kg}$ ). Its dentition and the proportions of its bones resembled those of later humans. The appearance of more advanced tools in the archaeological data from about 1.6 million years ago documents a development of cognitive abilities. It is a near-equivalent of "early H. erectus". Name proposed in 1975. Age: about 1.9 million years.

Brain size: about $800-1100 \mathrm{~cm}^{3}$.

Specimens: Nariokotome Boy or Turkana Boy (KNM-WT 15000).

Homo erectus - if we assume that $H$. ergaster was a separate species, $H$. erectus ("upright man") refers to later populations which, starting about 1.9 million years ago, spread over Southern Asia. Erectus was characterised by a large brain that became even larger over time (i.e., it was bigger in the later specimens than in the early ones). Other anatomical features include big browridges and elongated skull. Its skeleton was not very different from that of contemporary humans. Erectus most certainly used fire, perhaps as early as 800,000 years ago.

Announced: 1894 (E. Dubois) - as Pithecanthropus erectus

Age: about 1.9-0.3 million years, possibly up to 30 thousand.

Brain size: about $800-1250 \mathrm{~cm}^{3}$.

Specimens: Java Man (Trinil 2) - E. Dubois, 1891, Trinil, Java; Peking Man - W. C. Pei, 1927-37; Zhoukoudian, China.

Homo heidelbergensis - a name which is now used to refer to hominins who lived from about 800,000-300,000 years ago, who combined features of $H$. sapiens and $H$. erectus. In simple terms, it is a late European or AfroEuropean and African equivalent of erectus.

Announced: 1908 (O. Schoetensack).

Age: about $800-100$ thousand years.

Brain size: about $1100-1400 \mathrm{~cm}^{3}$.

Specimens: Heidelberg Man - 21 X 1907, Mauer near Heidelberg, Germany; ATD6 - J. Bermúdez de Castro's team, 1995, Gran Dolina, Atapuerca, Spain.

HOMO SAPIENS AND ITS CONTEMPORARIES

Homo neanderthalensis - although earlier discoveries were made (1829, Belgium, 1848, Forbes quarry in Gibraltar), the species owes its name 
to the fossils discovered in 1856 in the Neander valley near Düsseldorf. Neanderthals, otherwise very similar to contemporary humans, had a sturdy, muscular stature (the result of adaptation to a cold climate), a big nose, as well as a brain larger than in contemporary humans. Among the factors that made them different from $H$. sapiens was the lack of the chin bone, and a gap after the last molar. Genetic evidence indicates that Neanderthals interbred with Homo sapiens - between $2 \%$ and $4 \%$ of genes in the Eurasian populations are supposed to come from the Neanderthals.

Announced: 1863/64 (W. King).

Age: 200-30 thousand years.

Brain size: $1300-1750 \mathrm{~cm}^{3}$.

Specimens: Neanderthal 1 - J. Fuhlrott, 1856 r., Feldhofercabe, Neander Valley, Germany; the Old Man - A. and J. Bouyssonie, L. Bardon, August 1908, La Chapelle-aux-Saints, France-working from this skeleton, the French anatomist M. Boule made an erroneous reconstruction of Neanderthals' appearance; it is because of this reconstruction that Neanderthals are wrongly viewed as hideous hunchbacked ape-men.

Denisovan - recently discovered representative of the Homo genus (discovered in 2008, described in 2010; Denisova Cave in the Altai Mountains). The only discovery is a finger bone and two teeth. Mitochondrial DNA of the tooth indicates that it was closely related to the Neanderthals and probably interbred with Homo sapiens - the presence of Denisovan genes has been corroborated in such groups as the Melanesians and the Aborigines from Australia.

The situation of neurologists and neuropathologists of the $19^{\text {th }}$ century and the first half of the $20^{\text {th }}$ century is said to have resembled the situation of an oceanographer standing at the shore and trying to infer what is happening in the depths of the sea from the movement of waves. This state of affairs first started to change in the 1940s, when the Wada test started to be applied on a larger scale. The test involved administering barbiturates into either of the brain hemispheres and conducting psychological tests. Thanks to these, it was possible to draw conclusions about lateralisation of the functions in question, mainly connected with memory and language (Wada, 1949). The 1960s saw the beginning of neuroimaging - obtaining images of a living brain, which initially provided only static data. At the time scientists used computed tomography (CT) and magnetic resonance imaging (MRI). The 1970s brought electroencephalography (EEG), which 
enabled the dynamic, real-time recording of the functioning areas of the brain. These technologies were followed by tools that measured metabolic processes in the brain, such as the functional magnetic resonance imaging (fMRI) or magnetoencephalography (MEG) (Ahlsén, 2006: 161-166).

The key achievement of the neurosciences in the 1990s was the discovery of the so-called mirror neurons. It is a group of neurons which are active both when a person performs an action, and when the person observes someone else perform that action. For instance, when a person is watching someone grasping an object, the same neurons are activated as if the observer were performing the action herself. Mirror neurons were first discovered in the area F5 in macaques, which corresponds to Broca's area of the human brain (Rizzolatti et al., 1996). Later investigations corroborated the fact that the mirror system exists in humans as well (Iacoboni et al., 1999). The mirror neuron hypothesis posits the neural mechanism responsible for the balance and reversibility of roles between sending and receiving a message (parity requirement), which is an indispensable prerequisite for communication. When a monkey sees another monkey (or a human) reaching for a nut, it understands the sense of the action thanks to a copy of a motoric representation of this activity in its own brain. Thus, a mental connection emerges between the "sender" (the party performing the action) and the "receiver" (the party observing the action) that is based on a simultaneous representation of the same information. The mirror system also appears in important scenarios of language evolution, especially those proposed by Michael Arbib (e.g., 2005).

\subsubsection{Evolutionism}

The so-called modern evolutionary synthesis (neo-Darwinian synthesis), whose foundations were the heredity rules postulated by Gregor Mendel (1822-1884), led to important changes in ideas about biological evolution. As we have already stated, Darwin did not define how a crucial component of his theory - the mechanism of inheritance - works. A full explanation of this mechanism required the development of genetics, and especially population genetics, which investigated the distribution and change of alleles in groups (Fisher, 1918; 1930), using mathematical tools (Fisher, 1927). This development made it possible to explain both micro- and macroevolutionary changes in populations with the use of mathematical models (Dobzhansky, 
1937), and consequently the mechanism of natural selection. The breakthrough was made by the students of the founders of population genetics, such as George C. Williams (1926-2010), William D. Hamilton (1936-2000) or John Maynard Smith (1920-2004), whose research activity coincided with the development of research into DNA (primarily Watson and Crick, 1953).

Explaining the rules of inheritance using mathematical models in the description of evolutionary changes made it possible to depart from the view propounded in traditional ethology (see Box 2.7), which held that the species is the level at which natural selection operates. Ethologists used phrases such as "survival of the species" or "actions for the good of the species", which became fixed in the popular imagination to explain, for instance, altruism and cooperation (see Eibl-Eibesfeldt, [1970] 1996). After the new synthesis, such explanations no longer made sense, and evolutionists categorically stated that selection depends solely on whether and to what degree an individual can pass its genetic material on to the next generation (Williams, 1966). Similarly, these researchers tried to construct solutions to problems which were difficult for Darwinian theories, such as altruism and cooperation, noted earlier (see Hamilton, 1964a; 1964b on kin selection; Trivers, 1971 on reciprocal altruism and 1972 on parental investment). The application of the modern evolutionary theory to research into signalling theory with the use of game theory was another interesting theme for the issues we are exploring here.

Game theory, in its classic version, is a mathematical model which measures whether a strategy is optimal, esp. in situations of conflict (see von Neumann and Morgenstern, 1944). Maynard Smith applied game theory to research into the evolution of communication, starting with the question about the conditions under which - in a Darwinian world, which is governed by natural selection operating on individual organisms - these organisms will communicate honestly, and under which conditions they will do so dishonestly (Maynard Smith, 1982). Another central concept in Maynard Smith's approach is an Evolutionarily Stable Strategy (ESS) which assumes that a strategy used in a game is evolutionarily stable if once adopted by a population, it cannot be replaced by another strategy (Maynard Smith and Price, 1973). The most famous figure who has popularised the gene's eye view is Richard Dawkins (1976), who extended the use of evolution by natural selection to cultural phenomena (see Sections 2.1.2 and 2.2). 


\subsection{Contemporary evolution of language}

Contemporary research on the origins of language - the evolution of language - departs from earlier intellectual traditions and their speculative character, which was the main reason for the disrepute of such research (see 1.2.2) and for the kind of criticisms made by Doerfer and Fisiak, quoted earlier. However, the topic of the evolution of language is still encumbered with methodological difficulties, speculations, and just-so stories. For instance, the influential biologist Richard Lewontin used the last of these terms in his 1998 paper "The Evolution of Cognition: Questions We Will Never Answer”, and reiterated it in 2014 (Hauser et al., 2014). This is precisely why distancing from the old, speculative traditions is such an important element of the new identity of the evolution of language. By leaving behind the old tradition, researchers may turn to new, more empirical methods and to new problems, which can be solved with the means we have at our disposal.

\subsubsection{The evolution of language: A new research programme}

The contemporary evolution of language is less concerned with attempts to develop scenarios of the origins of language than it is with "constraints" (see Deacon, 2004; Johansson, 2005; Wacewicz and Żywiczyński, 2012). Clearly, scenarios are also important - they generate interest and help to create new hypotheses - but they are no longer the focal point of language evolution research. Currently, research does not emphasise what may have happened, but what cannot have happened and which scenarios should be dismissed as implausible. These include:

Box 3.5 Milestones in Contemporary Language Evolution Research 1990 - S. Pinker and P. Bloom's article in Behavioral and Brain Sciences $1990 \ldots$ - holistic language emergence scenarios (D. Bickerton, M. Donald, T. Deacon, R. Dunbar) $1996 \ldots$ - Evolang conference series 2002 - M. Hauser, N. Chomsky and T. Fitch's article in Science $2005 \ldots$ - secondary literature and coursebooks (e.g., Johansson, 2005; Hurford, 2007; Fitch, 2010) 
- syntax could not have evolved before discrete units (logical constraint);

- the language faculty cannot have emerged recently (e.g., 50,000 years ago) as a result of macromutation (this constraint results from evolutionary theory, population genetics, and data on Homo sapiens migrations, see e.g. Dediu and Levinson, 2014);

- language cannot have evolved solely from the modification of a system of communication of our ape ancestors; instead, it was based on their cognitive system (this constraint results from empirical data from primatology, which states that there is a radical difference between human and ape communication, and that there is a continuity between their cognitive systems);

- cheap signals - those whose production does not incur high costs - are not evolutionarily stable under standard conditions (elementary constraint from signalling theory, see Krebs and Dawkins, 1984).

Furthermore, the big questions about the beginnings of language remain in the background, and researchers of the evolution of language, in line with Kuhn's vision of science, are concerned with solving "puzzles" or answering "small questions" such as "are gestures which apes make intentional?" (Cartmill and Byrne, 2010) or "does sound symbolism facilitate acquiring new words by children?" (Imai and Kita, 2014).

The interdisciplinary integration of such types of research sometimes leads to a common conclusion and, based on converging evidence from many disciplines, it is possible to suggest a solution to the higher order problems. To illustrate this, Neanderthals were considered a species which lacked language, an assumption made on the basis of a reconstruction of their vocal tract made in the 1970s by Lieberman, which was deemed controversial even by his contemporaries (see Corballis, 2002: 143-144). The most recent data provided by archaeologists, palaeontologists and geneticists shows that $H$. neanderthalensis most likely did have language (see e.g., Johansson, 2012, Dediu and Levinson, 2013; Johansson, 2014). Anatomical reconstructions of Neanderthals in terms of production and perception of speech, based on the most recent discoveries of features such as the hyoid and auditory ossicles (see Box 3.5), suggest a lack of major differences between $H$. neanderthalensis and $H$. sapiens. Material cultures in Neanderthals too turns out to have been more similar to those of $H$. sapiens 
than had earlier been assumed. The material culture of Neanderthals was characterised by the presence of artefacts which scientists interpret to be art. Moreover, it is also possible that Neanderthals had ceremonial burials. Finally, a "human" version of the FOXP2 gene was found in the Neanderthal genome (Krause et al. 2007).

We may never know for sure whether Neanderthals had language. However, in the light of the available data we can state that it is more likely that they did than that they did not.

Researchers used to investigate "when" and "why" language emerged and to answer these questions they used holistic scenarios of language development. Nowadays, we are conscious of the fact that it is impossible to offer satisfactory, comprehensive and scientifically rigorous answers to questions raised in this way. Thus, research efforts are now focused on drawing up a new inventory of "big questions", which we develop in the sections and chapters that follow:

- What is language? (3.3);

- Is it possible to generally determine the stages of the development of language capacity? (3.4);

- What are the preconditions for the successive stages of the language faculty? (Chapter 4).

\subsubsection{New research trends in the evolution of language}

We can now say with full confidence that the evolution of language, having existed as a study area for 25 years, has managed to solidify and develop its profile. Thus, the evolution of language as a research discipline can be characterised by these features (expanded after Wacewicz, 2013):

- consolidation - apart from the scenarios which dominated the early efforts in language evolution (e.g., Dunbar, 1996; Gärdenfors, 2002), overview works also became available, both as introductory textbooks (e.g., Hurford, 2007; Fitch, 2010), and as secondary and tertiary literature, i.e. in handbooks or compendiums (Johansson, 2005; Tallerman and Gibson, 2011; Hurford, 2014);

- an empirical orientation - manifested in various ways, though particularly by a decreasing number of theoretical and speculative works, 
in favour of an increasing number of empirical studies, the results of which are reported at such conferences as Evolang;

- the importance of social factors - apart from the problem of articulation (i.e., issues pertaining to the vocal apparatus) and broadly construed cognitive issues (using symbols, combinatoriality, theory of mind, mimesis, etc.), more and more attention is being paid to the exploration of the social aspect of language, including its evolutionary stability (see a discussion in Wacewicz, 2015);

- expansion - extending the field to new thematic domains and thus to new research disciplines. These include the study of the brain (e.g., mirror neurons), or new cognitive capacities (e.g., recursion in visual perception);

- extension of the scope of comparative research (in biological terms) comparative research on communication and cognitive capacities of different animal species (apart from primates, research has targeted sea mammals, deer, dogs, rodents and birds). For instance, vocal imitation, which is poorly developed in nonhuman apes, is studied in song birds or dolphins, on account of its key role in language acquisition. The results of this research indicate that there may be a deep homology, i.e. similarity on the genetic level in unrelated groups of species - e.g., the functions of the FOXP2 gene in mice (Enard et al., 2009) or birds (Thompson and Scharff, 2013) are studied in this way;

- new empirical methods - apart from mathematical and computer modelling, which have constituted an important branch of evolution of language research from the beginning, a number of new empirical methods have started to be used. A good example is the Iterated Learning (IL) paradigm: a research method in which participants are instructed to acquire an artificial language and pass it on to new participants (similar to the game of Chinese whispers) (Kirby et al., 2008);

- "Big Data" - compiling large databases concerning the languages of the world and their structural properties, especially The World Atlas of Linguistic Structures (WALS Online - Dryer and Haspelmath, 2011), has made it possible to find the most interesting statistical dependencies in the structures of languages or between language structures and other data - e.g., ecological or demographic criteria (Atkinson, 2011; Dunn et al., 2011). For example, a study discovered a correlation between the average air temperature and the existence of tonal languages (Everett 
et al., 2015). Attempts to create linguistic laws or to describe the general properties of languages through the use of quantitative methods based on exploring large databases, are sometimes described as "nomothetic research" (Roberts and Winters, 2012). Applying this research method is controversial and seems to be insufficient for testing hypotheses; however, by discovering correlations between types of data, it can be very helpful in formulating new hypotheses;

- extending methodology to new areas of linguistics - such as pragmatics (Sperber and Origgi, 2010; Scott-Phillips, 2014), linguistic politeness (Wacewicz et al., 2015) or conversation analysis (Mills, 2011; Enfield and Sidnell, 2014; see 3.3.2.1). On the other hand, strictly linguistic methods are being used to analyse primate communication (e.g. Wierzbicka, 2014: 156-182; Schlenker et al., 2014).

Box 3.6 Interdisciplinarity and the Evolution of Language (Wacewicz, 2008; Christiansen and Kirby, 2003c)

In order to find out how language began one needs to:

- provide a definition of language, its structures and functions (linguistics and sociolinguistics); determine its localisation and language processing in the brain (neurolinguistics), which is impossible without an understanding of the general principles of how the brain works (neurobiology);

- know the ontogeny of language acquisition and the general development of the mind in children (psycholinguistics, developmental psychology) and to assess how societal and innate factors interact during this development (evolutionary psychology and anthropology);

- know the mechanism whereby children's capacity to acquire language is inherited (genetics of speech and language disorders);

- trace the evolution of hominins so as to find out as much as possible about their anatomy and brains from fossils and craniums (palaeoanthropology), and as much as possible about their lifestyle from artefacts (archaeology);

- infer the cognitive and linguistic competences of our extinct ancestors and because it is impossible to conduct experiments on them - to adapt data from animal research (ethology), especially humans' closest relatives, the apes and other primates (primatology);

- use computer models which show how the structure of language changes, or which show simulations of communicative processes in societies (computer modelling).

The overall scientific framework is delineated by the theory of evolution and genetics. 


\subsection{Evolution - of what? The taxonomy of "language"}

In his paper "Discussing the Evolution of the Assorted Beasts Called Language", Rudolf Botha (2000) lists thirteen different conceptualisations of language in just one collective work (a volume published after the first Evolang conference): from a process, through action, capacity, to social contract. Ray Jackendoff (2010) adds that "your theory of language evolution depends on your theory of language". The views on the evolutionary development of language will, to a great extent, depend on our construal of what language is in the first place.

As we know, any (healthy) infant raised in any human society will develop language, and conversely, no nonhuman organism will accomplish this feat; this confirms that there is a major difference at the biological level, indicating that language is an adaptation. At an early stage this exact difference - the human-specific foundations of language - was the focal point of research in the evolution of language, with researchers concentrating on the innate character of language and its phylogenetic development by means of biological evolution. Even today, the evolution of language, in a more narrow and primary sense, relates to language understood in biological terms - the fourth meaning of the term listed above (see Box 3.7). In this respect, Michael Arbib (2005) speaks of a language-ready brain. Biological readiness is the most important condition for acquiring language, though it is not identical with having it (language is acquired in ontogeny), and as such it does not guarantee the possibility of acquiring it. In other words, it is possible that at some point, a hominin population had language-ready brains but did not yet have a culturally developed linguistic code which would inhabit these brains.

Box 3.7 Four Senses of "Language" According to Sydney Lamb (2004)

Language $_{1}$ - corresponds to la parole - the actual use of language, i.e. specific utterances or speech acts in specific language users.

Language $_{2}$ - corresponds to la langue - an abstract system of rules and conventions, independent of specific users and prior to la parole.

Language $_{3}$ - I-Language - individual, internal and isolated cognitive processes in the mind of a given person; her linguistic knowledge.

Language $_{4}$ - an innate language capacity, genetically transmitted, which is a unique property of the $H$. sapiens species. 
Focus on the biological and innate dimension takes us only a small step closer to answering the question about the nature of language. Saying that the language faculty is inherently biological and hereditary is not the same as stating what "language" actually means. The most important attempt to organise the debate terminologically was taken up by Hauser, Chomsky and Fitch in 2002. In their influential paper in Science, they suggested two conceptualisations of the language faculty: in the broad and in the narrow sense.

Box 3.8 Models of Language According to Hauser, Chomsky and Fitch

- Hauser, Chomsky and Fitch's model of the language faculty from 2002. LB (Faculty of Language in the Broad Sense) $=$ CI (conceptual-intentional system) + SM (sensory-motor system) + FLN (Faculty of Language in the Narrow Sense). FLN = "computational core"

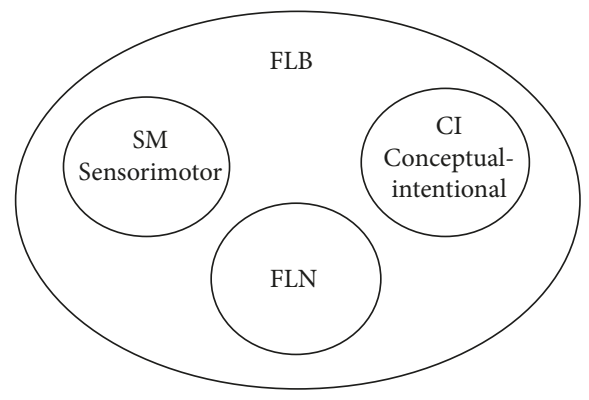

- Fitch, Chomsky and Hauser's model of language from 2005.

FLB = all elements which together constitute language capacity. FLN = these elements of FLB which are uniquely linguistic and, by extension, uniquely human

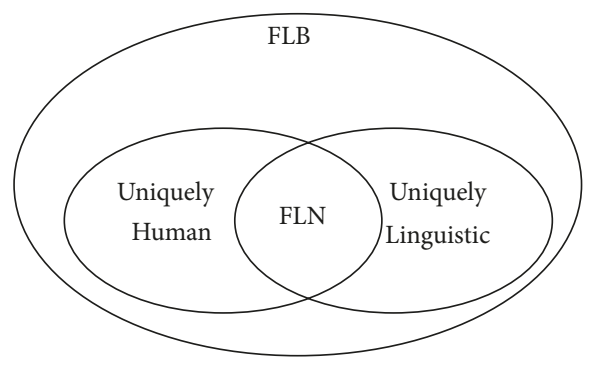


Hauser, Chomsky and Fitch (2002) define FLN (the narrow sense) exclusively as the "computational core", which involves mainly syntactic mechanisms of combining simple elements into complex hierarchically organised structures, which are also responsible for another property of language, namely discrete infinity. FLB (the broad sense) is the entirety of a broadly construed language faculty; apart from the key component, FLN, it comprises aspects of the conceptual-intentional system which serve language (conceptual-lexical resources) and of the sensory-motor system (for instance, understanding and producing the sounds of speech). In the ensuing text (Fitch et al., 2005), the same authors abandoned these definitions and expressly denied having them in mind, and formulated new definitions instead. FLN (the narrow sense) now comprises those elements of language faculty which are jointly exclusively human and exclusively linguistic. On the other hand, the newly defined FLB (the broad sense) includes all aspects of language faculty which are also shared with other animals and/or cognitive systems, of course also inclusive of those which are human-specific (FLN). ${ }^{43}$

Although the discrepancy between the 2002 and 2005 definitions was not spotted by commentators, it requires a more detailed discussion. The course that the authors took is surprising. As they themselves explain (e.g., Fitch, 2010: 22), because the term "language" itself is general and used in many senses, introducing the distinction between FLN and FLB was supposed to remove terminological barriers which could hinder interdisciplinary discussion. FLN has risen to the rank of a central concept, becoming the focus of many debates in the evolution of language. Meanwhile, due to the negligence of the authors, the term now exists in the literature in the two aforementioned, divergent meanings:

43 Fitch et al. (2005) declare that the statement about FLN as a computational core was only an empirical hypothesis, not a definition. This claim, however, is false, and the relation between hypothesis and definition is exactly the opposite. A close reading of the 2002 text does not leave any doubts that the authors define FLN explicitly as a computational core of language faculty, and thus use only a linguistic criterion (for a more specific discussion, see Wacewicz, 2007; 2012). 
- FLN1 - the "computational core", e.g., Armstrong and Wilcox (2007), Johansson (2005), Kurcz (2004), Lewandowska-Tomaszczyk (2008);

- FNL2 - “purely linguistic and only human” - e.g., Okanoya (2007), Parker (2006), Samuels (2009), Számadó and Szathmáry (2006);

FLN1 and FLN2 are sometimes used interchangeably (e.g. Kinsella (2009)). What is more, even the authors of the term FLN themselves in their later texts define it in two different ways (compare Tincoff and Hauser, 2006: 536; and Hauser et al., 2007: 105).

\subsubsection{Syntactic parser and the narrow sense of "language"}

Regardless of the different terminologies and the confusion they have caused, we shall have a look at the "narrow" approach towards the study of language and, consequently, its evolution. From this perspective, the notion of "language" closely corresponds to the original concept of FLN (Hauser et al., 2002), i.e. a "computational core". Language is thus a cognitive capacity whose development in ontogeny is genetically hard-wired, enabling the use of elementary units in order to create well-formed grammatical structures. Language in this sense is only "an abstract computational system", a syntactic parser that analyses syntax, which functions independently of other systems, and which does not have to be connected with communication (Hauser et al., 2002). Other systems are responsible for formulating thoughts, building the sense of an utterance, choosing words, or producing the sounds of speech, but - according to Chomsky and his followers - they are of secondary importance. The computational core is the "heart" of the system because it provides language with discrete infinity - the possibility to reorganise discrete elements of sentences - which in turn constitutes a basis for productivity, owing to which we can produce an infinite number of new sentences from a finite set of words.

One particular property of the language faculty in the narrow sense is recursion. Hauser et al. (2002) propound two bold hypotheses: that FLN, the computational core, is made up exclusively of recursion, and that recursion is the only feature of language faculty which is unique to humans (i.e., apart from it, all components of language capacity can be found in other organisms). The traditional definition of recursion in linguistics involves the embedding of a linguistic unit in another linguistic unit of the same type. 
For instance, the phrase "my father's mother" is recursively constructed because the nominal phrase "(a) mother" is embedded in a larger nominal phrase "my father's mother"; by the same token, the sentence "John knows Mary likes cookies" is recursive because it includes the clause "Mary likes cookies", which itself could be a sentence, and thus a sentence is embedded within another sentence. However, it seems that Chomsky and his colleagues have a wider definition of recursion in mind - the combination of symbols into hierarchical structures which can infinitely be applied to one and the same utterance. Some are inclined to interpret "recursion" as identical with the universal principle "Merge".

Such views express a syntactocentric conception of language (see below) which assumes that a communication system can be called language provided that it allows symbols to be combined according to syntactic and morphological rules - it is precisely this possibility which was supposed to make language, as Pinker puts it, an "organ of extreme perfection and complication" (1994: 22). It should now be noted that combinatorics, or even syntax, does not have to be limited to recursion. Johansson suggested four meanings in which the notion is used, especially in the context of language evolution studies. The least complex combinatorial property is structuring, i.e. combining elements into segments (syntagma) by means of rules. Another property, hierarchy, is one level higher. It is the property whereby some constituents are dependent on other constituents. For instance, in the nominal phrase "a pretty girl", the adjective "pretty" is dependent on the noun "girl", which makes the phrase nominal. Finally, recursion is a special manifestation of hierarchy, which - as we have already said - makes it possible to embed structures in other structures of the same type: phrases in phrases or sentences in sentences. Recursion provides for transformative flexibility, i.e. expressing similar ideas with many different structures.

We have already emphasised that what defines language for Chomsky is recursion - in evolutionary categories, a sudden emergence of recursion radically distinguishes language from whatever system of communication preceded language. As Johansson's analysis suggests, the development of syntactic combinatorics can be examined in terms of gradualism - from structuring and ordering operations, which seem to be within primates' reach (e.g., Bergman et al., 2003), to simple recursion which can, for 
instance, result from social interactions as an exaptation of recursive social calculus (Aiello, 1998; Worden, 1996; Cheney and Seyfarth, 2005).

Pinker and Jackendoff (2005; see also Jackendoff and Pinker, 2005) together with many other authors (Bickerton, 2014), argue with Hauser, Chomsky and Fitch, and point out that the latter's understanding of language reveals generativist assumptions and is a direct consequence of defining language from the perspective of a particular linguistic theory minimalism. In the evolution of language, biolinguistics is the approach which assumes the narrow sense of "language" - i.e. which conducts phylogenetic research from the perspective of generative grammar and minimalism.

It must be noted that such linguists as Bickerton, Pinker, or Jackendoff (who was himself a student of Chomsky) share many of Chomsky's assumptions about the nature of language and the mind:

- mentalism - language is first and foremost a cognitive ability in the heads/minds of people, and its existence as a communicative code only results from this cognitive ability;

- modularity - the language faculty is, to a large extent, an independent module, separate from other cognitive abilities (e.g. social competences); and

- nativism - humans acquire language thanks to an innate mechanism.

However, they do not agree that a generative syntax is the only noteworthy mechanism of language - an approach which Jackendoff has criticised for some time as syntactocentric (2002).

The supporters of the narrow sense of language, mostly scholars from Chomsky's intellectual circle, substantiate their theoretical choice by invoking such qualities as scientific rigour and simplicity:

In our view, for the purposes of scientific understanding, language should be understood as a particular computational cognitive system, implemented neurally, that cannot be equated with an excessively expansive notion of "language as communication".

In place of a complex rule system or accounts grounded on general notions of "culture" or "communication," it appears that human language syntax can be defined in an extremely simple way that makes conventional evolutionary explanations much simpler. 


\subsubsection{Language in the broad sense}

However, the majority position is that the evolution of language should explain the language faculty in a broad construal of this notion. The starting point is thus to understand language in its intuitive, common-sense meaning (rather than a meaning unnaturally circumscribed to fit a specific intellectual agenda) and to consider the phenomenon of linguistic communication in all its wealth and diversity. Construed in this way, the evolution of language has become a target of fierce criticism from Chomsky's camp, because it expressly claims that to explain language origins, we need a sort of a "theory of everything":

With the rise of a multitude of new sub-disciplines, specialized journals, and conferences, and with the gradual decline of the Chomskian paradigm as a unifying framework, more and more of what we learn about language remains confined to specialized professorial circles. However, to understand the origin of language requires a move in the opposite direction - a large-scale, collective interdisciplinary effort at theoretical synthesis. The detective-like analysis of circumstantial evidence knows no disciplinary borders. Everything counts. (Dor et al., 2014: 1-2)

.... very wide spectrum of entangled conditions is required - cultural, social, political, cognitive, and emotional. In other words, language is an internal component of a much wider continuum: social intercourse and culture in distinctively human form. This, then, is why the problem is so difficult: to explain language, we seem to need nothing short of "a theory of everything" - everything distinctive about human consciousness, life, and culture taken as a whole. (Dor et al., 2014: 12)

Such a point of view implicates understanding language faculty not as a monadic whole, but as an elaborate amalgam of other faculties, whose evolution could have taken place in a number of ways and at different stages. In this regard, Hurford (2003) comes up with the idea of a mosaic evolution, and Knight (personal communication), of an evolutionary puzzle, in contrast to the "magic component X", according to which language could have emerged in a single leap by upgrading the primate cognitive system with one key element. Charles Whitehead further notes that "any attempt to explain language as an isolated trait is akin to explaining the emergence of the credit card without considering the preconditions on which credit cards depend including commerce, money, banking, the digital computer, and the means to detect and punish fraud" (2014: 157). 


\section{Language: Not only syntax}

The ability to use syntax truly constitutes a qualitative difference between the way humans and other animals can communicate. Animal systems of communication have some combinatorial capacities, but by no means do they have anything that resembles the morphosyntax of human language. We can distinguish some hierarchically organised elements in birdsong (see e.g., Miyagawa et al., 2014), but they lack phrase structure with infinite productivity and - to our knowledge - they do not have semantics, i.e. they do not express referential meanings. Monkey alarm calls are to some extent semantic: for example, putty-nosed monkeys have two calls - "hack" alarms about birds of prey, and "pyow" about leopards - and they also have a combinatorial structure, since they can be parts of larger units. However, the combinatorics here is extremely simple and limited to joining simple elements; also, it does not accommodate compositionality. Compositionality, which is a property of language, stands for the fact that the meaning of the entire utterance is a sum of its components (e.g., "red" + "house" = "red house"). When putty-nosed monkeys connect "hack" and "pyow", it then constitutes a separate signal which precedes the movement of the whole group. Finally, even enculturated apes, such as Kanzi, who use a rudimentary form of language, are unable to build complex grammatical sentences (Givón and Savage-Rumbaugh, 2006).

However, even from a purely linguistic point of view, a compositional, recursive syntax is very far from being the only interesting aspect of language. Moreover, it is not the only property which is unique to human languages. Another property which belongs only to human languages involves lexical resources, i.e. words, which are characterised by arbitrariness, duality of patterning and compositionality; an adult human is estimated to know approximately 60000 words (Pinker, 1994: 150). Pinker and Jackendoff (2005) note that lexical resources do not have any equivalent in animal communication.

Thomas Scott-Phillips (2014) also indicates that the pragmatics of human language, which makes it possible to construct rich senses dynamically, is unique to humans. Owing to pragmatic mechanisms, it is possible to communicate complex meanings and intentions with very brief utterances. These are explicitly coded only by key fragments, leaving the rest of the intention to be reconstructed via contextual inference. According to ScottPhillips, what makes human language so radically different from animal 
communication is what Sperber and Wilson (1986) call "ostensive communication": messages in language do not so much convey meaning, as merely indicate a way towards proper interpretation. In Scott-Phillips's view, animal communication represented, for instance, by monkey calls, is a code (in Shannon and Weaver's sense, see Shannon, 1948). Saying "You look pretty" can be interpreted in many ways - in the most obvious context, it functions as a compliment, but in other cases it can be ironical, or it can be used as a strategy which precedes a request ("You look pretty. Could you..."). In contrast to the ostensive character of linguistic utterances, whose interpretation depends on the context and is decoded by the recipient of the messages produced by the speaker, monkey calls always have only one interpretation - for putty-nosed monkeys, "hack" will always be a warning against a bird of prey, and "pyow" a warning against a leopard.

From evolutionary and ethological perspectives, other linguistic phenomena also deserve some attention. One such phenomenon is the structure of conversation, with its peculiar procedures of low-level coordination of behaviours, such as turn-taking and preference organisation. The evolutionary emergence of these mechanisms (Mills, 2011) and how the system relates to cooperation (Żywiczyński, 2010; Żywiczyński and Wacewicz, 2012) have attracted the interest of researchers. Another example involves politeness: we can investigate whether, similar to language universals, there are strategies of linguistic politeness universal to all languages, and also why being linguistically polite seems to be an evolutionarily stable strategy, since being polite does not explicitly incur any costs (Wacewicz et al., 2015).

Most importantly, focusing on syntax could lead to a completely false conclusion: that it is the only qualitative difference between human and animal communication - "the magical component X" which, if poured into the brain of a non-human primate, would give it a language faculty. Even if we do bear in mind that human language is not simply an animal communication system with syntax "grafted" onto it, there is a risk that in focusing so exclusively on syntax we will miss what is truly important in the evolution of language. Syntax in and of itself does not explain other important features of language, e.g. semantic universals or displacement. Additionally, the hypothetical emergence of protolanguage - a system of communication which, as is maintained by the majority of researchers, did not have syntax (see 3.4.4) - assumes a few fundamental differences with regard to the cognitive 
capacities of other hominins. These include mimesis - an ability to learn by imitation and a conscious control of sequences of movements (Donald, 2000), symbolic communication (Deacon, 1997; 1998), an advanced theory of mind (e.g., Heyes, 1998), and most importantly, cooperation (e.g., Knight, 1998). We discuss these differences as "preadaptations", or the conditions for language to develop, in Chapters 4 and 5.

\section{Language: Not only speech}

Speech - communication in the vocal-auditory modality - is the most intuitive starting point in considerations about the origins of language. Although articulated speech is the prime and the most important means of linguistic communication, constraining the evolution of language to the evolution of speech would be wrong for several fundamental reasons. Firstly there are the aforementioned preadaptations, the conditions for the language to develop, where sensorimotor adaptations to spoken communication are subject to more fundamental social and cognitive adaptations. However, language is first and foremost not a uni-, but a multimodal phenomenon which uses - in parallel - numerous semiotic resources.

Speech is not the only form of language. Linguistic communication in the vocal-auditory channel can take the form of whistles (Meyer and Gautheron, 2006), in which phonemes or even longer units of a spoken language are coded as whistled sounds. People who have visual and hearing impairments communicate via touch with the use of special devices which transform a sound signal into a haptic one, or using the Tadoma Method, ${ }^{44}$ for instance by touching the mouth of speaker with their fingers, thereby registering the movements of the articulators and making it possible to decode the message. Language functions in many ways in the visual modality too, the most obvious example here being writing. It should be noted here that communicating via whistles, touch or writing are not new, autonomous languages, but only alternative methods of encoding the same natural language, which originally is spoken.

The situation is completely different when it comes to sign languages used by the Deaf community. Sign languages are fully-fledged languages.

44 A famous user of the Tadoma Method was the deaf-blind American writer and activist, Helen Keller (1880-1968). 
For example, the same utterance made in different sign languages needs to be translated by an interpreter (e.g., American Sign Language is more similar to French Sign Language than to British Sign Language - Yule, 2010). Sign languages are thus natural languages for deaf people and are classified as such in linguistic databases; they also have important structural, sociolinguistic, neurological and developmental properties which are also characteristic of spoken languages, for instance, arbitrariness, morphological and "phonological" (equivalents of phonemes and syllables) structures, historical change and developmental stages. Sign languages also diverge into dialects and undergo creolisation. We elaborate on sign languages and their status in Section 6.5.4.

Even in spoken languages, articulated speech is not the only way of transmitting messages. Natural conversation always comes together with gesticulation and other nonverbal forms of communication that Adam Kendon calls "extra-oral visible bodily action" (Kendon, 2014), such as swaying one's body or shaking one's head. Multimodality is more evident in the natural communication of cultures that do not have writing systems, and that use a wide range of semiotic resources. Speech in these cultures is commonly assisted by lexicalised onomatopoeia, and the non-lexical imitation of animal sounds. Such communities use whole-body pantomime in narrative, and incorporate music and dance in their communication. All these means of expression are elements of a semiotic spectrum in which the borders between individual resources are fluid, and their use changes dynamically between different genres of discourse (Lewis, 2014). In Chapter 6, we elaborate on the issues of modality and multimodality of language in the evolutionary context.

\section{Box 3.9 Writing}

Writing is a relatively new cultural invention (the first systems are estimated to have appeared 3200 years BCE) and as such, it does not have a direct connection to the origins of languages. Still, we need to bear in mind that written language has hugely influenced western linguistic thought, which has inevitably led to some theoretical prejudice in linguistics (Linell, 2005). 


\section{Language: Not only innateness}

The evolution of language, as an area of research, "evolves" too. In the first period of its evolution, the research programme was largely organised around the following points:

- language is a biological capacity (a system of adaptations), which

- "evolved from animal cognition not from animal communication" (Ulbaek, 1998: 33), and this

- happened gradually, through a Darwinian mechanism of natural selection (Pinker and Bloom, 1990).

Although such a point of view can still be considered mainstream, recent scholarship has aimed to update, expand, or sometimes even question such an approach (see Dor and Jablonka, 2014).

The first sign of a departure from this strict internalism is a gradual return to thinking about language in supra-individual terms. Going beyond the narrowness of FLN is not just a question of adding new cognitive abilities (to supplement syntax) which are necessary to acquire and use language. It is more about adding new capacities or aspects going beyond the body and the mind of a single person: "common ground", which enables mutual understanding, perspective taking and coordination (e.g., joint attention), social practices, customs, norms and rituals (Dor et al., 2014). These mechanisms and phenomena are present in individual minds, but they are also manifested in interpersonal communication. These mechanisms create a social "infrastructure" which is indispensable for language to function in a way similar to Whitehead's example of e-commerce, which makes it possible for a piece of plastic to function as a payment card. What is perhaps the most crucial to the emergence and functioning of linguistic communication is a foundation of cooperative social relations, whose importance we underscore in Chapter 5.

Many of these mechanisms involve non-biological heredity, which is becoming more and more central to discussions about the evolution of language. In the case of species such as humans, who are capable of extensively modifying their environment, subsequent generations not only inherit genes from their predecessors but also ecological niche constructed by them. Chris Sinha (e.g., 2009) uses here the term phenogenotype, which is not reduced to a genotype but covers a whole biocultural complex as well, 
such as when young beavers inherit not just their parents' DNA, but also a dam which their parents built. In humans, the process is enriched by what Sterelny (2012) terms hybrid learning. This involves deliberately introducing teaching aids into the environment, and structuring the environment in such a way that it facilitates pedagogical process; as Sterelny puts it, our minds are evolutionarily adapted to learning, but our environments are also constructed in such a way that it is easy to learn in (and about) them. Perhaps technological or ecological information is not the most important thing in learning; instead, the most important may be social norms, which are an example of double inheritance (Henrich and Henrich, 2007), i.e. transgenerational transmission of biological propensity for normativity as well as of culturally-specified systems of norms.

These examples indicate how biological and cultural evolution intertwine and interact. What is especially important is the fact that these two processes converge, which leads to biological and cultural co-evolution: a situation in which biological and cultural influences mutually amplify each other. Deacon (1997) presents co-evolution using the example of lactose tolerance. Human organisms in the Palaeolithic, similarly to other mammals, produced lactase - an enzyme digesting sugar in milk - only in early childhood. Domesticating animals meant that people had greater access to milk, though at the time they found it difficult to digest. What helped humans to drink milk without major side-effects was technology: processing milk made it possible to eliminate some lactose through fermentation. Under such circumstances, mutations 'switching on' lactase production in adults were highly adaptive and remained in the population. A greater prevalence of the biological capacity to digest milk, along with a growth in the cultural and technological possibilities of processing it, led to certain cultures becoming more dependent on milk, which further intensified selection pressures at both the biological and cultural levels. A similar process of co-evolution must have occurred in the case of language capacities (for an elaboration of this theory see Dor and Jablonka, 2014).

Secondly, what Chomsky calls E-language is not an epiphenomenon. Specific linguistic systems had their own dynamics of change which depended on the properties of individual minds, but which were not completely determined by them. Even if the biological component of language - our brains remains relatively unchanged, the linguistic code can be subject to change, 
which - as we remember - is evolutionary. The reproductive success of specific elements of linguistic systems - be they words, phonemes or grammatical rules - depends on whether they sound good or are easy to remember. Language is a beneficial parasite (Christiansen, 1994; see 2.2), and the brain is an environment to which language has to adapt (Christiansen and Chater, 2008).

What we mean here is evolution through natural selection, but on the level of glottogeny: the cultural evolution of languages as external systems of rules and elements. Such an intuition is not new. As early as 1907, David S. Jordan wrote:

There is a struggle for existence between words as among animals. For example the words begin and commence (Saxon and French) are in the English language constantly brought into competition. The fittest, the one which fits English purposes best, will at last survive. If both have elements of fitness, the field will be divided between them. The silent letters in words tell their past history, as rudimentary organs tell what an animal's ancestry has been. (Jordan, 2013 [1907]: 325)

Recently, new tools which make it possible to formally describe the mechanism of such a change have been developed. The most famous among them is the paradigm of Iterated Learning, developed in Edinburgh (considered to be the most important research centre for the evolution of language). It is founded on the observation that linguistic code is not telepathically transmitted from parents' to children's brains in an unchanged form, but rather that it is culturally transmitted and it undergoes changes in the process. Each time a language is transmitted from generation to generation, the linguistic output of the older generation $G_{1}$ constitutes input for the younger generation $G_{2}$.

The researchers from Edinburgh indicate that the transmission is not $100 \%$ accurate, owing to a number of factors called bottlenecks. They may be created by the producer of the output, such as resulting from speech defects or sound assimilation in rapid speech; they can result from the environment, such as noise or other disruptions, as well as factors in the social environment like current fashion; finally, they can result from the construction of the cognitive system of the receiver, his or her innate biases or the limitations of working memory (Kirby et al., 2004). All these factors may decide that a linguistic system $\mathrm{S}_{2}$, mastered by a younger generation, 


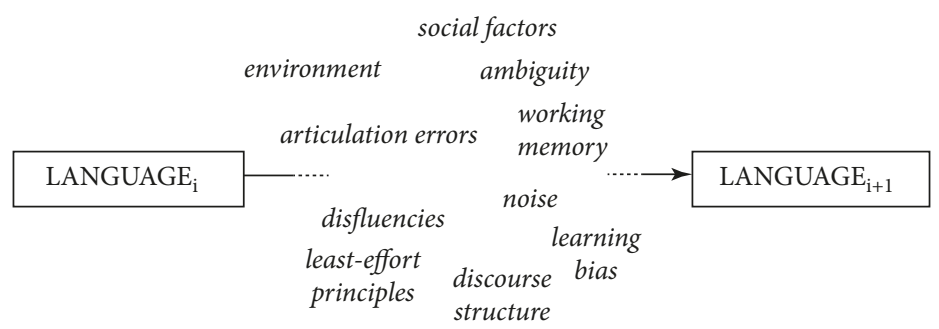

Fig. 3.4: Linguistic transmission in Iterated Learning (adapted from Kirby et al., 2004: 600). http://www.replicatedtypo.com/evolve-an-appname-results/10132. html. DOA 15 Mar 2017.

will slightly differ from the system $S_{1}$ of their predecessors. As it turns out, these small changes are not random, and their accumulation over tens and hundreds of such inter-generational transmissions leads to the linguistic code being regularised and streamlined. Demonstrations of this process in the laboratory are among the most interesting results of the work done in Edinburgh (Kirby et al., 2008).

\subsection{Stages}

Attempting to reconstruct, even in most general terms, the stages through which language evolution occurred will inevitably be a highly speculative enterprise. Still, even sketching a framework model of stages of the process can be useful, because it constitutes a cognitive aid which helps organise information. We propose such a framework model below (see Fig. 3.5). We are aware of the fact that our reconstruction is predicated on a number of theoretical decisions, such as the hypothetical status of protolanguage, which are not universally accepted. However, we have tried as much as possible to refer to existing consensuses.

It is important to remember about the hypothetical nature of the above "conceptual sketch". The individual features - the prerequisites and components of language - have a status of theoretical constructs singled out analytically, and the relative positions of particular stages reflect this author's own proposal and might not necessarily be a matter of a broad consensus. 


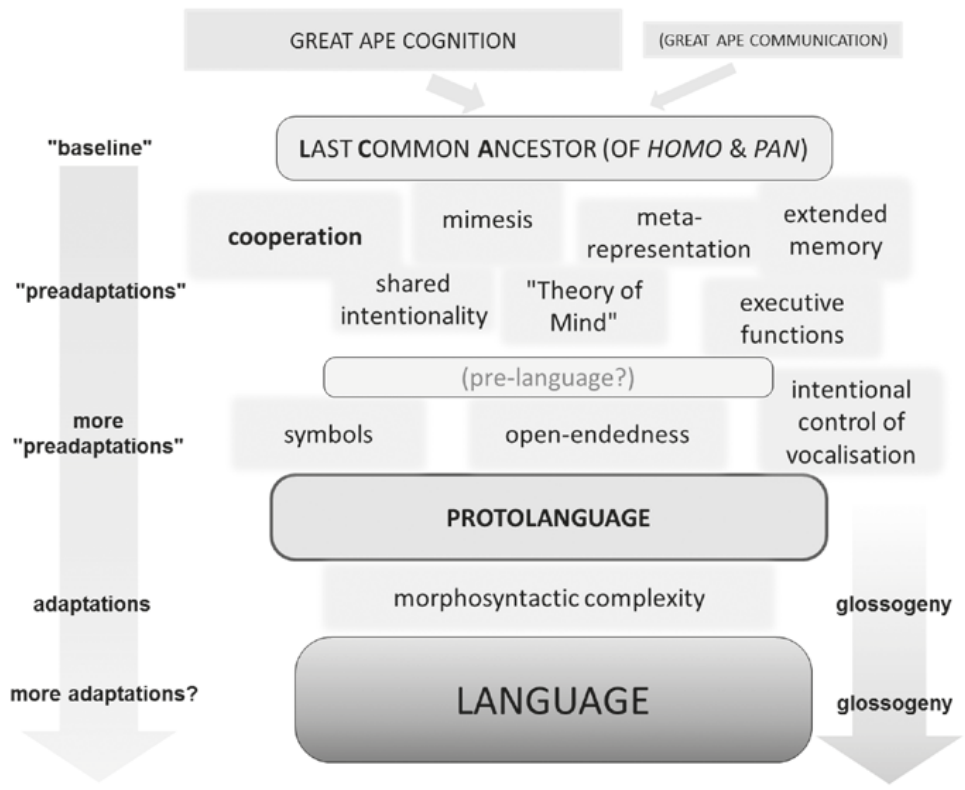

Fig. 3.5: The hypothetical stages of the development of language. The left and right arrows represent the process of biological evolution and cultural evolution, respectively.

\subsubsection{Baseline}

The intuitive view locates the origins of linguistic capacities in the vocal communication of primates and uses the existing communication systems as a model, e.g. monkey alarm calls (Hockett, 1964; Swadesh, 1971). Some researchers (e.g., Maynard Smith and Szathmáry, 1999: 161-162; Aitchison, 2000: 96-97) who go along with this intuition are prone to erroneously treat vervet monkeys' alarm calls as the prototypes of words in a human language. We can use here the analogy of a kite and a jet plane - any similarity between these modes of flight is only superficial, and the deep rules which govern how the two constructions are propelled are completely different. Currently, a majority of researchers agree that "language evolved from animal cognitive capacities, not from animal communication" (Ulbaek, 1998: 33). Contrary to what Hockett assumes 
(cf. Wacewicz and Żywiczyński, 2014), the foundations of language should not be sought in primate systems of communication, but rather in their cognitive capacities understood broadly, which, on the one hand, display an evolutionary continuity with those of humans, and on the other - constitute indispensable preconditions for the evolution of linguistic communication.

We are taking here as our baseline the hypothetical cognitive and communicative capacities of the last common ancestor of humans and chimpanzees (LCA), who lived approximately 6-7 million years ago. Our approximate reconstruction is based on data from other primates, in particular the data from the Pan species - common chimpanzees and bonobos, humans' closest living relatives. Data from other great apes (gorillas and orangutans) is also useful. Naturally, this is only an approximate reconstruction, because each of the species of great apes, over millions of years of its own evolutionary history, was subject to selection pressures which adapted their cognitive systems to the local habitat. On the other hand, the rich data from comparative studies increase the feasibility of reconstructing the last common ancestor's cognitive system. In our discussion, we will use data from primatology and comparative psychology.

\subsubsection{Preadaptations}

Although the term "preadaptation" is well-established in the literature, it is unfortunate and leads to mistakes because it may suggest an intentionality of change which is incompatible with evolutionary logic. Evolution does not plan ahead, which is why it cannot develop features which are supposed to become adaptive in the long term. The term "preadaptation" therefore does not imply that features emerged "so that" language could evolve from them. Rather, these are features which emerged independently and had their own distinctive adaptive value not connected with language. On the other hand, language could not have emerged without them because they constitute the foundations and preconditions for the evolutionary emergence of language. Preadaptations are connected both with anatomical infrastructure - articulatory and neural - as well as cognitive infrastructure, both of which were necessary for language to emerge. Preadaptations are discussed in detail in the next chapter. 


\subsubsection{Prelinguistic communication}

In our model, pre-language is the first of the hypothetical stages of language development. This stage should not be reified. We postulate the pre-language stage as a consequence of the model. Theorising about this stage is not based on empirical findings, which is why it should not be concluded that such a stage actually occurred. Pre-linguistic communication was made possible with the emergence of stable norms of cooperation and mimetic abilities, which allowed motoric programmes to be launched intentionally. Put simply, nonhuman apes do not communicate with language because such communication would not bring them much benefit (see Chapter 5). Once this barrier is removed and assuming that signs are produced intentionally, we can imagine the emergence of a very simple communicative system which is based on analogue, and not discrete, signals, such as pantomimic sequences or onomatopoeic vocalisations. When these signals become conventionalised and symbolic, the stage of protolanguage commences.

\subsubsection{Protolanguage ${ }^{45}$}

A majority of researchers acknowledge the gradualistic view of the evolution of language, at least in the sense that human language in its contemporary complexity did not emerge rapidly, but must have been predated by at least one stage of communication which qualitatively differed from the systems of communication of other primates. Making such an assumption is motivated by the general theory of evolution, which states that saltationist scenarios - those that postulate that big qualitative changes can occur "in one leap" - though not completely impossible, are prima facie much less credible than gradualistic scenarios of change, both in terms of the morphological features of organisms and of their cognitive capacities. The system of communication which preceded the emergence of fully fledged language is called protolanguage. Although it is less complex than language, it shares some features of language which cannot be found in animal communication. Derek Bickerton (1990: 122-125) popularised the term protolanguage ${ }^{46}$ and listed the following characteristic features of this system of communication:

45 From: Wacewicz, 2013.

46 Protolanguage in a phylogenetic sense should be distinguished from the same term from historical linguistics: protolanguage. There, protolanguage 
- lack of constraints on constituent order,

- lack of null elements,

- lack of subcategorised arguments of verbs,

- lack of mechanisms for the recursive expansion of phrases. Bickerton (1990: 109-122) notes that these features also characterise other systems:

- communication of language-trained apes;

- communication of children under 2;

- communication of "feral children" (individuals who grew up outside human societies and therefore did not have, as children, any contact with natural language);

- pidgins.

Simply speaking, the view of protolanguage Bickerton proposed is a symbolic lexicon, which is composed of arbitrary and conventional signs, and which has neither morphological nor syntactic organisation. Thus, the elements of the lexicon are arbitrary and conventional signs (symbols) which are ordered like "beads on a string". These elements are not subject to any formal rules and are only interpreted functionally. Pinker (1994: 366) suggests a simplified equation "protolanguage = language minus grammar", extending the comparison to the means of communication of immigrants, tourists, patients with aphasia, or even telegrams. Despite being useful, this analogy has its limitations. For instance, Bickerton himself did not include aphasic patients in his analysis, saying that their communication manifests other structural properties.

Nowadays, researchers into language evolution, even if they do not assume Bickerton's definition, agree on the usefulness of the notion of protolanguage (see Botha, 2012), whether to indicate an actual system of hominin communication or at least a transition stage between systems of animal communication and language. As Andrew Smith asserts (2008: 101):

Most scholars agree that there must once have been a predecessor of human language, or protolanguage, which did not contain the complex syntactic structures prevalent in modern languages (Bickerton, 1990; Carstairs-McCarthy, 1999; Hurford, 2003), but they disagree vehemently over the nature of protolanguage, and over how it developed into modern human language.

is a hypothetical, reconstructed ancestor of a given language family, e.g. Proto-Indo-European. 
Tecumseh Fitch (2010: 399-507), in his extensive discussion of the issue, distinguishes three main theoretical stances on the nature of protolanguage:

- lexical scenarios (e.g., Bickerton, 1990; Jackendoff, 1999),

- gestural scenarios (e.g., Corballis, 2002; Arbib, 2005),

- musical scenarios (e.g., Mithen, 2005; Fitch, 2010).

However, it seems that the categorisation Fitch proposes is incomplete because we are dealing with two distinctive aspects regarding the nature of protolanguage: the first one pertains to modality and/or the signal (vocal and musical scenarios of protolanguage), the other to the structural composition of the content of a message. It is on this latter plane that the debate over combinatorial vs. holistic protolanguage takes place.

Bickerton's suggestion is an example of a combinatorial scenario messages are built by ordering elements of a symbolic lexicon in short strings, which then are pragmatically interpreted. Holistic scenarios (Wray, 1998; Arbib, 2005) invert this order. A holistic protolanguage does not allow to build messages compositionally, and its individual utterances are "atoms" that lack any internal structure. From this point of view, the expressions which are acquired and used are indivisible wholes, and they convey the meaning corresponding to the meaning conveyed by full sentences or phrases in contemporary languages. It is the next stage of language development that could involve discovering the possibilities of deconstructing utterances and fragmenting language into elements which correspond to words as we now know them. This could have happened, for instance, by the process of the reanalysis of holistic messages into lexical items that are made up of similar elements of original holistic messages.

Holistic scenarios are intuitively less credible and nowadays have relatively few supporters. Commentators (e.g., Smith, 2006) list the weak points of such scenarios: a limited inventory of signals, problems with the ontogenetic acquisition of holistic meanings, problems with the reanalysis of holistic signals into lexical items. These remarks are corroborated by computational simulations (e.g., Johansson, 2008), whose results suggest that a stable, holistic protolanguage would have been possible only by making very rigorous assumptions, especially a very limited inventory of signals. 
However, Wray provides interesting linguistic arguments (e.g., Wray and Grace, 2007) that compositionality is not as obvious a property of language as we consider it to be. Being aware of the compositional structure of language may, to a large extent, be an artefact of a writing culture in general, and a formal linguistic analysis in particular. Wray and Grace make a distinction between using language in exo- and esoteric niches. In an exoteric niche, communication occurs mainly between strangers - between members of separate groups with different cultural backgrounds and often using a different language. In an esoteric niche, communication occurs between people who know each other well, inside a small group in which everyone is a native speaker of a given language. In such niches, the role of common ground and pragmatic interpretation is more important than compositionality and systematic rules. The early stages of protolanguage must have occurred in an esoteric niche; therefore, compositionality could have been a secondary property, developed over the course of an increasing number of messages, and possibly the development of writing, whose use imposes regularisation (see Box 3.9).

Yet another distinction within the scenarios of protolanguage, which also results from Fitch's description, and which he does not report on, pertains to the postulated order of the emergence of semantics and "syntax". For the majority of researchers, semantics (or protosemantics, as Johansson puts it (2005: 233)) - construed as a system of attributing meaning to communicative units - came before combinatorics, i.e. syntax in a general sense. Such a chronology is not only compatible with the scenarios devised by Bickerton and the supporters of the gestural protolanguage (Hewes, 1977a; Corballis, 2002; Arbib, 2005), but also with Wray's holistic approach or Mithen's (2005) musical and holistic scenario, where meaning was ascribed to elements of a holistic protolanguage. Tecumseh Fitch (2010: 503-507) is of a different opinion: referring to Darwin's (see 1.2.2) and Jespersen's (see 1.2.2) reflections on the origins of language, he suggests that the first form of protolinguistic communication was based on hierarchically organised songs, similar to the songs of some birds. Such a protolinguistic system, which Fitch calls "bare phonology", was extremely complex and was based on rules which allowed new units to be generated in the primal protolanguage. Thus, according to Fitch, combinatorial rules would have existed before a semantic component emerged. 


\subsubsection{From protolanguage to language}

Clearly the transition from protolanguage to contemporary language is strictly connected with the assumed scenario of protolanguage.

- For the majority of scholars, the shift from protolanguage to language occurs when the system of symbolic units is complemented by syntactic rules:

o by an incremental development of syntactic principles (e.g., Jackendoff, 2002), or

o by decomposing larger holistic expressions (e.g., Wray, 1998).

- For scenarios postulating that the combinatorial system predated semantics, similar to the aforementioned "bare phonology" proposed by Fitch, the emergence of language is achieved by adding semantics, when combined phonological units also started to carry referential meanings.

- For scenarios of gestural protolanguage, apart from the development of syntax, the transition of language from the visual to vocal modality is also a problem - we will address this issue in detail in Chapter 6.

What is also controversial is the pace and the mechanism of such a hypothetical transition. There exist two positions: the saltationist one postulates a rapid transition from protolanguage to language proper; the other position describes a gradual transition from protolanguage to language. The former scenario was advocated by Derek Bickerton in his influential Language and Species (1990), where he proposes that syntax emerged in a single "leap" thanks to a "lucky" macromutation that changed the way the brain functioned. Such a proposition refers directly to Chomsky's approach; it should be borne in mind, however, that Chomsky's idea of macromutation is far more radical, since it does not accept the intermediary stage of protolanguage and emphasises that language emerged suddenly, without any precursors (Chomsky, 1995; Berwick and Chomsky, 2011).

Most of those who view the transition from protolanguage to contemporary language as connected with the emergence of syntax support the gradualist scenario. Among them, we can also find "later Bickerton" (2009), who revised his earlier stance, admitting that his previous view was incompatible with the nature of evolutionary change. Jackendoff (2002) is 
in favour of a gradual emergence of the syntactic component. According to him, a lexical protolanguage - a set of symbolic units - first received a basic phrase-structure grammar which distinguished between semantic roles, with morphosyntax coming only later on.

Another line dividing theoretical approaches is the role of biological and non-biological factors. The researchers mentioned above represent a group which emphasises the role of the biological substrate - biologicallymotivated capacity to acquire language - as well as its biological evolution. An alternative scenario looks for the origins of syntax in cultural processes. One type of this kind of cultural change is grammaticalisation (Heine and Kuteva, 2007; Hurford, 2011). In this process, lexical units such as nouns or adjectives change into grammatical units, such as tense markers. For example, the English "going to" structure initially only meant the physical activity of moving one's body by means of walking, and then changed into an indicator of the future tense whose contemporary pronunciation is /'gpnə/.

Cultural evolution is faster than biological evolution (see 2.2) and evolutionary change within the structure of a linguistic code, at least theoretically, can lead to a shift from a protolanguage to a fully-fledged language, without any further changes on the biological plane. The Edinburgh group appears to favour this approach (see Scott-Phillips and Kirby, 2010). On the other hand, there is no reason for evolution by natural selection not to influence the users of protolanguage in continuing to shape their linguistic adaptations. What is more, there is no reason why adaptive change connected with language use should stop in populations of contemporary humans. For instance, a controversial study conducted by Dan Dediu and D. R. Ladd (2007) reports a correlation between the occurrence of tonal languages and the occurrence of two alleles connected with the size of the brain in the populations which use such languages.

\subsection{Conclusions}

In this chapter we have provided an account of the qualitative difference between glottogenetic reflection, whose history we described in the first chapter, and the evolution of language, which is a strictly scientificallyoriented field of research. We depicted the multi-faceted and complex nature 
of human language, which cannot be reduced to a single component, gene, selective pressure, or modality. We will specifically address the multimodal nature of language in the last chapter. Meanwhile, in the next chapter we will describe the prerequisites that made it possible for hominins to develop such a complex mechanism as language. 


\section{Chapter 4 Preadaptations for Language}

We use the term preadaptations in order to indicate any language-related differences between humans and their hypothetical common ancestors with chimpanzees. These differences constitute the preliminary conditions which made it possible for language to develop in our evolutionary lineage. The majority of the phenomena we discuss in this work are exaptations. These changes served, at least initially, goals other than language, and later began to play a role in its evolution. Nevertheless, some of the changes were directly involved in the development of the language faculty, and for this reason can be viewed as language adaptations. Following Hauser et al. (2002) we adopt a division into sensorimotor preadaptations, ultimately related to the production and reception of speech; and cognitive preadaptations, which we explain in the context of the relation between the evolution of language and the evolution of the brain. The most important of the preadaptations - cooperation - is addressed in a separate chapter.

\subsection{Speech}

Speaking is definitely one of the most complex human motor abilities. All the organs of the vocal apparatus that serve speech production initially performed other functions - mainly breathing and ingestion. The vocal tract has a characteristic inversed L-shape with the phonation apparatus, comprised of a pair of vocal folds located in the larynx. Vocal ligaments, covered with folds, are separated while breathing and producing voiceless sounds, but while producing voiced sounds, the ligaments pull together and open interchangeably. Over the larynx, up to the nasal meatus and oral cavity, there is the pharynx, which reaches its widest point at the level of the hyoid bone. Muscles attached to the hyoid bone enable movement of the larynx and the tongue. In consequence, pulling away the root of the tongue enlarges the oral cavity space at the cost of the pharyngeal space, and elevating the tongue reduces the space of the oral cavity, enlarging the pharyngeal space. 
These operations show in a simple way how the so-called double resonator system operates. The airstream travelling through the pharynx and lips can travel either from a smaller articulatory space (tongue pulled away) to a bigger one, or from a larger one (tongue elevated) to a smaller one (Nishimura et al., 2003). Many sounds the vocal tract can produce result from the functioning of this double resonator system. Its work is modulated by the tongue, lips and the soft palate movements which can close or open the nasopharyngeal space through which the airstream escapes during the production of nasal sounds.

A comparison of the human vocal tract and its corresponding structures present in nonhuman apes is crucial to the problem of the emergence of language, or at least of the emergence of speech. A relatively similar organisation and innervation of these organs in all nonhuman apes - including our closest relatives, chimpanzees - contrasted with a few fundamental differences visible in humans, suggests that changes occurred only after hominins separated their evolutionary lineage from that of Pan some 6-7 million years ago. The first striking difference is the contrast between the characteristic shape (the inversed L-shape) of the human vocal tract and the basically straight, pipe-like vocal tract in chimpanzees, which resembles

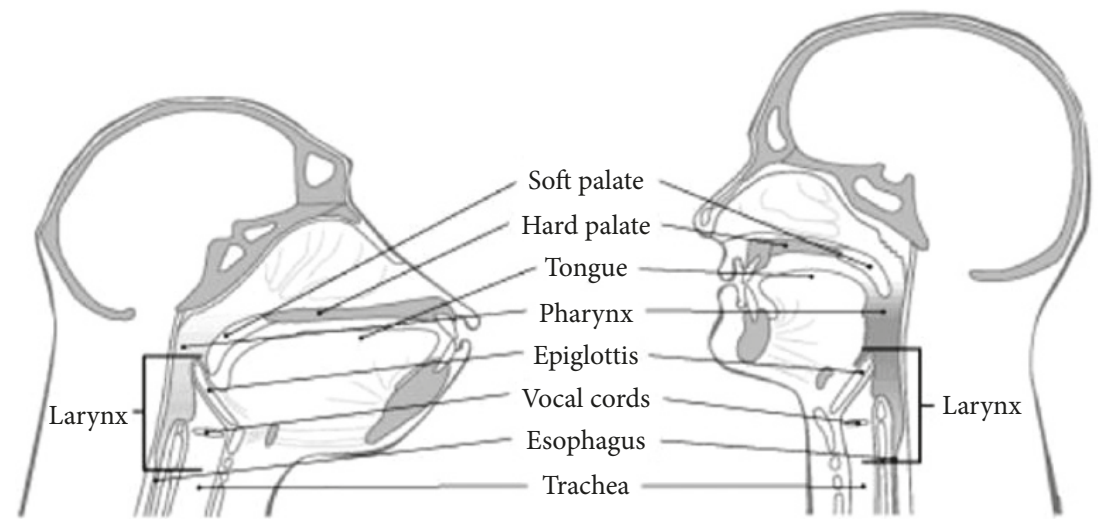

Fig. 4.1: Vocal tract cross-section: chimpanzee and human. http://pubpages.unh. edu/ jel/images/vocal_tract_chimp.gif. DOA 15 Mar 2017. 
a general scheme for the mammalian vocal tract (Lieberman and McCarthy, 1999; Aiello, 1998).

The ontogeny of the vocal tract is very interesting. When we look at infants, their vocal tract is not vertical and the larynx is situated high up, which resembles the anatomical structure of a chimpanzee's vocal tract (Lieberman and McCarthy, 1999). The larynx starts to descend in the third month of life and stops descending around the age of three (Lieberman and McCarthy, 1999; Fitch, 2000). Interestingly, the lowering of the larynx, on a much smaller scale, is observed in chimpanzees as well, but not in the other species of nonhuman apes (Nishimura et al., 2003). It is suspected that the phylogeny of these changes was twofold: the larynx started descending in the chimpanzee-human common ancestor; however, the lowering of the hyoid bone happened only in the hominin lineage. This led to a vertically situated larynx and the emergence of a large pharyngeal space above it (Johansson, 2005: 78-79).

Due to the role the lowered larynx plays in speech production, the evolution of the vocal tract has provoked the curiosity of researchers interested in the origins of language. In a series of publications, Philip Lieberman $(2001 ; 2002 ; 2003)$ argued that the shape of the vocal tract, and most importantly the low position of the larynx, is an adaptation to speech. $\mathrm{He}$ pointed out that the system found in neonates is adjusted to nursing, and only after a baby starts to babble (around the fifth month of life) does the larynx start to descend, which is supposed to facilitate articulation. This argument is further reinforced by the fact that apart from the acoustic amplification of the sound, enabled by the double resonator system, the deep location of the larynx serves no other immediate purpose, but rather complicates the coordination of ingestion and breathing, and carries the risk of choking, which can be fatal (e.g. Fitch, 2000). Tecumseh Fitch warns against taking Lieberman's argumentation at face value. With x-rays imaging, he shows that although the larynx of various mammals is located high at rest, it descends when animals produce vocalisations (e.g., in a barking dog or a bellowing deer: Fitch, 2000). Moreover, there are species, such as koala bears, whose larynx is lowered permanently; hence, it is not a uniquely human feature (Fitch 2002). This leads him to conclude that the position of the larynx does not predetermine language ability and does not rule out the possibility that the larynx descended in humans due 
to selection pressures unrelated to speech. Fitch proposes that one reason known from ethology as to why the larynx descended could have been the exaggeration of the body size during mating calls, which is also evident in the voice change of maturing boys, when the larynx and vocal folds grow (Fitch, 2002).

Other authors writing on anatomical differences in the vocal tracts of humans and chimpanzees draw attention to the significant distance between the soft palate and the pharyngeal wall in chimpanzees, which prevents them from closing the nasal tract by raising the soft palate (SavageRumbaugh and Lewin, 1994). Such an operation in humans enables them to articulate oral sounds when the air comes out through the mouth. Bart de Boer, on the other hand, explains the consequences of the loss of air sacs - sac-like structures that are located between the vocal folds and the hyoid bone in all apes, except for humans. De Boer, who simulated vocalisations with and without air sacs, came to the conclusion that the presence of such sacs may act to increase the volume, but it impedes or even precludes the possibility of differentiating between the vowel sounds (2012a; 2012b).

The evolution of the vocal tract has also been discussed by paleoanthropologists due to the influence of Lieberman who, having compared the hyoid bones of apes and Neanderthals, came to the conclusion that a descended larynx is characteristic only of Homo sapiens, and that Homo neanderthalensis could not have had the articulatory range approximating that of modern humans (Lieberman and Crelin, 1971). Nevertheless, further discoveries of the hyoid bone in Neanderthal skeletons from an Israeli cave Kebara (Bar-Yosef et al., 1992) and a Spanish cave El Sidrón (Santamaría et al., 2010) show that they bear similarities to the human hyoid bones in size and shape; this suggests that there are no significant differences between the human and Neanderthal vocal tracts (Hurford, 2014). Currently, based on anatomical features, most researchers agree with the view that Neanderthals were able to speak (Boë et al., 1999; 2002; d'Errico et al., 2005; see also Corballis, 2002: 144), and a growing number of them are inclined to say that Neanderthals were likely to have language (Johansson, 2013; Dediu and Levinson, 2013). 
Another important factor differentiating apes from humans concerns the innervation of the vocal apparatus. In particular, it concerns the neural control over the vocal folds. Humans have nerve fibres connecting the vocal folds with neocortical parts of the brain, and these enable us to consciously control the phonation processes, i.e. the production of voiced and voiceless sounds (Deacon, 1992). In apes and monkeys, vocalisations are controlled by parts of the brain which are evolutionarily older than others, and which are connected with the neural networks that allow swallowing and breathing (Deacon, 1997). Such an architecture leads to a relative lack of innovation in the vocal behaviour of apes and monkeys, at least in comparison with their gestural expression - in fact, their vocalisations are species-specific, but regional variations can occur. ${ }^{47}$ Due to the substantial automaticity of their vocal behaviour, attempts to teach apes to speak, or even to produce calls similar to those of other primate species, failed, as we documented in Chapter 1 (see also Fitch, 2000). Terrence Deacon states that a major obstacle to vocal complexity in primates is the automaticity of their vocalisations, and not merely the lack of conscious control over the vocal folds (Deacon, 2003). In phylogenetic terms, this means that human vocal behaviour must have started from the relaxation of selection pressures directed towards upholding automatic vocalisations, which went on to facilitate a change in the innervation of the vocal folds (Johansson, 2005: 81-82). It must be remembered that this change was not complete, and we can still find human behaviours controlled by the old pathways, such as laughter or the cry of pain, over which we have little volitional control (Deacon, 2000).

Humans also have much richer innervation of the chestal area than apes do, which enables greater breathing control and sound articulation based on the respiratory flow modulation (MacLarnon and Hewitt, 1999). While in other animals the duration of inhaling and exhaling is

47 Recent research questions this view and provides data about intentional vocal communication of nonhuman great apes (see: e.g. Clay and Zuberbühler, 2014). Specifically, nonhuman great apes are able to use their teeth and lips to produce sounds in an innovative, intentional way (Leavens et al., 2014). However, it does not deny the existence of the qualitative difference in the vocal control between humans and the other great apes. 
the same, when humans speak, they use up to $90 \%$ of the breath cycle for exhalation, adjusting the amount of air to the needs of the articulated sounds (Hurford, 2014). Comparative research on humans, nonhuman apes and hominin fossils that correlates the size of the vertebral canal with the whole body ratio, demonstrates that humans and Neanderthals show an increase in the innervation of the chest, while Australopithecines (two specimens examined) and Homo erectus (one specimen examined) show in the regard a resemblance to the anatomy of nonhuman great apes (MacLarnon and Hewitt, 1999). Most of paleoanthropologists connect this increase in the chest innervation and the resultant control over breathing with the development of bipedalism, specifically with the emergence of so-called "tempo breathing" which disconnected the breathing cycle from limb movements. As both the Australopithecus and the erectus were bipedal, comparative studies by Anna MacLarnon and Gwen Hewitt seem to challenge this position and indicate that the enhanced breath control was contingent on some other reason such as speech adaptation.

Another possible scenario posits that beginning with australopithecines, breathing was independent of walking. Based on this change, the mechanism for breath control visible in Homo neanderthalensis and Homo sapiens developed. According to this proposal, which has been supported by language evolution researchers (e.g. Johansson, 2005: 82; Hurford, 2014), breath control would be an exaptation, and not an adaptation for speech. Although the discovery by MacLarnon and Hewitt has not been challenged, another study shows how dangerous it is to extrapolate results - especially from a very limited number of fossils - to explain such phenomena as speech. There had initially been a conviction that speech development required increased neural control over the most important articulator - the tongue (e.g., MacNeillage, 1998). Anthropologist Richard Kay and his colleagues anticipated that it is possible to draw evolutionary conclusions on the basis of the size of the hypoglossal nerve canal, through which the hypoglossal nerve responsible for tongue movements leaves the cranium. Kay and his team measured the size of the canal in selected nonhuman great apes, a few australopithecines, one Homo habilis, a few Neanderthals, and archaic and modern people (Kay et al., 1998). The results suggested that the canal was significantly bigger in Neanderthals and humans than in 
nonhuman apes, australopithecines and $H$. habilis. Using these data, the researchers concluded that a speech-adapted tongue must have emerged no later than 400,000 years ago, and Homo erectus probably had it. Another team, led by paleoanthropologist David DeGusta, questioned these findings and showed that the vocal tract of nonhuman apes and australopithecines was within the human range when controlled for body size (DeGusta et al., 1999). Moreover, DeGusta et al. did not establish a correlation between the size of the canal and the number of nerve fibres going through it in extant species. Research like this on the size of the hypoglossal nerve canal is an example showing how cautious one should be in re-creating the evolution of such a complex phenomenon as language.

\subsection{Speech reception}

Unlike in the case of the vocal tract - the human hearing system is basically the same as in other animals and its structure does not differ significantly from the general mammalian anatomy (Johansson, 2005: 86). The hearing thresholds in humans and apes are similar (Spoor and Zonneveld, 1998), and cortical sound processing is also alike (Kaas and Hackett, 2000); the only major difference concerns speech sounds, which the human brain processes in different areas that non-linguistic sounds (Mueller, 1996). Although, as we noted, there are no major differences between humans and apes in terms of hearing thresholds, an interesting distinction was observed concerning the auditory range in which sounds are best received. The human ear is specialised for the perception of sounds ranging 2000$4000 \mathrm{~Hz}$; for chimpanzees these frequencies are lower (Pinker and Bloom, 1990; Moore, 2000; Martínez et al., 2004). Taking into consideration the fact that a majority of speech sounds fall within this range, it can be assumed that the increase of frequency is an adaptation for speech recognition. Assuming that frequency ranges can be assessed based on the shapes of auditory ossicles of the middle ear, palaeonthologist Ignacio Martinez examined these ossicles in Homo heildelbergensis - a probable ancestor of both humans and Neanderthals (Martínez et al., 2004). According to his measurements and assumptions, the range in Homo heidlebergensis was the same as that of modern humans, which led him to conclude that this particular species possessed speech. 

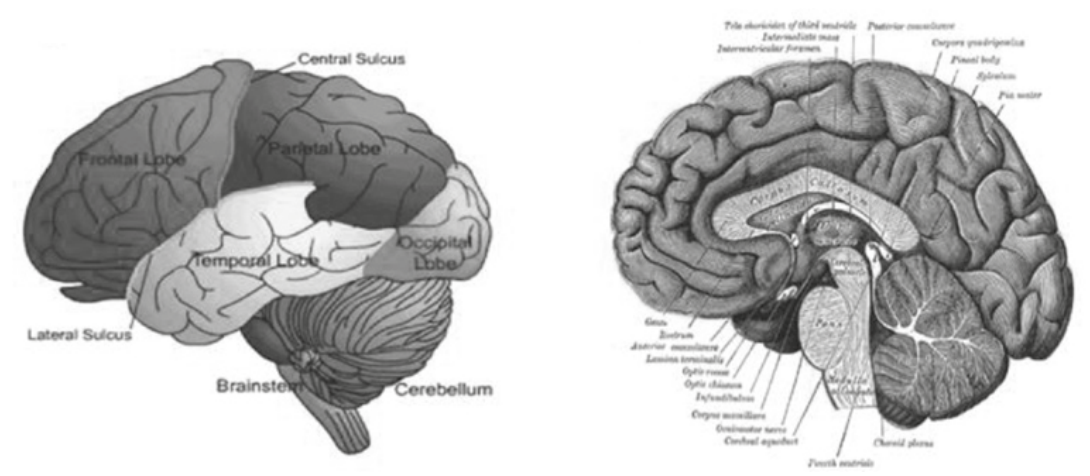

Fig. 4.2: Neocortical lobes and the cross-section of the brain. http://commons. wikimedia.org/wiki/File:Lobes_of_the_brain_NL.svg. DOA 12 June 2019.

Another problem with speech perception concerns animals' - and especially apes' - ability to discriminate between various human speech sounds. What we are addressing here is not the ability to hear particular sounds, but categorical perception, which consists in assigning sounds to particular categories. There are many anecdotes concerning the comprehension of human speech by domesticated pets - dogs, cats, horses or parrots. However, there are many more reliable studies at our disposal, such as those by Sue Savage-Rumbaugh (e.g. 1986) on how enculturated apes, for instance bonobos Kanzi and Panbanisha, comprehend human speech. There is also experimental evidence for animals' ability to recognise particular speech sounds. Patricia K. Kuhl obtained surprising results from a famous chinchilla experiment, which showed that these rodents can recognise voicing in English plosive consonants, discriminating between such phonemes as [p]-[b] or [t]-[d] (Kuhl and Miller, 1975). In turn, Ruth Tincoff's team showed that cotton-top tamarins (Saguinusoedipus), a Haplorhini species inhabiting South America, recognise the rhythms of various languages - the experiment used English, Dutch, Japanese and Polish - similar to the way infants recognise sounds (Tincoff et al., 2005). Another interesting study was presented by two Japanese researchers, Shozo Kojima and Shigeru Kiritani, and concerned speaker normalisation - a phenomenon known from speech perception as adapting phoneme classification to the speakers' characteristics, most importantly to their sex. Kojima and Kiritani showed 


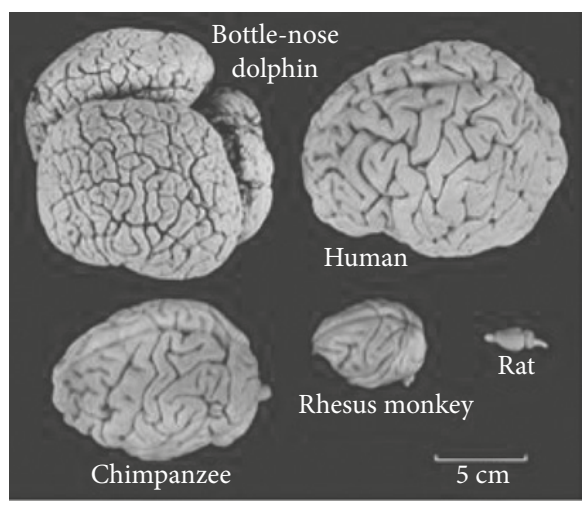

Fig. 4.3: Brains of selected mammals. https://www.psychologytoday.com/sites/ default/files/styles/article-inline-half/public/blogs/134094/2013/10/135685135585.jpg. DOA: 08 Aug 2015.

\begin{tabular}{|l|c|}
\hline Species & $\begin{array}{l}\text { Average absolute } \\
\text { brain weight (grams) }\end{array}$ \\
\hline Chimpanzee & 450 \\
\hline Human & 1,350 \\
\hline $\begin{array}{l}\text { Bottlenosed } \\
\text { dolphin }\end{array}$ & 1,600 \\
\hline $\begin{array}{l}\text { African } \\
\text { elephant }\end{array}$ & 6,075 \\
\hline Fin whale & 7,200 \\
\hline $\begin{array}{l}\text { Sperm } \\
\text { Whale }\end{array}$ & 9,200 \\
\hline
\end{tabular}

\begin{tabular}{|l|l|}
\hline EQ \\
\hline Human & $7.4-7.8$ \\
\hline Dolphin & 4.14 \\
\hline Killer whale & $2.57-3.3$ \\
\hline Chimpanzee & $2.2-2.5$ \\
\hline Rhesus Monkey & 2.1 \\
\hline Elephant & $1.13-2.36$ \\
\hline Whale & 1.8 \\
\hline Dog & 1.2 \\
\hline Cat & 1.0 \\
\hline Horse & 0.9 \\
\hline Sheep & 0.8 \\
\hline Mouse & 0.5 \\
\hline Rabbit & 0.4 \\
\hline
\end{tabular}

Fig. 4.4: The absolute size of the brain and encephalisation quotient in selected mammals (after Roth i Dicke, 2005).

that chimpanzees are able to conduct such a normalisation with regard to two vowels: [a] and [u] (Kojima and Kiritani, 1989).

As noted at the beginning of this section, speech processing takes place in a brain region different from the one that processes non-linguistic sounds. As Hurford argues, this is unsurprising since a majority of apes process 
intraspecies vocalisations differently to the way they process other sounds, and usually use the left cerebral hemisphere (Hurford, 2014). Moreover, there is evidence that apes and monkeys (Rendall et al., 1996; Ghazanfar and Hauser, 2001), and other mammals such as elephants (Poole, 1999), seals (Insley, 2000), hyenas (Holekamp et al., 1999) and dolphins (Janik et al., 2006), all have highly developed sound sensitivity and social intelligence, which enable them to recognise the sounds of the particular members of the group they live in (Johansson, 2005: 87). The most complete view of the cortical areas responsible for speech processing was obtained using fMRI scanning by a group led by Pascal Belin (Belin et al., 2000; Belin and Zatorre, 2003). Evidence for a specialised neural infrastructure for speech processing comes from studies of auditory verbal agnosia, a medical condition in which patients are unable to recognise speech, despite being able to recognise other sounds, such as music or ambient noise (Wolberg et al., 1990). Children who have not yet begun to acquire language display an ability to segment speech into either phonetically or syntactically relevant elements (Kuhl, 2000; Jusczyk, 1999). Nevertheless, these abilities are also used in processing some non-linguistic sounds, such as music (Johansson, 2005: 87). This may support the idea that speech segmentation in children does not result from any physiological mechanism that evolved specifically for language processing, but from mechanisms that subserve more general tasks (Johansson, 2005: 87). This has been confirmed by experiments showing monkeys to have similar segmentation abilities (Hauser et al., 2001).

Ultimately, as regards evolutionary adaptations for speech processing, we can assume, following Sverker Johansson (2005: 87), that the majority of these faculties do not deviate from the skills present in primates or other mammalian taxa. One exception to this is the development of the ability to hear in the frequency range necessary for phonemic recognition, and this appears to be the only adaptation facilitating speech comprehension.

\subsection{The brain}

The most important anatomical adaptations for language are those in the human brain. Unfortunately, even with the current technology, which enables us to research how the brain works in vivo (e.g. by means of fMRI, 
PET, MEG - see 3.1.3 Advances in the neurosciences), our knowledge of the relationship between linguistic behaviour and the neural activity of the cerebrum is far from complete. Moreover, taking into consideration how complex an organ the brain is, we are unlikely to arrive at a conclusive description of this relationship in the foreseeable future.

Let us start with some comparative and evolutionary facts. The evolutionary trend for mammals is linked to a considerable growth of the cerebral tissue, mainly involving an increase in the "new" cortex of the brain (also called the neocortex, the neopallium or the isocortex). The cortex, which initially appeared in the first mammals around 200 million years ago, is based on evolutionarily older brain structures, sometimes referred to as the "reptilian brain" (Lieberman, 2001). The structure of the human brain resembles that of other mammals, and in terms of the anatomy of the cortex, the structural division into four lobes - frontal, temporal, parietal and occipital - is identical to the architecture characteristic of the primate brain (Nishikawa, 1997; Johansson, 2005: 91).

With regard to the size of the brain, and its cortex in particular, significant variation can be observed among different mammals; primates and aquatic mammals of the order Cetacea have the biggest brains. Allometric studies, whose aim is to relate the total body size to individual body parts or some other features (such as body shape), developed a comparative measuring instrument for mammals - the so-called encephalisation quotient (EQ). EQ is a relative brain size measure, calculated as the ratio between the brain mass in a species on the one hand, and, on the other, an expected brain mass predicted by the body size of this species and the cost of its physiological processes. For example, the EQ for people ranges from 7.4 to 7.8 , which means that the human brain is more than seven times bigger than the size expected of a human-sized mammal. Allometry experts suggest that EQ is one of the intelligence indices as it shows the brain area which is not directly required for body maintenance and hence can be used for other purposes (see e.g. Roth and Dicke, 2005).

Traditionally, the descriptions of the evolution of specific structures in the human brain highlight changes in the frontal lobe growth (Deacon, 1997; Rilling and Insel, 1999). However, some later studies, especially those concerned with the comparative analysis of primate brain structures, show that there was a steady growth of all cortical parts of the human 
brain (Semendeferi and Damasio, 2000; Clark et al., 2003; MacLeod et al., 2003). Fossil evidence suggests that human evolution proceeded in two elementary stages. The first stage was associated with the development of bipedalism, which emerged early, perhaps soon after the Homo and Pan evolutionary lineages diverged, about 7 million years ago. The second stage is the encephalisation stage - the growth of the cortical tissue (Lewin and Foley, 2004). Until the emergence of Homo erectus about 2-1.8 million years ago, the brain mass was increasing marginally, remaining at a level similar to a chimpanzee's brain size, which on average ranges between 400 and 420 grams. The australopithecine brain did not exceed a mass of 600 grams with an EQ ranging from 2.2 to 3. In Homo habilis, the brain for the first time in the hominin evolution exceeded the mass of 600 grams and the estimated EQ was higher than 3. A marked increase in brain volume is visible in Homo erectus: it grew to almost 1000 grams around 1 million years ago; however, this increase in the brain weight was also accompanied by an increase in the body size. The brains of the later populations of Homo erectus weighed approximately 1200 grams - a value which was the same for $H$. heidelbergensis, who were their contemporaries. The value was also similar to the average value for $H$. sapiens, whose brain weighs about 1400 grams. H. neanderthalensis, on the other hand, had brains bigger than ours (about 1600 grams), although their EQ was similar to that of humans (Gallagher, 2014).

Since the brain tissue is energetically costly, the increase in the brain mass must have served an important adaptive purpose. As an organ, the brain is a heavy user of energy. Although it constitutes about $2 \%$ of the human body mass, it accounts for up to $15-20 \%$ of the total body caloric expenditure, and up to $50 \%$ in infants. Furthermore, it uses almost $15 \%$ of the cardiac output. Moreover, the expansion of the brain entails a number of anatomical problems (e.g. a big head poses difficulties with locomotion and balance), the greatest of which is the size of a newborn's head. Big heads in neonates mean that their bodies are big, too. This causes a serious difficulty and a risk to a woman in labour: bipedalism results in the distance between the legs in humans being smaller than in other apes; as a result, the birth canal is narrower in human females than in other apes, while the newborn's body is bigger. These great costs of hominin encephalisation mean that the growing brain must have been 
outweighed by even greater benefits - in other words, very strong selection pressures must have come into play.

The nature of the selective pressures responsible for the body mass and brain volume growth in our ancestors remain a mystery. The expensive tissue hypothesis, proposed by Leslie Aiello and Peter Wheeler (1995), provides only a partial answer. These researchers noticed that the sizes of the two types of expensive tissue - the brain and the gut - are inversely correlated: herbivores have a relatively large gut and small brains, whereas scavengers and predators have relatively big brains and small guts. A gradual change in diet into one that is more carnivorous ${ }^{48}$ may help explain what paved the way for brain growth from a physiological perspective, although it does not specify any concrete selection pressures towards encephalisation. Some researchers (e.g., Bickerton, 1998) maintain that the growing brain was a response to ecological challenges stemming from the nature of the environment, and most importantly, from problems with extracting food resources leading to extractive foraging - obtaining food from previously inaccessible sources, such as from within egg shells or from beneath the ground.

Nevertheless, the majority of researchers now support the statement that these challenges were of a social nature and were connected with community life. In social animals, reproductive success - especially that of males depends on social status, which in primates is less dependent on physical strength and more on social competence. The earliest social hypotheses stressed competition, such as the hypothesis of Machiavellian intelligence (Byrne and Whiten, 1988), according to which the main function of intelligence concerns quasi-political competition. Intelligence serves as an instrument of creating and breaking up alliances and undertaking actions to outsmart other members of the group in a way which allows one to benefit from manipulating others, while not being manipulated by others.

This line of reasoning is developed in the social brain bypothesis proposed by Robin Dunbar, who linked the costs of monitoring complex social behaviour and relationships in a large group directly with the size of the

48 Cooking may also have facilitated the brain growth and reduction of the gut (Wrangham, 2009). 
brain (Dunbar, 1996; 2007). Dunbar and his colleagues showed that the size of the brain - and especially the size of the neocortex, which is connected with cognitive functions - correlates with the size of the group (Dunbar, 1995). Moreover, they discovered other interesting dependencies, such as a correlation between the size of the non-visual neocortex and the length of the juvenile period in primates (Joffe, 1997).

Robin Dunbar's findings provide a basis for a discussion on the relation between scenarios and limitations in language evolution research. Insofar as the idea of the social brain occupies an important position in the field, its extension to speculations on the origins of language in the form of the popular "gossip" scenario (gossip hypothesis - Dunbar, 1996) encounters serious problems. In simple terms, according to this scenario, language emerged by replacing grooming as an adaptation for social tasks. The act of grooming in primates, changed from an act of hygiene into a tool for social interaction and maintenance of relationships. Nevertheless, its effectiveness is limited by the size of the group - in large groups, time would not permit grooming all of the important allies. According to Dunbar (1996), language may have taken over this function, becoming a form of vocal grooming. In another step, it may have become a tool for gossip, understood as an exchange of important information. Such a scenario, at least initially, does not explain the core features of language: its combinatorial nature and semanticity (transmission of messages with referential meaning). For instance, Bickerton (2003) points out that grooming could have been replaced by pleasant but meaningless sounds. Camilla Power (1998) has much more serious concerns - she notices a fundamental incongruence of Dunbar's theory with the demands of honest signalling (see 5.3). Grooming is an honest signal of affiliation precisely because it is time-consuming - the groomer is a reliable ally because he is prepared to pay such a cost. The more economical form of verbal grooming goes against this logic - such a signal is costless and therefore untrustworthy.

\subsection{Cognitive preadaptations}

\subsubsection{Mimesis}

Mimesis is a term in the field of human evolution proposed by the American psychologist Merlin Donald (1991; 2000), who defines it as an ability to 
create conscious representational acts which are intentional but not linguistic (Donald, 1991: 168). Donald perceives mimesis as a key cognitive ability in hominin evolution, distinguishing hominins from other apes which have only rudimentary mimetic abilities. Indeed, nonhuman apes can intentionally initiate planned actions, but humans are unique in having the ability to abstractly encode motor sequences as mental representations. Thanks to this ability, movements do not have to be initiated as responses to external cues; instead, they can be recalled from memory and autonomously initiated by the subject. Such autocuing takes place each time we practice a complex string of actions, such as completing a dance move or performing a boxing drill. An autocue activates when we engage our muscles in an action and track the sequence of movements in our imagination. Mimesis enables us to transfer our attention from the external world onto our body and to compare, in our imagination, the actual movements with the intended ones (Donald, 2012 in Zlatev, 2014a). Similarly, mimesis facilitates faithful imitation. It should be noted that human and primate imitation differs: in imitating an activity (e.g. opening a food container), people tend to focus on the movements and their precise imitation; chimpanzees, on the other hand, do not focus on the motion pattern but rather on its goal (e.g. opening a jar of candies). Tomasello (1999) dubbed the latter strategy as emulation, as opposed to imitation.

Therefore, mimesis facilitates a (precise) imitation of movements, dividing complex sequences into smaller discrete units (e.g., dancing steps), memorising the units and recalling them from memory to imagination, which helps to rehearse and practise them. Jordan Zlatev, who has developed Donald's ideas, lists a number of fields in which mimesis could have been applied by hominins: training in practical skills, memorising and planning, teaching (demonstration of practical actions) and learning, performing rituals and ceremonies. Finally, mimetic abilities could be used for pantomimic and gestural communication. Mimetic sequences can be of a representational nature - they can refer to the world and carry meaning, and can stand for objects or actions. Moreover, their externalisation, by means 
of body movements, offers opportunities for communicating meanings to others by means of pantomimic re-enactment. Zlatev (2014a: 201) states that " $[\mathrm{t}]$ he mimetic controller adds to this the ability to explicitly re-enact a past event though bodily motion, and perhaps more importantly, to go through the steps of a future act. This allows making the act more than a private <visualization $>$..., into a fully-fledged public representation, and thus much more accessible for oneself and for others ...”. Importantly, mimesis is not characterised by any obvious language-like features - arbitrariness, conventionality or systematicity - and its units are not symbols (see Zlatev et al., 2005). Mimetic control over body movements may be an indispensable condition for further development of linguistic communication. Gestural and multimodal conceptions of language development based on mimesis are described in Section 6.3.3.

\subsubsection{Theory of Mind}

Theory of Mind (ToM) is a slightly misleading term first used by primatologists David Premack and Guy Woodruff (1978), denoting the ability to understand and ascribe mental states - "the content of the mind" - to oneself and others. Possession of a theory of mind implies perceiving others as autonomous subjects who have their own objectives and own minds whose content can differ from our own. Thanks to ToM, we are able to understand that others can see and think things which are not available to our perception or cannot see and think of things which are available to our perception; for example, a person facing away from us does not have us in their scope of vision and does not know that we are approaching them. Theory of mind allows us to perceive others as intentional subjects whose actions are not just the effects of the laws of physics, but deliberate actions targeted towards particular goals (a stone falls down simply because of gravity, but a person goes to a shop because they want to do some shopping). We interpret the behaviours of animals or even inanimate objects in a similar way when we attribute consciousness and will to natural phenomena: "the mountain does not want to be ascended and defends itself with winds and avalanches".

Despite its name, ToM is an automatic cognitive ability and does not have to build on conscious theorising. The term "theory of mind" itself 
refers to the fact that this ability - similar to scientific theories - allows us to make an informed prediction by means of reference to unobservable events. If we know that John is hungry, we can in all likelihood anticipate his behaviour: that he will try to get food, even though "hunger" is an internal state which cannot be perceived directly, and we can only assume its presence. Social relations and the behaviour of others are constructed as unobservable states postulated by our "modules of the theory of mind" to predict and explain behaviour - if John kicked Philip, it means that John is mad at Philip.

In 1997, Michael Tomasello et al. suggested that apes did not have ToM. This opinion underwent a series of revisions, both from the perspective of new empirical data and from a more detailed analysis of the term. Until recently the "Sally-Anne" test was a procedure which checked whether individuals possessed theory of mind. The child saw the puppet Sally hide a toy in a basket and leave the room. Then another puppet, Anne, enters the room and takes the toy out of the basket and puts it in her box. After that, Sally comes back to the room. The child undergoing the test is asked: "Where will Sally look for her toy?" A child up to three years of age would typically point to the box, without taking into account the fact that the current location of the toy is known to them but not to Sally. From about the age of four, children start to give the right answer, taking into consideration Sally's state of mind and her false belief that the toy is still in the basket. ${ }^{49}$

Currently, the term theory of mind is not restricted to the attribution of false beliefs - it is an umbrella category that contains a number of distinct abilities. Their presence or absence in apes can be verified separately for each of these abilities. It turns out that nonhuman great apes:

- understand the goals and intentions of other individuals - for example, they behave differently depending on whether the caretaker is unable or unwilling to give them food, i.e. whether he fails to give them food

49 Such is the traditional view - recent research based on a simplified, nonverbal format of the test shows that even 15 -month-old children can assign false beliefs to others (Onishi and Baillargeon, 2005). 
by incompetence or does not want to give them food on purpose (Call et al., 2004);

- understand what others know or perceive - for example, they will not reach for food which is in the scope of vision of an alpha individual, but for food which is invisible to the alpha (Bräuer et al., 2007);

- do not understand false beliefs of other individuals (although further research can revise this).

The research on the theory of mind in apes conducted mainly by Michael Tomasello's group in the Max Planck Institute for Evolutionary Anthropology in Leipzig leads to an additional, but very important conclusion: apes are much better at tasks that are competitive than cooperative.

It is evident that human abilities in the area of ToM are more advanced than those possessed by apes. It is difficult to state unequivocally whether this is the result or a condition of language development. Most likely, both these aspects influence language ability in a positive way. Undoubtedly, ToM is crucial for linguistic communication at least in terms of pragmatics - the proper construction of an utterance and its comprehension in the way intended by the sender. The sender must take into consideration the state of mind of the other person: what the receiver knows, what may be obvious to him or her, what may be uninteresting, unclear, or offensive, etc. A reasonable interpretation of the answer, on the other hand, requires taking into consideration both the state of mind of the sender and conversational implicatures encoded in their message (e.g., "Do you have the time?", which can be interpreted as "Can you tell me the time?" or "Do you have the time to do something", depending on pragmatic factors; see Language: Not only syntax in Section 3.3.2).

\subsubsection{Metarepresentation}

ToM is closely linked with metarepresentation, a representation of a higher order, such as thinking about thinking. If a simple thought "It's a tree" is a representation of the first order, then becoming aware of this representation ("I know I can see a tree") is a second-order representation - a metarepresentation. Further orders of metarepresentation are most often of a social character, when by means of ToM we represent the mental states of others "inside of" our mind. "I know you can see a tree" is a 
second-order representation, but "I know that you know, that I am mad at John" is a third-order representation, etc. To describe this phenomenon, Robin Dunbar uses the term "levels of intentionality", though "intentionality" is used here in the philosophical sense of encompassing something in a thought, and not the psychological sense of purposefulness.

Metarepresentations take part in conscious reflection, analysis, and planning. The role of metarepresentation in the evolution of language manifests itself from the perspective of the social brain (see 4.3.), which underlines the importance of social relations. Alongside gossip, Dunbar grants a special role to story-telling and religion (Dunbar, 2007). Based on his earlier research, Dunbar ties together levels of intentionality/metarepresentation with brain capacity and speculates that Old World monkeys (e.g., macaques or baboons) have at their disposal first-order intentionality, while apes have second-order intentionality, and humans can even have fifth- or sixth-order intentionality (Dunbar, 2007). Of course, as in the case of other cognitive features, research on metarepresentation in languageless creatures is difficult, and thus the nature of the relationship between metarepresentation and language is unclear. Some basic level of metarepresentation is crucial for language; however, it is conceivable that higher levels are available only due to the linguistic encoding of information (i.e., I can think that "I know that John knows that Adam loves Mary" because I have the words and grammar allowing me to verbalise that thought). It is also possible that our metarepresentational and linguistic abilities developed simultaneously in a process of co-evolution.

\subsubsection{Memory}

Although memory is a fairly basic cognitive ability available to other animals, human memory is probably much more developed. Memory as such is not localisable to any specific brain regions, but it does have a neural implementation. Therefore, we shall assume that its capacity increased over time with the growth of the hominin brain. Similar to the theory of mind, "memory" is a vast category and can be divided into a few different types, each playing an important role in linguistic communication:

- working memory - memory resources used for current cognitive operations, i.e. online processing of stimuli and other mental representations; 
- episodic memory - a memory of specific, personally experienced events;

- lexical-semantic memory - remembering vocabulary and general facts, knowledge not based on personal experience.

While enculturated apes have at their disposal up to several hundred words, ${ }^{50}$ the vocabulary of an average (educated) adult is estimated to contain 50 to 60 thousand words, which illustrates the requirements of speaking a language with regard to lexical-semantic memory. It is possible that semantic memory is shaped by language use, as a result of storing linguistic information. The remaining types of memory can be preliminary conditions for language development.

Working memory is engaged, for instance, in linking sounds to words. If we notice that while speaking fast we produce around twenty phonemes per second, then the motor planning of several seconds of speech requires the processing hundreds of such units in working memory. A similar requirement applies to the conceptual-semantic layer of an utterance - retrieving words from the long-term memory and processing them. Frederick Coolidge and Thomas Wynn (e.g., 2005) propose a hypothesis of the enhanced working memory (EWM), identifying a hypothetical increase in working memory potential in the Homo lineage as an adaptation which was essential for the emergence of language. On the other hand, there is research that indicates that nonhuman apes have an impressive working memory chimpanzees score much better than humans in short-term spatial memory (eidetic memory) tests (Inoue and Matsuzawa, 2007). It is believed that this may be linked with the human specialisation for language, and the fact that ever since childhood working memory resources are devoted to linguistic tasks.

Although it is not formally tied to language, episodic memory could play a decisive role in its emergence. Episodic memory stores information about interactions i.e. a record of relations between people, especially from a firstperson perspective: "How did a given person act toward others and me (and vice versa)". In this way, episodic memory determines such mechanisms as

50 Some dogs are able to understand up to 1000 commands including names of objects (Chaser the dog, see Pilley and Reid, 2011); however unlike words, these are only lexical labels of non-combinatorial nature. 
reciprocity or reputation, which maintain trust. For the reasons we explain in Chapter 5, trust is crucial for language to evolve as a stable cooperative behaviour.

Some researchers claim that the core features of language are based on episodic memory: displacement (Deacon, 2011; Hurford, 2011; Tallerman, 2011) and mental time travel (Corballis, 2014). Comparative studies also tell us about the surprising abilities of animals: for example, some birds of the Corvidae family can store food in numerous, scattered places and find it again after several months (e.g., Emery and Clayton, 2001). Nevertheless, we must remember that like many other cognitive abilities of nonhuman animals, this seems to be limited to one domain. More domain-universal abilities to think of the future and to plan have been documented in nonhuman apes. Wild chimpanzees' practice of sharing the meat of their prey might bear the characteristics of a longterm social investment (Gomes and Boesch, 2009). In turn, in experimental conditions, chimpanzees and orangutans can forfeit a small reward in order to obtain a tool which, after some time and moving to a new place, will enable them to open a box containing a more precious reward (Osvath and Osvath, 2008).

\subsubsection{Executive functions}

Executive function is yet another general term. Although executive functions include other, less complex mechanisms, such as attention, memory, planning or reasoning, in general, they can be defined as higher-order cognitive abilities - abilities which control and coordinate other processes and cognitive resources. Neuroanatomically, executive functions are closely tied to the activity of the frontal lobes, especially to the prefrontal regions which, compared to other brain structures, are larger in hominins (Deacon, 1997).

The relation between executive functions and language is not obvious; nevertheless, we can hypothesise that it is fundamental for the use of symbols. Advanced executive functions imply a good ability for focusing attention and the inhibition of impulsive reactions. Symbolic representation is based on an arbitrary and conventional relation between the lexical label and its referent, and is independent of the sensory characteristics of 
its referent - e.g. the word apple is not red, round, or fragrant. To form such abstract links between the label and the referent, cognitive distancing from the stimulus may be crucial - disabling an automatic reaction, and substituting it with mental processing and focusing on a symbol as an intermediary factor. Research conducted by a team led by Sarah Boysen (1996) is a good example. In her experiment, the reversed contingency task, chimpanzees were given a choice between two symbols known to them, standing for food portions. However, the symbol and its meaning were reversed - the chimpanzee was actually given the portion it did not choose. Doing the task, chimpanzees quickly learnt to point to the symbol standing for the portion they intended to have. Their behaviour was different when instead of symbols of portions, they chose between portions of real food - they kept pointing to the larger portion. Despite numerous trials, due to the proximity of the food on display, the reward kept on influencing chimpanzees' decisions.

\subsection{Summary}

In the $20^{\text {th }}$ century, interest in the origins of language focused on these anatomical features of humans that enable us to produce articulated sounds. It seems that the elements of the human vocal apparatus, and the auditory apparatus to a lesser extent, show characteristics of advanced adaptations for communication in the vocal channel. Later research shows a greater awareness that cognitive preadaptations, such as mimesis, theory of mind, metarepresentation, memory and executive functions are more relevant to language. Currently, more and more attention is being devoted to adaptations of a socio-cognitive nature, with particular focus on the problem of cooperation. The next chapter will be dedicated to this topic. 


\section{Chapter 5 Cooperative Foundations: An Essential Requirement for Language}

Why don't apes use language? Comparative psychologists continue to surprise us with discoveries of ape behaviours that were thought to be exclusively human. The similarities are vivid, but stop at the "Rubicon" described by Müller and Descartes - the ability to talk. An intuitive view identifies anatomical differences as a reason - most importantly the differences in the construction of the vocal apparatus. It is clear from our discussion so far that such an explanation is completely wrong. More recent proposals have focussed on the supposed human uniqueness of the cognitive preadaptations for language use - the "cognitive infrastructure" (see Chapter 4). Currently, however, social factors have been gaining considerable attention, and "the greatest mystery" of the evolutionary origin of language is the cooperative information sharing (Fitch, 2010: 417). ${ }^{51}$

The easiest, and the best, answer to the question "Why don't apes speak?" may well be "Because it does not pay". An ape could inform another ape about the location of food, but it would be a better idea to lie to the other ape so that it goes away and the first ape could enjoy the food alone. If there exists a risk of manipulation that cannot be detected easily, ignoring such uncertain information seems a much better strategy. This aspect is easy to overlook since as humans we do not think twice about it - we are accustomed to the principle of trust that our society and communication are driven by. In linguistic and non-linguistic interactions, we assume reciprocity - "I will tell you the location of the food, and later you will help me back by telling me which plants are edible" - whereas lying is condemned or punished. Human societies are founded on an invisible platform of trust. We take it for granted, but without it, linguistic communication cannot function properly because words would become the equivalents of credit

51 The terms "cooperation" and "honesty" are used interchangeably here - the reason is given later. 
cards in a world devoid of trade, banks, transactions and prisons for forgers (cf. Dor et al. 2014: 4; Dor et al. 2014: 12).

The explanation of the evolution of this cooperative infrastructure is a central issue in language evolution research (Fitch, 2010; Hurford, 2007; Tomasello, 2008). By “cooperative infrastructure" we mean a whole range of closely related features or behavioural dispositions, mechanisms and phenomena, such as prosociality, trust, fairness, cooperation and in the broader sense even normativeness, reciprocity, reputation or morality. Later in this chapter, we provide a theoretical framework in which this can be discussed.

\subsection{Signalling theory ${ }^{52}$}

For a linguist, a standard starting point for a discussion on linguistic cooperation is the work of H. P. Grice, particularly his article "Logic and Conversation" ([1975] 1999). According to Grice, conversation - or broadly speaking, any linguistic interaction - is a thoroughly cooperative activity since it is based on an understatement. Conversants, to grasp the meaning of an utterance, must use inference - in Gricean terms conversational implicature. Therefore, it is crucial for the sender to formulate utterances in a way facilitating the receiver's comprehension. Grice stresses that compliance with the norm, which is essential to what he terms the cooperative priniciple $(\mathrm{CP})$, lies in the common interest of the interlocutors as it enables mutual understanding between them. Furthermore, they can achieve the goals they planned to achieve by means of a conversation. More specifically, the cooperation principle requires the participants to follow conversational maxims of quality, quantity, relation and manner; Grice (1999 [1975]: 70) writes:

I would like to be able to think of the standard type of conversational practice not merely as something that all or most do IN FACT follow but as something that it is REASONABLE for us to follow, that we SHOULD NOT abandon ... So I would like to be able to show that observance of the $\mathrm{CP}$ [cooperative principle] and maxims is reasonable (rational) along the following lines: that anyone who cares about goals that are central to conversation/communication (e.g. giving and receiving information, influencing and being influenced by others) must be

52 Explanations given in this and in the following section elaborate on the argumentation presented in Wacewicz and Żywiczyński, 2011. 
expected to have an interest, given suitable circumstances, in participation in talk exchanges that will be profitable only on the assumption that they are conducted in general accordance with the $\mathrm{CP}$ and the maxims.

Grice's works were a turning point, but the British philosopher only formally established an intuition that was obvious to any language user. Ruling out special cases such as sarcasm or poetry, we generally use language which is comprehensible when we are talking to each other, and we do not typically lie or expect to be lied to. We do not require our interlocutor to present hard evidence for the veracity of each sentence or each word she or he utters. It is difficult to imagine such a situation, as the abovementioned requirements make normal communication impossible. The honest and cooperative character of language must be assumed from the outset as its fundamental value.

Cooperation is natural and obvious in language as it exists now, but from a language origins perspective it becomes an explanatory goal. When we try to account for the origins of language, a general model for communication constitutes a starting point, one that successfully explains communication in animals in general ${ }^{53}$ : a naturalistic model or even a cynical model of communication. John Krebs and Richard Dawkins (1984), were the first to show that organisms do not communicate to provide others with information, but - in accordance with the predictions of the evolution through natural selection - to pursue their own goals. Communication is therefore a game between the actor and the reactor, in which each of the participants wants to maximise their payoff. ${ }^{54}$ Communication is "a process in which the actors use pre-designed signals and actions to modify the behaviour of the reactors" (Krebs and Davies, 1993), and takes place when "the action or cue given by one organism is perceived and changes the probability

53 "Signal evolution theory is the main body of theory applied to animal communication. So it is axiomatic that any scientific study of the evolution of language adopts this theoretical approach as starting point. To argue that the evolution of language is a special case to which signalling theory does not apply, we have to explain why not, within that theory's terms." (Power, 2014a: 50)

54 "Payoff" here is understood in the context of game theory. With regard to the evolution of behaviour by means of natural selection, we must keep in mind that the ultimate "currency" all the benefits and costs are translated into is reproductive success, or more broadly: fitness. 
distribution of the behaviour of the other organism in a way which is adaptive to one or both the organisms" (Wilson, 1975). To be more "cynical", "a signal is a way in which one organism (an actor) uses the muscle work of another organism (a reactor)" (Krebs and Dawkins, 1984: 380-381).

\subsection{The evolutionary stability of communication}

To explain the consequences of such an approach to the evolution of language, we shall briefly return to the basic logic behind evolution described in Chapter 2 (see also: the description of behavioural ecology in Box 2.7). The first step of the evolution-by-selection cycle is mutation which provides diversity - it enriches the gene pool with new alleles. These genes, even though they do not encode particular behaviours directly, have an indirect and statistical influence on the phenotype, including the tendency of an organism towards particular behaviours or behavioural strategies. Selection is the next step - the genes of some organisms are transmitted to the next generation in greater or smaller numbers. As a result of selection, those genes which encode beneficial strategies will gradually increase in the gene pool. According to evolutionary logic, only those strategies can survive that maximise payoffs - the best benefit-to-cost ratio in the context of how successful an organism is at passing its genes. The reproductive success of the individuals that follow a substandard strategy is below the population average, which means that natural selection acts to gradually eliminate their genes from the gene pool of the population; this in turn means the gradual elimination of the strategy itself from the population's behavioural repertoire. In contrast, a successful strategy is by definition a strategy that grants those who adopt it a greater genetic success, leading to its gradual expansion in the population. A strategy that - once adopted by the majority of individuals in the population - is impossible to be replaced by a different strategy goes by the name of evolutionarily stable strategy (ESS).

If we consider cooperative strategies, it becomes clear that they include an element of altruism, where altruism is defined as any action taken by an organism where that organism pays a cost so that another organism can benefit from it. In other words, cooperation is achieved via altruism, as this is how cooperation starts: first, one of the organisms helps the other organism and pays some cost to do this. The problem arises because the 
other organism may not reciprocate that help. Paying costs to reciprocate the help is not an EES - it can be easily superseded by a competing strategy of non-reciprocity, a more cost-effective strategy for an organism: bringing the organism and its genes a greater reproductive success. Similarly, helping, or paying costs which may not pay dividends, is not evolutionarily stable. In this way ${ }^{55}$ evolutionary game theory explains what is documented in the ethological data: both altruism and cooperation occur in nature only rarely and require special conditions.

A key element of the reasoning behind this idea, is that honest communication can be conceptualised as a form of cooperation, at least to the extent to which it is evolutionarily unstable and, analogically, can be superseded by competitive strategies. Volitional communication starts with signal production, which entails some cost each time. The cost may turn out to be a piece of valuable information about the location of food supplies, or the risk of drawing the attention of predators. Even if the cost of producing a signal is just a small amount of time, attention or energy, as is the case in linguistic communication, such behaviour is more costly than the alternative - no signal and thus no cost at all. As a result, natural selection will act to eliminate such a strategy for as long as the costs of signal production outweigh the benefits. In the case of language, reciprocated communication could be the benefit - if I give you a valuable piece of information, I can expect that, later on, you will also provide me with a valuable clue. Nevertheless, in the same way as was the case for cooperation, there is no motivation for reciprocity, since it is the competing strategy that leads to better fitness: "reap the rewards of communication, but don't pay the costs of reciprocation".

If we take into consideration the evolutionary stability of communication, we encounter another serious issue: the stability of the honest strategy is threatened with its alternative - lying ${ }^{56}$. The strategy "Rather than signalling truthfully, manipulate the receiver to your own advantage" brings

55 This is a simplification of a widely discussed problem in game theory, illustrated usually by the prisoner's dilemma game; see, for example, Axelrod, 1984.

56 "Honesty" and "lying" are treated metaphorically here. They refer very broadly to conscious and unconscious communicative strategies, including behavioural signals as well as morphological features of an organism. 
greater profit, and hence translates into better fitness and reproductive success, and will spread more rapidly in the population than the competing strategy of being "honest". The possibility of lying is yet another selection pressure acting on the receivers of the message. Those who are manipulated by such signals and, as a result, act against their own interest, have a lower reproductive success. This leads to the elimination of their genes from the gene pool of subsequent populations and, together with the genes, to the elimination of the strategy to "believe" signals. If there are no receivers, sending any messages becomes pointless. If the credibility of a signal cannot be assessed easily and properly, communication will stop.

\subsection{How to ensure the honesty of communication?}

Contrary to the above predictions, communication not only exists in nature, but is ubiquitous. Hence, there must be mechanisms which ensure the honesty of communication, or at least stabilise it evolutionarily, protectingboth the strategy of sending and the strategy of receiving messages. Generally speaking, there are three types of such mechanisms (see Scott-Phillips, 2008):

- indexicality (indexes),

- handicaps, and

- a pre-existing platform of cooperation, i.e. when the communicating organisms work towards common evolutionary goals.

Indexicality is a correlation between the form of the signal and its "meaning". An indexical signal cannot be "forged" due to the physical or morphological constraints. For instance, the frequency F0 of a bellowing deer will quite directly inform about its size because this particular frequency is a simple function of the size of the resonators, and its further decrease is physically impossible when maintaining the same body size. Conversation provides us with rich and interesting indexical information: paralinguistic features of an utterance inform us about the sex, age, or health condition of the interlocutor (whereas a young and fit person can pretend to be an elderly or an ill person, the converse will not work). The propositional content of an utterance, however, is not indexical.

Handicap, a concept proposed by Amotz Zahavi (1975), stresses the second source of the honesty of signals - their cost. This intuition can be 
expressed by distinguishing the basic cost of signal, i.e. one that is necessary for its production (efficacy cost), and from strategic cost, an extra cost that animal pays in addition to the efficacy cost as a warranty that the signal is honest (e.g., Maynard Smith and Harper, 2003). Particularly in the signalling of one's biological quality (e.g., in male displays in courtship), individuals of a better quality can pay costs that the lower quality individuals cannot afford. A peacock's tail is a classic example, although there are also a wealth of behavioural signals, such as stotting in Thomson's gazelles, which requires so much energy that only healthy individuals can afford to perform it. The differences between indices and handicaps is not obvious and hence it has become the subject of a theoretical debate (see e.g., Maynard Smith and Harper, 2003: 60-63). For our purposes, it is most important to state that linguistic signals are cheap and arbitrary - they are not grounded in either handicaps or indices.

A system of honest communication can emerge on the basis of preexisting cooperation or, more generally, when the evolutionary goals of the interacting animals are well aligned, so that manipulation is pointless. In nature, kinship is the most common basis for such cooperation - using a dishonest strategy towards relatives would not make sense from the perspective of kin selection (see 2.1.2), since by deceiving our genetic kin we would act against our own genetic interest. For this reason, the system of bee communication is not vulnerable to manipulation and is highly efficient. The general honesty of alarm calls is typically explained by reference to kin selection (see. 2.1.2).

Apart from the common genetic interest of a group of organisms, that is the strength of kinship, there are a range of ancillary mechanisms that can stabilise cooperation, especially “the four R's” of relatedness, reciprocity, reputation, retribution; (see e.g. Dugatkin, 2002). ${ }^{57}$ Evolutionarily inspired research on the emergence of human cooperation has become a very broad and intensively developing research field. The problem of cooperation is currently viewed from such perspectives as phenomenology or behaviourism, and studied with a broad scope of research methods - from

57 The role of group selection is also possible; however, the theoretical status of its mechanism is controversial (see 2.5.4). 
theoretical (e.g., West et al., 2011), to experimental (mainly in the social dilemma paradigm, e.g. Ledyard, 1995), to mathematical and computational modelling (e.g. Nowak, 2006). The volume of recent research on this topic is overwhelming (e.g., Henrich and Henrich, 2007; Hrdy, 2009; Tomasello, 2009; Bowles and Gintis, 2011; Sterelny, 2012). In the following section, we discuss only a selection of scenarios of the emergence of human cooperation, and here we limit ourselves to two chief claims.

Firstly, with the exception of humans, it is very difficult to find welldocumented and uncontroversial cases of stable cooperation in nature that would not be readily explained by a cost-benefit analysis, such as by referring to mutualism or symbiosis, or kin selection (see West et al., 2011). Cooperation based on reciprocal altruism does appear to exist in nature, but equally, it appears to be very rare (Clutton-Brock, 2009).

Secondly, the mechanisms identified as stabilising cooperation largely depend on language. In principle, language is not absolutely necessary for the existence of punishment, reciprocity, or even basic forms of reputation (e.g., forming an opinion about others based on direct observation of their behaviour). However, language is a tool that greatly amplifies the potential of each of these mechanisms, for example, by means of gossip that is connected with reputation (Dunbar, 1996), or the codification of norms against non-cooperative behaviours. It is language that makes it possible to inform others about dishonest individuals or to set up legal consequences for breaking contracts. Consequently, language makes it possible to place additional costs on those that behave uncooperatively, which often makes cooperation the more rather than the less profitable option. Finally, we should remember about the usefulness of language in coordinating the actions of many people, and at the same time forming a foundation for organised cooperation - large-scale cooperative action that generates a very large pool of benefits to the entire group (see Gärdenfors, 2002)

\subsection{The sources of human cooperativeness}

Due to the uniqueness of human communication, which is based on cheap signals and not limited to genetically related individuals, its development must have been preceded by the appearance of the norms of cooperation. It is easy to imagine that the emergence of language stabilised the function 
of such norms, but if we are to take seriously the arguments of signalling theory, it would be hard to imagine that any language-like communication could have developed in a population where cooperation is not rooted in norms. The history of the evolutionary emergence of language is closely linked with the history of the emergence of cooperation.

Although the cognitive abilities of great apes (e.g., understanding the laws of physics) are comparable to the abilities of three-year-old children, (Herrmann et al., 2007), and can even exceed the abilities of human adults in some areas (Inoue and Matsuzawa, 2007), humans differ qualitatively from them in terms of cooperative communication. "Nonhuman primates do not point to distal entities in their environments, they do not hold up objects for others to see and share, and they do not actively give or offer objects to other individuals. They also do not actively teach one another..." (Tomasello, 2000: 358). Apes have problems with understanding the informative function of pointing (Tomasello et al., 1997) - the fact explained as the result of a lack of a cooperative basis for communication. In one experiment chimpanzees ignored the researcher who cooperatively pointed at places where food was hidden; however, they used similar information in a competitive context, when the researcher did not want to inform anyone about anything but simply tried to grab the food for herself (Hare and Tomasello, 2004). In contrast, human infants as early as in the twelfth month of life present a motivation for a spontaneous, informative pointing aimed at sharing attention with another person (Liszkowski et al., 2004). This disposition for cooperative communication is visible even in the unique human morphology - the human sclera is believed to be white because of its cooperative function whereby we can precisely assess the direction of another person's gaze (cooperative eye hypothesis - Kobayashi and Kohshima, 1997; 2001).

There have been numerous attempts to explain the way human-specific, or, more broadly, prosocial cooperative behaviours develop. We discuss what we think are the four most important hypotheses (see also Zlatev, 2014b).

We have already critically discussed Robin Dunbar's idea that language evolved as a substitute mechanism of vocal grooming. Here, we refer to the key concept of the social brain hypothesis - the idea that the size of the brain, and especially the neocortex, is correlated with the group size 
(see 4.3). The pressure that, according to Dunbar, was to cause a change in the group size, and hence encephalisation, was the necessity of living on the savannah, where, for example, defence against predators forced hominins to form large groups. This must have changed the rules of social life, in the direction of counter dominance. Pawłowski et al. (1998) have made an important observation that among the primate species, greater corticalisation means a weaker correlation between the social status and the reproductive success of the male. This means that the species which have a larger neocortex succeed in the use of Machiavellian strategies to prevent the dominant males from monopolising access to fertile females; as a result, the reproductive success of all males in a group is distributed more evenly. Along with this decrease in the reproductive "reward" for domination, motivation to fight for status also diminishes. In hominin groups, the mechanism of reverse domination might have been strengthened as the whole group maintained its egalitarianism, monitoring the actions of the leaders and actively counteracting the excessive growth of their status. Egalitarianism weakens competitiveness between individuals in the group, which facilitates the emergence of cooperation.

Camilla Power and Chris Knight stress that this level of cooperation might have been stabilised by expensive signals such as taking part in rituals, which prevail as forms of religious activity of contemporary huntersgatherers (e.g., Power, 2014b; Knight, 2014). On the other hand, Terrence Deacon proposes marriage contracts as a possible scenario for the development of normative prosocial behaviours, as well as symbolic ones (Deacon, 1997). The growing brain must have led to increasingly dependent offspring who needed more parental investment and whose adolescence was prolonged. At some point, this selective pressure became so important that it began to favour the father's investment. If fathers got involved in childcare and other types of investment (providing high-protein food for the child and the mother), they would be subjected to a very strong selective pressure connected with paternal certainty to avoid supporting genetically unrelated children. This could result in increasingly monogamous societies in which the permanence of relations would lead to marriage contracts - a blueprint for other social contracts.

Arguments that refer to the social brain hypothesis and the principle of reverse domination emphasise the role the mechanism of sexual selection 
plays in the emergence of cooperation in humans. Hrdy and Fitch argue that at least a rudimentary level of cooperation in hominins was shaped by kin selection. As noted earlier, Hamilton's kin selection is a standard way of accounting for altruistic cooperation in closely related organisms, such as eusocial insects (see 2.1.2). Both Hrdy (2009) and Fitch (2010) draw attention to the fact that the reproductive model present in humans differs significantly from the scheme found in non-human great apes. Bipedalism itself complicated labour - the human pelvis changed due to the new style of locomotion, and hence the birth canal became narrower (see 4.3). Problems associated with childbirth and the postpartum period increased due to the growing encephalisation - mothers had to give birth to heavier children with larger heads. These changes are likely to have influenced parental care. The erect posture and progressive loss of prehensile feet caused problems to mothers who could no longer carry infants on their backs (as apes do); and it was also increasingly difficult for children to cling to their mothers (Falk, 2004). This caused problems especially during foraging, when mothers had to set the children aside. According to Fitch, who cites research on mother-child communication in modern humans (e.g., Fernald, 1992; Dissanayake, 2000; Falk, 2004), this was the context in which first musical forms of communication emerged (see 3.4), the honesty of which was stabilised by the genetic relationship between the mother and the child (Fitch, 2010: 492-494).

Hrdy emphasises the model of parental care. In non-human great apes orangutans, gorillas, and chimpanzees - it is only mothers who care for their children and protect them against abduction or injury. The human childcare system is unique among apes in this respect as it enables cooperative breeding or alloparenting, in which care is provided by the mother and her closest relatives, most often a grandmother or aunts. Hrdy argues that a prolonged period of altriciality - crucial for cognitive and social development - reduced mutual distrust in females and helped the emergence of the model of cooperative breeding, which became a blueprint for the development of other prosocial behaviours. She points to the presence of the phenomenon of cooperative breeding of the young in numerous monkey species, such as capuchin monkeys, though not in great apes, who have bigger brains (Hrdy, 2009). She suggests that combining the advanced cognitive abilities of great apes with cooperative breeding present in monkeys may have paved the way for uniquely human socio-cognitive architecture. 
Writing about the evolution of cooperation and the emergence of communication based on it, Michael Tomasello refers to numerous comparative studies on children and chimpanzees, many of them conducted by his team in the Max Planck Institute for Evolutionary Anthropology in Leipzig. Tomasello's starting point is the view that both language and prosociality characteristic of humans are the result of a cognitive adaptation which Tomasello terms shared intentionality (1999, 2008; Tomasello et al., 2012). This refers to the ability to take part in mutual or group activities, often long-term and complicated, which aim to achieve a common goal and in which each participant plays a specific role. At the ontogenetic level, the first sign of such a form of intentionality is joint attention, that is co-participation in the act of perception. Tomasello suggests that a change of ecological niche forced hominins to collaborate in the search for food. The mutual benefits each participant gained from the coordination of actions paved the way for cognitive changes which brought about the system of shared intentionality, as well as social changes which led to the emergence of a new norm - sharing honest and valuable information.

\subsection{Summary}

We do not favour any of the hypotheses presented above. It is easy to imagine a mosaic (see 3.3.2) pattern of the evolution of cooperation in which, for example, reversed domination, alloparenting and mutualistic collaborative foraging all played a prominent role. At the same time, through a positive feedback loop, the emerging cooperation is likely to have been stabilised by a broad range of ancillary mechanisms partly dependent on cooperative communication, such as reputation, customs, codified norms, ceremonies and rituals. In any case, as we have already mentioned, the existence of cooperation, and in particular the existence of norms of sharing honest information, is crucial for explaining how language evolved. 


\section{Chapter 6 The Problem of Modality Transition in Gestural Primacy Hypothesis}

In the final part of our work, we propose a study devoted to a specific problem in the field of language evolution, which is associated with the gestural primacy hypothesis. In this chapter, we present a summary of a wide range of arguments currently advanced for and against this position, supplying them with commentary and our own arguments. In addition to familiarising the reader with the details of this interesting proposal, this chapter will serve as an illustration of how research is conducted in the modern-day evolution of language.

The gestural primacy hypothesis, or simply the gestural hypothesis, occupies a central position in current reflections on the appearance and evolution of linguistic abilities. According to these theories, language phylogenetically derives from a gestural communication system, not a vocal one (the latter possibility is more intuitive, and hence many authors erroneously claim the vocal proposal to be unproblematic). We propose a wide definition of gestures here, including most of bodily signals produced or received in the visual modality. Many studies on this subject point to their fundamental problem: if language was originally gestural, why, when and how did the change or the transition of language to the vocal modality occur? So far, this problem has not found a satisfactory solution. In this chapter, firstly, we bring the topic closer to the reader, briefly discussing the arguments for gestural hypotheses, and secondly, we propose solutions to the problem of the modality transition. In essence, they boil down to the adoption of a multimodal perspective, which assumes that the evolution of language occurred with the participation of both modalities - the visual and the vocal. This assumption allows not only to solve the problem of the modality transition, which is problematic for the gestural primacy theories, but also explains the deep integration of speech and gestures embodying the human language ability. 


\subsection{Gestural primacy hypotheses in language evolution}

According to gestural primacy hypotheses, sometimes referred to as gestural $^{58}$, language phylogenetically stems from a gestural form of communication conveyed in the visual modality. Here, we adopt a broad definition of gesture operating (see 6.2.2). In an obvious way, these explanations of language origin compete with vocal-auditory hypotheses, which trace the beginnings of language to non-linguistic vocalisations (e.g. Burling, 2005; Dunbar, 1998; Mithen, 2005; MacNeilage, 2008). Vocal hypotheses are usually based on an intuitive assumption that the development of human communication from the original to its current language form was shaped entirely by the vocal modality. Although this assumption is somewhat natural, and hence, erroneously, often taken for granted. Especially in the popular thinking about language origins, conducted without a thorough knowledge of the subject, possibilities other than a vocal development of language are neglected (e.g. Kenneally, 2007). Such an attitude is often related to the lack of awareness concerning the status of sign language as fully fledged language (see 6.4.2); for example, Charles Hockett's influential proposal for the design features of language (see Box 3.3) focus on speech to the excluded of the gestural modality of linguistic expression.

Gestural scenarios of language origin have been considered by many authors, who represent both speculative philosophising and contemporary science. There are several types of gestural primacy hypotheses, differing in descriptions of gestural and vocal communication and the postulated level of organisation of the gestural system. These types include:

- gesture-before-speech hypotheses

- gestural protolanguage hypotheses

Broadly speaking, gestural hypotheses also embrace:

- gesture and speech hypotheses

58 Such terms as "the gestural primacy hypothesis" (GPH); gestural hypotheses; gesture-first hypotheses; from hand to mouth; language from gesture are all present in the literature; gesture together with speech falls into this category as well. 
Gesture-before-speech hypotheses (e.g. Corballis, 2002; Stokoe, 2001) assume that gestural language emerged before spoken one. Although these authors do not rule out the role of vocalisation in language emergence, they highlight that its function was limited to transmission of nonverbal information, such as emotions.

Gestural protolanguage hypotheses, in turn, assume that protolinguistic communication, before vocal language emerged, had relied mainly on gestures functioning as isolated signs devoid of syntax. Gestural primacy hypotheses come in two varieties:

o synthetic gestural protolanguage - gestures stand for words and represent their referents (objects or actions) that can be combined into short compositional strings (whereby the meaning of the whole string results from the meaning of its components), but they lack a syntactic or morphological structure (e.g. Hewes, 1973)

o holistic gestural protolanguage - gestures are equivalent to the whole utterance, representing complex thoughts or situations, e.g. "I am hungry" (Arbib, 2005).

Gesture and speech hypotheses focus on the close link between speech and gesture in the course of a linguistic expression. They assume that language development always engaged both modalities: the vocal and the visual (e.g. Goldin-Meadow, 2011; McNeill, 2012; Kendon, 1991). We discuss this problem in detail in Sections 6.5 and 6.6.

In spite of the differences between all these approaches, they are viewed jointly at this stage of our discussion. The importance of the gestural component is crucial to all them in opposition to the intuitive assumption about the dominance of the vocal-auditory channel in the evolutionary history of language. Here, we do not discuss the arguments for gestural hypotheses extensively (for more see Corballis 2002; Armstrong and Wilcox, 2007; Fitch, 2010) but reviews them only briefly in Sections 6.3.2 and 6.3.3. Our primary goal is an attempt at solving the core problem of most gestural hypotheses - the problem of modality transition described in Section 6.4, which could be formulated in the following way: if language originated as a system of mainly gestural expression, how can we account for its transition to the current, mainly vocal form? 


\subsection{Defining gestures}

A unilateral and theoretically neutral definition of gesture is problematic due to the multiple meanings of the term - both colloquial and technical. Broadly speaking, gestures comprise every expressive movement of motivated by emotion or thought, performed by means of any part of the body (Oxford English Dictionary, after: Kendon, 2004), including facial expression and eye movements. Kendon (2004) narrows down the scope of this definition and proposes that only those actions that can be interpreted as volitional and intentionally expressive rather than serving any other purpose (e.g. pragmatic ones) should be termed gestures. Then, under a very strict definition, the term gesture is reserved for idiosyncratic and spontaneous hand and arm movements synchronised with speech (McNeill, 1992). Some authors understand gestures as including instrumental actions (oriented towards physical objects) such as hand grasping (see Fogassi and Ferrari, 2004). Interestingly, the articulatory movements are sometimes classified as gestures as well (which we discuss in detail in Section 6.5.5).

Gestures do not solely belong to the domain of human communication. Importantly for language evolution studies, non-human great Aapes use this form of communication, (de Waal and Pollick, 2011; Pika et al., Pollick and de Waal, 2007; Tomasello, 2008), as well as more distantly related to us Old World monkeys (Maestripieri, 2007; Meguerditchian et al., 2011). Below, we compare two different perspectives on defining gestures: the interpersonal communication perspective and the primatological perspective.

\subsubsection{Gestures in interpersonal communication}

Gestures are an integral part of human communication. Due to a number of forms they assume and functions they perform (Goldin-Meadow, 2003), it is not easy to classify them into distinct categories. One of the most influential description of gestural behaviours - the gesture continuum - comes from McNeill (1992; 2005; 2012). Gestures are here placed on the continuum of behaviours:

gesticulation — speech-linked — pantomime - emblems/deictics — sign languages 
The continuum is arranged with respect to three criteria: 1) the amount of speech component decreases (from the left to the right side of the continuum; 2) the amount of lingusitc features increases; 3 ) the level of gesture conventionalisation increases.

The term gesticulation refers to the hand and arm movements accompanying speech (Kendon, 2004). However, although such movements are closely connected to speaking, they do not show any linguistic systematicity. Their spontaneous form stems from an ongoing coupling with the meanings expressed by words. Gesticulation is not a uniform category, and although various authors classify gestures differently (see Ekman and Friesen, 1969a, b; Krauss et al., 2000), we can distinguish the most frequently ocurring types:

- iconics - resemble the semantic content of an utterance by representing specific objects or actions;

- metaphorics - similar to iconic gestures; however, they represent more abstract concepts or ideas;

- beats - involve rhythmical movements of the arms - up/down, front/ back, or left/right; they do not have semantic relation to the content of speech but are synchronised with its rhythm;

- deictics (pointing) - their main function is pointing to objects that are part the context of a communicative situation. Due to their structure and function, they may constitute a separate category, but along with emblems, they may also classified as gesticulations.

Language-slotted gestures bear a strong similarity to gesticulations but differ in the syntagmatic relationship they have with words. Let's look at the following example: "the weather was good, but the food [hand wave]". The gesture completes the sentence and fills in the syntactically blank slot, which appears as a result of the omission of the predicate. Pantomime, on the other hand, has a completely different character - by definition, pantomime cannot be accompanied by speech. Pantomime typically uses a string of gestures to narrate an event. Although it is characterised by a sequential organisation of signs, it is devoid of syntactic properties. Next, the main function of emblems is replacing individual words. In their gestural repertoire, each culture or society has a set of emblems that are characterised by arbitrariness and conventionality - specific rules governing their use (in 
analogy to the phonological rules in language), intentionality ${ }^{59}$, and cultural transmission. An example of a Polish emblem is the "OK" gesture - raising the arm, putting the tip of the thumb and the tip of the index finger against each other, with the rest of the fingers directed upwards. Emblems have some properties characteristic of linguistic signs, but they are used as individual signals transferring short messages. Signs of sign languages occupy the right extreme of McNeill's gesture continuum. Sign languages have all the features of language systems, and the categorial difference between them and spoken languages is the modality - vocal-auditory for speech and motor-visual for gesture (see Section 6.4.2.) It should further be stressed that despite the common intuition, signs of sign languages constitute a system that is completely different from gesticulation not only in terms of its formal and communicative features, but also cortical localisation.

The above account situates gestures in the context of interpersonal communication, related to specific cognitive abilities, social structure, and spoken language. Defining gestures in other contexts, e.g. primate communication, requires consideration of different conditions. Below, we present selected definitions and typologies of gesture derived from primatological research.

\subsubsection{Gestures in nonhuman primates' communication}

Although primates use various means of communication, their gesture use has evoked a particular interest of researchers. Gestures differ from other communicative behaviours (de Waal and Pollick, 2011; Pollick and de Waal, 2007; Tomasello, 2008) in that they involve:

- acquisition by individual learning,

- intentional use and plasticity,

- relative independence from emotions,

- receiver-directedness.

Gestural communication based on ritualised behaviours is present mainly in nonhuman Great Apes, which suggests a phylogenetically late emergence of this form of communication (de Waal and Pollick, 2011).

59 Here and later in the text we use the term intentional in the psychological sense: "deliberate", "resulting from the intention of the subject" - not in the philosophical sense: "having intentional content", "presenting something". 
Comparative studies on gestural communication of nonhuman Great Apes (bonobos, Pan paniscus; chimpanzees, Pan troglodytes; gorillas, Gorilla gorilla; orangutans, Pongo pygmaeus) show that their gestures resemble (to an extent) gestures of infants and toddlers who are right at the beginning of language acquisition (Pika and Liebal, 2006). Similarities concern diversification of gestural repertoire and its intentional use in both groups. Differences are connected with the nature of gestures and the way they can be used: the majority of gestures in nonhuman primates are of dyadic character - the sender drawing the receiver's attention expresses a wish (the imperative gesture use); children, on the other hand, can use gestures triadically - they direct the receiver's attention to an external event or object in order to share attention or comment upon the common object of attention (the declarative gesture use). These differences stem, among others, from different cognitive bases (the "socio-cognitive abilities" see Tomasello, 2008; see 4.4 and 5.4 in this work) in humans and nonhuman primates. Furthermore, they shed light on the problem of language origins and the nature of interpersonal communication.

Primatologists studying the communicative behaviours of nonhuman primates devised a few gesture classifications. De Waal and Pollick (2011; as well as Pollick and de Waal, 2007) proposed to limit the term gesture to manual movements, which exhibit features different from other communicative movements (see: gesture characteristics, above). Tomasello (2008) characterised gestures broadly as intentional communicative behaviours executed in the visual modality, including body posture, facial expression and manual gestures, characterised by flexibility, and acquired by means of ontogenetic ritualisation. Pika (2008) proposes a slightly different definition - she understands gestures as expressive movements of the limbs, head and whole body, which:

- are receiver-directed;

- lack mechanical effects - such as pushing someone - which differentiates gestures from instrumental movements, the goal of which is other than communication $^{60}$;

60 The difficulty arises as the criterion inhibits the recognition of an important gesture class - touch gestures - which require some mechanical contact with the receiver. 
- provoke a particular answer;

- are performed intentionally (deliberately).

Intentionality is a crucial criterion in the aforementioned definitions. It enables the differentiation of gestural behaviours from other communicative behaviours of intrinsic, and hence, non-intentional character, which take many different forms in animal communication (Tinbergen, 1951). The intentionality of gestures is established by the following criteria:

- relative context-independence-the same gesture is used to attain different communicative goals, and different communicative goals are attained by the same gesture (de Waal and Pollick, 2011; Tomasello, 2008),

- audience-checking,

- response-waiting, and

- persistence.

As the problem of the sensory modality is key to our discussion, we adopt Simone Pika's (2008) gesture typology, which is largely modality-based. She distinguishes the following gesture types:

- auditory gestures - accompanied by sound production, e.g. hand clapping or chest-beating in gorillas;

- touch-side gestures - involve physical contact between the producer and the receiver, (e.g. a directed scratch in chimpanzees - the first referential gesture discovered in wild Great Apes) (see Pika and Mitani, 2009);

- visual gestures - engage only the visual modality.

In our work, we adopt a broad definition of gestures. We start with an intuitive understanding of gestures as intentional, communicative and hence non-instrumental hand and arm movements, but we extend the definition to the majority of bodily signals operating in the visual modality.

The prototypical examples of gestures are the movements of the arms, hands and fingers performed to transfer information. More peripheral examples embrace a variety of visual signals, such as proxemic behaviours, body postures and positions, intentionally executed facial expressions or even gaze patterns. Speech-related articulatory movements, although they may constitute a continuum with the movements mentioned above, especially facial expressions, are included in the gesture repertoire only if they can be perceived visually. 


\subsection{Arguments in favour of the gestural primacy hypotheses}

The first speculations on the role of gestures in language evolution appeared long before the idea became an object of science. It was not until the 1970 s that the gestural primacy hypothesis was based on more extensive empirical foundations. Currently, its numerous versions jointly constitute the most influential proposal in the discussion on the phylogeny of language. In the present section we outline the history of gestural hypotheses and summarise the most important evidence supporting them.

\subsubsection{Gesture and language origin - a brief historical background}

For many centuries - from antiquity to the $18^{\text {th }}$ century - it was commonly believed that gestures are a natural form of human communication and constitute an autonomous language common to all humans, as described in detail in the first chapter. The problem of gestures also appeared in historical speculations about the origin of language (a detailed reconstruction in Chapter 1). Condillac (1715-1780) assumed that before people learned to use speech, they communicated with each other through gestures and movements of the body. The priority of gestures was also postulated by Giambattista Vico (1688-1744), who perceived them as the most perfect way of depicting visual images. Edward Tylor (1832-1917) emphasised the multiplicity of communication modes, including gestural languages, pictograms and written language, at the same time postulating that studies of gestures and pictorial writing can be of help in the understanding of the beginnings of language. Wilhelm Wundt (1832-1920) sought the beginnings of language in the basic expressive movements that are different for different emotional experiences. In the first half of the $20^{\text {th }}$ century, the interest in similar problems weakened, but in the early 1970s a change took place, which marked the beginning of the contemporary debate on the role of gestures in the evolution of language.

\subsubsection{Hewes's position and the revival of concern with gesture in language evolution}

The modern hypothesis of gestural primacy was formulated by the American anthropologist Godron W. Hewes, already mentioned in 3.1.1, 
and whose arguments in favour of the gestural primacy hypothesis will be discussed in detail. In 1973, Hewes published a paper entitled "Primate Communication and the Gestural Origin of Language". The article is a synthesis of data coming from various fields of research and lays out a range of arguments supporting the gestural scenario of language emergence. Some of his arguments are still used in the ongoing debate on language evolution (see Corballis, 2002; Tomasello, 2008), whereas others have either been updated (in line with the newest research) or rejected. In the following section, we look at the most important arguments from Hewes's original proposal.

As already mentioned, Hewes's main argument focused relative successes in teaching nonhuman Apes a variation of sign language (Gardner and Gardner, 1969; see 3.1.1 and 3.1.3 Primate research), which contrasted with complete failure of many attempts to teach them spoken language. It can therefore be assumed that early hominins, whose cognitive abilities must have been much like those of modern nonhuman apes, were capable of creating a gestural protolanguage ${ }^{61}$. We must assume that although early hominins, just as other primates, used vocal communication, this system can not have been the starting point for the development of linguistic communication, which is arbitrary, compositional, etc. The main problem for such a scenario was lack of full volitional control over vocalisations (vocal apparatus). Based on the research available at that time, Hewes noticed that vocalisations of nonhuman apes are triggered by emotional stimuli; moreover, such vocalisations do not have an addressee - they are non-selective - and can be elicited in the absence of any other animal. Then, Hewes pointed out gestural communication of nonhuman apes is characterised by a set of strikingly different characteristics - volition, plasticity, innovation, and reliance on higher cognitive processes (importantly, results of current research - although they do not question the aforementioned qualitative difference between non-human apes' vocal and gestural

61 Although the very concept of "proto-language" occurs in many glottogenic scenarios (e.g. in Vico, Condillac or Herder), Hewes was the first to use it in a technical sense as a transitional stage between non-linguistic communication of primates and fully fledged language.. 
communication - point to a much more complex nature of vocal communication in nonhuman apes than was previously assumed ${ }^{62}$.)

Hewes relied on the research indicating that the buman vocal tract is a relatively late adaptation, present only in Homo sapiens (cf. Section 4.1). At the same time, he held that the species preceding Homo sapiens had abilities that required at least an elementary form of language: using fire, tool manufacture and big-game group hunting. Hewes assumed that a gestural protolanguage would be sufficient to sustain a culture organised around such activities.

Hewes $(1973 ; 1981 ; 1996)$ addressed a few crucial problems that continue to be discussed in the ongoing debate on the roles of gesture in language evolution. He underlined a possible role of the deictic gesture in the early stages of language development, and noticed the phenomenon of gestural imitation as a potential way of establishing a linguistic sign. Moreover, he stressed the significance of lateralisation and movement control in shaping gestural language. Interestingly, he discussed the depigmentation of the inner part of the hand in individuals whose skin colour is other than white - Hewes (1996) suggested that this feature may have helped increase visibility of the hands and hence, it might have emerged as an adaptation for gestural communication.

Finally, Hewes articulated the problem of "modality transition" 63 and proposed his own solutions to the issue, based on the idea of mouth gestures and sound symbolism as evolutionary mechanisms responsible fot the transition from gesture to speech (see also Section 6.5.5).

\subsubsection{Contemporary gestural hypotheses}

Currently, gestural hypotheses are still being developed and hold an important position in the debate on the phylogeny of language. In the following section, we present a few lines of evidence supporting gestural hypotheses

62 This more complex nature includes such features as functional reference, audience effects, productivity (devoid of compositionality), tactical deception review of new data, e.g. in: Slocombe (2011).

63 "A plausible theory of the primacy of gestural language over speech must, as has already been noted, account for its general replacement by spoken language" (Hewes, 1996: 587). 
that appeared after Hewes. They point to the iconic potential of gestures as the most intuitive form of linguistic expression, new findings on the brain functions, and mimesis - a uniquely human form of imitation.

\section{Iconicity of gestures}

William Stokoe, one of the pioneers of modern research into sign languages, demonstrated that their expressive potential is equal to that of spoken languages, and proposed solutions to key problems of language evolution (Stokoe, 1960). The first of these relates to the emergence of meanings and arbitrary speech sound, which can be addressed with reference to a gestural stage in language evolution, whereby the iconicity of a gesture (the resemblance of the visual form to content) creates a bridge between the sound and its referent. The other problem is connected with the origin of grammar. According to Stokoe (1991; later also Armstrong et al., 1995), the iconicity of a gesture allows us to represent simultaneously the activity, and the agent that performs the action as well as the patient that is affected by the action. In this respect, a single gesture can represent an action as a complex whole: the hands and arms function as a prototypical noun, their action is a prototypical verb - collectively, they create a prototypical sentence (Armstrong and Wilcox, 2007). The spatial nature of gestures facilitates an intuitive visualisation of semantic roles (the hand hits the hand or draws a path) and spatiotemporal relations.

On a par with theoretical arguments supporting the idea of gestural protolanguage, there are also interesting empirical data, especially from the experiments conducted by Susan Goldin-Meadow's research team. In one of the experiments, (Goldin-Meadow et al., 2008) the respondents were describing simple activities by means of speech, gesture and pictures. Verbal descriptions were compatible with the structure of the sentence of the respondents' native language. However, the gestural or pictorial descriptions, independent of the native language of the respondents, were characterised by a stable order: "actor - patient - act", congruent with the SOV word order. Based on this result, it can be purported that gestural communication presents a somewhat "natural" or "original" form of the mental representation of the event structure. In another experiment (Fay et al., 2013), the respondents, by means of gestures or nonverbal vocalisations 
communicated "meanings" from a finite repertoire - emotions, objects, or actions. Gestural communication proved more effective than the vocal one. The authors of the research considered it evidence in favour of the superiority of the visual modality for motivated expressions, and stated that this characteristic might have been useful in the initial stages of language development.

It should, however, be noted that the status of iconicity as a cognitive facilitator of the transition to symbolic communication is far-fetched. For instance, in ontogenesis, the iconic representations do not seem privileged over arbitrary ones, e.g. children do not acquire them easier or faster (Tomasello, 2008: 147). Also with respect to the cerebral realisation, the processing of iconic gestures and symbols is dissociated (Niederhut, 2012).

\section{Handedness and lateralisation}

Handedness and lateralisation were for a certain period of time used to formulate arguments supporting the gestural scenario of language origin. In the majority of people, the left hemisphere of the brain is responsible for both language processing tasks (it is here where the so-called "language areas" are located) and motor control of the dominant hand (90\% of all people are right-handed). The sources of this correlation are not entirely clear, but the available data show explicitly the systematic character of the correlation, e.g. the degree of language processing in the left hemisphere is directly proportional to the level of preference towards right-handedness (Knecht et al., 2000). There are also hypotheses on the evolution of language and lateralisation. Hewes (1973) assumed that lateralisation for precise movement control, and hence gesticulation, emerged before speech. According to Corballis (2003), representations of communicative movements of hands and arms were gradually absorbed by vocalisation governed by the left hemisphere of the brain. Furthermore, according to the throwing hypothesis proposed by Calvin (1982; 1983; see also Calvin and Bickerton, 2000), one of the first expressions of the lateralisation of brain functions and handedness was the action of throwing stones to hunt small game. Well-aimed throws require the calculation of a projectile's trajectory and creation of an appropriate motor plan that will coordinate movements of the body parts (including fingers, wrist, arm and torso). Calvin stated 
that one-hand throwing led to the selection of a dedicated neural circuit in the brain that facilitated such computations. The circuit was then exapted for tool production, gesticulation and eventually for articulated speech and syntax.

Currently, the relevance of handedness and lateralisation as evidence supporting gestural hypotheses is decreasing. First, the newest research challenges the position that handedness at the population level is a solely human feature. Although the data are ambiguous, it seems that our species differs from others only in the scale and systematicity of the phenomenon (e.g. Cashmore et al., 2008). If we look at nonhuman Great Apes, some studies (e.g. Harrison, 2008) do not confirm any preference at the level of population, while others (e.g. Hopkins, 2006) note its presence, most often right-handedness, at least in the case of some species and some activities. Similar data exist for other nonhuman primates - for example baboons show the preference to perform communicative gestures, but not instrumental ones, with their right hand (Meguerditchian et al., 2011). Furthermore, the left hemisphere controls vocal communication in many species including those distantly related to humans, e.g. frogs and birds (Corballis, 2003). These observations undermine the assumption that handedness is uniquely human, and that it resulted from selective pressures in the hominin history, such as the need for precise motor control necessary to manufacture tools. Brain neuroimaging proved that the claim of "left lateralization for language" is far-fetched, and the functions responsible for language processing engage various areas all over the cortex (e.g. Deacon, 1997; Lieberman, 2003).

\section{Broca's area and mirror neurons}

Neurocognitive research provided a few interesting clues leading to gestural hypotheses: they concern a revision of the view about the function of Broca's area and the discovery of mirror neurons. Our understanding of the role of Broca's area, originally believed to be primarily connected with speech production, has changed in the light of the new research (Fadiga et al., 2009). It was shown that this area is engaged in comprehending language, performing and observing manual activities, performing and listening to music and representing abstract hierarchical structures. On 
this basis, some authors (Fadiga et al., 2009) conclude that Broca's area is responsible for detection and representation of complex hierarchical/ syntactic relationships, irrespective of modality and use (i.e. whether it is used for production or reception). It is hypothesised that the evolutionary foundation of these abilities stems from the motor function connected with performing activities and - thanks to mirror neurons - their comprehension. These data suggest equation of the visual and the vocal modality as potential ways of the transmission linguistic information, concurrently granting phylogenetic primacy to the motor system.

Rizzolatti and Arbib (1998) proposed an interesting hypothesis of language evolution. It is based on mirror neurons, or a group of nerve cells that are active during, for example, performing activities such as grasping, as well as observing the same activity performed by someone else (see 3.1.3). They proposed that the mirror system implements a neural mechanism that allows the alternation of the role of the sender and the recipient (interchangeability) and equivalence (parity). The execution of a given gesture involves mainly the motor cortex, and the reception - the visual cortex, therefore the mechanisms of production and reception are different, whereas the meaning of the gesture in communication must be relatively the same. By activating the same fields of the mirror system, the gesture "counts" as the same for both the sender and the recipient (Arbib, 2005) and in this way the requirement of equivalence is fulfilled.

Arbib $(2002 ; 2005 ; 2012 \mathrm{a}, \mathrm{b})$ modified the initial idea, emphasising, along with the function of mirror neurons, the role of imitation and volitional control over communicative movements. The gradual model of language phylogeny was established: the first three stages involve all primates until the emergence of the common ancestor of the chimpanzee and Homo sapiens; the consecutive stages relate to changes after the split of the two species. The model is as follows (Arbib, 2005):

S1: grasping

S2: mirror system for grasping

S3: simple imitation (chimpanzees only)

S4: complex imitation (after the Homo-chimpanzee line split)

S5: proto-sign (key change leading to the emergence of an open repertoire of signs) 
S6: $\quad$ proto-speech (key change leading to the motor control over voice) S7: fully fledged language.

Although manual activities and the mirror system still constitute the basis for the model, the key role is assumed by pantomimic imitation comprised of proto-signs representing whole situations and activities (holistic protolanguage), which is only characteristic hominins. The development of pantomimic communication was accompanied by increasing the control of the tongue and larynx, which in the end led to arbitrary symbol-based communication in the vocal modality.

\section{Mimesis and pantomime}

Another influential line that appeals to imitation stems from the mimetic concept of language evolution, initially developed by Merlin Donald (1991; 2012). As already explained in Section 4.4.1, according to Donald, the fundamental difference between nonhuman primates' and human cognitive processes is related to mimesis - the ability to form conscious, self-initiated, intentional representations that are nonlingusitc. The mimetic ability enables us to remember motor schemas for such activities as jumping, throwing or dancing, as activities that are detached from their subject. Such representations do not have to be activated as a reaction to a direct stimulus - the object may consciously recall them from memory at any time (autocueing). Therefore, one may perform an activity at any time - be it an actual dance movement or just a dancebased exercise. Such a sequence of movements may also be recalled only from the working memory - where one imagines it "off-line" - as an action plan. The subject capable of mimetic representation can separate movement sequences (e.g. throwing a stone) observed in others, remember them, imagine them, and re-enact them on one's own. In this way, mimesis underpins imitation. An activity represented mimetically such as the imitation of a stone throw - is identified as the same by both the actor and the observer; hence, it can be used for communication. It should be noted that mimetic representations are neither arbitrary, nor conventional, nor compositional, and their nature is entirely corporeal. Furthermore, although mimesis is a multimodal ability, the visual modality is here of dominant importance. 
Jordan Zlatev (e.g. 2008) ${ }^{64}$ offers the most detailed explanation of Donald's concept. He puts forward a hierarchy of mimetic abilities arranged into the stages of their phylogenetic development:

- proto-mimesis - based on imitation taken from external observations (exteroception) of one's own body movements (proprioception), present in nonhuman apes and ontogenetically in newborn babies; it manifests itself through such activities as eye contact or simple coordination of behaviour;

- dyadic mimesis - based on volitional representation, present in its basic form in nonhuman apes; it underpins imitation or imagination, including the ability to form a representation of the future;

- triadic mimesis - based on communicative intention, present in humans and some enculturated nonhuman apes; its manifestations include iconic gestures or declarative pointing;

- post-mimesis 1 - based on norms and convention; present in humans (and in nonhuman apes taught symbolic communication); it manifests itself through symbolic communication;

- post-mimesis 2 - based on systematic and compositional usage of symbols in both communication and internal thought processes; only present in humans; it underpins the language ability and the ability to understand false premises.

Daniel Hutto (2008) espouses a similar position - the initial form of communication was, according to him, a mimetic re-enactment of events not segmented into any meaningful units, but having the form of a holistic, bodily representation. Hutto assumes that regular re-enactments of events might have had an important social function, establishing a basis for customs, strengthening bonds and gradually replacing grooming. Michael Tomasello (2008) acknowledges pantomime and pointing as the natural and the first human-specific forms of communication, representing a transition phase from nonhuman apes' communication to conventionalised language. Their basis (together with language) is founded on the exclusively

64 The mimetic standpoint of Zlatev's (e.g. 2008, 2014a) is closer to multimodal theories (see section 6.5), than stricte gestural ones. 
human form of sociality and motivation: shared intentionality based on the recursive mindreading and cooperative communication.

\section{Further arguments}

Wacewicz and Żywiczyński (2008) underscore greater secrecy of communication in the visual channel, which is suited to the transfer of a message to a selected addressee, rather than all individuals close-by. Evolutionary logic suggests that such selectivity might have been used at the early stages of the development of communication, when it was an evolutionarily unstable system - it lacked propositional content characteristic of language but was highly manipulative - as is typical of nonhuman animals (see 5.1-5.3). Some recent field experiments on chimpanzees resorting to the use of gesture in conditions requiring secrecy (Hobaiter and Byrne, 2012) confirm this idea.

An alternative approach to the role of gestures in the evolution of language comes from David McNeill (2012). In his view, theories assuming gestural primacy are not capable of explaining satisfactorily the deep and multilevel integration between gesture and language. These ideas diminish the role of gestures in embodying language in favour of speech. Assuming that gestures are an integral part of langauge, not only its complement, McNeill proposes that both types of semiosis (global and discrete) stem from the dynamic units of online verbal thinking which he terms Growth Points (GPs). They contain ideas simultaneously expressed in gesture and speech. In this way, ideas are expressed by means of imagistic and linguistic codes. According to McNeill, the acquisition of this ability is a critical moment in the cognitive development of humankind, leading to the emergence of language. We comment upon this proposal in Section 6.5.

\subsection{The problem of transition to speech}

The key problem of modality transition can be summarised in the following way:

If language emerged as a largely gestural phenomenon, how can we explain its transition to the current, mainly vocal form?

Although the transition from the hypothetical gestural language to the current - mostly vocal - communication system was already acknowledged 
by early authors as a difficulty (Hewes, 1973), the most extensive criticism comes from Fitch (2010), who stresses two points:

- the scale of anatomical and neural adaptations for spoken language in humans

- the completeness and functionality of the currently existing sign languages.

\subsubsection{Homo sapiens's adaptations to speech}

First of all, humans differ significantly from their closest relatives - nonhuman Great Apes - in terms of the anatomical structure and motor control of the vocal tract. The human species-specific features include (for a detailed discussion, see Section 4.1):

- descended larynx,

- lack of air sacs,

- a better innervation of the thoracic muscles,

- advanced ability for vocal imitation.

For some of these differences alternative explanations cannot be conclusively ruled out. For example, the lowered larynx may be a side effect of the erected posture or the reconfiguration of the face, or as the result of pressures for the enlargement of body size during vocalisation (for discussion see Fitch, 2010); the loss of air sacs may be the result of the proneness of this organ to infection; the better innervation of the chest may be an adaptation for breath control during physical effort; the ability for vocal imitation may be linked to musicality. Still, the most convincing interpretation is that all these changes constitute adaptations for articulated speech.

To sum up, from the perspective of researchers such as Fitch (2010), the extent of speech adaptations constitutes a crucial argument in favour of its early development, i.e. in hominins preceding Homo sapiens. At the same time, it becomes an argument against the gestural hypotheses only when we assume a "late" emergence of language. The facts relating to speech adaptations may be made compatible with the gestural hypotheses by assuming an "early" emergence of language based on even earlier visual proto-communication (e.g. a gestural protolanguage in Homo erectus), with gradual development of articulated speech. The hypothesis of early emergence of language 
is compatible with the view supported by new empirical data. For example, recent studies (Johansson, 2012; Dediu and Levinson, 2013) conclude that the reconstructions of the Neanderthal genome, anatomy (including the vocal tract), and ontogeny, while not directly confirming the presence of language in this species, support such a possibility. These new findings make the hypothesis of later emergence of language unlikely, but are consistent with the gestural scenarios, provided that the latter assume a sufficiently large timescale for the process of language evolution.

\subsubsection{Sign languages as fully-fledged languages}

A much greater problem comes from the completeness and functionality of the existing sign languages. Although it is not intuitive, this argument presents a serious challenge to gestural primacy hypotheses. To understand why this is the case, we must take a closer look at the nature of sign languages.

Sign languages are fully-fledged languages, equal in expressiveness and sophistication to spoken languages (Stokoe, 1960; Stokoe et al., 1965; Emmorey, 2002). It concerns both the properties of the code, the level of brain implementation, ontogenetic development (acquisition by children), glottogenesis (emergence and development of the language system itself), and most importantly functionality. Since their status as such is officially recognised by linguists, sign languages, similarly to spoken ones, are present in the databases of world languages e.g. Ethnologue or World Atlas of Linguistic Structures. ${ }^{65}$

Sign languages, similarly to spoken ones, use conventional and arbitrary signs that can express abstract or metaphorical concepts - an example of which is sign language poetry (e.g. Sutton-Spence, 2005). Similarly to speech, they have a combinatorial structure at the level of morphology, syntax and even "phonology"; hence, also the duality of patterning.

The cerebral areas processing sign language are largely identical with those processing speech (Corina et al., 1992), and the specialisation of the areas seems to be related to language processing in general - independently

65 Ethnologue: http://www.ethnologue.com/; World Atlas of Linguistic Structures: http://wals.info/. 
of modality - rather than non-linguistic aspects such as motor control of the articulators (Emmorey, 2002). Importantly, these centres are different from those responsible for spontaneous gesticulation. For this reason, damage to the language areas in deaf signers results in symptoms typical of aphasia, including its language-specific nature, while the ability for gesturing (e.g. Bellugi and Klima, 2001; Hickok et al., 1996) or pantomime (Emmorey, 2002) is preserved.

Acquisition of a sign language takes a similar time span to that of a spoken language, and is characterised by the same stages of development and the same phenomena such as babbling (its manual equivalent) or hyperregularisation of grammatical forms. Furthermore, children do not show any preferences towards either spoken or sign language while exposed to both of them in equal measure (Petitto and Marentette, 1991; Section 6.5.3 of this book).

The recent example of ISN (Idioma de Signos Nicaraguense), the Nicaraguan sign language, illustrates de novo emergence of a complete language system - with the stages of pidginisation and creolisation comparable to those in spoken languages (Kegl et al., 1999).

Most importantly, sign language researchers have shown that in terms of their communicative potential and efficiency, sign languages are equivalent to speech (Stokoe, 1960; Emmorey, 2002).

Despite these facts, human verbal communication is predominantly vocal, and sign languages generally perform only secondary or auxiliary functions. ${ }^{66}$ Such populations as in Al-Sajid (Israel), Adamorobe (Ghana), Kata Kolock (Bali) or Jukatana (Mexico) are exceptions, because there vocal communication is impeded by the incidence of hearing impairments. Apart form such communities, everywhere else the primary form of linguistic communication is speech. This fact implies that - if we accept the gestural hypotheses with their focus on the fact that language originated in the visual modality - we must account for a change of the dominant modality - a change difficult to explain when analysed more closely. Fitch

66 Usage of sign language signs or gestures as a replacement for speech is usually motivated by religious reasons, as in the case of some medieval monastic orders; cultural reasons, as in the case of the Warlpiri - indigenous people of Australia's signs; or practical reasons, as in the case of the San people, South African huntergatherers, during hunting. 
poses a question about selective pressures and mechanisms of such a change ${ }^{67}$. Many researchers (e.g. Burling, 2005; Corballis, 2003; Kendon, 1991; 2008; MacNeilage, 2008; Tallerman, 2011) agree that it is the most difficult problem for gestural hypotheses.

\subsection{Solutions}

Solutions to the problem presented in Section 6.4, although they may seem concurrent, they are logically independent from arguments opposing or favouring gestural hypotheses. Below, we suggest answers to the questions posed in Section 3, which are biologically plausible - we try to establish a link between the modality transition and knowledge of anatomy, evolution and brain functions.

Two general answers are possible. Firstly, we may point to potential selection pressures facilitating the development of vocal communication despite its original gestural basis. The other possibility, more interesting and discussed in Section 6.5.3, questions the very problem of "modality transition". According to this proposal, the separability of visual and vocal communication is only superficial, and the evolutionary emergence of language could have been happening in both these modalities simultaneously. On such a scenario, we would deal not so much with the binary replacement, but with the use of various semiotic resources in phylogenesis, including division of labour (nonverbal, analogue, holistic versus verbal, symbolic, combinatorial) between the two modalities (see also Zlatev, 2014a).

67 Fitch (2010: 434): “[A] significant disadvantage of gestural models is their difficulty in explaining the virtually complete transition to vocal, spoken language in modern Homo sapiens... Whatever their virtues, models of gestural protolanguage are incomplete without a detailed and compelling model of the transition to spoken language, as most gestural proponents have recognized" (Hewes, 1973; Corballis, 2002; Arbib, 2005); (2010: 442): "but the lack of a plausible selective force to drive signed language into vocal language remains a compelling argument against a fully gestural, and fully linguistic, protolanguage." 


\subsubsection{Traditional arguments}

An overview of possible solutions begins with the proposals already present in the literature and discussed in the context of gestural hypotheses. We find these observations interesting but insufficient as a solution to the problem under consideration. It is worth noting the fact that the following points demonstrate deficit communication in the visual channel, and as such they could be used as arguments against the gestural hypotheses.

- speech is more economical (e.g. Knight, 2000) - articulatory movements require less time and energy than hands, arms and body movements

- speech enables communication at poor visibility or in the dark (Rousseau, 1775)

- the voice attracts attention more effectively (Rousseau, 1775)

- speech does not engage hands, thereby allowing their use in practical tasks - work or carrying objects (e.g. Carstairs-McCarthy, 1996) during communication

- speech allows one to teach manual activities, such as tool making (Armstrong and Wilcox, 2007)

- acquisition of speech begins in the human foetal life, which grants a developmental advantage to this modality (Hewes, 1996)

- vocal communication facilitates continuous monitoring of the location of a child, which might have been important in hominins due to their hunter-gatherer lifestyle, and with lack of constant physical contact between mother and child, as is the case in other nonhuman Great Apes (Falk, 2009)

- voice is directed at everyone and not only to a specific individual (Tomasello, 2008).

Fitch (2010) criticises the majority of the arguments mentioned above. $\mathrm{He}$ states that it is difficult to speak of any superiority of speech over gesture in any of these aspects. Moreover, it is easy to find a counter argument for all theese enumerated above. Gestures are not visible in the dark, but they are visible by the firelight, and they can be used in the tactile modality, which is used by the visually impaired signers. The visual channel gains an advantage in long-distance or noisy communication; it also successfully attracts attention in these situations. Fitch notices that although the vocal modality frees hands and arms, the visual modality frees the mouth, which 
was very significant in the Palaeolithic Period - the fossil data show that hominins intensively used teeth to chew hard foods and perform various mechanical operations. Furthermore, the argument concerning the energetic effectiveness is not convincing because - as Fitch points out - speech is accompanied by spontaneous gesticulation, which eventually makes this way of communication equally costly.

We could include further arguments not mentioned by Fitch. During teaching manual activities, verbal instructions are much less effective than a demonstration or physical guidance of the learner's hands. Hewes's argument is too weak, especially in view of the developmental data on the equal pace of spoken and sign language acquisition (see Section 6.5.3). Falk's remark is interesting, but it does not require articulate and propositional language but just emission of any sound. Tomasello's proposition is also compelling but easy to counterpoise. The already-mentioned advantage of gestures is the secrecy of communication, allowing for a more accurate choice of addressee, and a limited possibility of being discovered by enemies and predators.

\subsubsection{Information duality}

Susan Goldin-Meadow (e.g. 2011) noticed that the visual modality could be used to successfully transmit both combinatorial-segmented and mimetic (holistic-imagery) information. The first possibility is realised through signs of sign language - separate units of discrete and arbitrary character, which can be combined into longer compositional structures (phrases, sentences). The other possibility is related to the use gesticulation or pantomime, where information is not composed of discrete units but is of holistic and imagistic nature. Goldin-Meadow argues that the vocal modality is primarily able to serve the transfer of discrete, combinatorial-segmented units (phonemes or morphemes). The ability to transfer mimetic information in vocal communication is limited to prosodic features and onomatopoeic or sound-symbolic units; therefore, their role is secondary.

In face-to-face interaction, an efficient transfer of both the information types mentioned above occurs simultaneously. Gesticulating accompanies speech almost all the time (Goldin-Meadow, 2003; Kendon, 2004) - it also holds for telephone conversation, or speech produced by visually impaired people. The visual modality may use a segmented code, but voice cannot 
transfer any mimetic information. Due to this fact, effective communication in a naturally occurring conversation manifests itself in speech, which encodes information in an arbitrary and segmented way, and gesticulation, which is used to transfer holistic information. Goldin-Meadow (2008) points out that this advantage of the visual modality might have paradoxically been the reason for the transfer from the hypothetical protolanguage to speech.

Erin Brown (2012; after Zlatev, 2014a) puts forward a similar proposal. According to her, the vocal modality started to be used because sound is a naturally poor vehicle for transferring motivated meanings, which in turn facilitates the transfer of arbitrary meanings. Similarly, Kendon ${ }^{68}$ notices that gesture is necessarily has a specific spatial form and location - referred to as "spatial concreteness," which is not true of speech. This feature is crucial in the transfer of displaced meanings, as well as to abstract concepts and ideas. Spatial concreteness of gestures may decrease their ability to express abstract meaning. Vocal signals, on the other hand, having no spatial characteristics, are easier to comprehend as abstract.

\subsubsection{Acquisition of sign and spoken languages in children}

Young children acquire sign languages with ease comparable to the acquisition of spoken languages. As mentioned in Section 6.4.2, parallel stages can also be noted in this process, including manual equivalent of babbling. Petitto and Marentette (1991) state that the ease of acquisition of signs also applies to hearing children who, if they have simultaneous access to sign language and speech, absorb both kinds of language equally well without showing visible preferences towards speech, and achieve the same developmental stages simultaneously for both modalities. Ontogenesis thus provides arguments for the fact that the "transition" to the vocal-auditory modality is in some sense apparent, because it concerns the level of E-languages (in the Chomskyan sense), and not the language faculty as (a set of) biological adaptations.

It is not possible that the ability to acquire sign language is a separate ability that has recently developed in parallel to the ability to acquire spoken

68 Protolang 2, conference speech, 19.09.2011, Toruń 
language. The number of people with hearing loss does not exceed several percent of the population, and completely deaf people amount to $1 \%$ (e.g. in the USA, respectively, 11 million and 1 million - Mitchell 2006), so the number is definitely too small to be selective in this direction. The human biological readiness to acquire a language seems to be of an amodal nature and allows for the implementation in the genstural or vocal modality and the other, if both are available in ontogenesis. This fact indicates that the "problem of transition into the vocal modality" may be not as acute at it may seem. This line of thinking is also supported by neurophysiological evidence, because, as we mentioned above, linguistic information, regardless of its modality (spoken word, sign), is processed in the same parts of the brain.

The link between the two modalities can also be noticed in the acquisition of spoken language and single gestures. Babbling (around 6-8 months), for example, is accompanied by rhythmical hand movements. Before uttering their first word, babies use deictic or even iconic gestures (around 10 months). Later, they start to combine gestures and speech expressing the same meaning, and further, gesture and speech expressing different meanings (saying: give and pointing to a fruit). Both modalities are also visible in the course of cognitive development. Golin-Meadow (2003) shows that at least some newly acquired concepts (conservation task, equivalence), before having a verbal representation, can first manifest themselves in gestures.

Interestingly, many experimental studies, many of which have been conducted by Susan Goldin-Meadow and her team, demonstrate that early gesture use predicts a wide range of linguistic achievements in later development. For example, the way an 18-month-old child uses gestures predicts their lexical repertoire and complexity of utterances in the future (Rowe and Goldin-Meadow, 2009). Another example is the aforementioned speech-gesture combination: the age in which a child can use such a combination may betray the age of when the child starts constructing two-word utterances (e.g. give apple).

\subsubsection{Natural connections between the hand and the mouth}

The division of communication into vocal and visual channels is useful, but we have to remember that these modalities are closely connected. The 
interplay is visible both at the level of message transfer and at the deeper level of cognitive and neural implementation of appropriate systems.

As early as in 1872, Darwin noticed that the person using scissors often moves their jaws to the rhythm of the act, and children learning to write bend the tongue, following the movements of the fingers. In fact, lip movements and hand movements seem to be largely controlled by the common and phylogenetically old motor control system. This is indicated both by the proximity of the cortical areas controlling the movements of these organs, as well as by experimental data. For example, electrical stimulation of the field 44 (homologue of a part of the Broca area in humans) in the Rhesus monkeys induces movements of the upper limb and lips (Petrides et al. in Meguerditchian et al., 2011; see also Corballis, 2003). The prefrontal cortex of macaques (F5) contains, in addition to mirror neurons, neurons that fire at the sight of an object which can be grasped, coding its size in order to prepare the appropriate plan of the hand movements at the same time using either the hand or the mouth (Murata et al., 1997; Rizzolatti et al., 1996).

The natural motor relations between the hand and the mouth in humans are documented by Gentilucci and Corballis (2006), who describe, among others, differences in mouth and voice spectrum in respondents expressing a given syllable, depending on whether they capture a small or large object when speaking. A similar pattern also occurs when the subjects observe the activity performed by another person, which indicates the involvement of the mirror neurons system. Higginbotham et al. (2008) report the results of electromyographic examinations in which they found that specific manual movements (precision grip, pointing, flexing fingers) result in the activity of articulators of bilabial plosive consonants. In turn, Vainio et al. (2014) inform about the characteristic differences in the duration of squeezing: the reaction time was shorter for the strength grip while voicing the syllable $[\mathrm{ka}]$ at the back of the mouth, while for the precision grip for the syllable [ti] produced at the front. Similarly, in chimpanzees, the execution of a precision grip is more often accompanied by clucking than other vocalisations (Meguerditchian et al., 2014, convergent observations in captive chimpanzees - Leavens et al., 2014).

It is believed that the natural hand-mouth relationship is rooted in mouth feeding behaviours, which were later exaptated for linguistic operations. 
This might have played a role in the transformation of gestural communication - the transition from hand gesture to mouth gesture (Gentilucci and Corballis, 2006).

\subsubsection{Articulatory movements as a type of gesture}

The motor speech perception theory provides an interesting insight into the problem of the gesture-to-speech transition (Liberman et al., 1967; Liberman and Mattingly, 1985; Liberman and Whalen, 2000). Accordingly, the motor system is responsible not only for speech production but also for speech comprehension. The theory holds that our mental representations of phonemes are not manifested as physical sounds, but as motor programs, and similarly phoneme recognition is possible not because of the link to its sound value, but through a reference to the movement sequence of the tongue and the other articulators. This idea points to the primacy of the motor aspect over an acoustic one, which allows us to describe speech as gesture i.e. as a system of orofacial gestures.

Conceptualising speech as gesture entails the co-occurrence of the visual and vocal component. The most obvious manifestation of this is lip-reading, which makes it possible to reproduce part of a message without access to sound (Summerfield, 1992). Also, in the field of automatic speech recognition, bimodal technologies are considered to be more accurate and more resistant to errors than monomodal ones (Chibelushi et al., 2002). Another proof of a deep integration of visual and auditory information is the McGurk effect (McGurk and MacDonald, 1976): placing the ga sound to a video where the lips pronounce the $b a$ sound, makes the observer hear the $d a$ sound. Such phenomena point to the multimodal character of speech perception and an important role that motor-visual components play in it.

\section{Orofacial gestures}

We define facial and mouth gestures (orofacial gestures) as volitional movements of facial muscles and the tongue other than articulatory movements of speech (although these may be accompanied by articulatory movements, see Orzechowski et al., 2014). In accordance with the theory of gestural primacy, orofacial gestures may initially have served a communicative function in the visual modality, after which the sounds 
accompanying their production may themselves have acquired the communicative meaning, thus enabling the transition to speech. Note that such an idea does not in itself identify the selection pressures responsible for such a transition, but indicates a biologically realistic mechanism for effecting the transtion. The potential of orofacial gestures has not escaped the attention of language evolution researchers, becoming an important element of numerous evolutionary scenarios. Darwin's observation mentioned previously was elaborated, for example, by British phonetician, Henry Sweet (see Woll, 2014), who speculated that the beginnings of speech were related to articulatory gesticulation, similar to its manual counterpart, which only later began to be accompanied by sounds. Later, Richard Paget's idea that oral-facial gestures and tongue movements imitate hand gestures later gained some popularity (see 1.2.2).

The potential of orofacial gestures did not go unnoticed by evolutionarilyminded scientists, becoming an important element of numerous scenarios:

- Hewes (e.g. 1973) identifies mouth gestures as the second, next to sound symbolism, link between gesture and speech;

- Corballis (e.g. 2003) argues that similar facial gestures might have been better identified because of the co-occurring sound;

- Studdert-Kennedy (2005) assumes that mimicry of facial expressions played a crucial role in the development of control over the articulators recurring acts of imitation led to an increasing control of various facial regions, which expanded to vocal articulators due to the link between mimicry and vocalisation;

- MacNeilage $(1998 ; 2008)$, although not a supporter of gestural theories, acknowledges the importance of facial gestures: based on the similarities between speech and sound-producing facial gestures of nonhuman apes (smacking); he proposes the following scenario: opening and closing of the mouth while chewing, sucking, and licking started to acquire communicative functions and took the form of facial gestures, which further transformed into syllables and phonemes;

- Meguerditchian, Cochet and Vauclair (2011) emphasise the importance of facial gestures from the perspective of neurobiological research on nonhuman apes, which reveals connections between the hand and the mouth, as discussed in Section 6.5.4; 
- Woll (2014) describes the phenomenon of echo phonology in sign languages; the echophonic signs, next to the manual component, have an oral component, i.e. the movement of the lips is an "echo" of the hand movement for the start and end of the movement as well as the dynamics and the type of movement. Woll, also referring to the results of neuroimaging studies (Capek et al., 2008), classifies echophonic signs as intermediate between spoken words and signs. He adds that echophonic elements, combining the iconic movement of the hand with an abstract sound representation, could play a role in the transition for gestural protolanguage to speech .

We write about the role of the orofacial gestures in Orzechowski, Wacewicz and Żywiczyński, 2014 (Orzechowski et al., 2014), where we pay attention to two other aspects of this issue. First, genetic disorders that impair linguistic (not only articulatory) abilities are often associated with a parallel general movement disorder of the facial region. Such a condition results from the mutation of the FOXP2 gene, which impairs both language (Enard et al., 2002) and non-linguistic facial and lip muscle movements (Marcus and Fisher, 2003); the same conditions result from the mutation of the FOXP2-regulated SRPX2 gene (Roll et al., 2006). This regularity is difficult to interpret unambiguously, but it may indicate a relationship between language and motor control of the orofacial area. Secondly, the auditory feedback mechanism seems to be interesting in this context. We expand Corballis's proposal, postulating that the benefit of adding the sound component is not limited to the recipient, but also applies to the sender, for whom it makes it easier to contral the production of orofacial gestures. This view is supported by empirical research, indicating that disrupted (e.g. delayed) auditory feedback or its lack leads to serious speech disorders (e.g. Yates, 1963).

\subsection{Conclusion - Towards multimodal hypotheses?}

Each of the extreme positions concerning language origins faces several fundamental explanatory difficulties. Theories deriving language from vocalisation have to face the weakness of the initial premises for later language adaptations: on a deeper analysis, primate vocalisations and language are two extremely different communication systems that have 
little in common except for the use of the vocal modality. In turn, the radical gestural perspective, which assumes the existence of original gesture language, struggles with the problem of the transition from the visual to vocal modality. In addition, neither position can provide a convincing explanation of the reasons for the deep integration of gestures with language.

In order to solve these difficulties, it is possible to adopt a multimodal perspective: the perception of gesture and voice not as two separate communication systems, but as different implementations of a single system. Here, language evolution is viewed as engaging both modalities in a strongly integrated way. Within its framework, we may assume a temporary specialisation or an advantage of one of the modalities resulting, for example, from the degree of development of individual linguistic adaptations to prevailing environmental requirements. This may be the strength of gestural hypotheses, which emphasise that in the early stages of protolanguage development the visual modality provided a more important source of information than the accompanying vocalisations.

It seems that the multimodal perspective allows for the most convincing integration of the arguments listed in Sections 6.5.2-6.5.5 by emphasising the importance of the visual modality in the early stages of the development of human linguistic ability.

The supporters of the multimodal perspective are, above all, gesturologists such as Kendon (2011), McNeill (2012), or Sandler (2013), whose research demonstrates a deep integration of gestures and speech (see Sections 6.2.1 and 6.5.2). Gestures form an integral part of conversation, to the extent they we use gestures e.g. during a telephone conversation, despite full awareness that the interlocutor cannot see us (Bavelas et al., 2008). Of particular importance are data from studies on people who are visually impaired from birth - who did not have the opportunity to acquire patterns of gestures through visual observation. As it turns out, such people also use gestures, even if they talk with other blind people (Iverson and GoldinMeadow, 1997). The stability of integration between gestures and speech is also evidenced by neuroscientific data, e.g. by dissociation of signs mentioned in Section 6.4.2, or by dissociation of instrumental movements, i.e. those which have a mechanical effect, e.g. grasping. The latter problem is illustrated by the case of I.W. (McNeill, 2005), who after losing the proprioceptive body schema was unable to perform instrumental movements 
without looking at his hands - however, his gesticulations were not subject to similar restrictions.

The multimodal perspective, however, is gaining popularity also in other circles of the language evolution researchers. Primatologists begin to notice the multimodal character of messages naturally occurring in primate communication. On the one hand, gestures are often accompanied by an intentional or unintentional sound production (e.g. Hobaiter and Byrne, 2012). On the other hand, as Falk (2009) recalls, primates' vocalisations are often rigidly paired with both a specific emotional state and a specific facial configuration that can be perceived visually. Slocombe et al. (2011) pay special attention to facial expressions as an important but neglected research component of the "overall message". In their overview of literature on primates communication, they identify a strong tendency to adopt a simplistic unimodal perspective. In addition, although primate vocalisations have traditionally been viewed as largely genetically conditioned, rigid and non-selective emotional behaviours, new research challenges such an extreme position (see Clay and Zuberbühler, 2014; Leavens et al., 2014).

The findings of neuroscience also encourage the adoption of a multimodal perspective. The starting point is the observation that the division into the vocal and visual modalities does not coincide with the criterion of the "language" of the message. Not only do sign languages remind us of that, but also naturally communication that is not inherently linguistic. For example, Gonseth et al. (2012) argue that pointing is an act occurring between modalities, where the indexicality of a communicative act is most often achieved as a result of collaboration between vocalisation and manual indication. This seems to be confirmed by processes in the brain, i.e. for the neural implementation of a given system, the decisive factor is not the type of modality, but the type of processing, e.g. iconicity or conventionality (Niederhut, 2012). The possibility that the most important dissociations, from the point of view of language, do not proceed according to the division into modality is a particularly promising direction of future research. 


\section{Epilogue}

This book was preceded by the excellent introductions to the science of language evolution authored by Sverker Johansson (2005), Tecumseh Fitch (2010) or James Hurford (2014). But we believe that our book has a distinct character and as such can play a role in popularising this area of knowledge. We set ourselves the task of presenting the evolution of language as a new field of study, outlining its conceptual background, the interdisciplinary nature of the research, and its developmental dynamics. At the same time, we flag those threads which are currently at the centre of discussions and disputes (e.g. modality), along with those which have been relegated to the periphery (e.g. speculative scenarios). We have paid particular attention to a problem that now appears to be fundamental in the language evolution research: the cooperative basis for linguistic communication. We have also taken care to present the basic conceptual tools in the field of evolutionary theory, combining this domain with a presentation of "evolutionary thinking", broadly understood as a set of useful, universal evolutionarily grounded heuristics for interpreting human behaviour and culture.

Chapters that survey the field are set alongside others that are more concerned with providing a commentary on the various research trajectories in language evolution. Accordingly, the opening chapter contains a comprehensive and systematic reconstruction of the thought on the beginnings of language, while the chapter closing the monograph presents our suggestions for an approach to one of the central issues in the evolution of language the problem of "modality transition" in the gestural hypotheses of language origins. At the same time, it provides an insight into how the construction of interdisciplinary, synthetic argumentation in the language evolution research is conducted.

We hope that the appeal of this book lies in the breadth of its scope. Selecting from the wealth of interdisciplinary material and the many heterogeneous research currents in the science of language evolution turned out to be an unexpectedly difficult task. Not being able to write about all of them, we decided to present a very general picture that is appropriate 
for introductory purposes. Such an approach allows the reader to form opinions on a broad range of phenomena studied in the evolution of language, and encourages individual exploration of fascinating topics, an exploration that will hopefully be facilitated by the book's extensive bibliographical section. 


\section{References}

Ahlsén, Elisabeth. 2006. Introduction to Neurolinguistics. Amsterdam: John Benjamins Publishing.

Aiello, Leslie C. 1998. "The Foundations of Human Language." The

Origin and Diversification of language. Eds. N. G. Jablonski and L. C.

Aiello. San Francisco: California Academy of Sciences. 21-34.

Aiello, Leslie C. and Peter Wheeler. 1995. "The Expensive-Tissue

Hypothesis: The Brain and the Digestive System in Human and Primate

Evolution." Current Anthropology 36.2. 99-221.

Aitchison, Jean. 2000. The Seeds of Speech. Language Origin and Evolution. Cambridge: Cambridge University Press.

Allison, Wayne L. 1971. In the Beginning Was the Word: (The Genesis of Language). Laie: Church College of Hawaii.

Amman, Johann K. 2009 (1692). The Talking Deaf. Gloucester: Dodo Press.

Arbib, Michael. A. 2002. "The Mirror System, Imitation, and the Evolution of Language." Imitation in Animals and Artifacts. Eds. K. Dautenhahn and C. Nehaniv. London: A Bradford Book. 229-280. Arbib, Michael. A. 2005. "From Monkey-like Action Recognition to Human Language: An Evolutionary Framework for Neurolinguistics." Behavioral and Brain Sciences 28. 105-167.

Arbib, Michael. A. 2012a. How the Brain Got Language. Oxford:

Oxford University Press.

Arbib, Michael. A. 2012b. "Précis of How the Brain Got Language: The

Mirror System Hypothesis." Language and Cognition 5.2-3. 107-131.

Armstrong, David. F., William C. Stokoe, and Sherman E. Wilcox.

1995. Gesture and the Nature of Language. Cambridge: Cambridge University Press

Armstrong, David. F. and Sherman E. Wilcox. 2007. The Gestural Origin

of Language. Oxford: Oxford University Press.

Ashcroft, Bill. 2001. "Language and Race." Social Identities 7.3.

311-328.

Assirelli, Oddone. 1950. L'Afrique polyglotte. Paris: Payot. 
Atkinson, Quentin D. 2011. "Phonemic Diversity Supports a Serial Founder Effect Model of Language Expansion from Africa." Science 332. 346-349.

Axelrod, Robert. 1984. Evolution of Cooperation. New York: Basic Books.

Bar-Yosef, Ofer et al. 1992. "The Excavations in Kebara Cave, Mt. Carmel.” Current Anthropology 33.5. 497-550.

Barbrook, Adrian C., Christopher J. Howe, Norman Blake, and Peter Robinson. 1998. "The Phylogeny of the Canterbury Tales." Nature 394. 839.

Barkow, Jerome H., Leda Cosmides, and John Tooby (Eds.). The Adapted Mind. Evolutionary Psychology and the Generation of Culture. New York: Oxford University Press.

Barnard, Alan. 1995. "Orang Outang and the Definition of Man: The Legacy of Lord Monboddo." Fieldwork and Footnotes: Studies in the History of European Anthropology. Eds. H. F. Vermeulen and A. A. Roldan. London: Routledge. 95-112.

Barney, Stephen A., Wendy J. Lewis, Jennifer A. Beach, and Oliver Berghof. 2006. The Etymologies of Isidore of Seville. Cambridge: Cambridge University Press.

Bateson, Patrick and Kevin N. Laland. 2013. "Tinbergen's Four Questions: an Appreciation and an Update." Trends in Ecology and Evolution 28.12. 712-718.

Bavelas, Janet, Jennifer Gerwing, Chantelle Sutton, and Danielle Prevost. 2008. "Gesturing on the Telephone: Independent Effects of Dialogue and Visibility." Journal of Memory and Language 58. 495-520.

Bechtel, William, Adele Abrahamsen, and George Graham. 1998. "The Life of Cognitive Science.” A Companion to Cognitive Science. Eds. W. Bechtel and G. Graham. Oxford: Blackwell. 1-104.

Belin, Pascal, Robert J. Zatorre, Philippe Lafaille, Pierre Ahad, and Bruce Pike. 2000. "Voice-selective Areas in Human Auditory Cortex." Nature 403. 309-312.

Belin, Pascal and Robert J. Zatorre. 2003. “Adaptation to Speaker's Voice in Right Anterior Temporal Lobe.” Neuroreport 14. 2105-2109.

Bellugi, Ursula and Edward Klima. 2001. "Sign Language." International Encyclopedia of the Social and Behavioral Sciences. Vol. 21. Eds. 
N. Smelser and P. Baltes. Oxford: Elsevier Science Publishers. 14066-14071.

Benor, Ehud. 1995. “Meaning and Reference in Maimonides' Negative Theology." Harvard Theological Review 88.3. 339-360.

Benzaquen, Adriana S. 2006. Encounters with Wild Children. Temptation and Disappointment in the Study of Human and Nature. Montreal and Kingston, London and Ithaca: McGill's Queen University Press.

Bergman, Thore. J., Jacinta C. Beehner, Dorothy L. Cheney and Robert

M. Seyfarth. 2003. "Hierarchical Classification by Rank and Kinship in Baboons." Science 302.5648. 1234-1236.

Berwick, Robert C. and Noam Chomsky. 2011. "The Biolinguistic

Program: The Current State of Its Development." The Biolinguistic Enterprise: New Perspectives on the Evolution and Nature of the Human Language Faculty. Eds. A. M. Di Sciullo and C. Boeckx. Oxford: Oxford University Press. 19-41.

Beuchot, Mauricio. 1996. "Some Traces of the Presence of Scepticism in Medieval Thought." Scepticism in the History of Philosophy. Ed. R. Popkin. Dordrecht: Kluwer Press. 37-43.

Bickerton, Derek. 1990. Language and Species. Chicago: The University of Chicago Press.

Bickerton, Derek. 1998. "Catastrophic Evolution: The Case for a Single Step from Protolanguage to Full Human Language.” Approaches to the Evolution of Language. Social and Cognitive Bases. Eds. J. Hurford, M. Studdert-Kennedy, and C. Knight Cambridge: Cambridge University Press. 341-358.

Bickerton, Derek. 2003. "Symbol and Structure: A Comprehensive Framework." Language Evolution. Eds. M.H. Christiansen and S.

Kirby. Oxford: Oxford University Press. 77-93.

Bickerton, Derek. 2009. Adam's Tongue: How Humans Made Language, How Language Made Humans. New York: Macmillan.

Bickerton, Derek. 2014. "Some Problems for Biolinguistics." Biolinguistics 8. 073-096.

Boer, Bart de. 2012a. "Air Sacs and Vocal Fold Vibration: Implications for Evolution of Speech." Theoria et Historia Scientiarum IX. 13-28.

Boer, Bart de. 2012b. "Loss of air sacs improved hominin speech abilities." Journal of Human Evolution 62.1. 1-6. 
Bolhuis, Johan. J., Ian Tattersall, Noam Chomsky, and Robert C. Berwick. 2014. "How could language have evolved?" PLOS Biology 12.8: e1001934.

Boswell, James. 1934-1950. Life of Samuel Johnson. Oxford: Clarendon Press.

Botha, Rudolf. 2000. "Discussing the Evolution of the Assorted Beasts Called Language." Language and Communication 20.2. 149-160.

Botha, Rudolf. 2012. "Protolanguage and the 'God Particle'." Lingua 122.12. 1308-1324.

Bowles, Samuel and Herbert Gintis. 2011. A Cooperative Species: Human Reciprocity and Its Evolution. Princeton: Princeton University Press.

Boysen, Sarah. T., Gary G. Berntson, Michelle B. Hannan, and John T. Cacioppo. 1996. "Quantity-based interference and symbolic representations in chimpanzees (Pan troglodytes)." Journal of Experimental Psychology: Animal Behavior Processes 22.1. 76-86.

Boë, Louis-Jean, Jean-Louis Heim, Kiyoshi Honda, and Shinji Maeda. 2002. "The Potential Neanderthal Vowel Space Was as Large as That of Modern Humans." Journal of Phonetics 30.3. 465-484.

Boë, Louis-Jean, Shinji Maeda, and Jean-Louis Heim. 1999. "Neandertal man was not morphologically handicapped for speech." Evolution of Communication 3.1. 49-77.

Brentari, Diane. 1998. A Prosodic Model of Sign Language Phonology. Cambridge, MA: MIT Press.

Bräuer, Juliane, Josep Call, and Michael Tomasello. 2007. "Chimpanzees Really Know What Others Can See in a Competitive Situation." Animal Cognition 10.4. 439-448.

Brown, Erin J. 2012. The evolution of symbolic communication: An embodied perspective Linguistics and English Language. School of Philosophy, Psychology and Language Sciences, University of Edinburgh. Unpublished PhD.

Herrmann, Esther, Josep Call, María Victoria Hernández-Lloreda, Brian Hare, and Michael Tomasello. 2007. "Humans have evolved specialized skills of social cognition: The cultural intelligence hypothesis.” Science 317.5843. 1360-1366.

Budzicz, Łukasz. 2012. “Znaczenie Myślenia Ewolucyjnego we Współczesnej Psychologii.” Nauka 3. 91-118. 
Bunak, Vikotr V. 1959. Cerep čeloveka i stadii ego formirovanija u iskopaemych ljudej i sovremennych ras. Moscow: Ryska.

Burke, John G. 2009. “The Wild Man's Pedigree: Scientific Method and Racial Anthropology." The Wild Man Within: An Image in Western Thought from the Renaissance to Romanticism. Eds. E. Dudley and M. E. Novak. Pittsburgh: University of Pittsburgh Press. 259-280. Burling, Robbins. 2005. The Talking Ape: How Language Evolved. Oxford: Oxford University Press.

Burnett, James (Lord Monboddo). 1774. Of the Origin and Progress of Language. Edinburgh-London: Balfour, Cadell. https://archive.org/ details/originandprogre01conggoog. DOA: 17 Jan 2019.

Burnett, James (Lord Monboddo). 1811. “Lord Monboddo's Account of Peter the Wild Boy." A Selection of Curious Articles from the Gentleman's Magazine. Vol. 4, Appendix. Ed. J. Walker. London: Longman, Hurst, Rees, Orme and Brown. 581-584.

Buss, David M. 2003. “The Evolution of Desire: Strategies of Human Mating." Psychological Topics 15.2. 239-260.

Butler, Samuel. 2005 (1878). Life and Habit. New York: Cosimo.

Byrne, Richard W. and Andrew Whiten. 1988. Machiavellian Intelligence: Social Expertise and the Evolution of Intellect in Monkeys, Apes and Humans. Oxford: Oxford University Press.

Cabezón, José Ignacio. 1994. Buddhism and Language: A Study of Indo-Tibetan Scholasticism. Albany: State University of New York Press.

Call, Josep, Brian Hare, Malinda Carpenter, and Michael Tomasello. 2004. "'Unwilling' versus 'unable': chimpanzees' understanding of human intentional action." Developmental Science 7.4. 488-498.

Calvin, William H. 1982. "Did Throwing Stones Shape Hominid Brain Evolution?" Ethology and Sociobiology 3. 115-124.

Calvin, William H. 1983. The Throwing Madonna: Essays on the Brain. New York: McGraw-Hill.

Calvin, William H. and Derek Bickerton. 2000. Lingua ex Machine: Reconciling Darwin and Chomsky with the Human Brain. Cambridge, MA: MIT Press.

Capek, Cheryl M., Daffyd Waters, Benice Woll, Mairead MacSweeney, Michael J. Brammer, and Philip K. McGuire. 2008. "Hand and mouth: 
cortical correlates of lexical processing in British Sign Language and speech reading English." Journal of Cognitive Neuroscience 20. 1220 1234. DOI: 10.1162/jocn.2008.20084.

Carneiro, Robert. 2001. “Origin Myths." California Journal of Science Education 1.2. 39-50.

Carpenter, C. Ray. 1940. "A Field Study in Siam of the Behavior and Social Relations of the Gibbon (Hylobates lar)." Comparative Psychology Monographs 16.5. 1-212.

Carstairs-McCarthy, Andrew. 1996. "Review of Armstrong, Stokoe \& Wilcox "Gesture and the nature of language"." Lingua 99. 135-138.

Carstairs-McCarthy, Andrew. 1999. The Origin of Complex Language. Oxford: Oxford University Press.

Cartmill, Erica A. and Richard W. Byrne. 2010. "Semantics of Primate Gestures: Intentional Meanings of Orangutan Gestures.” Animal Cognition 13.6. 793-804.

Cashmore, Lisa A., Natalie Uomini, and Amandine Chapelain. 2008. "The Evolution of Handedness in Humans and Great Apes: A Review and Current Issues." Journal of Anthropological Sciences 86. 7-35.

Cesare, Donatella Ester di. 2011. "Grammar of Messianic Times:

Naharaim." Journal of German-Jewish Literature \& Cultural History/ Zeitschrift fur deutschjudische Literatur und Kulturgeschichte 5.1-2. 55-95.

Changeux, Jean-Pierre, Philippe Courrège, and Antoine Danchin. 1973. "A theory of the epigenesis of neuronal networks by selective stabilization of synapses." Proceedings of the National Academy of Sciences 70.10. 2974-2978.

Chardin, Pierre Teilhard de. 2002 (1955). The Phenomenon of Man. New York: Perennial.

Cheney, Dorothy L. and Robert M. Seyfarth. 2005. "Constraints and Preadaptations in the Earliest Stages of Language Evolution." The Linguistic Review 22.2-4. 135-159.

Chibelushi, Claud C., Farzin Deravi, and John S. Mason. 2002. “A Review of Speech-Based Bimodal Recognition.” Multimedia, IEEE Transactions 4.1. 23-37.

Chomsky, Noam A. 1957. Syntactic Structures. Princeton: Mouton. 
Chomsky, Noam A. 1962. "A Transformational Approach to Syntax." Proceedings of the Third Texas Conference on Problems of Linguistic Analysis in English, May 9-12, 1958. Ed. A. A. Hill. Austin: University of Texas Press. 124-148.

Chomsky, Noam A. 1965. Aspects of the Theory of Syntax. MIT Research Laboratory of Electronics Special Technical Report 11. Cambridge, MA: MIT Press.

Chomsky, Noam A. 1972. Language and Mind. New York: Harcourt Brace Jovanovich.

Chomsky, Noam A. 1986. Knowledge of Language: Its Nature, Origin, and Use. Westport: Greenwood Publishing Group.

Chomsky, Noam A. 1995. The Minimalist Program. Cambridge, MA: MIT Press.

Chomsky, Noam A. 2010. "Some Simple Evo-devo Theses: How True Might They Be for Language?” The Evolution of Human Language. Eds. R. Larson, V. Déprez, and H. Yamakido. Cambridge: Cambridge University Press, 54-62.

Christiansen, Morten H. 1994. Infinite Languages, Finite Minds: Connectionism, Learning and Linguistic Structure. Edinburgh: Edinburgh University Press.

Christiansen, Morten H. and Nick Chater. 2008. "Language as shaped by the brain." Behavioral and Brain Sciences 31.5. 489-509.

Christiansen, Morten H. and Simon Kirby (Eds.) 2003a. Language Evolution. Oxford: Oxford University Press.

Christiansen, Morten H. and Simon Kirby. 2003b. "Language Evolution: The Hardest Problem in Science?” Language Evolution. Eds. M. Christiansen and S. Kirby. Oxford: Oxford University Press. 1-15.

Christiansen, Morten H. and Simon Kirby. 2003c. "Language Evolution: Consensus and Controversies." Trends in Cognitive Sciences 7.7. 300-307.

Clark, J. Desmond et al. 2003. "Stratigraphic, Chronological and Behavioural Contexts of Pleistocene Homo Sapiens from Middle Awash, Ethiopia.” Nature 423.6941. 747-752.

Clay, Zanna and Klaus Zuberbühler. 2014. "Vocal Communication and Social Awareness in Chimpanzees and Bonobos: Insights from Studies of Vocal Communication." The Social Origins of Language. Eds. 
D. Dor, C. Knight, and J. Lewis. Oxford: Oxford University Press. 141-156.

Clutton-Brock, Tim. 2009. "Cooperation Between Non-Kin in Animal Societies.” Nature 462. 51-57.

Colby, Chris. 1996. Introduction to evolutionary biology. The

TalkOrigins Archive 7. http://www.talkorigins.org/faqs/faq-intro-tobiology.html. DOA: 17 Jan 2015.

Collinder, Björn. 1956. Swedish Research on the Language and Folklore of the Lapps. Stockholm: P.A. Norstedt \& Söner.

Condillac, Étienne B. de. 1756 (1746). An Essay on the Origin of Human Knowledge (Essai sur l'origine des connaissances humaines). Trans. T. Nugent. London: J. Nourse.

Coolidge, Frederick L. and Thomas Wynn. 2005. "Working Memory, Its Executive Functions, and the Emergence of Modern Thinking." Cambridge Archaeological Journal 15.01. 5-26.

Corballis, Michael C. 2002. From Hand to Mouth: The Origins of Language. Princeton: Princeton University Press.

Corballis, Michael C. 2003. "From Mouth to Hand: Gesture, Speech, and the Evolution of Right-Handedness." Behavioral and Brain Sciences 26.2. 199-208.

Corballis, Michael C. 2014. "The Gradual Evolution of Language.” Humana.Mente: Journal of Philosophical Studies 7.27. 39-60.

Corina, David. P., Jyotsna Vaid, and Ursula Bellugi. 1992. "The Linguistic Basis of Left Hemisphere Specialization.” Science 255. 1258-1260.

Cosmides, Leda and John Tooby. 1997. "Evolutionary Psychology: A Primer." Center for Evolutionary Psychology. http://www.psych.ucsb. edu/research/cep/index.html. DOA: 17 Jan 2015.

Coulton, George Gordon. 1906. From St. Francis to Dante. London: David Nutt.

Critchley, Macdonald. 1960. The Language of Gesture. London: Arnold.

Crystal, David. 1987. The Cambridge Encyclopaedia of Language. Cambridge: Cambridge University Press.

Cuvier, Georges. 1817/1840. The Animal Kingdom, Arranged According to its Organization, Forming the Basis for a Natural History of Animals and an Introduction to Comparative Anatomy. London: WM.S. Orr and co. Amen Corner, Paternoster Row. 
d'Errico, Francesco, Christopher Henshilwood, Marian Vanhaeren, and Karen Van Niekerk. 2005. "Nassarius Kraussianus Shell Beads from Blombos Cave: Evidence for Symbolic Behaviour in the Middle Stone Age." Journal of Human Evolution 48.1. 3-24.

Danesi, Marcel. 1993. Vico, Metaphor and the Origin of Language. Bloomington: Indiana University Press.

Dante, Alighieri. 2017. The Divine Comedy. Trans. F. W. Longfellow. New York: Dover Publications.

Darwin, Charles. 2013 (1859). On the Origin of Species by Means of Natural Selection. Salt Lake City: The Project Gutenberg.

Darwin, Charles. 2011 (1871). The Descent of Man, and Selection in Relation to Sex. Salt Lake City: The Project Gutenberg.

Dawkins, Richard. 1976. The Selfish Gene. Oxford: Oxford University Press.

Dawkins, Richard. 1983. "Universal Darwinism." Evolution from Molecules to Man. Ed. D. S. Bendall. Cambridge: Cambridge University Press. 403-425.

Dawkins, Richard. 1996. The Blind Watchmaker: Why The Evidence Of Evolution Reveals A Universe Without Design. New York: W. W. Norton.

Dawkins, Richard. 2006. The Selfish Gene. 30th Anniversary Edition. Oxford: Oxford University Press.

Deacon, Terrence. 1992. "The Neural Circuitry Underlying Primate Calls and Human Language." Language Origins: A Multidisciplinary Approach. Eds. J. Wind, B. Chiarelli, B. Bichakjian, A. Nocentini and A. Jonker Wind. Dordrecht: Kluwer. 121-162.

Deacon, Terrence. 1997. The Symbolic Species: The Co-Evolution of Language and the Brain. New York: W. W. Norton.

Deacon, Terrence. 1998. "Language Evolution and Neuromechanisms." A Companion to the Cognitive Science. Eds. W. Bechtel and G.

Graham. Oxford: Blackwell. 212-225.

Deacon, Terrence. 2000. "Evolutionary Perspective on Language and Brain Plasticity." Journal of Communication Disorders 33. 273-291.

Deacon, Terrence. 2003. "Multilevel Selection in a Complex Adaptive System: The Problem of Language Origins." Evolution and Learning: 
The Baldwin Effect Reconsidered. Eds. B. H. Weber and D. J. Depew. Cambridge, MA: MIT Press. 81-106.

Deacon, Terrence. 2004. “The Symbolic Species: Wywiad z Terrence'em Deaconem.” Centrum Badań nad Ewolucją Języka UMK. http://www. cles.umk.pl//PDF/WywiadTD.html. (DOA: 6 Jul 2015.)

Deacon, Terrence. 2011. "The Symbol Concept.” The Oxford Handbook of Language Evolution. Eds. K. R. Gibson and M. Tallerman. Oxford: Oxford University Press. 393-405.

Dediu, Dand and D. Robert Ladd. 2007. "Linguistic Tone is Related to the Population Frequency of the Adaptive Haplogroups of Two Brain Size Genes, ASPM and Microcephalin." Proceedings of the National Academy of Sciences 104.26. 10944-10949.

Dediu, Dan and Stephen C. Levinson. 2013. "On the Antiquity of Language: The Reinterpretation of Neandertal Linguistic Capacities and Its Consequences." Frontiers in Psychology 4.397. DOI: 10.3389/ fpsyg.2013.00397.

Dediu, Dan and Stephen C. Levinson. 2014. "Social Origins and the Time Frame of Language Evolution.” The Social Origins of Language. Eds. D. Dor, C. Knight, and J. Lewis. Oxford: Oxford University Press. 184-195.

DeGusta, David, W. Henry Gilbert, and Scott P. Turner. 1999. "Hypoglossal Canal Size and Hominid Speech." Proceedings of the National Academy of Sciences 96.4. 1800-1804.

Dennett, Daniel C. 1994. "The Role of Language in Intelligence.” What is Intelligence? The Darwin College Lectures. Ed. J. Khalfa. Cambridge: Cambridge University Press. 370-383.

Dennett, Daniel C. 1995. "Darwin's Dangerous Idea.” The Sciences 35.3. 34-40.

Dessalles, Jean-Luis. 2007. Why We Talk. The Evolutionary Origins of Language. Oxford: Oxford University Press.

Diamond, Arthur S. 1959. The History and Origin of Language. London: Methuen.

Dissanayake, Ellen. 2000. "Antecedents of the Temporal Arts in Early Mother-Infant Interaction." The Origins of Music. Eds. N. L. Wallin, B. Merker, and S. Brown. Cambridge, MA: MIT Press. 389-410. 
Doane, Thomas William. 1910. Bible Myths and Their Parallels in Other Religions: Being a Comparison of the Old and New Testament Myths and Miracles with Those of Heathen Nations of Antiquity, Considering Also Their Origin and Meaning. New York: Truth Seekers.

Dobzhansky, Theodosius. 1937. Genetics and the Origin of Species. New York: Columbia University Press.

Dobzhansky, Theodosius. 1973. "Nothing in Biology Makes Sense Except in the Light of Evolution." American Biology Teacher 35. 125-129

Donald, Merlin. 1991. Origins of the Modern Mind: Three Stages in the Evolution of Culture and Cognition. Cambridge: Harvard University Press.

Donald, Merlin. 2000. "Preconditions for the Evolution of Protolanguages." The Descent of Mind. Psychological Perspectives on Hominid Evolution. Eds. M. C. Corballis and S. Lea. New York: Oxford University Press. 355-365.

Donald, Merlin. 2012. "The mimetic origins of language.” The Oxford Handbook of Language Evolution. Eds. M. Tallerman and K. R. Gibson. Oxford: Oxford University Press. DOI: 10.1093/oxfor $\mathrm{dhb} / 9780199541119.013 .0017$.

Dor, Daniel and Eva Jablonka. 2014. "Why We Need to Move from Gene-Culture Co-Evolution to Culturally Driven Co-Evolution." The Social Origins of Language. Eds. D. Dor, C. Knight, and J. Lewis. Oxford: Oxford University Press. 15-30.

Dor, Daniel, Christopher Knight, and Jerome Lewis (Eds.) 2014. The Social Origins of Language. Oxford: Oxford University Press.

Dreyfus, Georges B. J. 1997. Recognizing Reality: Dharmakirti's Philosophy and Its Tibetan Interpretations. Albany: State University of New York Press.

Drogosz, Anna. 2013. "Evolutionary Change Is a JOURNEY. From Darwin to Dawkins." Acta Neophilologica XV.2. 19-29.

Dryer, Matthew S. and Martin Haspelmath (Eds.) 2011. The World Atlas of Language Structures (WALS) Online. Munich: Max Planck Digital Library.

Dugatkin, Lee A. 2002. "Cooperation in Animals: An Evolutionary Overview." Biology and Philosophy 17. 459-476. 
Dunbar, Robin. 1995. "Neocortex Size and Group Size in Primates: A Test of the Hypothesis." Journal of Human Evolution 28.3. 287-296.

Dunbar, Robin. 1996. Grooming, Gossip and the Evolution of Language. London: Faber \& Faber.

Dunbar, Robin. 1998. "The social brain hypothesis." Evolutionary Anthropology: Issues, News, and Reviews: Issues, News, and Reviews 6.5. 178-190.

Dunbar, Robin. 2007. "The Social Brain Hypothesis and Its Relevance to Social Psychology." Evolution and the Social Mind. Eds. J. Forgas, M. Haselton, and W. von Hippel. New York: Psychology Press. 21-31.

Dunn, Michael, Simon J. Greenhill, Stephen C. Levinson, and Russell D. Gray. 2011. "Evolved Structure of Language Shows Lineage-Specific Trends in Word-Order Universals." Nature 473. 79-82.

Eco, Umberto. 1995. The Search for the Perfect Language. Oxford: Wiley-Blackwell.

Eibl-Eibesfeldt, Irenaus. 1996 (1970). Love and Hate: The Natural History of Behavior Patterns. New York: Aldine de Gruyter.

Ekman, Paul and Wallace V. Friesen. 1969a. "The Repertoire of Nonverbal Behavior: Categories, Origins, Usage, and Coding." Semiotica 1. 49-98.

Ekman, Paul and Wallace V. Friesen. 1969b. "Nonverbal Leakage and Clues to Deception." Psychiatry 32. 88-106.

Ekman, Paul and Wallace V. Friesen. 1972. "Hand Movements." The Journal of Communication 22. 353-374.

Gould, Stephen J. and Niles Eldredge. 1972. "Punctuated Equilibria: An Alternative to Phyletic Gradualism." Models in Paleobiology. Ed. T. J. M. Schopf. San Francisco: Freeman, Cooper and Company. 82-115. Emery, Nathan J. and Nicola S. Clayton. 2001. "Effects of Experience and Social Context on Prospective Caching Strategies by Scrub Jays." Nature 414.6862. 443-446.

Emmorey, Karen. 2002. Language, Cognition, and Brain: Insights from Sign Language Research. Hillsdale: Lawrence Erlbaum.

Enard, Wolfgang et al. 2002. "Molecular evolution of FOXP2, a gene involved in speech and language." Nature 418.6900. 869.

Enard, Wolfgang et al. 2009. "A Humanized Version of FOXP2 Affects Cortico-Basal Ganglia Circuits in Mice.” Cell 137.5. 961-971. 
Enfield, Nick and Jack Sidnell. 2014. "Language Presupposes an Enchronic Infrastructure for Social Interaction.” The Social Origins of Language. Eds. D. Dor, C. Knight and J. Lewis. Oxford: Oxford University Press. 92-104.

Everett, Caleb, Damián E. Blasi, and Seán G. Roberts. 2015. "Climate, Vocal Folds, and Tonal Languages: Connecting the Physiological and Geographic Dots." Proceedings of the National Academy of Sciences. 112.5. 1322-1327.

Fadiga Luciano, Laila Craighero, and Allesandro d'Ausilio. 2009.

"Broca's Area in Language, Action and Music." Annals of the New York Academy of Sciences 1169. 448-458.

Falk, Dean. 2004. "Prelinguistic Evolution in Early Hominins: Whence Motherese?" Behavioral and Brain Sciences 27.04. 491-503.

Falk, Dean. 2009. Finding Our Tongues: Mothers, Infants and the Origins of Language. New York: Basic Books.

Fano, Giorgio. 1962. Saggio sulle Origini del Linguaggio, Con una Storia Critica delle Dottrine Glottogoniche. Torino: Guilio Einaudi.

Farrar, Frederic William. 1860. An Essay on the Origin of Language Based on Modern Researches, and Especially on the Works of $M$. Renan by Frederic W. Farrar. London: J. Murray.

Farrar, Frederic William. 1870. "Philology and Darwinism.” Nature 1.21. 528-529.

Fay, Nicolas, Michael Arbib, and Simon Garrod. 2013. "How to Bootstrap a Human Communication System." Cognitive Science 37. 1356-1367.

Ferber, Ilit. 2010. "Herder: On Pain and the Origin of Language." The Germanic Review 85.3. 205-223.

Fernald, Anne. 1992. "Human Maternal Vocalizations to Infants as Biologically Relevant Signals: An Evolutionary Perspective." The Adapted Mind. Evolutionary Psychology and the Generation of Culture. Eds. J. H. Barkow, L. Cosmides, and J. Tooby. New York: Oxford University Press. 391-428.

Ferretter, Luke. 1998. "The Trace of the Trinity: Christ and Difference in St. Augustine's Theory of Language." Literature and Theology 12.3. 256-267.

Fisher, Ronald A. 1918. "On the Correlation between Relatives on the Supposition of Mendelian Inheritance." Proceedings of the Royal Society of Edinburgh 52.399-433. 
Fisher, Ronald A. 1927. “On Some Objections to Mimicry Theory; Statistical and Genetic." Transactions of the Royal Entomological Society of London 75.2. 269-278.

Fisher, Ronald A. 1930. "The Distribution of Gene Ratios for Rare Mutations." Proceedings of the Royal Society of Edinburgh 50. 205-220.

Fisher, Simon E., Faraneh Vargha-Khadem, Kate E. Watkins, Anthony P. Monaco, and Marcus E. Pembrey. 1998. "Localisation of a Gene Implicated in a Severe Speech and Language Disorder." Nature Genetics 18. 168-170.

Fisiak, Jacek. 1985. Wstęp do Współczesnych Teorii Lingwistycznych. Warszawa: WSiP.

Fitch, Tecumseh W. 2000. "The Evolution of Speech: A Comparative Review." Trends in Cognitive Sciences 4.7. 258-267.

Fitch, Tecumseh W. 2002. "The Evolution of Language Comes of Age." Trends in Cognitive Sciences 6.7. 278-279.

Fitch, Tecumseh W. 2004. "Kin Selection and 'Mother Tongues':

A Neglected Component in Language Evolution." Evolution of Communication Systems: A Comparative Approach. Eds. D. K. Oller and U. Griebel. Cambridge, MA: MIT Press. 275-296.

Fitch, Tecumseh W., Marc D. Hauser, and Noam A. Chomsky. 2005. "The Evolution of the Language Faculty: Clarifications and Implications." Cognition 97.2. 179-210.

Fitch, Tecumseh W. 2010. The Evolution of Language. Cambridge: Cambridge University Press.

Fogassi, Leonardo and Pier F. Ferrari. 2004. "Mirror Neurons, Gestures and Language Evolution." Interaction Studies 5. 345-363.

Formigari, Lia. 1988. Language and Experience in 17th-Century British Philosophy. Philadelphia: John Benjamins.

Formigari, Lia. 1974. "Language and Society in the Late Eighteenth Century." Journal of the History of Ideas 35.2. 275-292.

Frisch, Karl von. "Dialects in the Language of the Bees." Scientific American 207. 78-89.

Furness, William H. 1916. "Observations on the Mentality of Chimpanzees and Orangutans." Proceedings of the American Philosophical Society 55. 281-290. 
Fyler, John M. 2010. Language and the Declining World in Chaucer, Dante, and Jean de Meun. Cambridge: Cambridge University Press.

Gallagher, Andrew. 2014. "Absolute and Relative Endocranial Size in Neandertals and Later Pleistocene Homo." HOMO: Journal of Comparative Human Biology 65.5. 349-375.

Gallup, Gordon. 1970. “Chimpanzees: self-recognition.” Science 167. 86-87.

Gärdenfors, Peter. 2002. Cooperation and the evolution of symbolic communication. Lund University.

Gardner, R. Allen and Beatrice T. Gardner. 1969. "Teaching Sign Language to a Chimpanzee." Science 165. 664-672.

Gardner, R. Allen and Beatrice T. Gardner. 1971. "Two-Way

Communication with an Infant Chimpanzee." Behavior of Nonhuman Primates. Eds. A. Schrier and F. Stollnitz. New York: Academic Press. 117-184.

Garner, Richard Lynch. 1900. Apes and Monkeys: Their Life and Language. Boston-London: Ginn \& Company.

Gentilucci, Maurizio and Michael C. Corballis. 2006. "From Manual Gesture to Speech: A Gradual Transition.” Neuroscience and Biobehavioral Reviews 30. 949-960.

Ghazanfar, Asif A and Marc D. Hauser. 2001. "The Auditory Behaviour of Primates: A Neuroethological Perspective.” Current Biology 11. 712-720.

Givón, Thomas and Sue Savage-Rumbaugh. 2006. "Can Apes Learn Grammar? A Short Detour into Language Evolution.” Crosslinguistic Approaches to the Psychology of Language: Research in the Tradition of Dan Isaac Slobin. Eds. J. Guo, E. Lieven, N. Budwig, S. Ervin-Tripp, K. Nakamura, and S. Ozcaliskan. London: Psychology Press. 299-309.

Gleason, Jean B. and Nan B. Ratner. 2005 (1998). Psycholingwistyka. Trans. J. Bobryk. Gdańsk: Gdańskie Wydawnictwo Psychologiczne.

Gode, Alexander and John M. Moran. 1986. Two Essays on the Origin of Language. Chicago: The University of Chicago Press.

Goldin-Meadow, Susan. 2003. Hearing Gesture: How Our Hands Helps Us Think. Cambridge, MA: The Belknap Press of Harvard University Press.

Goldin-Meadow, Susan. 2008. "Gesture, Speech, and Language.” Proceedings of the 7th International Conference on the Evolution of 
Language. Eds. A. Smith, K. Smith, and R. Ferrer-i-Cancho. London: World Scientific. 427-428.

Goldin-Meadow, Susan. 2011. "What Modern-day Gesture Can Tell Us about Language Evolution.” The Oxford Handbook of Language Evolution. Eds. M. Tallerman and K. R. Gibson. Oxford: Oxford University Press. 545-557.

Goldin-Meadow, Susan, Wing C. So, Asli Özyürek, and Carolyn Mylander. 2008. "The Natural Order of Events: How Speakers of Different Languages Represent Events Nonverbally." Proceedings of the National Academy of Sciences of the USA 105.9163-9168.

Gomes, Christina M. and Christophe Boesch. 2009. "Wild Chimpanzees Exchange Meat for Sex on a Long-Term Basis." PLOS ONE 4.4. DOI: https://doi.org/10.1371/journal.pone.0005116

Gong, Tao, Lan Shuai, and Bernard Comrie. 2014. "Evolutionary Linguistics: Theory of Language in an Interdisciplinary Space." Language Sciences 41. 243-253.

Gonseth, Chloe, Anne Vilain, and Coriandre Vilain. 2012. "Ontogeny of Two Communicative Tools: Distance Encoding and Multimodality in Deictic Pointing." Proceedings of the 9th International Conference (EVOLANG 9). Eds. T. Scott-Phillips, M. Tamariz, E. Cartmill, and J. Hurford. New Jersey: World Scientific. 150-157.

Goodall, Jane. 1969. "Some Aspects of Reproductive Behaviour in a Group of Wild Chimpanzees, Pan Troglodytes Schweinfurthii, at the Gombe Stream Chimpanzee Reserve, Tanzania, East Africa.” Journal Reproduction of Fertility. 6. 353-355.

Goodall, Jane. 1971. In the Shadow of Man. Boston: Houghton Mifflin Publishing.

Goodall, Jane. 1986. The Chimpanzees of Gombe. Boston: Houghton Mifflin Publishing.

Gopnik, Myrna. 1990. "Feature Blindness: A Case Study.” Language Acquisition 1.2. 139-164.

Gould, Stephen J. and Richard C. Lewontin. 1979. "The Spandrels of San Marco and the Panglossian Paradigm: A Critique of the Adaptationist Programme." Proceedings of the Royal Society of London. Series B, Biological Sciences 205.1161. 581-598.

Gould, Stephen J. 1994. “The Evolution of Life on Earth.” Scientific American 271. 85-91. 
Gould, Stephen J. 1999. Niewczesny Pogrzeb Darwina. Trans. N. Kancewicz-Hoffman. Warszawa: Prószyński.

Gowlett, John A. 2003. "What Actually Was the Stone Age Diet?" Journal of Nutritional and Environmental Medicine 13.3. 143-147.

Gowlett, John A. 2009a. "Artefacts of Apes, Humans, and Others: Towards Comparative Assessment and Analysis." Journal of Human Evolution 57.4. 401-410.

Gowlett, John A. 2009b. “The Longest Transition or Multiple Revolutions?" Sourcebook of Paleolithic Transitions. Eds. M. Camps and P. Chauhan. New York: Springer. 65-78.

Graves, Joseph L. Jr. 2003. The Emperor's New Clothes: Biological Theories of Race at the Millennium. Newark: Rutgers University Press.

Green, Richard E. et al. 2010. "A Draft Sequence of the Neandertal Genome.” Science 328.5979. 710-722.

Grice, Herbert P. 1999 (1975). "Logic and Conversation." The Discourse Reader. Eds. A. Jaworski and N. Coupland. London: Routledge. 66-77.

Guttman, Burton. 2005. Evolution: A beginner's guide. Oxford: Oneworld Publications.

Gärdenfors, Peter. 2002. Cooperation and the Evolution of Symbolic Communication. Lund: Lund University.

Haeckel, Ernst. 1874. Anthropogenie; oder, Entwicklungsgeschichte des Menschen. Leipzig: Wilhem Engelmann.

Hamilton, William D. 1964a. "The Genetical Evolution of Social Behavior I.” Journal of Theoretical Biology 7.1.1-16.

Hamilton, William D. 1964b. "The Genetical Evolution of Social Behaviour II.” Journal of Theoretical Biology 7.1. 17-52.

Hamilton, William D. 1972. "Altruism and related phenomena, mainly in social insects." Annual Review of Ecology and Systematics 3.1. 193-232.

Hare, Brian and Michael Tomasello. 2004. Chimpanzees Are more Skilful in Competitive than in Cooperative Cognitive Tasks." Animal Behaviour 68, 571-581.

Harnad, Stevan. 2002. "Symbol Grounding and the Origin of Language." Computationalism: New Directions. Ed. M. Scheutz. Cambridge, 
MA: MIT Press. 143-158. http://users.ecs.soton.ac.uk/harnad/Papers/ Harnad/harnad02.symlang.htm http://cogprints.org/192/00/rolelang. htm ED 04/2006. (DOA: 6 Jul 2015.)

Harpham, Geoffrey G. 2009. "Roots, Races, and the Return to Philology." Representations 106.1. 34-62.

Harrison, Rebecca. 2008. "What Can the Study of Handedness in Nonhuman Apes Tell Us about the Evolution of Language." Proceedings of the 7th International Conference on the Evolution of Language (EVOLANG 7). Eds. A. Smith, K. Smith, and R. Ferrer-iCancho. London: World Scientific. 427-428.

Hauser, Marc D., Elissa L. Newport, and Richard N. Aslin. 2001. "Segmentation of the Speech Stream in a Non-human Primate:

Statistical Learning in Cotton-top Tamarins." Cognition 78. B53-B64.

Hauser, Marc D., Noam A. Chomsky, and Tecumseh W. Fitch. 2002. "The Faculty of Language: What Is It, Who Has It, and How Did It Evolve?" Science 298. 1569-1579.

Hauser, Marc D., Charles Yang, Robert C. Berwick, Ian Tattersall, Michael J. Ryan, Jeffrey Watumull, Noam A. Chomsky, and Richard C. Lewontin. 2014. "The Mystery of Language Evolution.” Frontiers in Psychology 5. DOI: 10.3389/fpsyg.2014.00564.

Hauser, Marc D., David Barner, and Tim O’Donnell. 2007. “Evolutionary Linguistics: A New Look at an Old Landscape.” Language Learning and Development 3.2. 101-132.

Hawhee, Debra. 2006. "Language as Sensuous Action: Sir Richard Paget, Kenneth Burke, and Gesture-Speech Theory." Quarterly Journal of Speech 92.4. 331-354.

Hawks, John. 2011. "Selection for Smaller Brains in Holocene Human Evolution.” arXiv preprint arXiv:1102.5604.

Hayes, Keith J. and Catherine Hayes. 1952. "Imitation in a Home-Raised Chimpanzee." Journal of Comparative and Physiological Psychology 45. 450-459.

Heams, Thomas, Philippe Huneman, Guillaume Lecointre, and Marc Silberstein (Eds.) 2014. Handbook of Evolutionary Thinking in the Sciences. New York: Springer.

Heine, Bernd and Tania Kuteva. 2007. The Genesis of Grammar: A Reconstruction. Oxford: Oxford University Press. 
Henrich, Joseph and Natalie Henrich. 2007. Why Humans Cooperate: A Cultural and Evolutionary Explanation. Oxford: Oxford University Press.

Herder, Johann Gottfried. 1967-68. Sämtliche Werke Vol. V. Hildesheim: Georg Olms Verlagsbuchhandlung.

Hewes, Gordon W. 1973. "Primate Communication and the Gestural Origin of Language." Current Anthropology 14.1-2. 5-24.

Hewes, Gordon W. 1975. Language Origins: A Bibliography. The Hague: Mouton.

Hewes, Gordon W. 1976. "The Current Status of the Gestural Theory of Language Origin." Annals of the New York Academy of Sciences 280.1. 482-504.

Hewes, Gordon W. 1977a. “A Model for Language Evolution.” Sign Language Studies 15. 97-168.

Hewes, Gordon W. 1977b. "Language Origin Theories." Language Learning by a Chimpanzee: The Lana Project. Ed. D. Rumbaugh. New York: Academic Press. 3-53.

Hewes, Gordon W. 1981. "Pointing and Language." The Cognitive Representation of Speech. Eds. T. Myers, J. Laver, and J. Anderson. Amsterdam: North Holland. 263-269.

Hewes, Gordon W. 1996. "A History of the Study of Language Origins and the Gestural Primacy Hypothesis." Handbook of Human Symbolic Evolution. Eds. A. Lock and C. R. Peters. Oxford: Oxford University Press. 263-269.

Heyes, Cecilia M. 1998. "Theory of Mind in Nonhuman Primates." Behavioral and Brain Sciences 21.1. 101-148.

Hickok, Gregory, Ursula Bellugi, and Edward S. Klima. 1996. “The Neurobiology of Sign Language and Its Implications for the Neural Basis of Language.” Nature 381. 699-702.

Higginbotham, David, Matthew I. Isaak, and James N. Domingue. 2008. "The Exaptation of Manual Dexterity for Articulate Speech: An Electromyogram Investigation." Experimental Brain Research 186.4. 603-609.

Hobaiter, Cat and Richard W. Byrne. 2012. "Gesture Use in Consortship: Wild Chimpanzees' Use of Gesture for an 'Evolutionarily Urgent' Purpose." Developments in Primate Gesture Research 6. 129-146. 
Hockett, Charles F. 1958. A Course in Modern Linguistics. New York: Macmillan.

Hockett, Charles F. 1959. “Animal 'Languages’ and Human Language.” Human Biology 31. 32-39.

Hockett, Charles F. 1960a. "The Origin of Speech." Scientific American 203. 88-111.

Hockett, Charles F. and Robert Ascher. 1964. "The Human Revolution." Current Anthropology 5.3. 135-147.

Hockett, Charles F. 1966. "The Problem of Universals in Language.” Universals of Language. Ed. J. Greenberg. Cambridge, MA: MIT Press. $1-29$.

Hockett, Charles F. 1977 (1960b). "Logical Considerations in the Study of Animal Communication." The View from Language: Selected Essays 1948-1974. Athens: The University of Georgia Press. 124-162.

Hockett, Charles F and Stuart A. Altmann. 1968. "A Note on Design Features." Animal Communication: Techniques of Study and Results of Research. Ed. T. Sebeok. Bloomington: Indiana University Press. 61-72.

Holekamp, Kay I., Erin E. Boydston, Micaela Szykman, Isla Graham, Karen J. Nutt, Sarah Birch, Audra Piskiel, and Mandeep Singh. 1999. "Vocal Recognition in the Spotted Hyaena and Its Possible Implications Regarding the Evolution of Intelligence." Animal Behaviour 58.2. 383-395.

Hopkins, William D. 2006. "Comparative and Familial Analysis of Handedness in Great Apes." Psychological Bulletin 132.4. 538-559. Hrdy, Sarah B. 2000. Mother Nature: Maternal Instincts and How They Shape the Human Species. New York: Ballantine Books.

Hrdy, Sarah B. 2009. Mothers and Others: The Evolutionary Origins of Mutual Understanding. Cambridge, MA: The Belknap Press of Harvard University Press.

Hurford, James R. 1999. "The Evolution of Language and Languages.” The Evolution of Culture. Eds. R. Dunbar, C. Knight, and C. Power. Edinburgh: Edinburgh University Press. 173-193.

Hurford, James R. 2003. "The Language Mosaic and its Evolution." Language Evolution: The States of the Art. Eds. M. H. Christiansen, and S. Kirby. Oxford: Oxford University Press. 38-57. 
Hurford, James R. 2007. The Origins of Meaning: Language in the Light of Evolution. Oxford: Oxford University Press.

Hurford, James R. 2011. "The Origins of Meaning.” The Oxford Handbook of Language Evolution. Eds. M. Tallerman and K. R. Gibson. Oxford: Oxford University Press. 370-381.

Hurford, James R. 2014. The Origins of Language: A Slim Guide. Oxford: Oxford University Press.

Hutto, Daniel D. 2008. "First Communions: Mimetic Sharing without Theory of Mind." The Shared Mind: Perspectives on Intersubjectivity. Eds. J. Zlatev, T. Racine, C. Sinha, and E. Itkonen. Amsterdam: John Benjamins Publishing. 246-276.

Iacoboni, Marco, Roger P. Woods, Marcel Brass, Harold Bekkering, John C. Mazziotta, and Giacomo Rizzolatti. 1999. "Cortical Mechanisms of Human Imitation.” Science 286. 2526-2528.

Idel, Moshe. 1989. Language, Torah and Hermeneutics in Abraham Abulafia. Albany: SUNY Press.

Imai, Mutsumi and Sotaro Kita. 2014. "The Sound Symbolism

Bootstrapping Hypothesis for Language Acquisition and Language Evolution." Philosophical Transactions of the Royal Society B:

Biological Sciences 369.1651. 20130298.

Inoue, Sana and Tetsuro Matsuzawa. 2007. "Working Memory of Numerals in Chimpanzees." Current Biology 17.23. R1004-R1005.

Insley, Stephen J. 2000. "Long-term Vocal Recognition in the Northern Fur Seal." Nature 406. 404-405.

Itani, Junichiro. 1963. "Vocal Communication of the Wild Japanese Monkey." Primates 4.2. 11-66.

Itard, Jean M. G. 1802 (1801). [Mémoire et Rapport sur Victor de l'Aveyron] An Historical Account of the Discovery and Education of a Savage Man: Or, the First Developments, Physical and Moral, of the Young Savage Caught in the Woods Near Aveyron in the Year 1798. London: Richard Phillips. Digital version available at: http://books.google. $\mathrm{pl} /$ books?id=E63cRcnV2hIC\&printsec=frontcover\&source=gbs_ge_sum mary_r\&cad=0\#v=onepage\&q=lait\&f=false (DOA: 186 Sep 2015.)

Iverson, Jana M. and Susan Goldin-Meadow. 1997. "What

Communication Got to Do with It? Gesture in Congenitally Blind Children." Developmental Psychology 33. 453-467. 
Jackendoff, Ray. 1999. "Possible Stages in the Evolution of the Language Capacity." Trends in Cognitive Sciences 3.7. 272-279.

Jackendoff, Ray. 2002. Foundations of Language. Brain, Meaning, Grammar, Evolution. New York: Oxford University Press.

Jackendoff, Ray. 2010. "Your Theory of Language Evolution Depends on Your Theory of Language." The Evolution of Human Language: Biolinguistic Perspectives. Eds. R. Larson, V. Deprez, and H. Yamakido. Cambridge: Cambridge University Press. 63-72. Jackendoff, Ray and Steven Pinker. 2005. "The Nature of the Language Faculty and Its Implications for Evolution of Language." Cognition 97.2. 211-225.

Jahoda, Gustav. 1999. Images of Savages: Ancients [sic] Roots in Modern Prejudice in Western Culture. London: Routledge.

Janik, Vincent M., Laela S. Sayigh, and Randall S. Wells. 2006. "Signature Whistle Shape Conveys Identity Information to Bottlenose Dolphins." Proceedings of the National Academy of Sciences 103.21. 8293-8297. Jasiński, A. 2010. “C. F. Hockett i jego 13 Uniwersaliów Językowych.” Evolectorium. http://evolectorium.com/, DOA: 12 Feb 2015. Jespersen, Otto. 1922. Language: Its Nature, Origin and Development. London: Allen and Unwin.

Joffe, Tracey. H. 1997. "Social Pressures Have Selected for an Extended Juvenile Period in Primates." Journal of Human Evolution 32.6. 593-605.

Johansson, Sverker. 2005. Origins of Language: Constraints on Hypotheses. Amsterdam: John Benjamins Publishing. Johansson, Sverker. 2008. "Seeking Compositionality in Holistic ProtoLanguage without Substructure - Do Counterexamples Overwhelm the Fractionation Process?" Proceedings of the 7th International Conference on the Evolution of Language. Eds. A. Smith, K. Smith, and R. Ferrer-i-Cancho. London: World Scientific. 171-178.

Johansson, Sverker. 2012. "The Case for Neanderthal Language How Strong Is It?" Proceedings of the 9th International Conference (EVOLANG 9). Eds. T. Scott-Phillips, M. Tamariz, E. Cartmill, and J. R. Hurford. New Jersey: World Scientific. 173-180. Johansson, Sverker. 2013. "The Talking Neanderthals: What Do Fossils, Genetics, and Archeology Say?” Biolinguistics 7. 35-74. 
Johansson, Sverker. 2014. "How Can a Social Theory of Language Evolution Be Grounded in Evidence?" The Social Origins of Language. Eds. D. Dor, C. Knight, and J. Lewis. Oxford: Oxford University Press. 56-64.

Jones, William. 1924 (1786). Discourses Delivered Before the Asiatic

Society: And Miscellaneous Papers, on the Religion, Poetry, Literature, etc., of the Nations of India. London: C. S. Arnold.

Jordan, David S. 2013 (1907). Evolution and Animal Life: An Elementary Discussion of Facts, Processes. London: Forgotten Books.

Jusczyk, Peter W. 1999. "How Infants Begin to Extract Words from Speech.” Trends in Cognitive Sciences 3. 323-328.

Kaas, Jon. H. and Troy A. Hackett. 2000. "Subdivisions of Auditory

Cortex and Processing Streams in Primates." Proceedings of the National Academy of Sciences 97. 11793-11799.

Kainz, Friedrich. 1960-1962. Psychologie der Sprache. Vols. I-II.

Stuttgart: Ferdinand Enke Verlag.

Kastinger Riley, Helene M. 1979. "Some German Theories on the Origin of Language from Herder to Wagner." The Modern Language Review 74.3. 617-632.

Kawai, Masao. 1965. "Newly-Acquired Pre-Cultural Behavior of the Natural Troop of Japanese Monkeys on Koshima Islet.” Primates 6.1. $1-30$.

Kawamura, Syunzo. 1959. "The Process of Sub-Culture Propagation Among Japanese Macaques.” Primates 2.1. 43-60.

Kay, Richard F., Matt Cartmill, and Michelle Balow. 1998. "The Hypoglossal Canal and the Origin of Human Vocal Behavior." Proceedings of the National Academy of Sciences of the USA 95. 5417-5419.

Kaye, Frederick B. 1924. "Mandeville on the Origin of Language." Modern Language Notes 39.3. 136-142.

Kegl, Judy, Ann Senghas, and Marie Coppola. 1999. "Creation Through Contact: Sign Language Emergence and Sign Language Change in Nicaragua." Language Creation and Language Change: Creolization, Diachrony, and Development. Ed. M. DeGraff. Cambridge, MA: MIT Press. 179-237.

Kellner, Menachem. 2006. Maimonides' Confrontation with Mysticism. Oxford: Littman Library of Jewish Civilization. 
Kellogg, Winthrop N. and Luella A. Kellogg. 1933. The Ape and the Child: A Comparative Study of the Environmental Influence upon Early Behavior. New York: Hafner.

Kendon, Adam. 1972. "Some Relationships Between Body Motion and Speech." Studies in Dyadic Communication. Eds. A. Seigman and B. Pope. Elmsford: Pergamon Press. 177-216.

Kendon, Adam. 1975. "Gesticulation, Speech and the Gesture Theory of Language Origins.” Sign Language Studies 9. 349-373.

Kendon, Adam. 1983a. "Gesture and Speech: How They Interact."

Nonverbal Interaction. Eds. J. M. Wiemann and R. Harrison. Beverly Hills: Sage. 13-46.

Kendon, Adam. 1983b. "Gesture." Journal of Visual Verbal Languaging 3.2. 21-36.

Kendon, Adam. 1991. "Some Considerations for a Theory of Language Origins." Man 26. 199-221.

Kendon, Adam. 2004. Gesture: Visible Action as Utterance. Cambridge: Cambridge University Press.

Kendon, Adam. 2008. "Signs for Language Origins?" The Public Journal of Semiotics II.2. 2-29.

Kendon, Adam. 2011. "Some Modern Considerations for Thinking about Language Evolution: A Discussion of the Evolution of Language by Tecumseh Fitch.” The Public Journal of Semiotics 3.1. 79-108.

Kendon, Adam. 2014. "The 'Poly-Modalic' Nature of Utterances and Its Relevance for Inquiring into Language Origins.” The Social Origins of Language. Eds. D. Dor, C. Knight, and J. Lewis. Oxford: Oxford University Press. 67-76.

Kenneally, Christine. 2007. The First Word. New York: Viking. Kinsella, Anna R. 2009. Language Evolution and Syntactic Theory. Cambridge: Cambridge University Press.

Kirby, Simon, Hannah Cornish, and Kenny Smith. 2008. "Cumulative Cultural Evolution in the Laboratory: An Experimental Approach to the Origins of Structure in Human Language." Proceedings of the National Academy of Sciences 105.31. 10681-10686.

Kirby, Simon, Kenny Smith, and Henry Brighton. 2004. "From UG to Universals: Linguistic Adaptation Through Iterated Learning." Studies in Language 28.3. 587-607. 
Klawiter, Andrzej. 2004. "Powab i Moc Wyjaśniająca Kognitywistyki.” Nauka 3. 101-120.

Knecht, Stefan, Bianca Dräger, Michael Deppe, Lars Bobe, Hubertus Lohmann, Agnes Flöel, Bernd E. Ringelstein, and Henning Henningsen. 2000. "Handedness and Hemispheric Language Dominance in Healthy Humans." Brain 123. 2512-2518.

Knight, Chris. 1998. "Ritual/Speech Coevolution: A Solution to the Problem of Deception." Approaches to the Evolution of Language. Social and Cognitive Bases. Eds. J. R. Hurford, M. Studdert-Kennedy, and C. Knight. Cambridge: Cambridge University Press. 68-91.

Knight, Chris. 2000. "Play as Precursors of Phonology and Syntax." The Evolutionary Emergence of Language. Eds. C. Knight, M. StuddertKennedy, and J. Hurford. Cambridge: Cambridge University Press. 99-119.

Knight, Chris. 2014. "Language and Symbolic Culture: An Outcome of Hunter-Gatherer Reverse Dominance." The Social Origins of Language. Eds. D. Dor, C. Knight, and J. Lewis. Oxford: Oxford University Press. 228-246.

Kobayashi, Hiromi and Shiro Kohshima. 1997. "Unique Morphology of the Human Eye.” Nature 387.6635. 767-768.

Kobayashi, Hiromi and Shiro Kohshima. 2001. "Evolution of the Human Eye as a Device for Communication." Primate origins of human cognition and behavior. Ed. T. Matsuzawa. Tokyo: Springer Japan. 383-401.

Kojima, Shozo and Shigeru Kiritani. 1989. "Vocal-auditory Functions in the Chimpanzee: Vowel Perception." International Journal of Primatology. 10.3. 199-213. 10.1007/BF02735200.

Komendziński, Tomasz. 2002. "Ewolucyjna Psychologia Poznawcza Stevena Pinkera w Kontekście Rozwoju Nauk Kognitywnych.” Kognitywistyka i Media w Edukacji 6.1-2. 115-154.

Krause, Johannes, Lalueza-Fox, Carles, Ludovic Orlando, Wolfgang Enard, Richard E. Green, Hernán A. Burbano, Jean-Jacques Hublin, Catherine Hänni, Javier Fortea, Marco de la Rasilla, Jaume Bertranpetit, Antonio Rosas, and Svante Pääbo. 2007. "The Derived FOXP2 Variant of Modern Humans was Shared with Neandertals." Current Biology 17.21. 1908-1912. 
Krauss, Robert. M., Yihsiu Chen, and Rebecca F. Gottesman. 2000. "Lexical Gestures and Lexical Access: A Process Model." Ed. D. McNeill. Language and Gesture. New York: Cambridge University Press. 261-283.

Krebs, John R. and Richard Dawkins. 1984. "Animal Signals: MindReading and Manipulation." Behavioural Ecology: An Evolutionary Approach. Eds. J. R. Krebs and R. Dawkins. Oxford: Blackwell. 380-402.

Krebs, John R. and Nicholas B. Davies. 1993. An Introduction to Behavioural Ecology (3rd edition). Cambridge: Blackwell Scientific Publications.

Krukonis, Greg and Tracy Barr. 2011. Evolution for Dummies. Hoboken, NJ: John Wiley.

Kuckenburg, Martin. 2006. Mowa i Pismo. Narodziny Mowy i Pisma. Warszawa: Państwowy Instytut Wydawniczy.

Kuhl, Patricia. K. 2000. "A New View of Language Acquisition." Proceedings of the National Academy of Sciences 97. 11850-11857.

Kuhl, Patricia K. and James D. Miller. 1975. "Speech Perception by the Chinchilla: Voiced-voiceless Distinction in Alveolar Plosive Consonants.” Science 190.4209. 69-72.

Kurcz, Ida. 2004. "Communicative Competence and Theory of Mind." Psychology of Language and Communication 8.2. 5-18.

La Mettrie, Julien. Offray de. 2011 (1748). [L'homme-machine] Człowiek-maszyna. Trans. S. Rudniański. Warszawa: Państwowe Wydawnictwo Naukowe.

Laërtius, Diogenes. Lives of Eminent Philosophers. Trans. C. D. Yonge https://www. gutenberg.org/files/57342/ 57342-h/57342-h.htm. DOA: 4 Mar 2019.

Lai, Cecilia S., Simon E. Fisher, Jane A. Hurst, Faraneh Vargha-Khadem, and Anthony P. Monaco. 2001. "A Forkhead-Domain Gene Is Mutated in a Severe Speech and Language Disorder." Nature 413.6855. 519-523.

Lamb, Sydney. 2004. "What is a language?" Language and Reality. Ed. J. Webster. London: continuum, 394-414.

Land, Stephen K. 1977. "Adam Smith's 'Considerations Concerning the First Formation of Languages'." Journal of the History of Ideas 38.4. 677-690. 
Le Page, Michael. 2008. "A Guide for the Not-yet Perplexed.” New Scientist 198.2652. 24-25.

Leavens, David. A., Jared P. Taglialatela, and William D. Hopkins. 2014. "From Grasping to Grooming to Gossip: Innovative Use of Chimpanzee Signals in Novel Environments Supports both Vocal and Gestural Theories of Language Origins." The Evolution of Social Communication in Primates: A Multidisciplinary Approach. Eds. M. Pina and N. Gontier. New York: Springer. 179-194.

Ledyard, John. O. 1995. "Public Goods: a Survey of Experimental Research." The Handbook of Experimental Economics. Eds. J. H.

Kagel and A. E. Roth. Princeton: Princeton University Press. 111-194.

Lem Stanisław. 1984. Głos Pana. Kraków-Wrocław: Wydawnictwo Literackie.

Lenneberg, Eric H. 1964. "A Biological Perspective of Language.” New Directions in the Study of Language. Ed. E. H. Lenneberg. Cambridge, MA: MIT Press. 65-88.

Lenneberg, Eric. H. 1976. "Problems in the Comparative Study of Language." Evolution, Brain, and Behavior: Persistent Problems. Eds. R. B. Masterson, W. Hodos, and H. Jerison. Hillsdale, NJ: Erlbaum. 199-213.

Levelt, Willem J. M. 2004. "Speech, Gesture and the Origins of Language." European Review 12.4. 543-549.

Lewandowska-Tomaszczyk, Barbara. 2008. “Czym jest Język? Dzisiejsze Kontrowersje w Paradygmatach Generatywnych i Kognitywnych." Metodologie Jezykoznawstwa: Współczesne Tendencje i Kontrowersje. Ed. P. Stalmaszczyk. Kraków: Lexis. 9-26.

Lewin, Roger and Robert A. Foley. 2004. Principles of Human Evolution (2nd Edition). Oxford: Blackwell.

Lewis, Jerome. 2014. "BaYaka Pygmy Multi-modal and Mimetic Communication Traditions." The Social Origins of Language. Eds. D. Dor, C. Knight, and J. Lewis. Oxford: Oxford University Press. 77-91. Lewontin, Richard. C. 1998. "The Evolution of Cognition: Questions we will Never Answer.” An Invitation to Cognitive Science 4. 107-132.

Liberman, Alvin. M., Franklin S. Cooper, Donald P. Shankweiler, and Michael Studdert-Kennedy. 1967. "Perception of the Speech Code." Psychological Review 74. 431-461. 
Liberman, Alvin. M. and Ignatius G. Mattingly. 1985. “The Motor Theory of Speech Perception Revisited.” Cognition 21. 1-36.

Liberman, Alvin. M. and Doug H. Whalen. 2000. "On the Relation of Speech to Language.” Trends in Cognitive Sciences 4. 187-196.

Lieberman, Daniel. E. and Robert C. McCarthy. 1999. "The Ontogeny of Cranial Base Angulation in Humans and Chimpanzees and its Implications for Reconstructing Pharyngeal Dimensions." Journal of Human Evolution 36.5. 487-517.

Lieberman, Philip and Edmund S. Crelin. 1971. "On the Speech of Neanderthal Man.” Linguistic Inquiry 2.2. 203-222.

Lieberman, Philip. 2001. Human Language and our Reptilian Brain. Cambridge: Harvard University Press.

Lieberman, Philip. 2002. "On the Nature and Evolution of the Neural Bases of Human Language." Yearbook of Physical Anthropology 45. 35-62.

Lieberman, Philip. 2003. "Motor Control, Speech, and the Evolution of Human Language." Language Evolution. Eds. M. H. Christiansen and S. Kirby. New York: Oxford University Press. 255-271.

Lifschfitz, Avi. 2012. "Language and Enlightenment." The Berlin Debates of the Eighteenth Century. Oxford: Oxford University Press.

Linell, Per. 2005. The Written Language Bias in Linguistics: Its Nature, Origins, and Transformations. London: Routledge.

Liszkowski, Ulf, Malinda Carpenter, Anne Henning, Tricia Striano, and Michael Tomasello. 2004. "12-month-olds Point to Share Attention and Interest.” Developmental Science 7. 297-307.

Lovejoy, Arthur O. 1923. “The Supposed Primitivism of Rousseau's 'Discourse on Inequality'.” Modern Philology 21.2. 165-186.

Lovejoy, Arthur O. 1933. "Monboddo and Rousseau." Modern Philology 30.3. 275-295.

Łastowski Krzysztof. 2004. "Lamarck i Darwin. U Podstaw Idei Ewolucji." Teoria i Metoda w Biologii Ewolucyjnej. Ed. K. Łastowski. Poznań: Zysk i S-ka, Poznań. 57-88.

Łomnicki Adam. 2012. Ekologia Ewolucyjna. Warszawa: Wydawnictwo Naukowe PWN.

MacLarnon, Ann M. and Gwen P. Hewitt. 1999. "The Evolution of Human Speech: The Role of Enhanced Breathing Control.” American Journal of Physical Anthropology 109.3. 341-363. 
MacLeod, Carol. E., Karl Zilles, Axel Schleicher, James K. Rilling, and Kathleen R. Gibson. 2003. "Expansion of the Neocerebellum in Hominoidea." Journal of Human Evolution 44.4. 401-429.

MacNeilage, Peter. F. 1998. "The Frame/Content Theory of Evolution of Speech Production." Behavioral and Brain Sciences 21.04. 499-511.

MacNeilage, Peter. F. 2008. The Origin of Speech. Oxford: Oxford University Press.

Maestripieri, Dario. 2007. “Gestural Communication in Three Species of Macaques (Macaca mulatta, M. nemestrina, M. arctoides): Use of Signals in Relation to Dominance and Social Context." Gestural Communication in Nonhuman and Human Primates. Eds. K. Liebal, C. Muller, and S. Pika. Amsterdam: John Benjamins Publishing. 53-68. Mandeville, Bernard de. 1728. The Fable of the Bees. Part II. London: J. Roberts. https://archive.org/details/fableofbeesparti-00mand. (DOA: 6 Jul 2017.)

Marcus, Gary F. and Simon E. Fisher. 2003. "FOXP2 in Focus: What Can Genes Tell Us about Speech and Language?" Trends in Cognitive Sciences 7.6. 257-262.

Marks, Jonathan. 2002. What it Means to be $98 \%$ Chimpanzee: Apes, Human Beings, and Their Genes. Berkeley: University of California Press.

Martínez, Ignacio, Manuel Rosa, Juan Luis Arsuaga, Pilar Jarabo, Rolf Quam, Carlos Lorenzo, Ana Gracia, Jose Miguel Carretero, JoseMaria Bermudez de Castro, and Eudald Carbonell. 2004. "Auditory Capacities in Middle Pleistocene Humans from the Sierra de Atapuerca in Spain." Proceedings of the National Academy of Sciences of the United States of America 101.27. 9976-9981.

Maynard Smith, John. 1964. "Group Selection and Kin Selection.” Nature 201. 1145-1147.

Maynard Smith, John and George R. Price. 1973. "The Logic of Animal Conflict." Nature 246. 15-18.

Maynard Smith, John. 1982. Evolution and the Theory of Games. Cambridge: Cambridge University Press.

Maynard Smith, John and Eors Szathmáry. 1999. The Origins of Life. From the Birth of Life to the Origin of Language. Oxford: Oxford University Press. 
Maynard Smith, John and David Harper. 2003. Animal Signals. Oxford: Oxford University Press.

McGurk, Harry and John MacDonald. 1976. "Hearing Lips and Seeing Voices." Nature 264. 746-748.

McNeill, David. 1985. "So You Think Gestures Are Non-Verbal.” Psychological Review 92.3. 350-371.

McNeill, David. 1992. What Gestures Reveal About Thought. Chicago: The University of Chicago Press.

McNeill, David. 2005. Gesture and Thought. Chicago: The University of Chicago Press.

McNeill, David. 2012. How Language Began: Gesture and Speech in Human Evolution. Cambridge: Cambridge University Press.

McPherron, Shannon. P. et al. 2010. "Evidence for Stone-tool-assisted Consumption of Animal Tissues before 3.39 million years ago at Dikika, Ethiopia." Nature 466.7308. 857-860.

Meguerditchian, Adrien, Helene Cochet, and Jacques Vauclair. 2011. "From Gesture to Language: Ontogenetic and Phylogenetic Perspectives on Gestural Communication and its Cerebral Lateralization." Primate Communication and Human Language: Vocalisation, Gestures, Imitation and Deixis in Humans and Non-humans. Eds. A. Vilain, J. Schwartz, C. Abry, and J. Vauclair. Amsterdam: John Benjamins Publishing. 89-118.

Meguerditchian, Adrien, Marie Plouvier, Jill D. Pruetz, and William D. Hopkins. 2014. "From Hand to Mouth: Fine Precision Grip During Mutual Grooming Elicited Wide Lip Movements in Wild Fongoli Chimpanzees." Proceedings of the 10th International Conference. Eds. E. A. Cartmill, S. Roberts, H. Lyn, and H. Cornish. Singapore: World Scientific. 487-488.

Meyer, Julien and Bernard Gautheron. 2006. "Whistled Speech and Whistled Languages." Encyclopedia of Language and Linguistics (2nd edition). Ed. K. Brown. Oxford: Elsevier, 573-576.

Miller, Geoffrey F. 2000. The Mating Mind. New York: Doubleday.

Mills, Gregory J. 2011. "The Emergence of Procedural Conventions in Dialogue." Proceedings of the 15th Workshop on the Semantics and Pragmatics of Dialogue. Seattle: Cognitive Science Society. 210-211.

Mitchell, Ross. E. 2006. "How many Deaf People are there in the United States? Estimates form the Survey of Income and Program Participation." Journal of Deafness and Deaf Education 11. 112-119. 
Mithen, Steven J. 2005. The Singing Neanderthals: the Origins of Music, Language, Mind and Body. London: Weidenfeld and Nicholson.

Miyagawa, Shigeru, Shiro Ojima, Robert C. Berwick, and Kazuo Okanoya. 2014. "The Integration Hypothesis of Human Language Evolution and the Nature of Contemporary Languages." Frontiers in Psychology 5. DOI: 10.3389/fpsyg.2014.00564.

Moore, David R. 2000. “Auditory Neuroscience: Is Speech Special?” Current Biology 10. R362-R364.

Morgan, Elaine. 1982. The Aquatic Ape. New York: Stein and Day. Morgan, Lewis. H. 1887. Ancient Society; Or, Researches in the Lines of Human Progress from Savagery, Through Barbarism to Civilization. New York: H. Holt.

Morgan, Thomas. J. H. et al. 2015. "Experimental Evidence for the Co-evolution of Hominin Tool-making Teaching and Language." Nature Communications 6. 6029. DOI: 10.1038/ncomms7029. Morris, Desmond. 1967. The Naked Ape; a Zoologist's Study of the Human Animal. London: Random House.

Mueller, Ralph-Axel. 1996. "Innateness, Autonomy, Universality? Neurobiological Approaches to Language." Behavioral and Brain Sciences 19. 611-675.

Murata, Akira, Luciano Fadiga, Leonardo Fogassi, Vittorio Gallese, Vassilis Raos, Giacomo Rizzolatti. 1997. “Object Representation in the Ventral Premotor Cortex (area F5) of the Monkey." Journal of Neurophysiology 78.4. 2226-2230.

Murray, Alexander. 1823. Philosophical History of the European Languages. Edinburgh: Archibald Constable.

Müller, Friedrich M. 1866. Lectures on the Science of Language: Delivered at the Royal Institution of Great Britain in April, May, and June 1861 [and February, March, April, and May 1863]. Vol. 2. London: Longmans Green.

Nash, Gary B. 2009. "The Image of the Indian in the Colonial Mind." The Wild Man Within: An Image in Western Thought from the Renaissance to Romanticism. Eds. E. Dudley and M. E. Novak. Pittsburgh: University of Pittsburgh Press. 55-86.

Neumann, John von and Oskar Morgenstern. 1944. Theory of Games and Economic Behavior. Princeton: Princeton University Press. 
Niederhut, Dillon. 2012. "Gesture and the Origin of Language." Proceedings of the 10th International Conference (EVOLANG 10). Singapore: World Scientific. 266-273.

Nishikawa, Kiisa. C. 1997. "Emergence of Novel Functions During Brain Evolution.” Bioscience 47.6. 341-354.

Nishimura, Takeshi, Akichika Mikami, Juri Suzuki, and Tetsuro Matsuzawa. 2003. "Descent of the Larynx in Chimpanzee Infants." Proceedings of the National Academy of Sciences 100.12. 6930-6933. Novak, Maximillian E. 2009. “The Wild Man Comes to Tea.” The Wild Man Within: An Image in Western Thought from the Renaissance to Romanticism. Eds. E. Dudley and M. E. Novak. Pittsburgh: University of Pittsburgh Press. 183-222.

Nowak, Martin. A. 2006. "Five Rules for the Evolution of Cooperation." Science 314. 1560-1563.

Ogden, Charles. K. and Ivor A. Richards. 1923. The Meaning of Meaning. London: Kegan, Trench, Trubner.

Okanoya, Kazuo. 2007. "Language Evolution and an Emergent Property." Current Opinion in Neurobiology 17. 271-276.

Onishi, Kristine. H. and Renee Baillargeon. 2005. "Do 15-month-old Infants Understand False Beliefs?” Science 308.5719. 255-258.

Orzechowski, Sylwester, Sławomir Wacewicz, and Przemysław Żywiczyński. 2014. "Orofacial Gestures in Language Evolution. The Auditory Feedback Hypothesis." Proceedings of the 10th International Conference (EVOLANG 10). Eds. E. S. Cartmill, S. Roberts, H. Lyn, and H. Cornish. Singapore: World Scientific. 221-227.

Osvath, Mathias and Helena Osvath. 2008. "Chimpanzee (Pan troglodytes) and Orang-utan (Pongo abelii) Forethought: Self-control and Pre-experience in the Face of Future Tool Use." Animal Cognition 11.4. 661-674.

Parker, Anna R. 2006. "Evolving the Narrow Language Faculty: Was Recursion the Pivotal Step?" The Evolution of Language. Eds. A. Cangelosi, A. Smith, and K. Smith. Singapore: World Scientific. 239-246.

Pawłowski, Bogusław, Lowen, C. B., and Robin Dunbar. 1998. "Neocortex Size, Social Skills and Mating Success in Primates." Behaviour 135.3. 357-368. 
Pepys, Samuel. 1970 (1666). The Dairy of Samuel Pepys. Berkeley: University of California Press.

Petitto, Laura. A. and Paula F. Marentette. 1991. "Babbling in the Manual Mode: Evidence for the Ontogeny of Language.” Science 251. 1493-1496.

Pickstock, Catherine. 2011. "The Late Arrival of Language: Word, Nature and the Divine in Plato's Cratylus." Modern Theology 27.2. 238-262.

Pigliucci, Massimo. 2009. “An Extended Synthesis for Evolutionary Biology." Annals of the New York Academy of Sciences 1168.1. 218-228.

Pika, Simone, Katja Liebal, Josep Call, and Michael Tomasello. 2005. "The Gestural Communication of Apes." Gesture 5. 41-56.

Pika, Simone and Katja Liebal. 2006. "Differences and Similarities Between the Natural Gestural Communication of the Great Apes and Human Children." Proceedings of the 6th International Conference on the Evolution of Language (Evolang 6). Eds. A. Cangelosi, A. Smith, and K. Smith. Singapore: World Scientific. 267-274.

Pika, Simone. 2008. "What is the Nature of the Gestural Communication of Great Apes?" The Shared Mind: Perspectives on intersubjectivity. Eds. J. Zlatev, T. Racine, C. Sinha, and E. Itkonen. Amsterdam: John Benjamins Publishing. 165-186.

Pika, Simone and John C. Mitani. 2009. “The Directed Scratch: Evidence for a Referential Gesture in Chimpanzees?" The prehistory of Language. Eds. R. Botha and C. Knight. Oxford: Oxford University Press. 166-180.

Pilley, John. W. and Alliston K. Reid. 2011. "Border Collie Comprehends Object Names as Verbal Referents.” Behavioural Processes 86.2. 184-195.

Pinker, Steven. 1994. The Language Instinct: How the Mind Creates Languages. New York: HarperCollins.

Pinker, Steven and Paul Bloom. 1990. "Natural Language and Natural Selection.” Behavioral and Brain Sciences 13.4. 707-784.

Pinker, Steven. 1997. How the Mind Works. New York: W.W. Norton.

Pinker, Steven and Ray Jackendoff. 2005. “The Faculty of Language: What is Special about it?" Cognition 95.2. 201-236. 
Plotnik, Joshua. M., Frans B. M. de Waal, and Diana Reiss. 2006. "SelfRecognition in an Asian Elephant." PNAS 103. 17053-17057.

Pollick, Amy. S. and Frans B. M. de Waal. 2007. “Ape Gestures and Language Evolution." Proceedings of the National Academy of Sciences of the USA 104. 8184-8189.

Poole, Joyce. H. 1999. "Signals and Assessment in African Elephants: Evidence from Playback Experiments.” Animal Behaviour 58. 185-193.

Power, Camilla. 1998. “Old Wives' Tales: The Gossip Hypothesis and the Reliability of Cheap Signals." Approaches to the Evolution of Language. Eds. J. R. Hurford, M. Studdert-Kennedy, and C. Knight. Cambridge: Cambridge University Press. 111-129.

Power, Camilla. 2014a. "Signal Evolution and the Social Brain." The Social Origins of Language. Eds. D. Dor, C. Knight, and J. Lewis. Oxford: Oxford University Press. 47-55.

Power, Camilla. 2014b. "The Evolution of Ritual as a Process of Sexual Selection" The Social Origins of Language. Eds. D. Dor, C. Knight, and J. Lewis. Oxford: Oxford University Press. 196-207.

Premack, David. 1970. “The Education of Sarah: A Chimpanzee Learns the Language." Psychology Today 4. 55-58.

Premack, David and Ann J. Premack. 1974. "Teaching Visual Language to Apes and Language-deficient Persons." Language Perspectives: Acquisition, Retardation and Intervention. Eds. R. L. Schiefelbusch and L. L. Lloyd. Baltimore: University Park Press. 347-375.

Premack, David and Guy Woodruff. 1978. "Does the Chimpanzee have a Theory of Mind?" Behavioral and Brain Sciences 1.04. 515-526.

Price, George R. 1972. "Extension of Covariance Selection Mathematics." Annals of Human Genetics 35.4. 485-490.

Reeves, Joshua. 2014. "The State of Babel After the Fall: Philo Judaeus and the Possibility of Rhetoric." Advances in the History of Rhetoric 17.1. 34-42.

Reich, David et al. 2011. "Denisova Admixture and the First Modern Human Dispersals into Southeast Asia and Oceania." The American Journal of Human Genetics 89.4. 516-528.

Reinhardt, Tobias. 2008. "Epicurus and Lucretius on the Origin of Language.” The Classical Quarterly 58.1. 127-140. 
Renan, Joseph. E. 1848 (1858). De l'Origine du langage. Oeuvres Complètes. Vol. VIII. Paris: Calmann-Levy. 11-123.

Rendall, Drew, Dorothy L. Cheney, and Robert M. Seyfarth. 1996. "Proximate Factors Mediating "Contact" Calls in Adult Female Baboons (Papio cynocephalus ursinus) and Their Infants." Journal of Comparative Psychology 114.1. 36-46.

Richards, Robert J. 2008. The Tragic Sense of Life. Ernst Haeckel and the Struggle of Evolutionary Thought. Chicago: The University of Chicago Press.

Riley, Kastinger. 1979. "Some German Theories on the Origin of Language from Herder to Wagner." The Modern Language Review 74.3. 617-632.

Rilling, James K. and Thomas R. Insel. 1999. "Differential Expansion of Neural Projection Systems in Primate Brain Evolution.” Neuroreport 10.7. 1385-1623.

Rizzolatti, Giacomo and Michael A. Arbib. 1998. "Language within Our Grasp." Trends in Neurosciences 21. 188-194.

Rizzolatti, Giacomo, Luciano Fadiga, Leonardo Fogassi, and Vittorio

Gallese. 1996. "Premotor Cortex and the Recognition of Motor Actions." Cognitive Brain Research 3. 131-141.

Robe, Stanley L. 2009. "Wild Men and Spain's Brave New World.” The Wild Man Within: An Image in Western Thought from the Renaissance to Romanticism. Eds. E. Dudley and M. E. Novak. Pittsburgh: University of Pittsburgh Press. 39-54.

Roberts, Sean and James Winters. 2012. "Social Structure and Language Structure: The New Nomothetic Approach.” Psychology of Language and Communication 16.2. 89-112.

Roebroeks, Wil, Jan Kolen, and Eelco Rensink. 1988. "Planning Depth, Anticipation and the Organization of Middle Palaeolithic Technology: The Archaic Natives Meet Eve's Descendants.” Helinium 28.1. 17-34.

Rogalski, Andrzej K. 2008. "Znaczenie Modi Significandi w Średniowiecznych Traktatach Gramatyczno-Logicznych.” Roczniki Filozoficzne, LVI.1. 253-278.

Roll, Patrice, Gabrielle Rudolf, Sandrine Pereira, Barbara Royer, Ingrid E. Scheffer, and Annick Massacrier et al. 2006. "SRPX2 Mutations 
in Disorders of Language Cortex and Cognition." Human Molecular Genetics 15.7. 1195-1207.

Rosenkranz, Bernhard. 1961. Der Ursprung der Sprache: Ein

Linguistisch-Anthropologischer Versuch. Heidelberg: Carl Winter.

Rosik, Mariusz and Icchak Rapoport. 2009. Wprowadzenie do Literatury

i Egzegezy Żydowskiej Okresu Biblijnego i Rabinicznego. Wrocław: TUM.

Rossi, Eduard. 1962. Die Entstehung der Sprache und des Menschlichen Geiste. Basel: Ernst Reinhardt.

Roth, Gerhard and Ursula Dicke. 2005. "Evolution of the Brain and Intelligence." Trends in Cognitive Sciences 9.5. 250-257.

Rots, Veerle. 2005. "Wear Traces and the Interpretation of Stone Tools." Journal of Field Archaeology 30.1. 61-73.

Rousseau, Jean J. 2005 (1755). Discourse on the Origin of Inequality. New York: Cosimo Classics.

Rousseau, Jean J. 1762. Émile, ou De l'éducation. La Haye: Jean Néaulme.

Rousseau, Jean J. 1781. “L'Essai sur l'origine des langues.” Oeuvres posthumes de J. J. Rousseau. III. Genève: Du Peyrou. 211-327.

Rousseau, Jean J. 1965 (1755). Rozprawa o Pochodzeniu i Podstawach Nierówności Między Ludźmi. Trans. H. Elzenberg. Kraków: PWN.

Rowe, Meredith L. and Susan Goldin-Meadow. 2009. "Early Gesture Selectively Predicts Later Language Learning." Developmental Science 12. 182-187.

Rumbaugh, Duane M. and Timothy V. Gill. 1975. "Conversations with a Chimpanzee in a Computer-Controlled Environment.” Biological Psychiatry 10. 627-641.

Révész, Geza. 1946. Ursprung und Vorgeschichte der Sprache. Berno: Francke.

Sampson, Geoffrey. 1980. "Schools of Linguistics." Linguistics 410.9. 61. Samuels, Bridget. 2009. "The Third Factor in Phonology." Biolinguistics 3.2-3. 355-382.

Sandler, Wendy. 2013. "Vive la Différence: Sign Language and Spoken Language in Language Evolution." Language and Cognition 5.2-3. 189-203. 
Santamaría, David et al. 2010. “The Technological and Typological Behaviour of a Neanderthal Group from El Sidrón Cave (Asturias, Spain)." Oxford Journal of Archaeology 29.2. 119-148.

Sapir, Edward. 1907. Herder's "Ursprung der Sprache”. Chicago: The University of Chicago Press.

Saussure, Ferdinand de. 1960 (1916). Cours de Linguistique Générale. Paris: Payot.

Savage-Rumbaugh, Emily Sue, Duane M. Rumbaugh, and Sally Boysen.

1978. "Symbolic Communication Between Two Chimpanzees (Pan

Troglodytes).” Science 201.4356. 641-644.

Savage-Rumbaugh, Emily Sue, John L. Scanlon, and Duane M.

Rumbaugh. 1980. "Communicative Intentionality in the Chimpanzee."

The Behavioral and Brain Sciences 3. 620-623.

Savage-Rumbaugh, Emily Sue, Rose A. Sevcik, Duane M. Rumbaugh, and Elizabeth Rubert. 1985a. "The Capacity of Animals to Acquire Language:

Do Species Differences have Anything to Say to Us?" Philosophical

Transactions of the Royal Society of London B 308: 177-185.

Savage-Rumbaugh, Sue E., Duane M. Rumbaugh, and Kelly A.

McDonald. 1985b. "Language Learning in Two Species of Apes."

Neuroscience and Biobehavioral Reviews 9. 653-665.

Savage-Rumbaugh, Sue E. 1986. Ape Language: from Conditioned

Response to Symbol. New York: Columbia University Press.

Savage-Rumbaugh, Sue E. and Roger Lewin. 1994. Kanzi - the Ape at the

Brink of a Human Mind. New York: John Wiley.

Schleicher, August. 1863. Die Darwinsche Theorie und die

Sprachwissenschaft. Offenes Sendschreiben an Herrn Dr. Ernst

Haeckel. Weimar: H. Boehlau.

Schleicher, August. 1874 (1850). A Compendium of the Comparative Grammar of the Indo-European, Sanskrit, Greek, and Latin

Languages. Trans. and Ed. H. Bendall. London: Trübner. A shortened version of: Die Sprachen Europas in Systematischer Übersicht.

Schlenker, Philippe, Emmanuel Chemla, Kate Arnold, Alban Lemasson, Karim Ouattara, Sumir Keenan, Claudia Stephan, Robin Ryder, and Klaus Zuberbühler. 2014. "Monkey Semantics: Two "Dialects” of Campbell's Monkey Alarm Calls." Linguistics and Philosophy 37.6. 439-501. 
Scott-Phillips, Thomas C. 2008. "On the Correct Application of Animal Signalling Theory to Human Communication." Proceedings of the 7th International Conference on the Evolution of Language. Eds. A. Smith, K. Smith and Ramon Ferrer i Cancho. Singapore: World Scientific. 275-282. Scott-Phillips, Thomas C. 2010. "Evolutionary Psychology and the Origins of Language." Journal of Evolutionary Psychology 8.4. 289-307.

Scott-Phillips, Thomas C. and Simon Kirby. 2010. "Language Evolution in the Laboratory." Trends in Cognitive Sciences 14.9. 411-417. Scott-Phillips, Thomas C. 2014. Speaking Our Minds: Why Human Communication Is Different, and How Language Evolved to Make It Special. Basingstoke: Palgrave Macmillan.

Semendeferi, Katerina and Hanna Damasio. 2000. "The Brain and its Main Anatomical Subdivisions in Living Hominoids Using Magnetic Resonance Imaging.” Journal of Human Evolution 38.2. 317-332. Shannon, Claude E. 1948. "A Mathematical Theory of Communication." The Bell System Technical Journal 27.3. 379-423.

Shattuck, Roger. 1994 (1980). The Forbidden Experiment: The Story of the Wild Boy of Aveyron. New York: Kodansha America.

Sherman, Paul. W. 1977. "Nepotism and the Evolution of Alarm Calls." Science 197.4310. 1246-1253.

Sherwin, Byron L. 2014. "The Tower of Babel in Eliezer Ashkenazi's Sefer Ma'aseh Hashem." Jewish Bible Quarterly 42.2. 83-88.

Sinha Chris. 2009. "Language as a Biocultural Niche and Social Institution.” New Directions in Cognitive Linguistics. Eds. V. Evans and N. S. Pourcel. Amsterdam: John Benjamins Publishing. 289-310.

Slocombe, Katie E. 2011. "Have We Underestimated Great Ape Vocal Capacities?" The Oxford Handbook of Language Evolution. Eds. M. Tallerman and K. R. Gibson. Oxford: Oxford University Press. 90-95.

Slocombe, Katie E., Bridget M. Waller, and Katja Liebal. 2011. "The Language Void: the Need for Multimodality in Primate Communication Research.” Animal Behaviour 81.5. 919-924.

Smith, Andrew D. M. 2008. "Protolanguage Reconstructed." Interaction Studies 9.1. 100-116.

Smith, Kenny. 2006. “The Protolanguage Debate: Bridging the Gap?” Proceedings of the 6th International Conference on the Evolution 
of Language. Eds. A. Cangelosi, A. Smith, and K. Smith. Singapore: World Scientific. 315-322.

Sober, Elliot and David S. Wilson. 1998. Unto Others: The Evolution and Psychology of Unselfish Behavior. New York: Harvard University Press.

Sommerfelt, Alf A. 1954. “The Origin of Language.” Journal of World History 1. 885-902.

Sperber, Dan and Deirdre Wilson. 1986. Relevance: Communication and Cognition. Oxford: Blackwell and Cambridge: Harvard University Press. Sperber, Dan and Gloria Origgi. 2010. "A Pragmatic Perspective on the Evolution of Language." The Evolution of Human Language. Eds. R. K. Larson, H. Deprez, and H. Yamakido. Cambridge: Cambridge University Press. 124-131.

Sprinker, Michael. 1980. "Gerard Manley Hopkins on the Origin of Language." Journal of the History of Ideas 41.1. 113-128.

Sponheimer, Matt, Julia A. Lee-Thorp, Darryl de Ruiter, Daryl Codron, Jacqui Codron, Alexander T. Baugh, and Francis Thackeray. 2005. "Hominins, Sedges, and Termites: New Carbon Isotope Data from the Sterkfontein Valley and Kruger National Park." Journal of Human Evolution 48.3. 301-312.

Spoor, Fred and Frans Zonneveld. 1998. "Comparative Review of the Human Bony Labyrinth." American Journal of Physical Anthropology 107.27. 211-251.

Sterelny, Kim. 2012. The Evolved Apprentice: How Evolution Made Humans Unique. Cambridge, MA: MIT Press.

Stokoe, William. C. 1960. Sign Language Structure. Silver Spring: Linstok. Stokoe, William C., Dorothy C. Casterline, and Carl G. Croneberg. 1965. A Dictionary of American Sign Language on Linguistic Principles. Silver Spring: Linstok.

Stokoe, William C. 1991. "Semantic Phonology." Sign Language Studies 71. 107-114.

Stokoe, William C. 2001. Language in Hand: Why Sign Came Before Speech. Washington, DC: Gallaudet University Press.

Studdert-Kennedy, Michael. 2005. "How Did Links between Perception and Production Emerge for Spoken Language?" Language Origins: 
Perspectives on Evolution. Ed. M. Tallerman. Oxford: Oxford University Press. 12-19.

Summerfield, Quentin A. 1992. "Lipreading and Audio-Visual Speech

Perception." Philosophical Transactions of the Royal Society B 335. 71-78.

Sutton-Spence, Rachel. 2005. Analysing Sign Language Poetry. New York: Palgrave Macmillan.

Swadesh, Morris. 1971. The Origin and Diversification of Language. Chicago: Alidne \& Atherton.

Szathmáry, Eors and John Maynard Smith. 1995. “The Major Evolutionary Transitions.” Nature 374.6519. 227-232.

Szlendak, Tomasz and Tomasz Kozłowski. 2008. Naga Małpa przed Telewizorem. Popkultura w Świetle Psychologii Ewolucyjnej. Warszawa: Wydawnictwa Akademickie i Profesjonalne.

Számadó, Szabolcs and Eors Szathmáry. 2006. "Selective Scenarios for the Emergence of Natural Language." Trends in Ecology and Evolution 21.10. 555-561.

Süssmilch, Johann P. 1766. Der göttliche Ursprung der Sprache. Berlin: Buchladen der Realschule. https://archive.org/ details/ versucheinesbew00ssgoog DOA: 6 Jul 2015.

Tallerman, Maggie. 2011. "Protolanguage." The Oxford Handbook of Language Evolution. Eds. K. R. Gibson and M. Tallerman. Oxford: Oxford University Press. 479-491.

Tallerman, Maggie and Kathleen R. K. Gibson. (Eds.) 2011. The Oxford Handbook of Language Evolution. Oxford: Oxford University Press.

Taub, Liba. 1993. "Evolutionary Ideas and "Empirical” Methods: The Analogy Between Language and Species in the Works of Lyell and Schleicher." British Journal for the History of Science 26. 171-193.

Tehrani, Jamshid J. 2013. "The Phylogeny of Little Red Riding Hood." PLOS ONE 8.11. e78871.

Thompson, C. K., and Constance Scharff. 2013. “A Bird's-Eye View of FoxP2.” Birdsong, Speech, and Language. Eds. J. J. Bolhuis and M. Everaert. Cambridge, MA: MIT Press. 455-470.

Tinbergen, Niko. 1951. The study of Instinct. New York: Oxford University Press. 
Tinbergen, Niko. 1963. "On Aims and Methods of Ethology.” Zeitschrift für Tierpsychologie 20.4. 410-433.

Tincoff, Ruth, Mark Hauser, Fritz Tsao, Geertrui Spaepen, Franck Ramus, and Jacques Mehler. 2005. "The Role of Speech Rhythm in Language Discrimination: Further Tests with a Non-human Primate.” Developmental Science 8.1. 26-35.

Tincoff, Ruth and Mark Hauser. 2006. "Cognitive Basis for Language Evolution in Nonhuman Primates." Encyclopaedia of Language and Linguistics (2nd edition). Ed. K. Brown. Amsterdam: Elsevier. 533-538.

Tomasello, Michael, Josep Call, and Andrea Gluckman. 1997.

"Comprehension of Novel Communicative Signs by Apes and Human Children.” Child Development 68.6. 1067-1080.

Tomasello, Michael. 1999. "The Human Adaptation for Culture." Annual Review of Anthropology 28. 509-529.

Tomasello, Michael. 2000. "Primate Cognition: Introduction to the Issue.” Cognitive Science 24.3. 351-361.

Tomasello, Michael. 2008. Origins of Human Communication. Cambridge, MA: MIT Press.

Tomasello, Michael. 2009. Why We Cooperate. Cambridge, MA: MIT Press.

Tomasello, Michael, Alicia P. Melis, Claudio Tennie, Emily Wyman, and Esther Herrmann. 2012. "Two Key Steps in the Evolution of Human Cooperation.” Current Anthropology 53.6. 673-692.

Tooby, John and Leda Cosmides. 1992. "The Psychological Foundations of Culture." The Adapted Mind: Evolutionary Psychology and the Generation of Culture. Eds. J. H. Barkow, L. Cosmides, and J. Tooby. Oxford: Oxford University Press. 19-136.

Tooby, John and Leda Cosmides. 2005. "Conceptual foundations of evolutionary psychology." The Handbook of Evolutionary Psychology. Ed. D. Buss. Hoboken: John Wiley \& Sons. 5-67.

Trivers, Robert L. 1971. "The Evolution of Reciprocal Altruism." The Quarterly Review of Biology 46.1. 35-57.

Trivers, Robert. L. 1972. "Parental Investment and Sexual Selection." Biological Laboratories. Ed. B. Campbell. New York: Harvard University Press. 136-179. 
Tylor, Edward B. 1863. "Wild Men and Beast Children.” Anthropological Review 1. 21-32.

Tylor, Edward B. 1867. "On Traces of the Early Mental Condition of Man." Notes on the Proceedings at the Meetings of the Royal Institution of Great Britain 5. 83-93.

Tyson, Edward B. 1699. “Orang-Outang, Sive Homo Sylvestris: Or, the Anatomy of a Pygmie Compared with that of a Monkey, an Ape, and a Man.” 234. https://ia700505.us.archive.org/20/items/ orangoutangsiveh00tyso/orangoutangsiveh00tyso.pdf. DOA: 6 Jul 2015.

Ulbaek, Ib. 1998. "The Origin of Language and Cognition." Approaches to the evolution of language. Social and cognitive bases. Eds. J. Hurford, M. Studdert-Kennedy, and C. Knight. Cambridge: Cambridge University Press. 30-43.

Uomini, Natalie T. 2011. "Handedness in Neanderthals." Neanderthal Lifeways, Subsistence and Technology. Eds. N. J. Conard and J. Richter. Springer: Heidelberg. 139-154.

Vainio, Lari, Mikko Tiainen, Kaisa Tiippana, and Martti Vainio. 2014. "Shared Processing of Planning Articulatory Gestures and Grasping." Experimental Brain Research 232.7. 2359-2368.

Vico, Giambattista. 1948 (1725). [Scienza Nuova di Giambattista Vico] The New Science of Giambattista Vico. Trans. Based on the 3rd edition (1744) Thomas G. Bergin, M. H. Fish. Ithaca, NY: Cornell University Press.

Waal, Frans B. M. de and Amy S. Pollick. 2011. "Gesture as the Most Flexible Modality of Primate Communication." The Oxford Handbook of Language Evolution. Eds. K. R. Gibson and M. Tallerman. Oxford: Oxford University Press. 82-89.

Wacewicz, Sławomir. 2007. "Debata Hauser, Chomsky, Fitch - Pinker i Jackendoff. Nowoczesny Spór o Pochodzenie Ludzkiej Zdolności Językowej." Modularność umystu. Ed. S. Wróbel. Kalisz: WPA UAM. 79-94.

Wacewicz, Sawomir. 2008. "Ewolucja Języka: Horyzont Metodologiczny.” Metodologie Jezykoznawstwa. Wspótczesne Tendencje i Kontrowersje. Ed. P. Stalmaszczyk. Kraków: LEXIS. 27-42. Wacewicz, Sławomir and Przemysław Żywiczyński. 2008. "Broadcast Transmission, Signal Secrecy And Gestural Primacy Hypothesis.” 
The Evolution of Language. Proceedings of the 7th International Conference (EVOLANG 7). Eds. A. Smith, K. Smith, and R. Ferrer-iCancho. Singapore: World Scientific. 354-361.

Wacewicz, Sławomir and Przemysław Żywiczyński. 2011. “The Cooperative Nature of Language from the Phylogenetic Point of View." Jezyk Poza Granicami Jezzyka. Czesść 2. Aspekty Filozoficzne. Ed. J.

Dębowski. Olsztyn: Wydawnictwo Instytutu Filozofii UWM. 213-224.

Wacewicz, Sławomir and Przemysław Żywiczyński. 2012. "Beyond

Protolanguage. Contemporary Problems in the Evolution of

Language." Theoria et Historia Scientiarum 9. 5-11.

Wacewicz, Sławomir. 2012. "The Narrow Faculty of Language: What

Is It, Who Has It, and How Is It Defined?” Theoria et Historia Scientiarum 9. 217-229.

Wacewicz, Sławomir. 2013. “Ewolucja Języka - Współczesne

Kontrowersje." Metodologie Jezykoznawstwa I. Ewolucja Jezyka.

Ewolucja Teorii Jezykoznawczych. Ed. P. Stalmaszczyk. Łódź:

Wydawnictwo Uniwersytetu Łódzkiego. 11-26.

Wacewicz, Sławomir and Przemysław Żywiczyński. 2014. "Language

Evolution: Why Hockett's Design Features are a Non-Starter.”

Biosemiotics. DOI: 10.1007/s12304-014-9203-2.

Wacewicz, Sławomir and Przemysław Żywiczyński. 2015. "From the

Narrow to the Broad. Multiple Perspectives on Language Evolution.”

Theoria et Historia Scientiarum 11. 5-18.

Wacewicz, Sławomir. 2015. "The Shades of Social. A Discussion of 'The

Social Origins of Language'." Theoria et Historia Scientiarum. Eds. D.

Dor, C. Knight, and J. Lewis. 11. 191-209.

Wacewicz, Sławomir, Przemysław Żywiczyński, and Luke McCrohon.

2015. "Linguistic Politeness from an Ethological Perspective:

Theoretical Questions and Empirical Issues." Theoria et Historia

Scientiarum 11. 81-98.

Wada, Juhn. 1949. "A New Method for the Determination of the Side of Cerebral Speech Dominance: a Preliminary Report on the Intracarotid Injection of Sodium Amytal in Man.” Igaku Seibutsugaku 14. 221222. b65-0250002.

Wallace, Alfred R. 1864. “'The Origin of Human Races' and the Antiquity of Man Deduced from the Theory of 'Natural Selection.' "' Journal of the Anthropological Society of London 2. clviii-clxxxvii. 
Wallace, Alfred R. 1881. "Review of Tylor's Anthropology.” Nature 24. 242-245.

Wallace, Alfred R. 1889. Darwinism: An Exposition of the Theory of

Natural Selection with Some of Its Applications. London: Macmillan.

Warren, John. V. 1987. "The evolution of evolution." Transactions of the American Clinical and Climatological Association 98. 1.

Watson, James D. and Francis H. Crick. 1953. "Molecular Structure of Nucleic Acids.” Nature 171.4356. 737-738.

Wescott, Roger W. 1967. “The Evolution of Language: Re-Opening a Closed Subject.” Studies in Linguistics 47. 416-428.

Wescott, Roger W., Gordon Hewes, and William Stokoe (Eds.) 1974. Language Origins. Silver Spring: Linstok.

West, Stuart. A., Claire El Mouden, and Andy Gardner. 2011. "Sixteen Common Misconceptions About the Evolution of Cooperation in Humans." Evolution and Human Behavior 32.4. 231-262.

Whitehead, Charles. 2014. "Why Humans and not Apes: the Social Preconditions for the Emergence of Language." The Social Origins of Language. Eds. D. Dor, C. Knight, and J. Lewis. Oxford: Oxford University Press. 157-170.

Whiten, Andrew, Jane Goodall, William C. McGrew, Toshisada Nishida, Vernon Reynolds, Yukimaru Sugiyama, Caroline Tutin, Richard W. Wrangham, and Christophe Boesch. 1999. "Cultures in Chimpanzees." Nature 399.6737. 682-685.

Whitney, William D. 1872. Oriental and Linguistic Studies: The Veda, the Avesta; the Science of Language. New York: Scribner, Armstrong \& Co. Wierzbicka, Anna. 2014. Imprisoned in English: The Hazards of English as a Default Language. Oxford: Oxford University Press.

Wilkins, Wendy K. and Jennie Wakefield. 1995. "Brain Evolution and Neurolinguistic Preconditions." Behavioral and Brain Sciences 18.1. 161-226.

Williams, George C. 1966. Adaptation and Natural Selection: A

Critique of Some Current Evolutionary Thought. Princeton: Princeton University Press.

Wilson, Edward. O. 1975. Sociobiology. The New Synthesis. Cambridge, MA: Harvard University Press. 
Wilson, Edward. O. 1979. On Human Nature. Cambridge, MA: Harvard University Press.

Wilson, Robert A. and Frank C. Keil (Eds.) 1999. The MIT Encyclopedia of the Cognitive Sciences. Cambridge, MA: MIT Press.

Wolberg, Cory S., James A. Temlett, and Veronica U. Fritz. 1990. "Pure Word Deafness." South African Medical Journal 78. 668-670.

Woll, Bencie. 2014. "Moving from Hand to Mouth: Echo Phonology and the Origins of Language." Frontiers in Psychology 5. 662. DOI: 10.3389//fpsyg.2014.00662.

Worden, Robert. P. 1996. "Primate Social Intelligence.” Cognitive Science 20. 579-616.

Workman, Lance and Will Reader. 2004. Evolutionary Psychology. Cambridge: Cambridge University Press.

World English Bible. http://www.gutenberg.org/cache/epub/8228/pg8228images.html. DOA: 4 Mar 2019.

Wrangham, Richard. 2009. Catching fire: How cooking made us human. New York: Basic Books.

Wray, Alison. 1998. "Protolanguage as a Holistic System for Social Interaction." Language and Communication 18.1. 47-67.

Wray, Alison and George W. Grace. 2007. “The Consequences of Talking to Strangers: Evolutionary Corollaries of Socio-cultural Influences on Linguistic Form.” Lingua 117.3. 543-578.

Wróbel, Szymon. 2005. "Ewolucjonizm wobec Architektury Umysłu." Principia. Pisma koncepcyjne z filozofii i socjologii teoretycznej XLIXLII. 197-229.

Wundt, Wilhelm. 1900. Völkerpsychologie. Vol. I-II. Die Sprache. Leipzig: Engelmann.

Yamauchi, Hajime, Terrence Deacon, and Kazuo Okanoya. 2012. "The Myth Surrounding the Ban by Société Linguistique de Paris." Proceedings of the 9th International Conference (EVOLANG 9). Eds. T. Scott-Phillips, M. Tamariz, M., E. Cartmill, and J. Hurford. Singapore: World Scientific. 569-570.

Yates, Allan. J. 1963. "Delayed Auditory Feedback.” Psychological Bulletin 60.3. 213-251.

Yule, George. 2010. The Study of Language (4th edition). New York: Cambridge University Press. 
Zahavi, Amotz. 1975. "Mate Selection - a Selection for a Handicap." Journal of Theoretical Biology 53.1. 205-214.

Zlatev, Jordan. 2008. "The Co-evolution of Intersubjectivity and Bodily Mimesis." The Shared Mind: Perspectives on Intersubjectivity. Eds. J. Zlatev, T. Racine, C. Sinha, and E. Itkonen. Amsterdam: John Benjamins Publishing. 215-244.

Zlatev, Jordan. 2014a. "Human Uniqueness, Bodily Mimesis and the Evolution of Language." Humana Mente. Journal of Philosophical Studies 27. 197-219.

Zlatev, Jordan. 2014b. “The Co-evolution of Human Intersubjectivity, Morality, and Language." The Social Origins of Language. Eds. D. Dor, C. Knight, and J. Lewis. Oxford: Oxford University Press. 249-266.

Zlatev, Jordan, Tomas Persson, and Peter Gärdenfors. 2005. “Triadic Bodily Mimesis is the Difference." Behavioral and Brain Sciences 28.05. 720-721.

Zuk, Marlene. 2013. Paleofantasy: What Evolution Really Tells us about Sex, Diet, and How We Live. New York: W.W. Norton.

Żywiczyński, Przemysław. 2004. Buddhism and Meaning: Comparative Assessment of Buddhist Views on Cognition, Meaning, and Language. Toruń: Wydawnictwo Naukowe Uniwersytetu Mikołaja Kopernika. Żywiczyński, Przemysław. 2010. The Axiology of Spoken Interaction: An Essay on the Organisation of Conversational Behaviour. Torun: Wydawnictwo Naukowe Uniwersytetu Mikołaja Kopernika.

Żywiczyński, Przemysław. 2018. Language Origins: From Mythology to Science. Berlin: Peter Lang.

Żywiczyński, Przemysław and Sławomir Wacewicz. 2012. "The Cooperative Nature of Conversation. Evidence from Conversational Exchanges." Proceedings of the 9th International Conference (EVOLANG 9). Eds. T. Scott-Phillips, M. Tamariz, E. Cartmill, and J. Hurford. Singapore: World Scientific. 392-399. 


\section{List of Figures}

Fig. 1.1: The Tower of Babel by Pieter Bruegel the Elder. https:// commons.wikimedia.org/wiki/File:Pieter_Bruegel_the_ Elder_-_The_Tower_of_Babel_(Vienna)_-_Google_Art_ Project.jpg. DOA 12 June 2019.

Fig. 1.2: Statement of the Société de linguistique de Paris banning glottogenetic speculation.

Fig. 2.1: How natural selection works (chart adapted from

A.R. Wallace). http://www.globalchange.umich.edu/ globalchange1/current/lectures/selection/boxes.gif. DOA: 08 Aug 2015.

Fig. 2.2: Mutation and natural selection. http://www.daviddarling. info/images/natural_selection.png. DOA: 08 Aug 2015.

Fig. 2.3: The traditional - and erroneous - depiction of anthropogenesis. http://www.bbc.co.uk/worldservice/ news/2008/10/081007_endofevolution.shtml. DOA: 08 Aug 2015.

Fig. 2.4: The correct depiction of anthropogenesis. http://www. amnh.org/education/resources/rfl/web/hhoguide/familytree.html. DOA: 08 Aug 2015.

Fig. 3.1: Developments that led to the contemporary research field of the evolution of language.

Fig. 3.2: The evolution of primates.

Fig. 3.3: Lexigrams used by Duane Rumbaugh and Sue SavageRumbaugh's research group. https://sites.google.com/site/ austinstoll12communication/home/lexigram. DOA: 15 Mar 2017.

Fig. 3.4: Linguistic transmission in Iterated Learning (adapted from Kirby et al., 2004: 600). http://www.replicatedtypo. com/evolve-an-appname-results/10132.html. DOA 15 Mar 2017.

Fig. 3.5: The hypothetical stages of the development of language. The left and right arrows represent the process of biological evolution and cultural evolution, respectively.

Fig. 4.1: Vocal tract cross-section: chimpanzee and human. http:// pubpages.unh.edu/ jel/images/vocal_tract_chimp.gif. DOA 15 Mar 2017. 
Fig. 4.2: Neocortical lobes and the cross-section of the brain. http://commons.wikimedia.org/wiki/File:Lobes_of_the_ brain_NL.svg. DOA 12 June 2019.

Fig. 4.3: Brains of selected mammals. https://www. psychologytoday.com/sites/default/files/styles/articleinline-half/public/blogs/134094/2013/10/135685135585.jpg. DOA: 08 Aug 2015. 159

Fig. 4.4: The absolute size of the brain and encephalisation quotient in selected mammals. 


\section{Glossary}

Adamic language in religions which stem from Judaism, the language which Adam was supposed to have used in the garden of Eden.

adaptation (adaptive feature) a feature which results from the selection pressure and which increases the adaptation of an organism to its environment (i.e., one that increases the likelihood that it will survive and/or reproduce). adaptationism a view which emphasises the role of natural selection in shaping phenotypes and which considers that a majority of features are adaptations which emerged via natural selection; its extreme version is called panadaptationism.

allele an "alternative version" of a gene. A gene has a certain place in a chromosome, called the locus. Thus, alleles are alternative versions of genes which occupy the same locus in a chromosome. Mutations cause new alleles to emerge.

allometry investigating the relation between the size of the body and its shape.

anthropogenesis the emergence of humans.

anti-essentialism in the theory of meaning, a view which states that words do not capture the essence of the objects to which they refer.

apes big primates that do not have a tail, mainly great apes - of which the extant species are the chimpanzee, the bonobo, the gorilla, and the orangutan - and humans.

arbitrariness a feature of most linguistic signs, which describes a lack of resemblance between the referent of a sign and its form.

artificial selection a process whereby humans purposefully selectively breed animals and plants because of a desired feature.

chromosome a set of aligned genes in a cell with the DNA and structural proteins. All cells in most organisms which use sexual reproduction are diploid, which means that they contain a pair of chromosomes, each of which contains one chromosome from the father and one from the mother. cognitive science an interdisciplinary science about the mind and cognitive processes, which is a combination of brain sciences, psychology, philosophy of mind, artificial intelligence, and cognitive linguistics, as well as other related disciplines. 
comparative philology (later: historical linguistics) the comparative study of languages with the aim of establishing their historical relationship. compositionality the property of language thanks to which the meaning of combined elements (e.g., "a yellow wall") is the sum of its basic elements ("yellow" + "a wall”); idiomaticity is the opposite of compositionality. conceptualism a view in the theory of meaning which says that linguistic meanings refer directly to conceptions.

conventionalism a view in the theory of meaning which says that meanings of words result from the conventions of a given language community; conventionalism is often contrasted with realism.

cranium the part of the skull which houses the brain.

creationism a non-scientific view, motivated by religion, which says that the universe and life were created by a deity.

differential reproductive success (DRS) the fact that organisms do not reproduce at the same pace. Some leave more offspring (or rather, they transmit more of their genes, see kin selection) than others. As a result, their genes are more and more often represented in the gene pool of a given population over the successive generations, leading to the dissemination of the phenotypes they encode.

discrete infinity a language trait that allows the combination of discrete (separate) elements such as words into an infinite number of new, grammatically correct sequences such as sentences.

displacement one of the core features of language; the ability to talk about objects, events, etc., distant in time and/or space.

dispute over universals a dispute about general concepts and names referring to them; the field of the dispute was marked by realistic and nominalistic positions.

encephalisation the relation between the size of the brain and body size in a given species.

endocast a cast of the inside of the skull showing its internal surface, which, to a degree, reflects the size of each of the cortical areas of the brain.

essentialism in the theory of meaning, a view connected with realism which says that words capture the essence of the objects they refer to.

eugenics a deliberate change of genotypes in human populations; artificial selection in humans. Positive eugenics aims to "improve" the genetic pool in a human population by favouring the reproduction of people who 
possess the desired features; negative engenics serves the same purpose by stopping the reproduction, or even by extermination, of the people who have undesired features.

exaptation a feature whose contemporary "function" is not the same as it used to be in the original version of the feature; e.g. birds' wings are used for flying, but flying was not the original function of these anatomic structures that later on developed into wings; wings are therefore an exaptation.

exclusivism a stance which says that evolution, especially by natural selection, does not affect humans, or some of their features.

feral children children who were (partially or completely) deprived of socialisation.

fitness an organism's ability to successfully pass on its genes (= to produce offspring). Organisms that are fit have phenotypic features which increase their survivability and their chances of producing offspring.

Forbidden Experiment, The (language deprivation experiment) an experiment consisting in depriving children of any language stimulus, the purpose of which is to check whether the child left in such conditions would acquire language, and if so, to see which language this would be.

gene a unit of heredity which is highly stable; i.e. stable to such a degree that an unchanged gene can be inherited over many generations.

gene pool genetic variability in the population, i.e. the set of all alleles in all individuals forming a population.

gene's eye view the genocentric concept according to which the best description of evolution can be obtained at the gene level, i.e. treating genes as units subject to selection.

genetic determinism an erroneous view which overestimates the role of genes in the development of phenotypes.

genetic drift a change in the frequency of existing genes in a population resulting from a random event and not selection pressures.

genotype the genetic equipment of a given organism; influences the phenotype.

glottogeny, naturalistic speculations on the origins of language (as opposed to a more recent, scientific approach to the evolution of language)

gradualism a notion which states that macroevolution takes place gradually, slowly, and at a relatively steady pace. 
grammaticalisation a process of historical change in language, whereby lexical morphemes (such as verbs or nouns) change into grammatical morphemes (e.g., plural or the past tense markers).

great apes orangutans, gorillas, chimpanzees, bonobos and humans. We use the word "human" in reference to hominins - H. sapiens and its extinct bipedal ancestors.

group selection a natural selection process, in which the selection occurs at the level of groups, and not - as in the traditional conception of natural selection - at the level of organisms; it is commonly thought to be much weaker than selection at the level of genes and individuals.

hominins (earlier: hominids; Latin name: Hominini) H. sapiens and its extinct ancestors; we use this name to refer to humans and our bipedal ancestors in the genuses Homo, Australopithecus, and other lines that separated from the ancestors of chimpanzees; great apes other than H. sapiens do not belong to this group.

inclusive fitness an organism's ability to pass on its genes, not necessarily by producing own offspring. By helping organisms which have a similar genotype (relatives), the organism helps them to pass their genes, which are, for the most part, identical to its own genes - thus it passes on its genes "by proxy".

Intelligent Design a pseudo-scientific approach, very close to creationism, which says that the development of life on Earth is propelled by a conscious and intelligent supernatural entity, rather than by evolution through natural selection.

intentionality (1) in psychology, deliberateness: performing actions on purpose, rather than because of some automatic mechanisms;

(2) in philosophy, "aboutness", the property of thought to be about something, having content, representing something.

lateralisation asymmetric distribution of specialisations between the brain hemispheres, which results in one cerebral cortex hemisphere (the left in the majority of humans) handling most of the functions connected with language.

linguistic relativism the view according to which the use of a particular ethnic language has an impact on its user's conceptualisation of the world. macroevolution refers to evolutionary changes, mostly to changes that are inherently adaptive, which in the long run lead to major phenotypic changes, including the emergence of new species. 
meme a unit of cultural evolution: a thought, melody, saying, etc. which can be a cultural replicator and whose copies can be transferred and undergo cultural evolution.

microevolution relates to small evolutionary changes - in particular, the adaptive ones - that occur within a genetic pool in a relatively short time perspective.

monogenic hypothesis in relation to the origin of language, the view according to which modern languages come from a single original language; in reference to the origin of man, the view that all modern people come from a single group of common ancestors.

multiregional hypothesis an evolutionary model of anthropogenesis, according to which the common ancestors of all modern humans evolved about 2 million years ago.

mutation a change in the genetic material caused by an error in DNA transcription. The term usually means heritable mutations that affect the phenotype because these are important in evolution. Mutations are random - they appear randomly, rather than in response to a current need.

natural selection has two meanings:

In contrast with sexual selection, it describes the influence of the environment (e.g., illnesses, water and food shortages, predation) which results in certain organisms dying faster than other organisms of the same species.

In the standard version, it incorporates the influence of the environment and sexual selection; whereby organisms pass on more of their genes to the next generation than do other organisms of the same species. Thus construed, natural selection results from three necessary conditions: diversity, heredity, and differential reproductive success.

neuroimaging technologies allowing researchers to monitor the working brain and the activity of its individual areas while performing various types of tasks.

neurolinguistics the science of brain processes related to language behaviours.

nominalism in the dispute about universals, a position according to which general concepts and general terms do not correspond to existing entities.

ontogeny the history of individual development - in contrast to phylogeny, which is the history of the evolutionary development of the whole species. 
panadaptationism the extreme version of adaptationism, which overestimates the role of selection and adaptation, and marginalises the role of other evolutionary and developmental processes in shaping the phenotype.

phenotype all the features of a given organism, both morphological and behavioural (appearance, anatomy, behaviour, etc.). Phenotype results from the expression of genotype an organism has, as well as the course of its ontogeny (the development of an individual).

phylogeny the evolutionary history of a whole species, genus, order, etc., measured in thousands and millions of years - as compared with the history of an individual organism (ontogeny) which spans over one generation and is measured in years.

polygenic hypothesis in relation to the origin of language, the view according to which modern languages come from many ancient languages. polylingualism the phenomenon of the existence of many languages. population the sum of all organisms belonging to a specific group or species that live in the same geographical area and are capable of reproduction. pre-Adamism the view that before Adam, biblical people already existed, the so-called pre-Adamites.

preadaptation a feature whose emergence is a prerequisite for the evolutionary development of another, different feature. For example, in birds, feathers created for thermoregulation could be a preadaptation for feathers supporting flight. Because preadaptation could erroneously suggest that evolution has a goal, this term is often replaced by exaptation.

primatalogy the science of primates.

prosociality behaviour (or, a tendency towards a behaviour)that does not take into account only the good of the individual, but also the benefits and perspectives of others.

psycholinguistics a science that studies mental processes related to the acquisition and use of language.

punctuated equilibrium a model of evolutionary changes in which, after long periods of relative stagnation (stasis), adaptive changes occur that appear relatively rapid by contrast.

realism in relation to the theory of meaning, the view that linguistic meanings refer directly to existing beings; in a dispute about universals, a standpoint according to which the existing general concepts have material referents. 
recapitulationism a historical view on evolution, currently considered erroneous, that "ontogeny recapitulates phylogeny", meaning that individual ontogenetic stages (i.e., during the development of each individual) are a reflection and summary of analogous phylogenetic stages, and thus of the evolutionary development of the whole genus and species.

reverse engineering the process whereby a complex object or mechanism is dismantled to reveal its design; deconstructing (literally or conceptually) a finished product to determine how it was made.

saltationism the view that evolutionary change is rapid and so major changes can be effected over several generations.

selection pressure any relatively stable aspect of the environment (e.g., the activity of a certain type of predator or virus; female preferences in mate selection), which affects the reproductive success of organisms, and leads to the emergence or amplification of certain features or behaviours (e.g., speed, beauty, or resistance to parasites).

semiotic resources all means of conveying meaning, such as speech, writing, sign language, but also gesticulation, pantomime, singing, and dance or art. sexual selection a situation in which organisms which are perceived to be more attractive by the opposite sex pass more of their genes on to the next generation than other organisms of the same species. In this book, it is defined as a sub-type of natural selection.

signification the process of assigning meaning by means of linguistic signs or semiotic resources other than language.

social Darwinism an umbrella term for the social, political and economic viewpoints which started developing in the 1880s, and which appealed to the theory of natural selection and the phrase which Spencer coined, "survival of the fittest". Elements of social Darwinism can be found in laissez-faire capitalism, eugenics, imperialism and fascism.

spandrel a feature of an organism, which in itself is not an adaptation, but which was created as a by-product of selection for another feature (for example, the red colour of blood).

universal Darwinism (alternatively generalised Darwinism or universal selection theory) the application of Darwinism to phenomena that go beyond biological evolution. Proponents of universal Darwinism formulate three conditions of natural selection - diversity, heredity and diversity of reproductive success - so that they can be used to study changes occurring 
in non-biological domains, for example in psychology, economics, culture, medicine, linguistics or physics.

veil of language an epistemological view according to which language prevents or, in a milder form, makes it difficult to get to know reality. 


\section{Index of Names}

A

Abulafia, Abraham 24, 27, 239

Aiello, Leslie 132, 153, 163, 219

Aitchison, Jean 142, 219

Arbib, Michael 85, 95, 120, 127, 146, 147, 187, 199, 206, 219,

231,253

Armstrong, David 130, 187, 196, 207, 219, 224, 262

Aristotle 24

Augustine 20, 21, 27, 231

Axelrod, Robert 177, 220

B

Bickerton, Derek 86, 112, 122, 132, 144-148, 163, 164, 197, 221,223

Boer, Bart de 154, 221

Botha, Rudolf 127, 145, 211, 222, 237, 251

Boysen, Sarah 172, 222, 255

Broca, Paul 53, 54, 115, 120, 198, 199, 211, 231

Buffon, Georges-Louis 32, 61

Burnett, James (Lord

Monboddo) 33, 223

Buss, David 61, 72, 79, 223, 259

C

Call, Josep 222, 223, 251, 259

Chardin, Pierre Teilhard de 59, 103, 224

Cheney, Dorothy 132, 221, 224, 253

Chomsky, Noam 86, 96, 99, 100, 103, 105, 106, 115, 122, 128-133, 139, 148, 209, $221-225,232,236,260$
Christiansen, Morten 13, 51, 61, $71,85,95,99,126,140,221$, 225, 238, 246

Condillac, Étienne Bonnot de 37 , 38, 40-44, 48, 54, 56, 193, 194, 226

Corballis, Michael 123, 146, 147, 154, 171, 187, 194, 197, 198, 206, 211-214, 226, 229, 233

Cosmides, Leda 66, 72, 73, 75, $79,220,226,231,259$

$\mathrm{D}$

Dante, Alighieri 19, 20, 226, 227, 233

Darwin, Charles 13, 35, 49-51, 53-62, 65, 69, 71, 76, 79, 81, $95,112,120,147,211,213$, 223, 227-229, 231, 235, 246, 255, 262, 273

Dawkins, Richard 61, 66, 69, 70, 74, 79, 83, 87, 121, 123, 175, $176,227,229,244$

Deacon, Terrence 71, 81, 112 , 136, 139, 155, 161, 171, 182, $198,227,228,263$

Dennett, Daniel 69, 81, 228

Descartes 30, 173

Dessalles, Jean-Louis 82, 98, 228

Dobzhansky, Theodosius 59, 120,229

Donald, Merlin 122

Dor, Daniel 228, 229

Dunbar, Robin 82, 122, 124, 163, 164, 169, 180-182, 186, $230,238,250$ 
E

Eibl-Eibesfeldt, Irenäus 121, 230

Ekman, Paul 103, 189, 230

Emmorey, Karen 204, 205, 230

F

Falk, Dean 183, 207, 208, 216, 231

Farrar, Frederic William 49, 51,231

Fay, Nicolas 196, 231

Fisher, Ronald 113, 120, 214, 231, 232, 244, 247

Fitch, Tecumseh 11, 18, 37, 43, $68,98,112,122,124,128,129$, 132, 146-148, 153-155, 173, 174, 183, 187, 203, 205-208, $217,232,236,242,260$

Foley, Robert 65, 162, 245

Friesen, Wallace V. 103, 189, 230

Furness, William 55, 104, 107, 232

G

Gärdenfors, Peter 124, 180, 233, 235, 264

Goldin-Meadow, Susan 187, 188, 196, 208-210, 215, 233, $234,239,254$

Goodall, Jane 14, 107, 234, 262

Gould, Stephen J. 76, 78-80, 86, $88,90,230,234,235$

Gowlett, John 78, 115, 235

Grice, H. P. 174, 175, 235

\section{$\mathrm{H}$}

Haeckel, Ernst 46, 47, 51, 90, 235, 253, 255

Haldane, J. B. S. 67, 113

Hamilton, William D. 64, 66, 67, $121,183,235$
Harnad, Stevan 81, 235, 236

Hauser, Marc 102, 122, 128-130, 132, 151, 160, 232, 233, 236, 259,260

Herder, Johann Gottfried von 41-43, 45, 48, 49, 55, 194, 231, 237, 241, 253, 255

Hewes, Gordon 28, 31, 33, 35, $37,38,40,41,44-46,54-57$, 103, 104, 147, 187, 193-197, 203, 206-208, 213, 237, 262

Hockett, Charles 68, 99-102, 142, 186, 238, 240, 261

Hopkins, William 198, 238, 245, 248, 257

Hrdy, Sarah B. 67, 180, 183, 238

Hurford, James 11, 96, 122, 124, 133, 145, 149, 154, 156, 159, $160,171,174,217,221,234$, $238,239,240,243,252,260$, 263, 264

Hutto, Daniel 201, 239

Huxley, Thomas 50

I

Itard, Jean Marc Gaspard 35, 36, 43, 239

$\mathrm{J}$

Jackendoff, Ray 105, 127, 132, 134, 146, 148, 240, 251, 260

Jespersen, William 55, 56, 58, 98, 147, 240

Johanson, Donald 116

Johansson, Sverker 11, 37, $61,69,70,79,87,98,112$, 122-124, 130, 131, 146, 147, 153-157, 160, 161, 204, 217, 240, 241 
K

Keller, Hellen 136

Kendon, Adam 98, 103, 137, 187, 188, 189, 206, 208, 209, 215,242

Kirby, Simon 13, 51, 95, 99, 125, 126, 140, 141, 149, 221, 225, 238, 242, 246, 256, 265

Knight, Chris 133, 136, 182, 207, 221, 226, 228, 229, 231, 238, 241-243, 245, 251, 252, 260-262, 264

Krebs, John 74, 123, 175, 176, 244

L

Lamarck, Jean-Baptiste de 51, 84, 85, 246

Leakey, Mary 117

Leakey, Richard 116, 117

Leavens, David 155, 211, 216, 245

Lenneberg, Eric 105, 106, 245

Lewin, Roger 65, 154, 162, 245, 255

Lewontin, Richard 76, 79, 80, 122, 234, 236, 245

Liebal, Katja 191, 247, 251, 256

Lieberman, Daniel 153

Lieberman, Philip 114, 123, 153, 154, 161, 198, 246

Linnaeus, Carl 32, 33, 38, 61

Lorenz, Konrad 74, 247

Lucretius 28, 29, 252

Lyell, Charles 50, 60, 258

M

MacNeilage, Peter 186, 206, 213, 247

Maimonides, Moses 24, 27, 221, 241
Mandeville, Bernard de 36-38, 56, 241, 247

Matsuzawa, Tetsuro 170, 181, 239, 243, 250

McNeill, David 103, 187, 188, 190, 202, 215, 244, 248

Meguerditchian, Adrien 188, 198, 211, 213, 248

Mendel, Gregor 66, 112, 120, 231

Mettrie, Julien Offray de la 33,244

Miller, Geoffrey 71, 82, 158, 244, 248

Mithen, Steven 146, 147, 186, 249

Müller, Friedrich Max 48-51, 53, 173, 247, 249

O

Ockham, William 23, 24

P

Paget, R. A. S. 57, 58, 213, 236

Pawłowski, Bogusław 182, 250

Pepys, Samuel 33, 251

Peter the Wild Boy 35, 223

Philo of Alexandria 20, 24

Pika, Simone 188, 191, 192, 247, 251

Pinker, Steven 77, 86, 87, 98, 122, 131, 132, 134, 138, 145, 157, 240, 243, 251, 260

Plato 22-24, 29, 251

Pollick, Amy 188, 190-192, 252, 260

Power, Camilla 164, 175, 182, 238, 252

Premack, David 104, 108, 112, 166,252 
R

Renan, Ernest 47-49, 53, 231, 253

Rizzolatti, Giacomo 120, 199, 211, 239, 249, 253

Rousseau, Jean-Jacques 36, 38-42, 44, 48, 49, 56, 207, 246, 254

Rumbaugh, Duane 112, 134, $154,158,233,254,255,265$

S

Sapir, Edward 47, 55, 255

Savage-Rumbaugh, Sue 112, 134, 154, 158, 233, 255, 265

Schleicher, August 46, 47, 51, 247, 255, 258

Seyfarth, Robert 132, 221, 224, 253

Smith, Adam 44, 60, 234, 236, 240, 244, 250

Smith, John Maynard 13, 66, $69,95,121,142,179,247$, 248, 258

Spencer, Herbert 39, 71, 81, 273

Sperber, Dan 126, 135, 257

Sterelny, Kim 139, 180, 257

Stokoe, William 103, 187, 196, 204, 205, 219, 224, 257, 262

Studdert-Kennedy, Michael 95, 213, 221, 243, 245, 252, 257, 260

Swadesh, Morris 101, 142, 258

Sweet, Henry 213

Szathmáry, Eörs 13, 95, 130, $142,247,258$

$\mathrm{T}$

Tallerman, Maggie 11, 124, 171, 206, 228, 229, 234, 239, 256, 258,260
Tinbergen, Niko 74, 91, 192 , 220, 258, 259

Tomasello, Michael 165, 167, 168, 174, 180, 181, 184, 188, 190-192, 194, 197, 201, 207, 208, 222, 223, 235, 246, 251, 259

Thomas, Aquinas 19, 24

Trivers, Robert 121, 259

Tylor, Edward 56, 193, 260, 262

Tyson, Edward 31, 33, 34, 39,260

V

Vico, Giambattista 29, 30, 36, 193, 194, 227, 260

Victor of Aveyron 35, 43, 239

W

Waal, Frans de 188, 190-192, 252, 260

Wallace, Alfred R. 54, 56, 65, 103, 230, 261, 262, 265

Wernicke, Carl 54, 115

Wescott, Roger W. 102, 103, 262

Whiten, Andrew 14, 70, 163, 223, 262

Whorf, Benjamin 47

Wilcox, Sherman 130, 187, 196, 207, 219, 224

William, Calvin 223

William, Jones 45, 241

Williams, George C. 66, 121, 262

Wilson, Deirdre 83, 106, 135

Wilson, Edward O. 64, 74, 176, 257, 262, 263

Woll, Bencie 213, 214, 223, 263

Woodruff, Guy 166, 252 
Wrangham, Richard 78, 163,

262, 263

Wray, Alison 146-148, 263

Wundt, Wilhelm 56-58, 193, 263

Y

Yerkes, Robert 107
$\mathrm{Z}$

Zahavi, Amotz 178, 264

Zlatev, Jordan 102, 165, 166, 181, 201, 206, 209, 239, 251, 264

Zuberbühler, Klaus 155, 216, 225,255 



\section{Subject Index}

A

Adamic language 18, 19, 21, 26,267

adaptation $39,65-67,77,80$, $82,85,88,92,98,106,119$, $127,136,138,149,151,153$, $156,157,160,164,170,172$, 195, 203, 209, 214, 215, 220, $234,242,259,262,267$, 272,273

adaptationism (see also

panadaptationsim) 77,79 , 267,272

allele $61,83,88,120,149,176$, 267,269

alloparenting 183, 184 altruism 121, 176, 177, 180, 235,259

anthropogenesis 50, 54, 74, 88-90, 265, 267, 271 anthropology 32, 44, 56, 126, $168,184,219,220,223,230$, $237,238,246,257,259,262$ apes $13,14,31,33,34,41,45$, $54,55,79,85,90,92,101$, 104, 107, 108, 111, 114, 116, $123,125,126,134,143-145$, 152-160, 162, 165, 167-171, 173, 181, 183, 188, 190-192, 194, 195, 198, 201, 203, 207, 213, 223, 224, 233, 235, 236, 238, 247, 251, 252, 255, 259, $262,267,270$

arbitrariness 19, 22, 24, 102, $134,137,189,267$ articulation $42,113,141,153$
Australopithecus 89, 114, 116, 117, 156, 270

B

behaviourism 105, 179

biolinguistics 96, 132, 221, 240, 254

bonobo 13, 31, 109-112, 143, $158,191,225,267,270$

Buddhism 26, 223, 264

C

Christianity 19 chromosome 64, 95, 267

cognitive science 58,60, 106, 220, 225, 227, 231, 232, 240, 241, 245-248, 254, 256, 259, 263, 267

comparative philology

(comparative linguistics) 34 , 45, 48, 53, 97, 236, 268 convention 23-25, 28-30, 37, $40,127,132,144,145,166$, 171, 189, 200, 201, 204, 216, 248, 268

cooperative breeding 183 creationism 74, 268, 270

Critical Period Hypothesis 36, 106 cultural evolution 69-72, 85, $96,139,140,142,149,242$, 265, 271

D

Darwinism 45, 46, 51, 54, 69, $76,83,227,231,262,273$ 
design features of language 99-102, 186, 261 displacement 100-102, 135, 171,268

E

echo phonology 214, 263 encephalisation 108, 159, 161-163, 182, 183, 266, 268 enculturated apes 134, 158, 170, 201

Epicurean philosophy 28, 29 eugenics 76, 268, 269, 273 evolutionarily stable strategy $121,135,176,177$ evolutionary psychology 71-76, 79, 100, 126, 220, 226, 231, 256, 259, 263

evolutionism 15, 35, 49, 59, 60, $62,64,66,68,70,72,74-78$, $80,82,84,86,88,90,92$,

93, 120

exaptation 132, 151, 156, 237, 269,272

executive functions $171,172,226$

F

feral children $35,38,56$,

145,269

FLB 128, 129

FLN 128-130, 138

forbidden experiment 18,19 , 256, 269

FOXP2 113, 114, 124, 125, 214, $230,243,247,258$

\section{G}

game theory $121,177,247,249$ gene 13, 61-64, 66-71, 75, 78, 80-84, 87, 93, 97, 112-114,
119-126, 138, 150, 176-179, 183, 214, 227-230, 232, 240, $244,247,252,254,267-273$ gene pool 61, 63, 64, 66, 67, 83, $176,178,268,269,271$ generative grammar 99 ,

105,132

genetic determinism 92, 269 genetic drift $61,79,80,269$ genotype $64,70,71,84,138$, 268-270, 272 gesture-first hypothesis 103, 186, 193, 199, 239 gestures 29, 35, 36, 38, 40, 41, 43, 48, 55, 56, 57, 103, 123, 185, 187-193, 195-198, 201, 202, 205, 207-210, 212-216, $224,232,244,248,250,260$ glottogeny 44, 45, 47, 51, 53, $55-57,96,140,269$ gradualism 86, 131, 230, 269 grammaticalization 149, 270 Great Apes (Hominidae) 13, 14, 33, 108, 114, 143, 156, 167, 181, 183, 188, 190-192, 198, 203, 207, 224, 238, 251, 267,270

grooming 164, 181, 201, 230, 245,248 group selection $74,83,84$, 247,270

$\mathrm{H}$

handicap 35, 178, 179, 222, 264 hominin 90, 97, 114-116, 118, $126,127,136,145,150,152$, 153, 156, 162, 165, 169, 171, 182-184, 194, 198, 200, 203, 207, 208, 221, 231, 249, 257,270 
Homo sapiens 31-33, 45, 54, 76, $88,89,90,118,119,123,154$, 156, 162, 195, 199, 203, 206, 225,270

I

iconicity 29, 104, 196, 197, 216 inclusive fitness $66-68,270$ indexicality 178,216 intentionality $143,169,184$, 190, 192, 202, 255, 270 iterated learning 125, 140, 141, 242, 265

L

Lamarckism 84, 85

language acquisition $36,91,92$, 97, 106, 115, 125, 126, 191, 208, 239, 244

language-ready brain 85,127

last common ancestor 101, 143 lateralisation 119, 195, 197, 198,270

lexigram 112, 265

linguistic competence 105,126 , 132, 168

\section{M}

Machiavellian intelligence 163, 223

macroevolution 62, 120, 269,270

macromutation $85,86,123,148$ meme (memetics) 70 mentalism 34, 132 microevolution 271 mimesis $125,136,164-166,172$, 196, 200, 201, 264 modularity 106,132 morphosyntax 134, 149 mutation $61,64,65,78,84-86$, 113, 114, 123, 139, 148, 176, 214, 232, 253, 265, 267, 271 mutualism 180

N

nativism 105,132

natural selection 50, 51, 54, 59-67, 69, 72, 73, 77, 78-82, $85,87,88,92,98,113,121$, $140,149,175-177,227,261$, 262, 265, 267, 270, 271, 273

Neanderthal 45, 54, 89, 90, 114, 118, 119, 123, 124, 154, 156, 157, 162, 204, 222, 240, 246, $249,255,260$

neo-Darwinian

synthesis 113,130 neurolinguistics 115,126 , 219, 271

O

onomatopoeia 49, 137

ontogeny 90-92, 97, 126, 127, 130, 153, 204, 234, 246, 251, 271-273

ostensiveness 135

$\mathbf{P}$

palaeontology $58,61,114$ panadaptationism 77,79 , 267, 272

pantomime $35,56,103,188$, 189, 200, 201, 205, 208, 273 phenotype $64,70,79,84-86$, $88,113,113,114,176$, 267-269, 272 phonation 151,155 phylogenesis 206 pre-Adamism 28, 272 
preadaptation $15,136,143,151$, 152, 154, 156, 158, 160, 162, 164-173, 224, 272 primatology $13,33,45,107$, 126, 143, 243

prosociality $174,184,272$ protolanguage $30,36,56,97$, 101, 103, 135, 141, 144-149, 186, 187, 194-196, 203, 206, 209, 214, 215, 221, 222, 229, 256, 258, 261, 263 psycholinguistics 126, 272 punctuated equilibria 86,230

\section{R}

recapitulationism 90, 91, 273 recursion 125, 130, 131, 250 reverse engineering 60,273

$S$

saltationism 85, 86, 273

selective pressure $150,163,182$, 198, 206

selfish gene 87,227

sexual selection $62,81,82,182$, 259, 271, 273

shared intentionality 184, 202 sign language $33,56,91,104$, 108, 136, 137, 186, 190, 194, 196, 204, 205, 208, 216, 222, 224, 230, 237, 241, 242, 257, 258,273

signalling theory $11,121,123$, $174,175,181,256$

signification 23,273

social brain 163, 164, 169, 230, 252

sound symbolism 55, 123, 195, 213, 239

spandrel 80, 234, 273

$\mathrm{T}$

theory of mind 125,136 , 166-169, 237, 239, 244, 252

$\mathrm{U}$

Universal Darwinism 69, 227, 273

universal grammar 11, 22, 105, 106 universals (dispute over) 18, 268

W

wild man (Homo ferus) 32, 38 


\section{Dis / Continuities \\ Toruń Studies in Language, Literature and Culture}

Edited by Mirosława Buchholtz

Volume 1 Mirosława Buchholtz / Grzegorz Koneczniak (eds.): The Visual and the Verbal in Film, Drama, Literature and Biography. 2012.

Volume 2 Mirosława Buchholtz: The Beautiful and the Doomed: Essays on Literary Value. 2013.

Volume 3 Joanna Mstowska: Various Aspects of Mimesis in Selected Sea Novels of Frederick Marryat, James F. Cooper and Richard H. Dana. 2013.

Volume 4 Agnieszka Łowczanin / Dorota Wiśniewska (eds.): All that Gothic. 2014.

Volume 5 Mirosława Buchholtz / Dorota Guttfeld / Grzegorz Koneczniak (eds.): Henry James Goes to War. 2014.

Volume 6 Mirosława Buchholtz: Henry James and the Art of Auto/biography. 2014.

Volume 7 Tadeusz Sławek: Henry David Thoreau - Grasping the Community of the World. 2014.

Volume 8 Mirosława Buchholtz / Eugenia Sojka (eds.): Alice Munro: Reminiscence, Interpretation, Adaptation and Comparison. 2015.

Volume 9 Sławomir Wacewicz: Concepts as Correlates of Lexical Labels. A Cognitivist Perspective. 2015.

Volume 10 Dorota Guttfeld (ed.): Facets of Domestication. Case Studies in Polish-English and English-Polish Translation. 2015.

Volume 11 Jarosław Hetman: Ekphrastic Conceptualism in Postmodern British and American Novels. Don DeLillo, Paul Auster and Tom McCarthy. 2015.

Volume 12 Mirosława Buchholtz / Grzegorz Koneczniak (eds.): World War I from Local Perspectives: History, Literature and Visual Arts. Austria, Britain, Croatia, France, Germany, Ireland, Israel, Italy, Poland and the United States. 2015.

Volume 13 loana Zirra / Madeline Potter (eds.): The Literary Avatars of Christian Sacramentality, Theology and Practical Life in Recent Modernity. 2016.

Volume 14 Anna Suwalska-Kołecka / Izabella Penier (eds.): Art, Ethics and Provocation. 2016.

Volume 15 Katarzyna Więckowska / Grzegorz Koneczniak (eds.): Literary and cultural forays into the contemporary. 2017.

Volume 16 Agnieszka Łowczanin: A Dark Transfusion: The Polish Literary Response to Early English Gothic. Anna Mostowska Reads Ann Radcliffe. 2018.

Volume 17 Przemysław Żywiczyński / Marta Sibierska / Waldemar Skrzypczak (eds.): Beyond Diversity: The Past and the Future of English Studies. 2018.

Volume 18 Przemysław Żywiczyński: Language Origins. 2018.

Volume 19 Dorota Filipczak: Brian Moore's Eponymous Heroines. Representations of Women and Authorial Boundaries. 2018.

Volume 20 Przemysław Żywiczyński / Sławomir Wacewicz: The Evolution of Language: Towards Gestural Hypotheses. 2019.

www.peterlang.com 
